ORNL/M-2711

Metals and Ceramic Division

\title{
ION IMPLANTATION EFFECTS ON SURFACE-MECHANICAL PROPERTIES OF METALS AND POLYMERS
}

G. R. Rao

Date Published: April 1993

Prepared by the

OAK RIDGE NATIONAL LABORATORY

Oak Ridge, Tennessee 37831-6285 managed by MARTIN MARIETTA ENERGY SYSTEMS, INC.

for the U.S. DEPARTMENT OF ENERGY under contract DE-AC05-84OR21400 


\section{ACKNOWLEDGEMENTS}

The author would first and foremost like to thank Prof. Bryan Chin for his constant support, guidance and help throughout the duration of this work. The author would also like to thank Dr. Eal Lee for his enthusiastic help and guidance and Dr. Louis Mansur for his steady encouragement and support, both of whom made the sojourn at Oak Ridge National Laboratory very pleasant. The author would like to thank Dr. Monty Lewis for patiently teaching him the intricacies of operating particle accelerators, Mr. Sylvester Cook for performing several of the implantations, and Dr. William Allen and Mr. Roy Buhl for helping with various aspects of accelerator operations. Thanks are due Dr. Lynn Boatner, for

providing single crystal specimens, Dr. Ken Farrell for use of his creep machines and more importantly, for very helpful discussions regarding various aspects of metal creep, Dr. Z. L. Wang for EELS analysis of the polymer specimens, Mr. Wade Jones for TEM specimen preparation, Dr. Janet Pawel for reading parts of the manuscript and Mr. Alex Fischer for helping with TEM operations. The author would especially like to thank his mother, Ms. Saraswathi Rao without whose patience, support and understanding, this work could not have been accomplished. The author would like to invoke the memories of his late grandfather, Dr. S. Ramachandra Rao (Ph.D, Physics, 1930, D.Sc, 1932, London) and his late father, Dr. R. Rajan (Ph.D, Physics, 1964), who were responsible for his starting this venture in the first place. This research was sponsored by the Division of Materials Sciences, U.S. Department of Energy, under contract No. DE-AC05-84OR21400 with Martin Marietta Energy Systems, Inc. 
DISSERTATION ABSTRACT

ION-IMPLANTATION EFFECTS ON SURFACE-MECHANICAL

PROPERTIES OF METALS AND POLYMERS

\author{
Gopal Rajan Rao \\ Doctor of Philosophy, August 28, 1992 \\ (M.S., Auburn University, 1988) \\ (B.E., South Gujarat University, 1985) \\ 204 Typed Pages \\ Directed by Bryan A. Chin
}

The present work was undertaken to study ion implantation effects on surfacesensitive mechanical properties of metals and polymers. Fatigue properties of eight complex (E-series) alloys based on the composition Fe-13Cr-15Ni-2Mo-2Mn$0.2 \mathrm{Ti}-0.8 \mathrm{Si}-0.06 \mathrm{C}$ (E1) and single crystal $\mathrm{Fe}-15 \mathrm{Cr}-15 \mathrm{Ni}$ specimens, implanted with $400 \mathrm{keV} \mathrm{B}^{+}$and $550 \mathrm{keV} \mathrm{N}^{+}$to a total dose of $2.3 \times 10^{16}$ ions $/ \mathrm{cm}^{2}$ were examined. High temperature $\left(600^{\circ} \mathrm{C}\right)$ creep properties of $\mathrm{B}^{+} / \mathrm{N}^{+}$-implanted and $1 \mathrm{MeV} \mathrm{Ar}^{+}$ implanted complex (E1) alloy and ternary $\mathrm{Fe}-13 \mathrm{Cr}-15 \mathrm{Ni}$ (B1) alloy were also investigated.

The dual implantation increased hardness but decreased fatigue life of the eight complex alloys. This was attributed to a shift from slip band crack initiation to grain boundary cracking. The existence of an optimum strengthening level was determined above which crack initiation occurred at grain boundaries rather than at slip bands. Similarly, evidence was provided for the shift to grain boundary 
cracking for four simple $\mathrm{Fe}-13 \mathrm{Cr}-15 \mathrm{Ni}$ alloys. The single-crystal specimens also showed a reduced fatigue life after implantation due to concentration of slip along intense slip bands. High temperature creep properties of the E1 and B1 specimens were significantly improved after $\mathrm{B}^{+} \mathrm{N}^{+}$- implantation and an increase in the time to rupture by over $70 \%$ was found. Examination of the failed specimens showed that all specimens failed by intergranular fracture and ion implantation delayed intergranular void nucleation and crack initiation. This was the first effort to study multiple-ion-implantation effects on creep properties of alloys. The $\mathrm{Ar}^{+}$-implantation increased creep life of the B1 alloy but decreased life for the E1 alloy. This was attributed to competing effects of $\mathrm{Ar}^{+}$-bubble formation at grain boundaries and strengthening of matrix by bubbles as well as irradiation damage effects.

Four polymers, polyethylene (PE), polypropylene (PP), polystyrene (PS) and polyethersulfone (PES) were implanted with $200 \mathrm{keV} \mathrm{B}^{+}$to three different doses. PS was also implanted with $100 \mathrm{keV} \mathrm{B}^{+}$ions and with 200,500 and $1000 \mathrm{keV} \mathrm{Ar}^{+}$ ions to three doses to study energy and ion-species dependence. Near-surface hardness changes were investigated using a nanoindentation technique. The $\mathrm{B}^{+}$implanted polymers were also investigated for effects on tribological properties. The near-surface hardness of all the ion-implanted polymers increased with dose and energy. Implantation effects were found to be sensitive to the structure of the polymer. The hardness changes were explained in terms of cross-linking and the deleterious effects of chain-scission. Microstructural correlations were also obtained. Good improvernents were obtained for wear properties though there was again a sensitive dependence on dose. An optimum dose was found at which minimal wear was observed. No specific correlations were made between friction coefficient, hardness and wear resistance. 


\section{TABLE OF CONTENTS}

I. INTRODUCTION .................................................................................. 1

Ion Implantation Effects in Metals 2

Ion Implantation Effects in Polymers 4

II. REVIEW OF LITERATURE …………………................................... 6

Ion Implantation ……………………................................................... 6

Historical Perspective $\quad 6$

Range and Energy Loss

Ridiation Damage $\quad 11$

Compositional Changes 11

Precipitate Formation and Evolution 12

Phase Transformations 12

Mechanical Properties of Ion-Implanted Metals .................................... 13

Microhardness 13

Fatigue $\quad 18$

Creep 36

Mechanical Properties of Ion-Implanted Polymers ................................. 44

Microstructure $\quad 49$

Microhardness $\quad 52$

Wear $\quad 55$

III. EXPERIMENTAL PROCEDURES ……………................................. 62

Specimens and Materials …………........................................................ 62

Metals $\quad 62$

Polymers $\quad 65$

Ion Implantation ……................................................................................. 68

Metals $\quad 71$

Polymers $\quad 71$

Mechanical Tests ..................................................................................... 73

Fatigue Testing of Metal Specimens $\quad 73$

Creep Testing of Metal Specimens

Microhardness $\quad 75$

Wear Testing of Polymers $\quad 76$

Specimen Characterization .................................................................. 77

Optical Microscopy $\quad 77$

Transmission Electron Microscopy $\quad 77$ 
IV. RESULTS AND DISCUSSION: METALS ......................................... 79

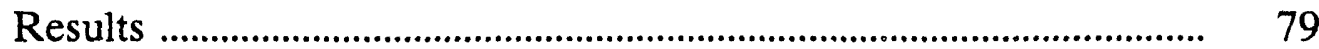

Ion Depth Ranges $\quad 79$

Microhardness Results $\quad 81$

Fatigue Testing $\quad 85$

Fatigue Data $\quad 85$

Optical Microscopy $\quad 89$

Transmission Electron Microscopy 94

Creep Testing $\quad 97$

Creep Data $\quad 97$

Optical Microscopy 101

Discussion ............................................................................................... 105

Fatigue 105

Ion Implantation Effects 105

Possible Fatigue Mechanisms 107

Model for Observed Fatigue Behavior 112

Creep 125

Ion Implantation Effects 125

Mechanisms of Intergranular Creep Fracture $\quad 126$

Possible Creep Mechanisms $\quad 128$

V. RESULTS AND DISCUSSION: POLYMERS …………………….... 134

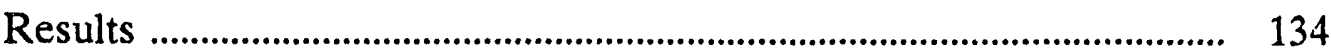

Ion Implantation Effects $\quad 134$

Microhardness Results 138

Tribological Properties of Ion-Implanted Polymers 142

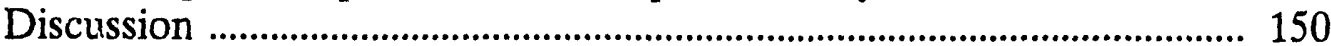

Ion Irradiation Effects 150

Microhardness 152

Measurement Technique 152

Ion Dose, Energy and Species Effects 155

Implant Layer Microstructure $\quad 157$

$\begin{array}{ll}\text { Tribological Properties } & 165\end{array}$

VI. COMPARISON OF ION IMPLANTATION EFFECTS

IN METALS AND POLYMERS ................................................ 168

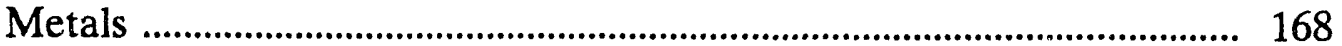

Polymers ............................................................................................... 170

VII. CONCLUSIONS _............................................................................ 172

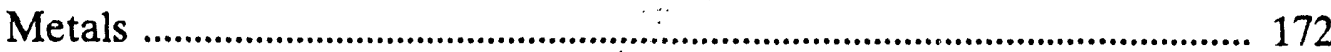

Fatigue $\quad \cdots \cdots$

Creep 173

Polymers .............................................................................................. 175

viij 
Hardness

175

Tribological Properties

176

VII. REFERENCES

177 


\section{LIST OF TABLES}

1. Hardness increases in several metals implanted with $\mathrm{N}^{+}$.

Hardness was measured using a depth sensing nanoindentation technique [36]

2. Alloy compositions of the Fe-13Cr-15Ni alloys used by Lee and Mansur [6]

3. Hardness values of four simple $\mathrm{Fe}-13 \mathrm{Cr}-15 \mathrm{Ni}$ alloys implanted with $\mathrm{B}$ and $\mathrm{N}$ under various conditions, determined using the nanoindentation technique [6]

4. A summary of several strain controlled fatigue tests on various metals [5]

5. Summary of several stress controlled fatigue studies[5]

6. Normalized hardness using the nanoindentation technique before fatigue testing for unimplanted and implanted $\mathrm{Ni}$ [56]

7. Dependence on fatigue life and relative number of grains containing PSBs in $\mathrm{Ni}$ on the $\mathrm{B}$ ion dose [49]

8. The effects of surface alloying on the high temperature behavior of a $\mathrm{Ti}$ and an $\mathrm{Al}$ alloy [61]

9. Minimum creep rates for unimplanted and Te-implanted type 304 SS [62]

10. Typical molecular species emitted from PE and PS subjected to ion irradiation [9]

11. Alloy compositions for the eight E-series alloys used in the study in weight percent 
12. Some physical and mechanical properties of the polymers used in this study

13. The various implantation conditions used for the four polymers studied

14. Knoop hardness values and Nanoindentation hardness values for the eight E-series alloys showing percent increase in hardness due to the implantation for each technique

15. Fatigue tests results for the eight E-series alloys indicating the percentage decrease in fatigue life for the implanted specimens.................

16. Steady state creep rates for the B1 and E1 creep specimens 102

17. Results of TRIM calculations for the four polymers implanted under various conditions 


\section{LIST OF FIGURES}

1. Energy of the implanted ions shown as a function of stopping power. The low energy regime corresponds to nuclear energy loss and the high energy regime represents electronic energy loss [after 2]

2. Typical distribution of implanted ions. The figure shows definitions of projected range $\left(R_{p}\right)$, total range $\left(R_{\text {total }}\right)$ and straggle $\left(\Delta R_{p}\right)$ [after 2]

3. (a) Vicker's hardness results obtained by Pavlov et.al. for $30 \mathrm{keV}$ Ar implanted steel, (b) Results obtained by Kanaya et.al. for $24 \mathrm{keV} \mathrm{N}$ implanted steel [31]

4. Fatigue results for $\mathrm{Cu}, \mathrm{Ni}$ and AISI 310 S.S. implanted with 115 $\mathrm{keV} \mathrm{C}^{+}$( $\mathrm{n}$ - unimplanted, i - implanted) showing a slight increase in fatigue life of $\mathrm{Ni}$ but a decrease for $\mathrm{Cu}$ and steel after implantation [40]

5. Possible sequence of events suggested by Grummon et.al. for crack initiation at slip bands that penetrate the modified surface layer [after 56]

6. Normalized hardness-depth profiles of implanted Ni before and after fatigue testing [57]

7. Fatigue results for stress and strain controlled fatigue tests for copper implanted with $100 \mathrm{keV} \mathrm{Al}, \mathrm{B}$ and $\mathrm{Cr}$ showing ion size effects $[43,50]$

8. Fatigue results obtained by $\mathrm{Hu}$ et.al. for AISI 1018 low C-steel implanted with N.Aging promoted formation of a finely dispersed metastable $\mathrm{Fe}_{16} \mathrm{~N}_{2}$ phase, resulting in improved fatigue life [50]

9. Effects of $\mathrm{N}^{+}$and $\mathrm{C}^{+}$implantation on fatigue properties of Ti-6Al-4V alloy $[50,52]$

10. Fatigue results for single and dual $\mathrm{B}$ and $\mathrm{N}$ implantation in 
the four B-series $\mathrm{Fe}-13 \mathrm{Cr}-15 \mathrm{Ni}$ alloys used by Lee and Mansur showing the significant improvement in fatigue life for the dual implanted specimens [6]

11. Creep curves for cadmium crystals showing the effect of removal of a surface hydroxide film and increasing strtss [60]

12. Creep results for Mo implanted with $\mathrm{Ge}, \mathrm{Te}$ and $\mathrm{C}$ as a function of temperature [8]

13. Typical processes occurring in polymers subjected to ion irradiation, as a function of dose [after 9]

14. Residual gas analysis results for Teflon and Kapton during $200 \mathrm{keV}$ $\mathrm{Si}^{+}$implantation [77]

15. G-values obtained by Lewis et.al. for various species ejected from $\mathrm{PE}$ and Kapton as a function of stopping power [78]

16. Hardness improvements in various polymers after ion implantation obtained by Lee et.al. Hardness values, reported at $100 \mathrm{~nm}$ depth, were measured using the nanoindenter [10]

17. Hardness values of polycarbonate implanted with $\mathrm{B}^{+}$, given as a function of ion dose at two different energies [95]

18. Optical micrographs of wear tracks on implanted Kapton tested using a nylon ball. Insets show morphology of wear debris for each case [10]

19. Wear tracks on PC implanted with $200 \mathrm{keV} \mathrm{B}^{+}$at various doses. The intermediate dose implanted material showed no wear tracks.

The wear of the nylon ball is also shown [95]

20. The miniature bending fatigue specimen used for the fatigue tests

21. The modified SS-3 creep specimen configuration used in this study

22. Molecular structures of the repeating units for the four polymers used in this study

23. Schematic representation of the triple ion irradiation facility at ORNL 
24. Bending fatigue machine for testing the miniature fatigue specimens ...... 74

25. Results of TRIM calculations showing implant depth distribution for $400 \mathrm{keV} \mathrm{B}^{+}$and $550 \mathrm{keV} \mathrm{N}^{+}$implantations. The figure also shows number of vacancies produced due to nuclcar energy loss and ionization due to electronic energy loss

26. Knoop hardness results for the eight E-series alloys

27. Typical nanoindentation results, shown here for the control E-1 specimen. (a) shows the load-displacement plot from one indent and (b) shows calculated hardness values as a function of depth

28. Nanoindentation hardness results for the E-alloys at a depth of $100 \mathrm{~nm}$

29. Fatigue test results for the control and $B, N$ implanted E-series alloys showing a decrease in fatigue life after implantation for all eight alloys

30. Optical micrographs of the surface of control and implanted specimens showing a suppression of slip at the surface in the implanted specimens

31. Crack initiation study in a control E-1 specimen showing crack initiation at slip bands and subsequent growth $(\mathrm{N}$ is the number of elapsed cycles)

32. Optical micrographs of implanted E-specimens showing grain boundary cracks

33. Typical TEM micrographs of control fatigue specimens showing microstructures as a function of position on the specimen cross-section.(a) close to the neutral axis, (b) intermediate locations, (c) cell structure close to the surface and (d) L-structure close to the specimen surface

34. Typical cross-sectional TEM images of the implanted layer in fatigued specimens

35. Implant layer microstructures observed in a TEM using backthinned specimens 
36. Creep test results for the $\mathrm{B} 1$ specimens for control, $\mathrm{Ar}^{+}$and $\mathrm{B}^{+} / \mathrm{N}^{+}$-implanted cases tested at $600^{\circ} \mathrm{C}$

37. Creep tests results for the control, $\mathrm{Ar}^{+}$-implanted and $\mathrm{B}^{+} \mathrm{N}^{+}$implanied E1 specimens tested at $600^{\circ} \mathrm{C}$

38. The surface of the control B1 specimen after the creep test showing " $r$ " type cracks and voids

39. The surface of the control E1 specimen showing wedge type cracks primarily at triple grain junctions

40. Fatigue results for the B-series alloys showing triple implantation reduced fatigue life though dual implantation significantly increased it [104]

41. Optical microscopy of B,N,C implanted B1 alloy specimen showing grain boundary cracks. No G.B. cracks were observed in the control, single or dual implanted specimens

42. Fatigue test results for the control and $B, N$ implanted single crystal $\mathrm{Fe}-15 \mathrm{Cr}-15 \mathrm{Ni}$ specimens compared with the E-series specimen results

43. Optical micrographs of the control and implanted single crystal specimen surfaces showing the suppression of slip bands

44. Crack initiation at intense slip bands on the $\mathrm{B}, \mathrm{N}$ implanted single crystal specimens

45. Modéi of PSB in a single crystal specimen forming extrusions at both ends

46. Stress raisers at the extrusion on the surface. The figure also shows the roughening of the extrusions to form type II stress raisers

47. A PSB within a grain showing effects on the grain boundaries

48. Effects of the presence of an implanted layer at the specimen surface

49. (a) Possible mechanisms of " $r$ " type void formation at grain boundaries indicating various sources of stress concentration. 
(b) Formation of " $r$ " voids by interaction of g.b. with a slip band and subsequent sliding at the g.b.

50. Grain boundary sliding at a triple point junction causing "w" type wedge crack

51. G-values for different gaseous species released from the polymer surface during irradiation, shown here for Ar implantation of PS

52. Typical color changes observed during ion irradiation of polymers, shown here for PS at two energies

53. Typical nanoindentation hardness results shown here for pristine and $200 \mathrm{keV} / 1.7 \times 10^{15} \mathrm{~B}^{+} / \mathrm{cm}^{2}$ implanted PES

54. The hardness results for $200 \mathrm{keV} \mathrm{B}{ }^{+}$implanted PE, PP, PS and PES as a function of dose

55. Hardness results for $\mathrm{B}^{+}$and $\mathrm{Ar}^{+}$implanted PS at various energies showing ion energy and species effects

56. Hardness results for the $\mathrm{B}^{+}$implanted polymers in terms of measured hardness values and hardness increases, as a function of dose

57. Results of wear tests on $\mathrm{B}^{+}$implanted PE as a function of dose 144

58. Results of wear tests on $\mathrm{B}^{+}$implanted PP as a function of dose 145

59. Results of wear tests on $\mathrm{B}^{+}$implanted PES as a function of dose 146

60. Results of wear tests on 100 and $200 \mathrm{keV} \mathrm{B}^{+}$implanted PS as a function of dose

61. Friction coefficient data for the wear tests on 100 and $200 \mathrm{keV}$ $\mathrm{B}^{+}$implanted PS as a function of time

62. Analysis of nanoindentation of polymers

63. TEM of unimplanted and B,N,C implanted Tefzel showing bright and dark regions. EELS showed that the bright regions had a $15 \%$ greater $\mathrm{C}$ concentration than the dark regions [122]

64. EELS spectra for the B,N,C implanted Tefzel [105] 160 
65. Conductivity changes in Ar implanted PS as a function of ion dose and energy compared with hardness changes in the same materials

66. Raman spectra for unimplanted and Ar implanted PS obtained for various doses. The spectrum for Diamond-like C-film on PS is also shown 


\section{INTRODUCTION}

The bombardment and implantation of material surfaces with energetic ions can have significant effects on surface-sensitiv, physical, chemical and mechanical properties such as electrical, optical, corrosion resistance, catalytic and tribological properties. Bulk properties can also be affected if they are controlled by surface properties such as, for example, fatigue and creep properties of materials [1].

Ion implantation results in significant changes in the near-surface chemistry and microstructure of materials. The incident ions can have energies ranging from tens to thousands of $\mathrm{keV}$ as they strike the target material. The ions come to rest at characteristic depths beneath the target surface which are a function of ion energy. There is a transfer of energy to the host lattice during the slowing-down of the ions. This results in the displacement of target atoms and some level of breakdown in the lattice structure if the target material is crystalline. The incident ions assume a distribution of concentration vs depth which is Gaussian in nature. The incident atoms also alter the chemical composition of the implanted region $[1,2]$.

Ion implantation is a unique process. Any element can be implanted into any solid thereby creating novel microstructures near the surface. There are no solubility constraints, theoretically, due to the non-equilibrium nature of the 
process. The absence of a sharp interface eliminates adhesion problems normally encountere $J$ for thin films. The process can be performed at low temperature and is controllable and reproducible. From a technological standpoint, the process can be added to the end of a production line without sacrificing bulk properties or altering the dimensions of the part. Lastly, it is an environmentally safe process which does not generate waste products, unlike some other surfacemodification techniques. However, ion implantation is a fairly expensive process and is best suited for specialized paris with a high initial cost. The penetration of the ions is shallow, limiting the depth of the mocified layer. Also, ion implantation is a line-of-sight process, which is a limitation when implanting parts with complex shapes $[1,3]$.

In the present study, some of the effects of ion beam treatments on metals and polymers were investigated. In particular, the effects on surface-sensitive mechanical properties were explored and the responses of metals and polymers to ion beams were compared.

\section{ION IMPLANTATION EFFECTS IN METALS}

Ion implantation can significantly alter the fatigue properties of materials. In metals, the critical event for fatigue failure is the initiation of surface cracks, usually in slip bands. Some of these fatigue cracks may grow and link up, eventually leading to catastrophic failure [4]. Ion implantation has been shown to delay and suppress the initiation of cracks in slip bands. The implanted layer 
alters the nature of slip at the surface by solid solution strengthening and precipitation hardening as well as inducing residual compressive stresses. Slip reversibility and slip homogenization are commonly observed during fatigue of ion implanted metals [5].

Most studies till now have concentrated on implanting one ion species in a given metal. However, implantation of more than one ion species may produce very interesting and unique microstructures and have significant effects on fatigue properties of metals. In a recent study performed at Oak Ridge National Laboratory (ORNL) by Lee and Mansur [6], boron and nitrogen ions were singly as well as simultaneously implanted into four simple model $\mathrm{Fe}-13 \mathrm{Cr}-15 \mathrm{Ni}$ based alloys. Their results showed that while single implantation yielded modest or no improvements in the fatigue properties of the alloys, simultaneous dual implantation significantly improved fatigue properties of all four alloys. The authors speculated that the interaction of the implanted species with each other to form boron nitride or with the minor alloying elements present in the alloys caused the observed improvements in hardness and fatigue properties.

The present study attempts to extend the work done by Lee and Mansur by considering multiple ion implantation in more complex model alloys, which are similar to engineering alloys. The main motivation for this investigation stems from the need for a better understanding of microstructural changes caused by multiple ion implantation and the consequent effects on macroscopic fatigue properties of the alloys. It is anticipated that this investigation would extend the 
boundaries of knowledge regarding ion implantation effects on fatigue properties of metal alloys in general.

The effects of ion implantation on high temperature creep deformation of metals has been little explored. It has been known that surface films of thickness in the range of tens of nanometers can have a significant effect on creep rates of metals, provided the films were diffused on the surface [7]. In one study on molybdenum, it was observed that carbon implantation decreased the creep rate, thereby increasing the creep life. This effect was further enhanced by postimplantation annealing [8]. In the present study, the effects of simultaneous boron and nitrogen implantation on high temperature properties of the ternary $\mathrm{Fe}-13 \mathrm{Cr}$ $15 \mathrm{Ni}$ and a complex alloy based on the $\mathrm{Fe}-13 \mathrm{Cr}-15 \mathrm{Ni}$ composition have been investigated. The effects of argon implantation were also studied. This work was also carried out to further understand ion implantation effects on mechanical properties of metals in general.

\section{ION IMPLANTATION EFFECTS IN POLYMERS}

The damage effects due to ion implantation become progressively more extensive going from metals to semiconductors to organic films [9]. In polymers, bond breakage results in the formation of smaller molecules, many of which are volatile and can escape from the polymer surface. Hence, unlike in metals where radiation damage can be annealed out, ion implantation of polymers creates 
irreversible changes. These changes have been shown to alter optical and electrical properties dramatically [9].

Ion implantation, however, can have significant effects on near-surface mechanical properties as well. This aspect has been little explored, probably due to the inherently weak mechanical properties of polymers. A recent study at Oak Ridge National Laboratory by Lee et.al. has shown that ion implantation can significantly improve near-surface hardness and this may have several novel technological applications [10]. The ORNL work represents the first effort to improve surface mechanical properties of polymers using multiple ion implantation. However, several questions remain unanswered and the present investigation was undertaken to try to answer some of these questions.

This study attempts to investigate the effects of ion dose, ion energy and molecular structure of the polymer on the observed surface property changes due to ion implantation. It also explores microstructural changes in the near-surface regions of the ion-implanted polymers and possible consequent effects on mechanical properties. The overall aim of this work is to obtain a better understanding of ion irradiation effects in metals and polymers, and to compare the effects in the two classes of materials based on the disparity of atomic structure in the materials. 


\section{LITERATURE REVIEW}

\section{ION IMPLANTATION}

\section{Historical Perspective}

The history of ion-solid interactions can be traced back to the turn of the century with the discovery of the emission of energetic particles from radioactive materials [11]. Rutherford used the backscattering of alpha particles from thin foils to propose that the nucleus of an atom consists of a heavy positively-charged core [12]. Bohr used this hypothesis to develop his idea of the structure of the atom [13]. Bohr also worked on the theory of stopping of ions in solids [11].

The present field of research using ion beams to modify material surfaces can be regarded as an outgrowth of nuclear physics and radiation effects, and several of the early researchers in the field were nuclear physicists by training [14]. Ion implantation has been used for introducing specific amounts of dopants into semiconductors for use in the electronic industry since the 1960s. There has been significant research performed on applications of ion implantation in silicon as evidenced by the number of available books $[15,16]$ as well as conference proceedings [17].

The earliest reports of ion implantation into metal surfaces with the express intention of modifying mechanical properties originated from Harwell in the 
United Kingdom, where Dearnaley, Hartley and co-workers implanted nitrogen into steel and showed that the friction and wear properties as well as fatigue properties could be improved [18-20]. Since then, many researchers have worked on various aspects of ion implantaticn of metals.

\section{$\underline{\text { Range and Energy Loss }}$}

Several basic processes occur when energetic ions penetrate the surface of a material. Each of these processes contributes towards the final microstructure of the implanted layer which governs mechanical property changes. An incident ion striking a target eventually loses its energy and comes to rest within the material. The energy loss occurs in three basic ways: (1) nuclear collisions, (2) electronic collisions with excitation of bound electrons and (3) charge exchange between the ion and atoms in the target. The stopping power or specific energy loss is the sum of the above three processes and may be written as [2]:

$$
S=\left(\frac{d E}{d x}\right)=\left(\frac{d E}{d x}\right)_{\text {muclear }}+\left(\frac{d E}{d x}\right)_{\text {electronic }}+\left(\frac{d E}{d x}\right)_{\text {exchange }}
$$

A typical time scale for this process would be approximately $10^{-14} \mathrm{~s}$. [19]. Nuclear energy loss can be modelled as an elastic collision between the incident ion and the nucleus whereas electronic energy loss can be visualized as inelastic collisions with electrons in the target. Thus, the nuclear component of stopping is maximum at lower energies whereas electronic stopping power is greater at higher energy as shown in figure 1 [2]. While electronic collisions do not significantly alter the 
incident ion direction, nuclear collisions can strongly affect the projectile dirertion and are responsible for displacing target atoms. Sputtering of neii surface atoms is also a consequence of nuclear collisions [2]. The above energy loss processes are described by the LSS (Lindhard, Scharff, Schiott) theory derived from classical mechanics and the Thomas-Fermi model of the atom [22].

The damage caused by nuclear collisions has been modelled in terms of secondary displacements by Kinchin and Pease and may be stated as [23]:

$$
\begin{gathered}
N_{d}=0 \quad T_{d}<E_{d} \\
N_{d}=1 \quad E_{d} \leq 2 T_{d} \leq 2 E_{d} \\
N_{d}=\frac{\beta T_{d}}{2 E_{d}} \quad T_{d} \geq 2 E_{d}
\end{gathered}
$$

where $N_{d}$ is the number of displaced atoms (vacancy-interstitial pairs), $E_{d}$ is a threshold energy (in the range of tens of $\mathrm{eV}$ ) for displacing a host atom, $\beta$ represents the deviation from a hard sphere interatomic potential and $T_{d}$ is the nuclear stopping energy lost by the incident ion $[20,21]$.

The range of implantation can be represented ideally by a first order Gaussian distribution about an average depth due to the statistical nature of the energy loss and angular deviations at every collisional event [21]. These concepts are shown in figure 2. It should be noted here that the projected range $R_{p}$ is a function of 


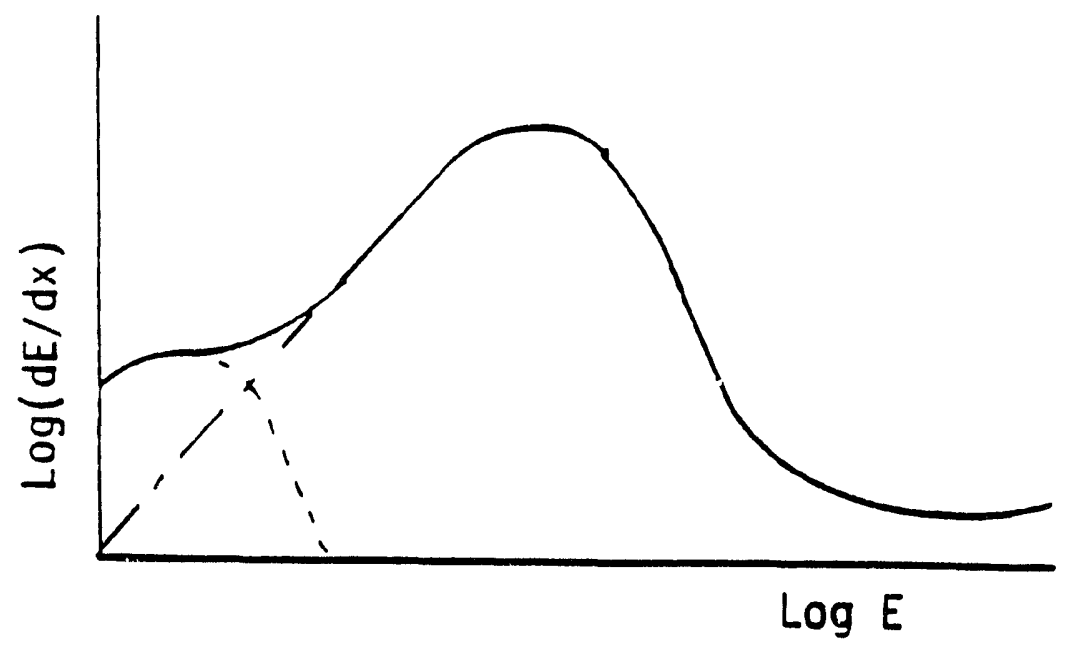

Figure 1. Energy of the implanted ions shown as a function of stopping power. The low energy regime corresponds to nuclear energy loss and the high energy regime represents electronic energy loss [after 2]. 

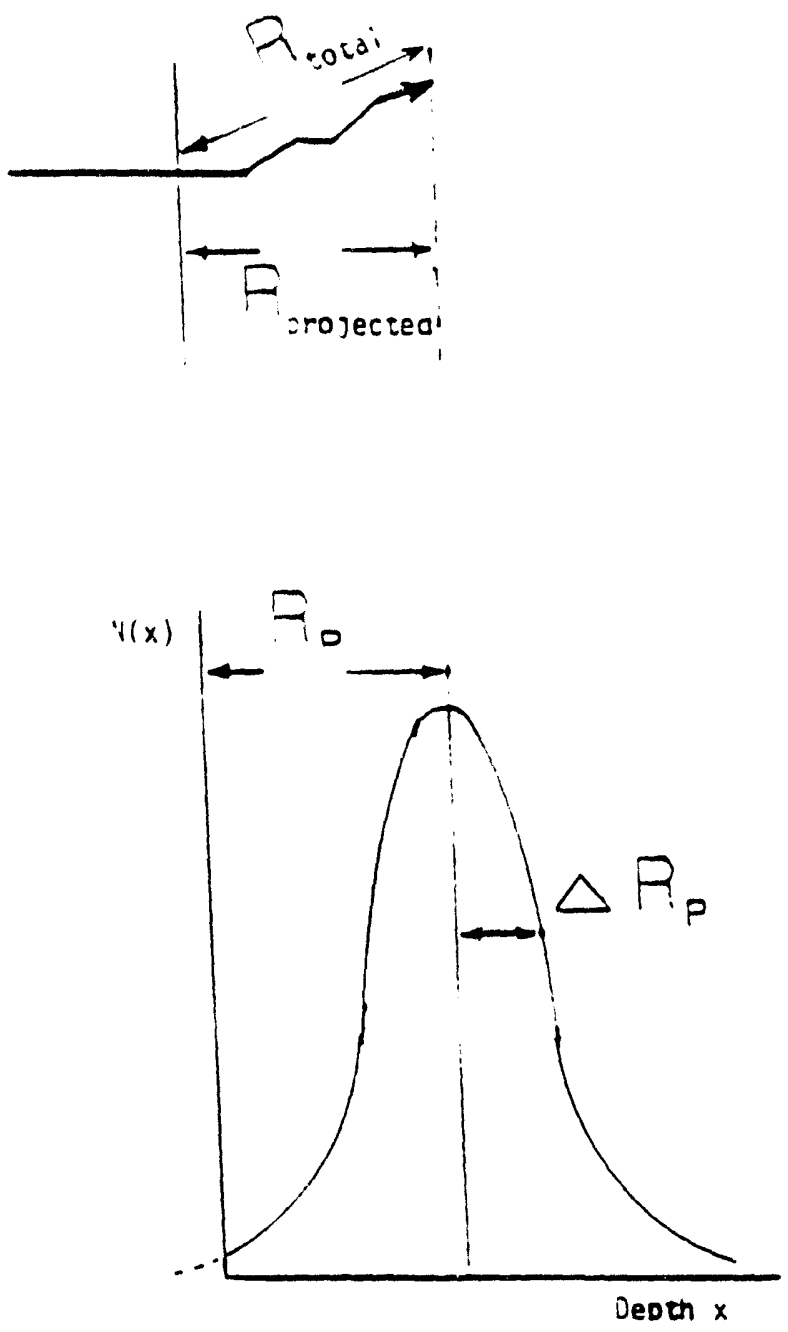

Figure 2. Typical distribution of implanted ions. The figure shows definitions ui projected range $\left(R_{p}\right)$, total range $\left(R_{\text {total }}\right)$ and straggle $\left(\Delta R_{p}\right)$ [after 2]. 
incident ion energy and with increasing energy, the projected range as well as distribution about that range increase [2].

\section{Radiation Damage}

The main consequence of nuclear energy loss is the displacement of target atoms from their lattice positions. Depending upon the energy exchanged in the collision, the displaced atom undergoes a series of collisions resulting in a rearrangement of the local structure. This series of collisions is knor $n$ as a cascade $[2,14,22]$. This results in the creation of several vacancies and interstitials. Interstitials are mobile at low temperatures while vacancies become mobile at higher temperatures. These defects thus can further interact to form defect structures such as clusters and dislocation loops which can have significant effects on mechanical properties $[21,22]$.

\section{Compositional Changes}

Ion implantation can produce non-equilibrium and metastable phases since the process is an athermal one and is not governed by solubility limits [21,24]. Solubilities exceeding the equilibrium value by 10 to 30 times have been reported [21]. Therefore ion implantation represents a convenient method of overcoming the empirical Hume-Rothery rules for solid solutions.

In one study by Borders and Poate, gold and tungsten were implanted in Copper. Channeling angular scans indicated that the implanted gold was $100 \%$ substitutional and $\mathrm{W}$ was $\sim 90 \%$ substitutional. While $\mathrm{Au}$ is normally soluble in $\mathrm{Cu}, \mathrm{W}$ is immiscible and the implantation had resulted in a metastable solid 
solution [21]. Similarly, in a study conducted on $\mathrm{Al}$ implanted in $\mathrm{Ni}$, a limiting concentration of 70 at-\% $\mathrm{Al}$ in $\mathrm{Ni}$ was determined, forming an extended solid solution. After annealing for shc:t periods of time, $\mathrm{NiAl}$ and the metastable $\mathrm{Ni}_{2} \mathrm{Al}$ were formed. $\mathrm{Ni}_{2} \mathrm{Al}$ is not shown on the phase diagram [24].

\section{Precipitate Formation and Evolution}

Several studies have reported the formation of precipitate particles subsequent to implantation. This occurs when the implanter atoms are mobile during implantation and equilibrium solubilities are exceeded. When both conditions are met, precipitate formation is promoted [21]. For example, when nitrogen was implanted in Ti-6 Al-4V, fine TiN particles were found to form in the implanted layer [25]. This has been attributed to the high density of sites for heterogeneous nucleation and in general, ar low temperatures, a high density of small precipitates were formed $[21,24]$.

Post-implantation annealing accelerates the precipitation process since implanted atonis become mobile and the equilibrium phase precipitates out. Similarly, in many cases, post-implantation aging treatment also promotes formation of precipitates [26]. Increased dose at a particular energy appears to increase the size of precipitates that form at the expense of particle density [27].

\section{Phase Transformations}

Several studies have shown that with increasing concentraticn of implanted atoms, there is a spontaneous formation of new phases [21]. An example of this process is the formation of an amorphous metallic phase by hig! "uence 
implantation [28]. Hohmuth et al. have observed amorphization in iron after boron, silicon or phosphorus implantation [29]. In general, it has been observed that metalloids or glass-formers generally yield the amorphous state at some fluence. Amorphous phases have only been found for metalloid/metal radii ratios between 0.58 and 0.88 [24].

It is clear from the above brief discussion that the residual damage structure during and just after implantation is eventually responsible for subsequent property effects. The cascades induced determine the type and number of defects. The final microstructure depends on the subsequent kinetics of the defects and this eventually determines any changes in mechanical properties.

\section{MECHANICAL PROPERTIES OF ION-IMPLANTED METALS}

\section{Microhardness}

Hardness can be defined as a measure of the resistance to deformation, or more appropriately, permanent or plastic deformation [30]. Hardness tests are easy to perform and they represent a convenient way of quantitatively measuring the effects of ion implantation. This must however, be done with caution since there are several factors involved in hardness testing and the results need to be interpreted with care [31]. Most studies relating to hardness of implanted metals were done in the context of improving wear properties.

Knoop and Vickers tests were initially used to measure surface hardness. Pavlov et al. measured Vickers hardness of $30 \mathrm{keV} \mathrm{Ar}^{+}$-implanted steel. The 
results are shown in figure 3(a) using a $10 \mathrm{~g}$ load. Figure 3(b) also shows results obtained by Kanaya et al. for $24 \mathrm{kev}$ nitrogen implanted steel to a dose of approximately $10^{17} / \mathrm{cm}^{2}$ [31]. However, in both these scudies, the indenter probably penetrated through the implanted layer and in the latter study, the observed hardness increase was attributed to structural transformation due to the high intensity of implantation current [31].

\section{Test Techniques}

The Knoop test is better suited for measuring hardness of the implanted layer because one diagonal is $1 / 7$ th the length of the other and penetration depth is shallower than for the Vickers indenter. Kant et al. used this technique to estimate the near surface hardness of boron implanted beryllium at various fluences and energies. Measurements were made using 5, 10 and $25 \mathrm{~g}$ loads. The lighter loads yielded higher hardness values but, in general, the lighter loads also result in greater error in measurement due to inaccuracies in measuring small diagonals [32]. The microhardness values were found to increase with increasing dose and reached a maximum of four times the unimplanted hardness value for the $5 \mathrm{~g}$ load and 40 at- $\% \mathrm{~B}^{+}$-implanted sample [32].

Since even the lowest loads in conventional microhardness tests produce indentations comparable to or greater than the implanted layer thickness, with associated plastic deformation extending to several times this depth, ultra low-load microindentation testers have been developed [33-35]. In the technique developed by Pethica and co-workers, hardness values are estimated as a function of 
a

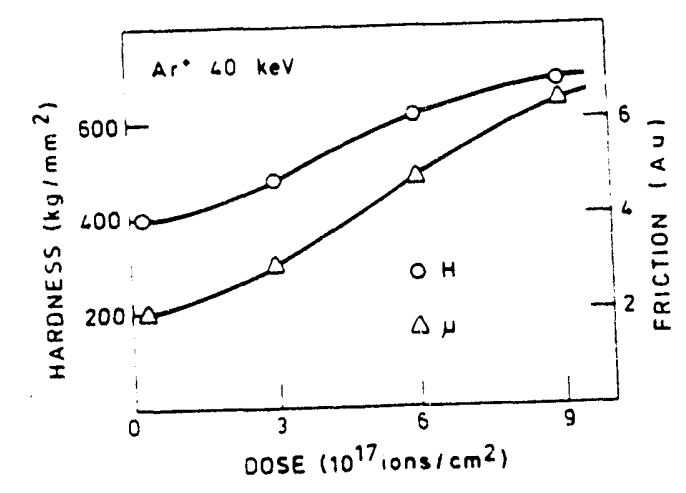

b

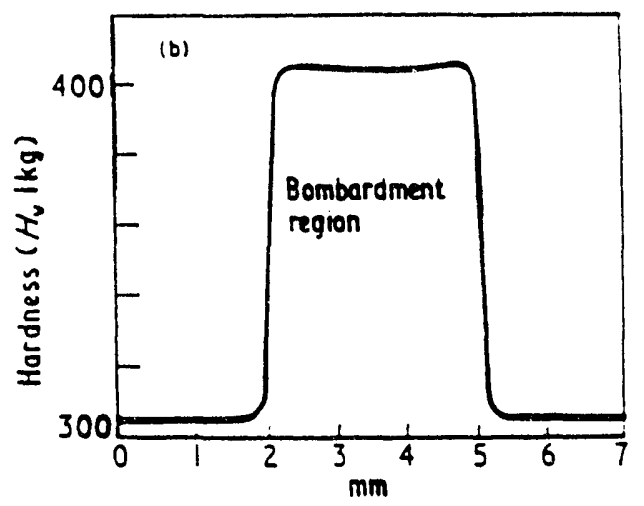

Figure 3. (a) Vickers hardness results obtained by Pavlov et al. for $30 \mathrm{keV}$ Ar implanted steel as a function of dose, (b) Results obtained by Kanaya et al. for $24 \mathrm{keV} \mathrm{N}$ implanted steel to a dose of $10^{17}$ ions $/ \mathrm{cm}^{2}$ [31]. 
penetration depth from the measured load and projected contact area of the indenter at a specific depth [34].

Factors Responsible for Surface Hardness Changes

There are several competing factors that could be responsible for the increase in near surface hardness of metals due to ion implantation. Radiation damage is an important one. Residual compressive stress due to interstitial atoms as well as substitution by larger atoms causing solid solution strengthening would also increase hardness. Precipitation hardening is also significant if the implanted species react to form fine precipitates [24].

Hutchings et al. have measured the microhardness of several metals implanted with nitrogen and relative hardness data are shown in Table 1 [36]. The greater effectiveness in hardening aluminum was attributed to its greater tendency to form nitrides. Interstitial hardening was considered to be responsible for the trend observed for iron, cobalt and nickel in Table 1. TiN precipitates were considered to be responsible for hardening of Ti-6AJ-4V $[24,36]$. Bourcier et al. have studied oxygen implanted $\mathrm{Al}$ and examined the hardening caused by the implantation. $\mathrm{A}$ factor of four increase in indentation load was observed for 20 -at $\%$ oxygen implantation. Extremely fine, hard oxide particles with radii $0.7-1.8 \mathrm{~nm}$ were detected in the implanted alloys using TEM $[37,38]$. Multiple Ion Implantation Effects on Microhardness

Lee and Mansur implanted four alloys based on the Fe-13Cr-15Ni system (Table 2) with $\mathrm{B}^{+}$and $\mathrm{N}_{2}^{+}$ions singly and simultaneously [6]. The hardness was 
Table 1.

Hardness increases in several metals implanted with $\mathrm{N}^{+}$.

Hardness was measured using a depth sensing nanoindentation technique [36]

\begin{tabular}{|c|c|c|c|}
\hline Metal & $\begin{array}{c}\text { Relative Hardness } \\
\text { Index }\end{array}$ & Crystal Structure & $\begin{array}{r}-\Delta \mathrm{H} \text { Nitride } \\
\text { (KJ/Mole) }\end{array}$ \\
\hline
\end{tabular}

Al

4.20

fcc

322

$\mathrm{Fe}$

1.84

bcc

11

Co

1.40

hep

$-10$

$\mathrm{Ni}$

1.04

fcc

$-1$ 
estimated using the nanoindentation technique and the results are shown in Table 3. Simultaneous implantation yielded the greatest improvement. This was attributed to the formation of very fine precipitates although this could not be confirmed using TEM. Damage induced defect hardening and solution strengthening were also considered to contribute towards the final hardness increase [6].

\section{Fatigue}

Fatigue is a commonly observed form of material failure caused by cyclic loading at stresses below the yield stress. A review of fatigue research history as well as a summary of the fundamental processes involved is given in [39]. It is now well established that fatigue failure starts with the initiation of microcracks at or near singularities which lie at or just below the surface. These singularities may be slip bands, inclusions, pre-existing microcracks, scratches, grain boundaries etc. Several of these microcracks may grow or coalesce to form larger cracks eventually leading to final failure [39]. The most common site for initiation of microcracks at the surface in many metals are persistent slip bands (PSBs). Persistent slip bands are formed at the surface fairly early during the fatigue history of the material and the name originates from the fact that even when the surface is removed by polishing, further cyclic loading produces slip bands at the same positions on the surface [39].

The critical event in fatigue failure is the initiation of microcracks. Since the initiation has been shown to occur at the surface, it was recognized that ion 
Table 2.

Alloy compositions of the Fe-13Cr-15Ni alloys used by Lee and Mansur [6].

\begin{tabular}{lllllllll}
\hline ALLOY & Fe & Cr & Ni & Mo & Ti & Si & C & $P$ \\
\hline B-1 & BaL. & $: 3.79$ & $: 4.96$ &. &. &. &. &. \\
B-5 & Bal. & $: 3.68$ & $: 4.94$ &. & 0.17 &. & 0.040 & $\cdot$ \\
B-6 & Bal. & $: 3.36$ & $: 5.04$ & $i .97$ & 0.19 &. & 0.056 &. \\
B-12 & Bal. & $: 3.58$ & $: 5.15$ &. & 0.17 & 0.83 & 0.044 & 0.049 \\
\hline
\end{tabular}


Table 3.

Hardness values of four simple $\mathrm{Fe}-13 \mathrm{Cr}-15 \mathrm{Ni}$ alloys implanted with $\mathrm{B}$ and $\mathrm{N}$ under various conditions, determined using the nanoindentation technique [from 6]

\begin{tabular}{|c|c|c|c|c|}
\hline \multirow[b]{2}{*}{ Implantation } & \multicolumn{3}{|c|}{ Hardness $(G P a)(=0.2)$} & \multirow{2}{*}{$\begin{array}{c}\text { Hardness } \\
\text { improvement }\left(?_{c}\right)\end{array}$} \\
\hline & BI & BS & $\mathrm{B} 12$ & \\
\hline Vone $(S A)$ & 1.8 & 1.8 & 1.8 & \\
\hline None $(\mathrm{CW})$ & 2.0 & 2.0 & 2.0 & \\
\hline $1 \% \mathrm{~B} / \mathrm{RT}^{\circ}$ & 3.5 & $\cdots$ & $\cdots$ & 94 \\
\hline $1 \% \mathrm{~N} / \mathrm{RT}$ & 3.4 & $\cdots$ & $\cdots$ & 89 \\
\hline $1 \% \mathrm{BN} / \mathrm{RT}$ & +.0 & $\cdots$ & $\cdots$ & 122 \\
\hline $2.5 \% \mathrm{BN} / \mathrm{RT}$ & 3.5 & 3.5 & 3.6 & 94 \\
\hline $0.5 \% \mathrm{BN} / 675^{\circ} \mathrm{C}$ & $\cdots$ & 2.1 & 2.1 & 17 \\
\hline DPH (none SA) & 160 & 182 & 184 & \\
\hline Grain size (ASTM) & 3.6 & 4.9 & 5.2 & \\
\hline
\end{tabular}

${ }^{2}$ All allovs are solution annealed at $1150{ }^{\circ} \mathrm{C}$ for 15 min.

${ }^{\circ}$ Atomic $\left(B\right.$ or $N$ ) or tormula (BN) percent. and RT indicates up to $200{ }^{\circ} \mathrm{C}$. 
implantation may retard the initiation of microcracks leading to an increase in the overall fatigue life. The earliest reported work originated from Harwell in the United Kingdom, where Hartley and co-workers implanted 18/8/1 stainless steel and titanium with $200 \mathrm{kev} \mathrm{N} \mathrm{N}^{+}$ions to a dose of $2 \times 10^{17} / \mathrm{cm}^{2}$. They observed that the fatigue life increased by a factor of $10[20]$.

A review of research until 1985 on effects of ion implantation on the fatigue properties of metals has been published by Vardiman [5]. The various studies can be broadly divided into strain controlled and stress controlled fatigue studies. Several of the strain controlled studies have been summarized in Table 4 [5]. Studies have been mainly conducted on copper, nickel, some steels and titanium alloys. Several stress controlled fatigue tests have also been conducted on ionimplanted metals and some of the results are summarized in Table 5 [5]. In several of these studies, an endurance limit was observed below which failure did not occur in over $10^{7}$ cycles and the fatigue behavior improvement is shown as an endurance limit increase in Table 5.

\section{Surface Slip Band Suppression}

Several investigators observed surface slip suppression or slip homogenization.

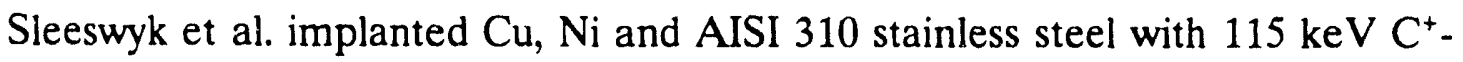
ions and conducted high strain (low cycle) fatigue tests on the dumbbell-shaped specimens [40]. The fatigue results are shown in figure 4 . The $\mathrm{C}^{+}$ 
Table 4.

A summary of several strain controlled fatigue tests on various metals [5].

\begin{tabular}{|c|c|c|c|c|c|c|c|c|}
\hline ¿े & $\stackrel{P}{\forall}$ & $\mathscr{F}$ & $\ddot{q}$ & $\Xi$ & L & $\mathscr{\sigma}$ & 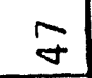 & $\stackrel{\infty}{\sigma}$ \\
\hline 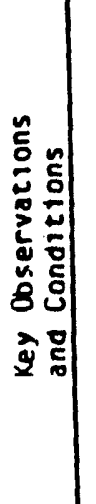 & 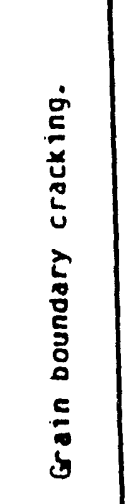 & 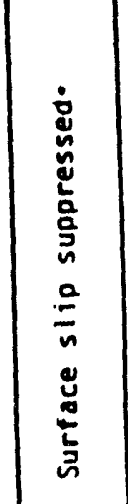 & 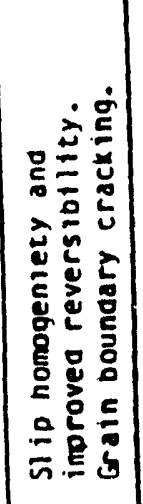 & 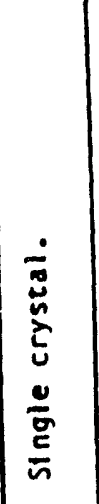 & 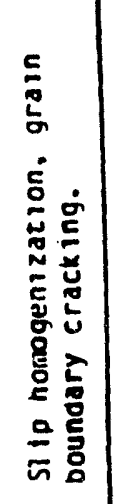 & 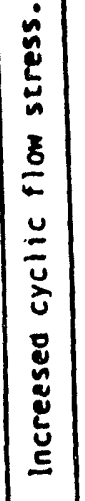 & 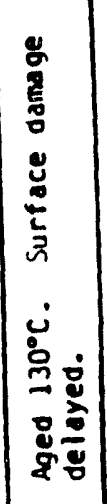 & 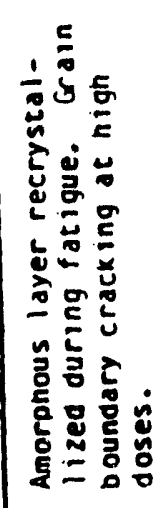 \\
\hline | & 气̆ & 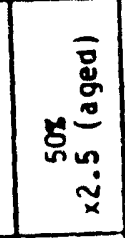 & 总 & $\begin{array}{l}\stackrel{0}{0} \\
x \\
0 \\
0 \\
x\end{array}$ & $\overline{\bar{E}}$ & ஜ̆ & 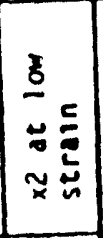 & 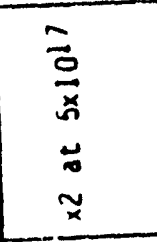 \\
\hline | & $\begin{array}{l}\tilde{O} \\
0\end{array}$ & 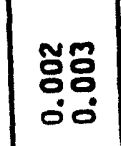 & 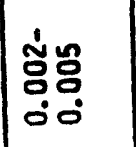 & 它号: & 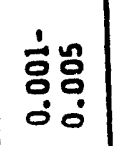 & ' & 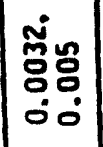 & $\begin{array}{l}0 \\
0 \\
0 \\
0\end{array}$ \\
\hline 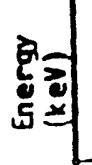 & $\cong$ & $\frac{\overline{\mathbf{z}}}{\mathrm{m}}$ & 으 & ¿ & 吕 & $\stackrel{\Xi}{\circ}$ & 点 & 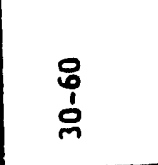 \\
\hline 吾 & $\frac{0}{0}$ & 章言 & $\frac{n}{0}$ & $\frac{n}{0}$ & $\frac{n}{0}$ & $\frac{0}{0}$ & $\overrightarrow{\overrightarrow{0}}$ & $\begin{array}{l}\frac{\infty}{0} \\
\frac{1}{1} \\
\stackrel{0}{0}\end{array}$ \\
\hline 도 & 七 & 举考 & 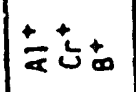 & $\stackrel{+}{<}$ & \pm & $\stackrel{+}{\alpha}$ & \pm & $\stackrel{+}{+}$ \\
\hline 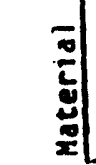 & $\exists=\tilde{y}$ & 芯菅 & 3 & 3 & $\stackrel{z}{ \pm}$ & $\begin{array}{l}= \\
\geq\end{array}$ & $\begin{array}{l}\bar{g} \\
\tilde{u} \\
n \\
0 \\
0 \\
0\end{array}$ & $\bar{z}$ \\
\hline
\end{tabular}


Table 5.

Summary of several stress controlled fatigue studies [5].

\begin{tabular}{|c|c|c|c|c|c|c|c|}
\hline & $\ddot{v}$ & $\stackrel{q}{8}$ & 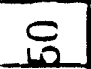 & tal= & $E$ & $\sim$ & مص \\
\hline & 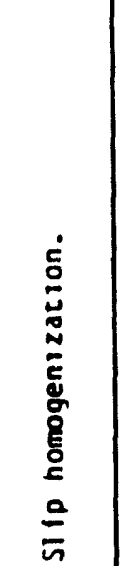 & 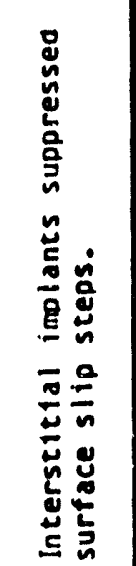 & 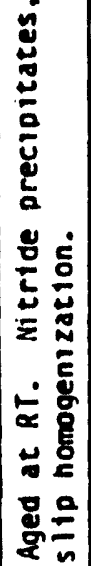 & 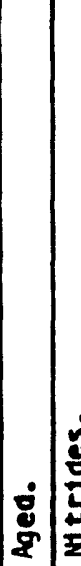 & 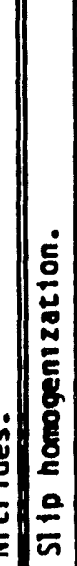 & 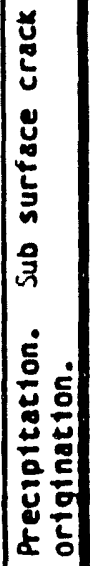 & 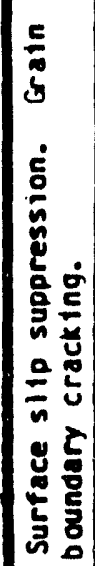 \\
\hline & มูะ & 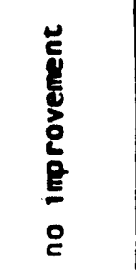 & $\underline{g}$ & 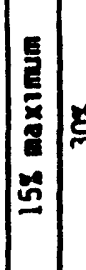 & $\stackrel{n}{\circ}$ & 占善 & $\Xi$ \\
\hline & 음 & 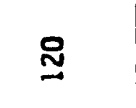 & 品 & : & 8 & $\approx$ & 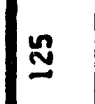 \\
\hline & $\stackrel{n}{\frac{n}{0}}$ & $\stackrel{0}{\frac{0}{x}}$ & $\overrightarrow{\underline{0}}$ & 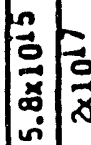 & $\frac{0}{x}$ & $\frac{\vec{\partial}}{\partial}$ & $\overrightarrow{\mathrm{d}}$ \\
\hline & ¿t心 & $コ^{+} \underbrace{+} \sigma^{+}$ & \pm & \pm \pm & 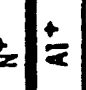 & \pm \pm & $t$ \\
\hline & & & 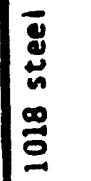 & $\left|\begin{array}{l}\bar{y} \\
\bar{u} \\
\vdots \\
\bar{\Xi} \\
\vdots\end{array}\right|$ & 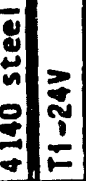 & 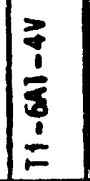 & 冚 \\
\hline
\end{tabular}



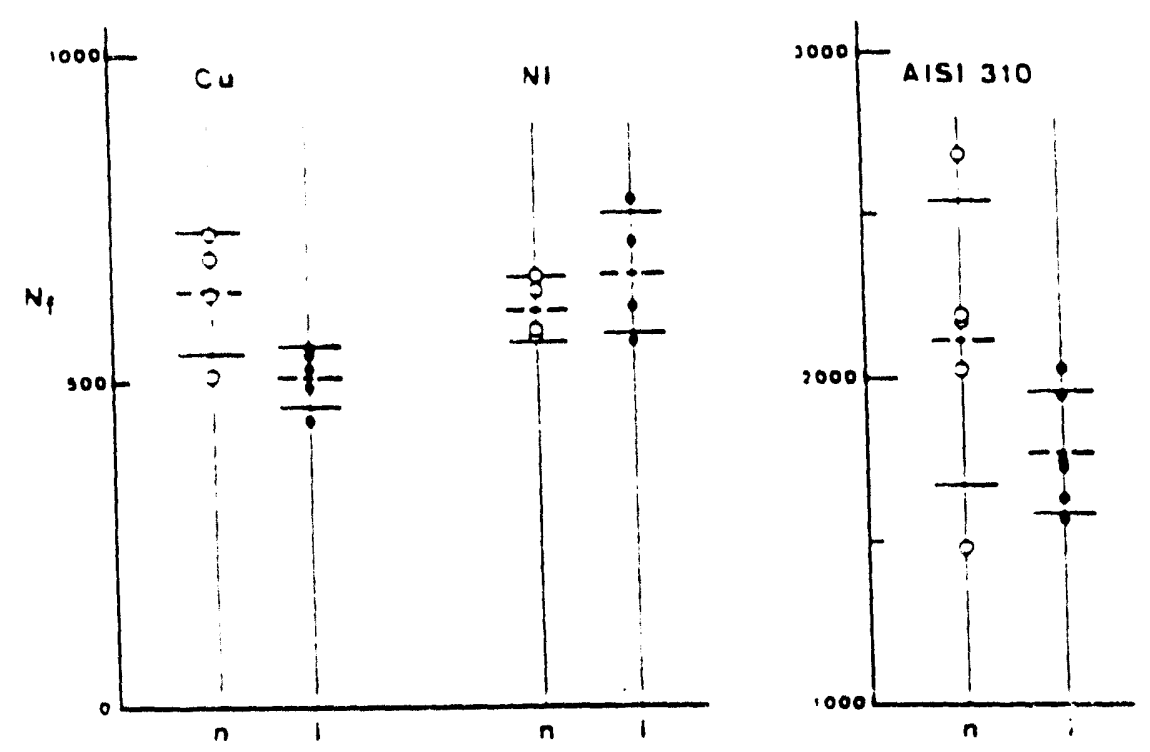

Figure 4. Fatigue results for $\mathrm{Cu} . \mathrm{Ni}$ and AISI $310 \mathrm{SS}$ implanted with 115 $\mathrm{keV} \mathrm{C}^{+}$( $\mathrm{n}$ - unimplanted, $\mathrm{i}$ - implanted) snowing a slight increase in fatigue life of $\mathrm{Ni}$ but a decrease for $\mathrm{Cu}$ and steel after implantation [40]. 
implantation decreased the life of copper and steel by approximately $20 \%$ and $15 \%$ respectively, whereas in the case of $\mathrm{Ni}$ there was an increase in average fatigue life of about $10 \%$. In the copper and steel specimens, coarsening of slip lines was observed in the implanted specimens and the consequent stress concentrations were considered by the authors to be responsible for the decrease in fatigue life. In the case of $\mathrm{Ni}$, in the implanted specimens, it was observed that slip lines ending on grain boundaries often induced a secondary set of slip lines in the adjacent grain which probably helped lower stress concentrations, leading to an increase in fatigue life [40].

Grummon et al. have examined changes caused by ion beam surface microalloying on the development of fatigue damage structures which precede crack nucleation [54-56]. Layers of $\mathrm{Ni}$ and $\mathrm{Al}$ of tens of $\mathrm{nm}$ thicknesses were deposited by vacuum evaporation on Ni substrates and irradiated with $500 \mathrm{keV}$ $\mathrm{Kr}^{+}$ions to form an ion-beam-mixed surface layer. The layer delayed the initial emergence of PSBs and reduced the number and intensity of slip band features. Surface slip bands consisted of single "persistent slip steps" in the implanted material and subsurface plastic strain localization in the material with the modified surface layer. In the surface modified materials, many PSBs extended up to the surface film but did not penetrate it. This, however, was thought to produce high local stresses in the layer leading to rupture of the surface layer and producing slip offsets which presumably developed into crack nuclei as shown in figure 5 [56]. 

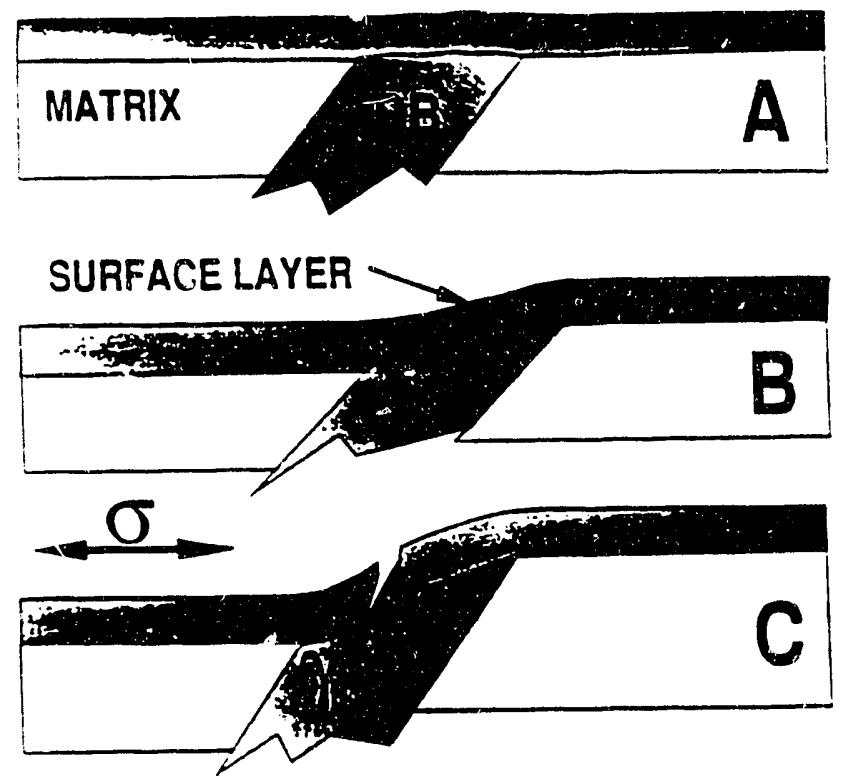

Figure 5. Possible sequence of events suggested by Grummon et al. for crack initiation at slip vands that penetrate the modified surface layer [after 56]. 
Morrison et al. have similarly performed fatigue damage studies on $\mathrm{Al}^{+}$implanted and self implanted $\mathrm{Ni}$, implanted to various doses and energies at low and high temperatures [57]. Both the $\mathrm{Al}^{+}$and self implantation increased near surface hardness. The primary hardening mechanism in ihe self-implanted specimens was implantation induced lattice defects and in this case, the authors ubserved cyclic softening which resulted in the formation of clear channels and easy penetration of the implanted region by subsurface PSBs. In the $\mathrm{Al}^{+}$ implanted specimens, hardening was caused by solid solution, and possibly precipitation hardening, and no cyclic softening was observed. Penetration of subsurface PSBs to the surface was suppressed. The results are given in Table 6 and hardness profiles are indicated in figure $6[5 \pi]$.

\section{Ion Size Effects}

The effects of ion type and size were explored in one study on copper [43,50]. Figure 7 shows the fatigue results for $100 \mathrm{keV} \mathrm{Al}, \mathrm{B}$ and $\mathrm{Cr}$ implantation, to a dose of $5 \times 10^{16} 10 n s / \mathrm{cm}^{2}$. Al-implantation had the most significant effect whereas boron implantation decreased the fatigue resistance to cyclic stress. Optical microscopy indicated that the extent of persistent slip band formation decreased after implantation, with $\mathrm{Al}$ having the greatest effect. Most of the microcracks were observed at grain boundaries, whereas some cracks were associated with PSBs. The cracks at PSBs were more frequent in the unimplanted specimens than in the $\mathrm{Al}$ implanted specimens. Based upon size effects, $\mathrm{Al}$ and $\mathrm{Cr}$ implantation 
Table 6.

Normalized hardness using the nanoindentation technique before fatigue testing for unimplanted and implanted $\mathrm{Ni}$ [56].

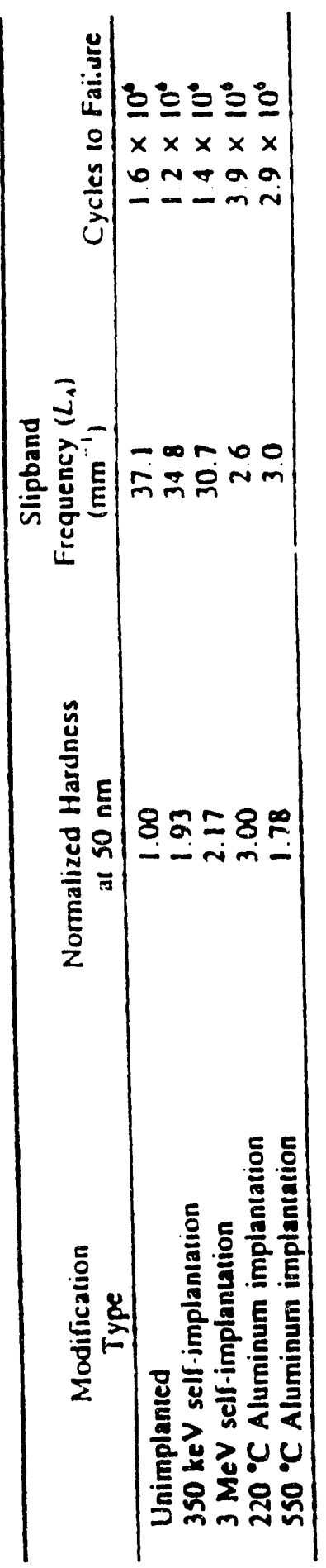



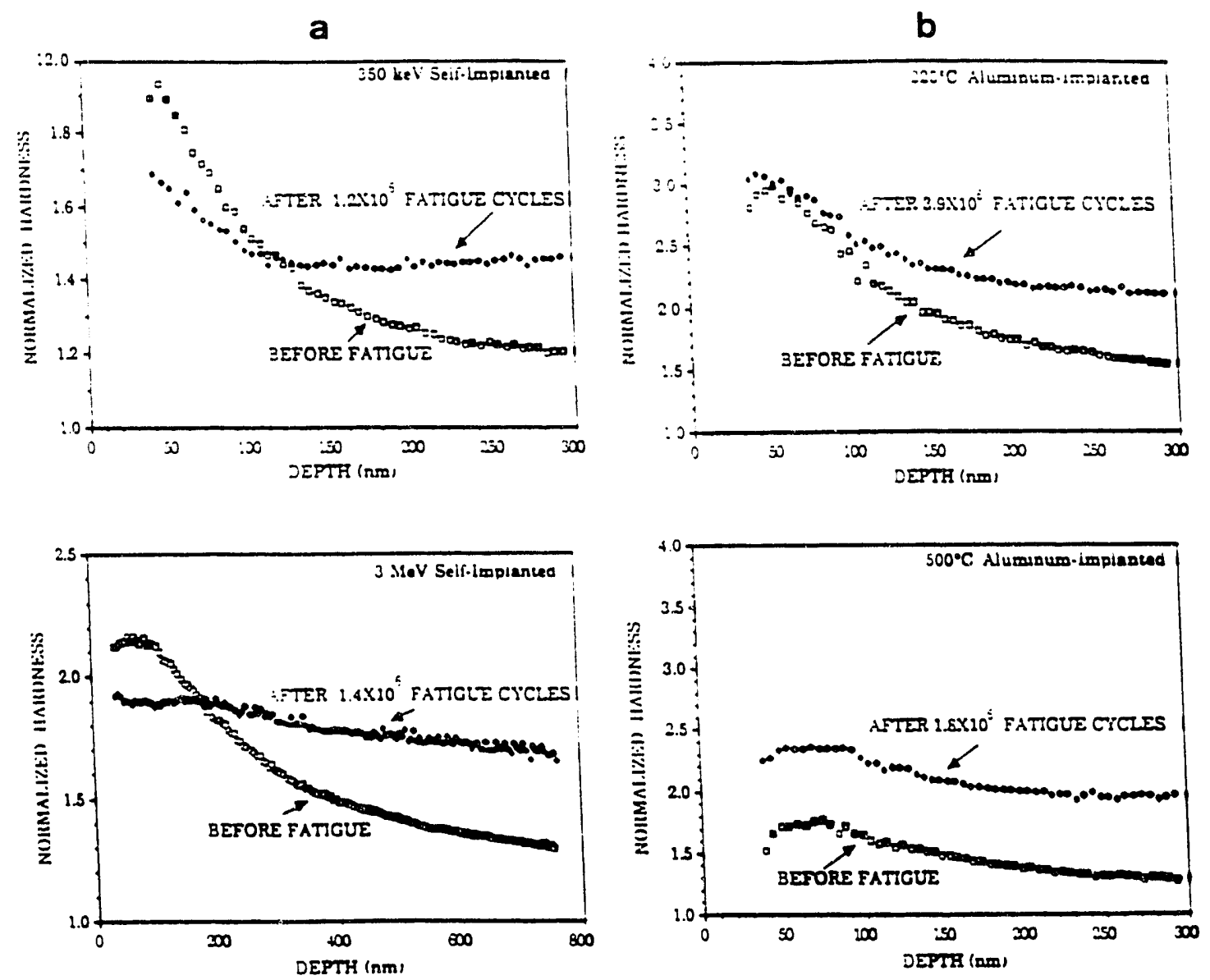

Figure 6. Normalized hardness-depth profiles of implanted Ni before and after fatigue testing [57]. 
a

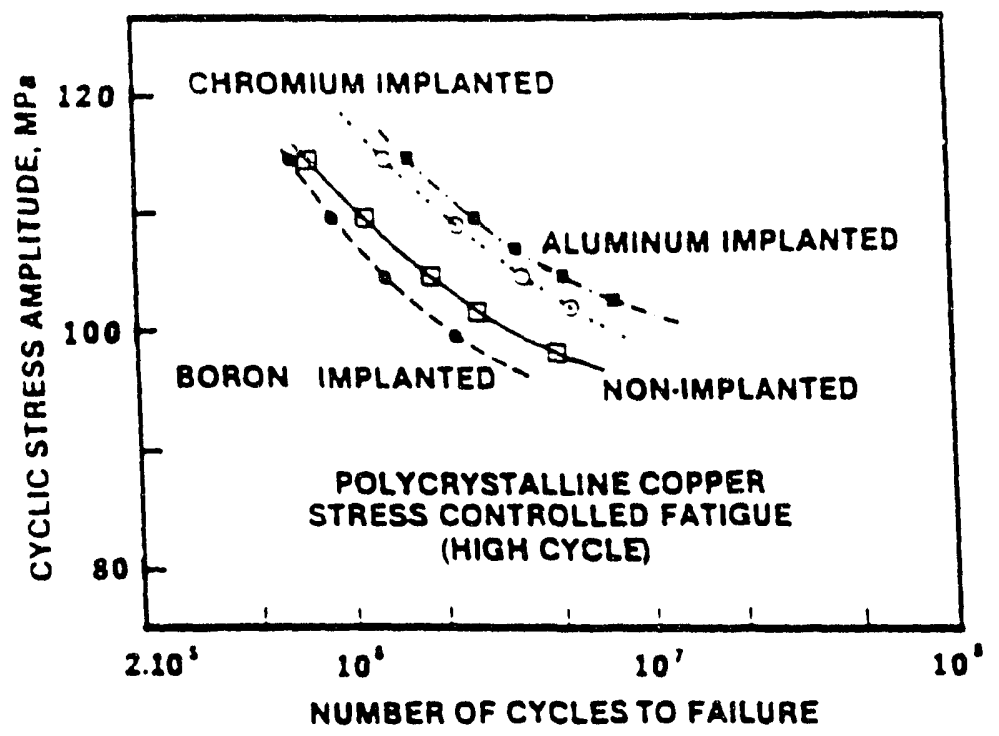

b

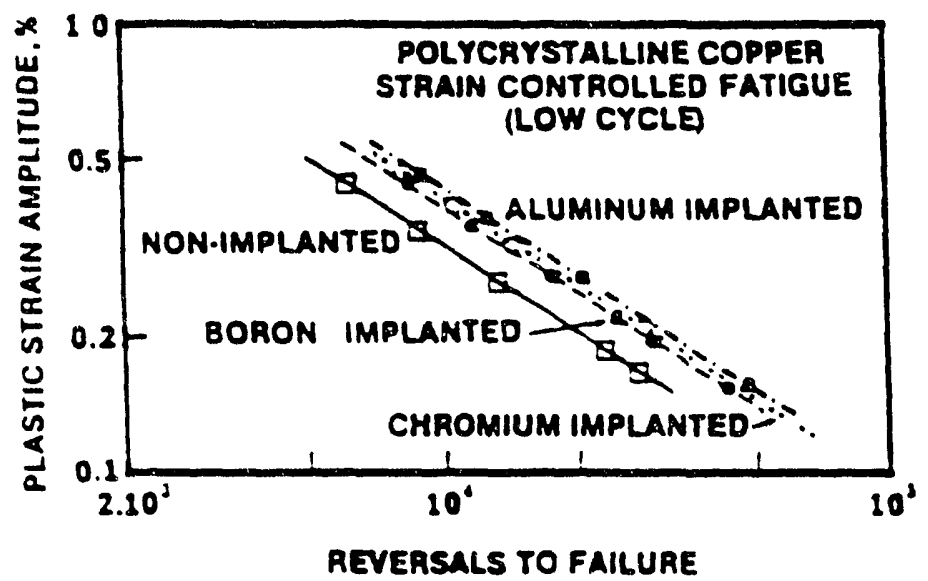

Figure 7. Fatigue results for stress and strain controlled fatigue tests for copper implanted with $100 \mathrm{keV} \mathrm{Al}, \mathrm{B}$ and $\mathrm{Cr}$ showing ion size effects $[43,50]$. 
would be anticipated to induce residual compressive stress whereas B implantation would be expected to produce residual tensile stresses. These tensile stresses caused the observed effects in B-implanted copper [43]. The authors attributed the improvement observed in $\mathrm{Al}$ implanted copper to an increase in stacking fault energy [50].

\section{Precipitate Effects}

Precipitation induced by ion implantation can have significant effects on fatigue properties. Hu et al. implanted AISI 1018 low carbon steel with $150 \mathrm{keV}$ $\mathrm{N}_{2}{ }^{+}$[26]. They conducted rotating bending tests at $5000 \mathrm{rpm}$. Their results are shown in figure 8. While the as-implanted specimens showed no consistent improvement in fatigue life, aging the specimens for a few months at room temperature or artificially for 6 hours at $100^{\circ} \mathrm{C}$ significantly improved fatigue life. A finely dispersed metastable nitride, $\mathrm{Fe}_{16} \mathrm{~N}_{2}$, and the presence of nitrogen martensite was observed [26,58]. The as implanted steels contained $10 \mathrm{~nm} \mathrm{Fe}{ }_{16} \mathrm{~N}_{2}$ particles while the aged specimens contained, in addition, a fine $2 \mathrm{~nm}$ precipitate as well as evidence of martensite [50]. Plain carbon steel is the cnly material to yield an improved fatigue life after a post implantation heat treatment [50]. In one study, 4140 steel showed an improvement after $\mathrm{N}^{+}$implantation. Surface hardening and the presence of second phases have been postulated to be the cause of fatigue life improvement in this case [5].

Some work has also been done on fatigue life modification of Ti-6Al-4V alloy with nitrogen and carbon implantation. Nitrogen implantation, with or without 


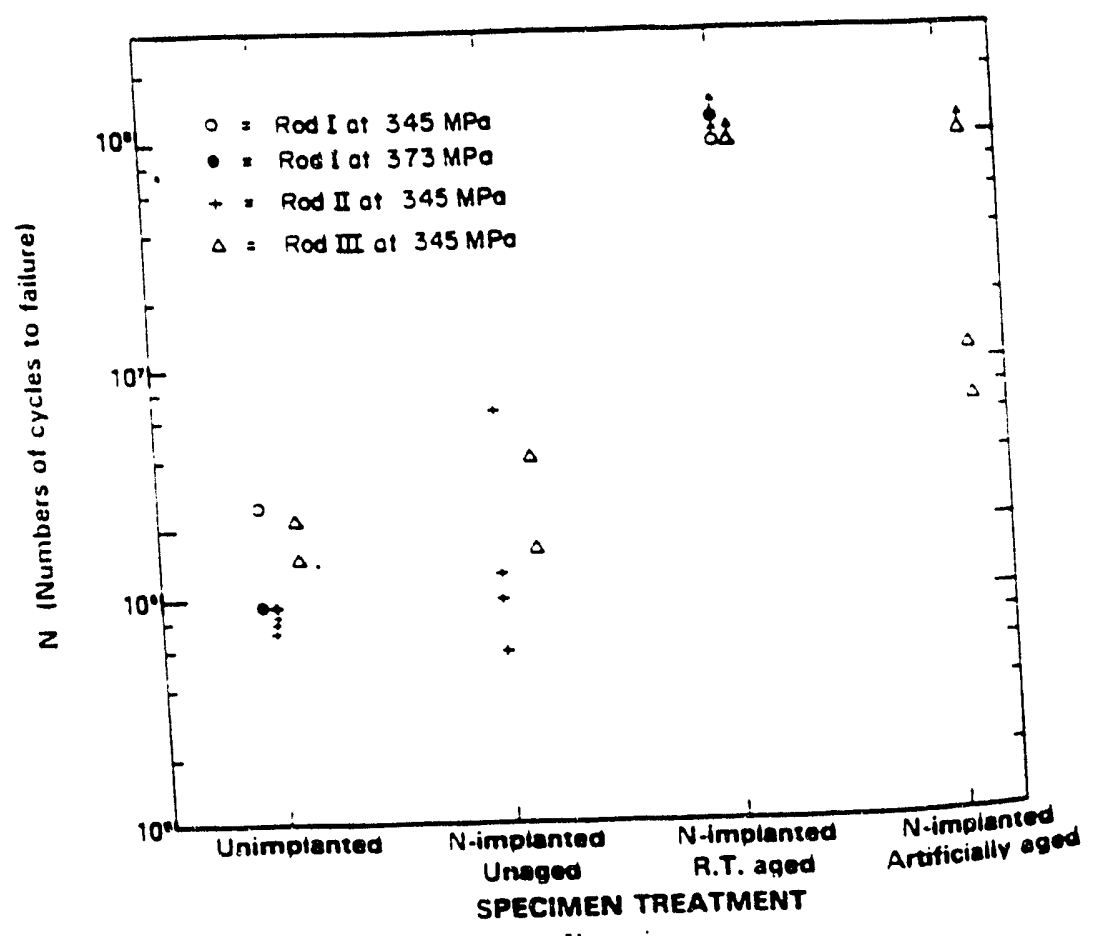

Figure 8. Fatigue results obtained by $\mathrm{Hu}$ et al. for AISI 1018 low C-steel implanted with $\mathrm{N}$. Aging promoted formation of a finely dispersed metastable $\mathrm{Fe}_{16} \mathrm{~N}_{2}$ phase, resulting in improved fatigue life [50]. 


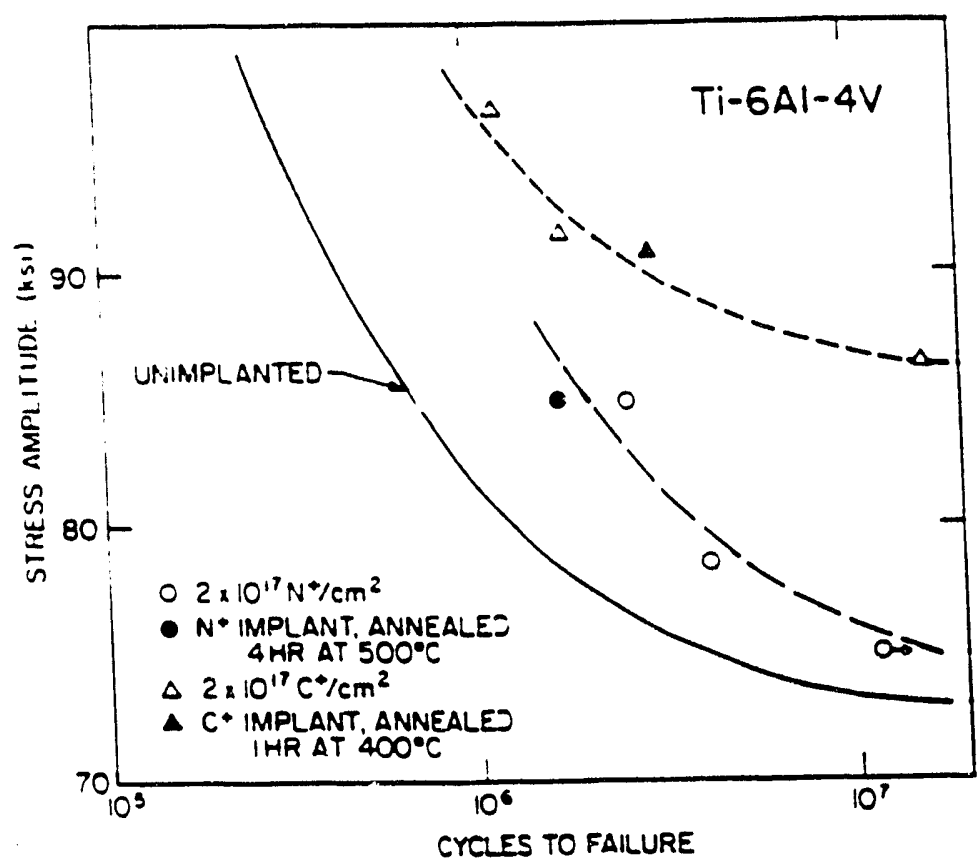

Figure 9. Effects of $\mathrm{N}^{+}$and $\mathrm{C}^{+}$implantation on fatigue properties of Ti$6 \mathrm{Al}-4 \mathrm{~V}$ alloy $[50,52]$. 
annealing caused only modest changes in fatigue properties whereas carbon implantation had a more significant effect, although again, annealing did not enhance the effect. The effectiveness of carbon was hypothesized to be due to the formation of $\mathrm{Ti}$ and $\mathrm{V}$ carbides which can form very easily. The results are shown in figure $9[50,52]$.

\section{Grain Boundary Effects}

Grain boundary cracking was observed in some strain controlled fatigue studies particularly in high-strain fatigue tests. Since grain boundary cracking would not be expected to be significantly affected by ion implantation, modest or no improvements were observed in several of the ion implanted polycrystalline materials in contrast to the single crystal copper results. Among the various strain controlled fatigue tests shown in Table 3, single crystal copper yielded the best improvement in fatigue life after $\mathrm{Al}^{+}$implantation [44].

Hohmuth et al. have implanted polycrystalline $\mathrm{Ni}$ with $60 \mathrm{keV} \mathrm{B}^{+}$ions to different doses and have conducted fatigue tests [48]. They found two major effects with increasing dose: (1) the relative number of grains containing persistent slip bands decreased and (2) the PSB surface relief in the implanted region was less marked. The fatigue results are indicated in Table 7 . The authors contend that the decrease in PSB surface relief due to the implantation should lead to a decrease in the extent of microcrack initiation. However, the incompatibility of stresses at grain boundaries between grains with a high relative misorientation, which would normally be relieved by slip band formation in the 
Table 7.

Dependence on fatigue life and relative number of grains containing PSBs in Ni on the B ion dose [48].

\begin{tabular}{llll}
\hline $\begin{array}{l}\text { Speci. } \\
\text { men }\end{array}$ & $\begin{array}{l}\text { Implantation } \\
\text { dose } \\
\left(\mathrm{B}^{*} \text { ions }\right. \\
\left.\mathrm{cm}^{-2}\right)\end{array}$ & $\begin{array}{l}\text { Fatigue } \\
\text { lifetime } \\
\text { (cycles) }\end{array}$ & $\begin{array}{l}\text { Pelative } \\
\text { number of } \\
\text { grains con- } \\
\text { taining PSBs }\end{array}$ \\
\hline 521 & 0 & 22000 & 1.00 \\
522 & $1 \times 10^{16}$ & 21000 & 0.85 \\
523 & $1 \times 10^{17}$ & 37000 & 0.61 \\
524 & $5 \times 10^{17}$ & 50000 & 0.46 \\
525 & $1 \times 10^{18}$ & 20200 & 0.34 \\
\hline
\end{tabular}


unimplanted specimens, would now lead to microcrack initiation at grain boundaries in the implanted specimens [48].

\section{Multiple Ion Implantation Effects}

Lee and Mansur have investigated the effects of simultaneous multiple ion implantation on the fatigue properties of $\mathrm{Fe}-13 \mathrm{Cr}-15 \mathrm{Ni}$ base model alloys [6]. They implanted $400 \mathrm{keV} \mathrm{B}^{+}$and $1.1 \mathrm{MeV} \mathrm{N}_{2}{ }^{+}$ions, singly and simultaneously into four $\mathrm{Fe}-13 \mathrm{Cr}-15 \mathrm{Ni}$ base alloys whose compositions are shown in Table 7. Their results (figure 10) show that while the single implantation caused only modest or no improvements in fatigue life, the simultaneous dual implantation yielded the greatest improvement. The implantations improved slip reversibility and delayed crack initiation. They concluded that changes in surface stacking fault energy and the nature of precipitate formation played significant roles. Their work suggested that simultaneous multiple implantation could be of significant benefit in improving fatigue properties of metals [6].

\section{Creep}

Creep can be defined as time dependent permanent deformation at stresses well below the yield strength of the material. Time-dependent deformation is significant at higher temperatures, typically $>0.5 \mathrm{~T}_{m}$ [59]. The process can usually be divided into three stages: (1) transient creep, where strain rate decreases with time, (2) steady-state, where the strain rate remains constant - this stage is associated with an approximately invariant microstructure due to a balance between dislocation generation and annihilation, and (3) tertiary creep, where 


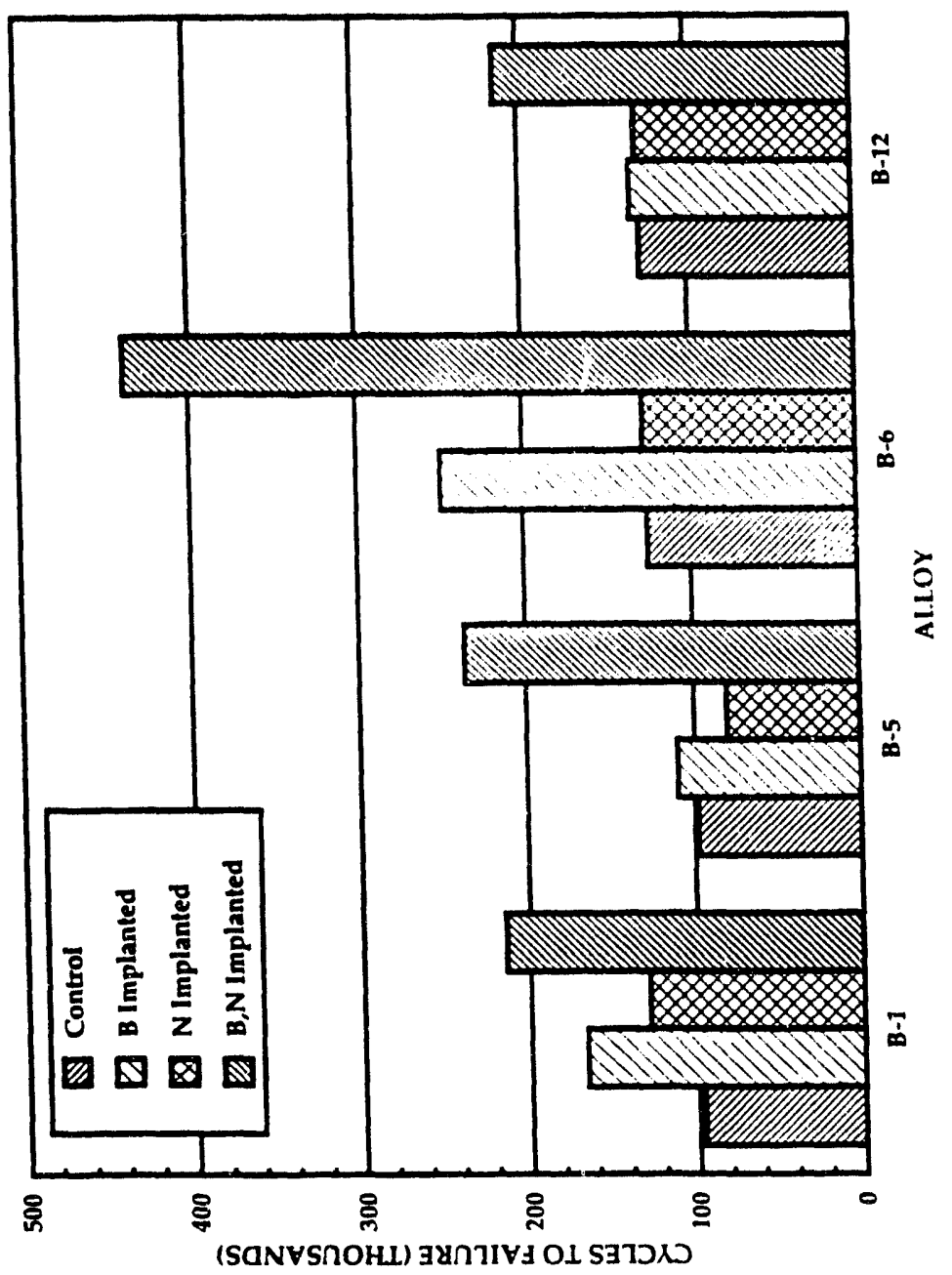

Figure 10. Fatigue results for single and dual $\mathrm{B}^{+}$and $\mathrm{N}^{+}$implantation in the four B-series $\mathrm{Fe}-13 \mathrm{Cr}-15 \mathrm{Ni}$ alloys used by Lee and Mansur showing the significant improvement in fatigue life for the dual implanted specimens [6]. 
creep strain increases with time - this stage, which precedes final fracture, is associated with the coalescence and growth of cavities leading to microcracking and final failure [59].

Creep is a complex process and is sensitive to microstructure, stress, temperature and environment. Surface films have been shown to have a pronounced effect on creep. In a study on cadmium, Cd single crystals were creep tested with a $35 \mu \mathrm{m}$ thick hydroxide film on the surface. During the test, the film was removed by the addition of $\mathrm{H}_{2} \mathrm{SO}_{4}$. This caused the creep rate to suddenly increase as shown in figure 11 [60].

The surface layer thus plays an important role in creep properties of materials. Studies have shown that dislocation densities after creep were higher at the surface of $\mathrm{Al}$ alloys to a depth of $60-100 \mu \mathrm{m}$ as compared to the interior [61]. In one study, Ti was vacuum coated onto the surface of type 304 stainless steel and diffused to form a $40 \mu \mathrm{m}$ deep alloy layer. The stress rupture life of the steel was significantly increased (by a factor of 5) at temperatures ranging from $704^{\circ}$ to $815^{\circ} \mathrm{C}$. Similar studies on $\mathrm{Ti}(6 \mathrm{Al}-4 \mathrm{~V})$ and an $\mathrm{Al}$ alloy coated with diffuse layers have also shown similar results as indicated in Table 8 [61].

There have been very few studies on the effects of ion implantation on high temperature properties of metals. Hall has investigated the effects of germanium, tellurium and carbon implantation on high temperature deformation behavior of molybdenum [8]. Creep tests were performed on the specimens with temperature increased periodically to observe temperature effects. Tests were performed on 


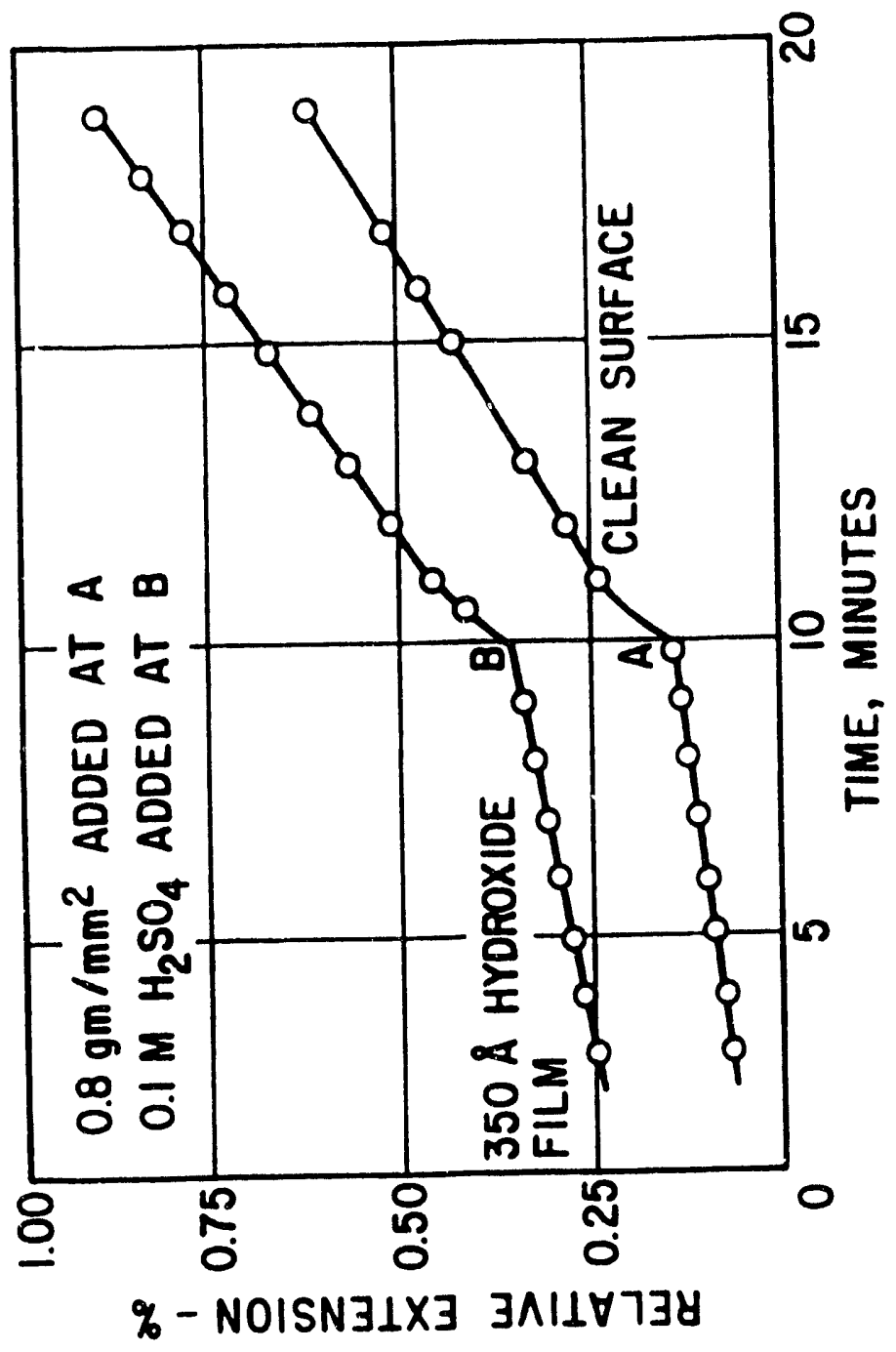

Figure 11. Creep curves for cadmium crystals showing the effect of removal of a surface hydroxide film at B and increasing stress at A [60]. 
Table 8.

The effects of surface alloying on the high temperature behavior of a $\mathrm{Ti}$ and an $\mathrm{Al}$ alloy. $\mathrm{R}^{*}$ is the ratio of minimum creep strains for bare and coated specimens [61].

\begin{tabular}{|c|c|c|c|c|}
\hline $\begin{array}{r}\text { Stress } \\
\text { kst (MPa) }\end{array}$ & $\begin{array}{c}\text { Temperature } \\
{ }^{\circ} \mathrm{C} \\
\end{array}$ & Coating & $\varepsilon_{8}$ & $\overline{R^{\star}}$ \\
\hline $\begin{array}{ll}80 & (551.6) \\
80 & (551.6)\end{array}$ & $\begin{array}{l}260 \\
260\end{array}$ & $\begin{array}{l}0 \\
\mathrm{Al}\end{array}$ & $\frac{T 1(6 \mathrm{Al}-4 \mathrm{~V})}{1.3 \times 10^{-8}}$ & $\begin{array}{l}1 \\
3\end{array}$ \\
\hline $\begin{array}{ll}85 & (586.1) \\
85 & (586.1)\end{array}$ & $\begin{array}{l}260 \\
260\end{array}$ & $\begin{array}{l}0 \\
\mathrm{Al}\end{array}$ & $\begin{array}{l}3 \times 10^{-8} \\
1 \times 10^{-8}\end{array}$ & $\begin{array}{l}1 \\
3\end{array}$ \\
\hline $\begin{array}{ll}80 & (551.5) \\
80 & (551.6)\end{array}$ & $\begin{array}{l}288 \\
288\end{array}$ & $\begin{array}{l}0 \\
\text { Al }\end{array}$ & $\begin{array}{l}7.6 \times 10^{-8} \\
10^{-8}\end{array}$ & $\begin{array}{r}1 \\
>8\end{array}$ \\
\hline $\begin{array}{ll}85 & (586.1) \\
85 & (586.1)\end{array}$ & $\begin{array}{l}288 \\
288\end{array}$ & $\begin{array}{l}0 \\
\text { Al }\end{array}$ & $\begin{array}{l}1.66 \times 10^{-7} \\
4.3 \times 10^{-9}\end{array}$ & $\begin{array}{r}1 \\
38\end{array}$ \\
\hline $\begin{array}{l}40(275.8) \\
40(275.8) \\
40(275.8)\end{array}$ & $\begin{array}{l}150 \\
150 \\
15\end{array}$ & $\begin{array}{l}0 \\
\mathrm{Cr} \\
\mathrm{Cu}\end{array}$ & $\begin{array}{l}\frac{7075-\mathrm{T} 6}{1.6 \times 10^{-6}} \\
4 \times 10^{-7} \\
5.5 \times 10^{-7}\end{array}$ & $\begin{array}{l}1 \\
4 \\
3\end{array}$ \\
\hline $\begin{array}{ll}35 & (241.3) \\
35 & (241.3) \\
35 & (241.3)\end{array}$ & $\begin{array}{l}150 \\
150 \\
150\end{array}$ & $\begin{array}{l}0 \\
\mathrm{Cr} \\
\mathrm{Cu}\end{array}$ & $\begin{array}{l}5.4 \times 10^{-7} \\
1.8 \times 10^{-8} \\
1 \times 10^{-9}\end{array}$ & $\begin{array}{r}1 \\
30 \\
54\end{array}$ \\
\hline $\begin{array}{ll}25 & (172.4) \\
25 & (172.4) \\
25 & (172.4)\end{array}$ & $\begin{array}{l}177 \\
177 \\
177 \\
\end{array}$ & $\begin{array}{l}0 \\
\mathrm{Cr} \\
\mathrm{Cu}\end{array}$ & $\begin{array}{l}6.8 \times 10^{-7} \\
8.3 \times 10^{-8} \\
1.1 \times 10^{-8}\end{array}$ & $\begin{array}{l}1 \\
8 \\
6 \\
\end{array}$ \\
\hline
\end{tabular}



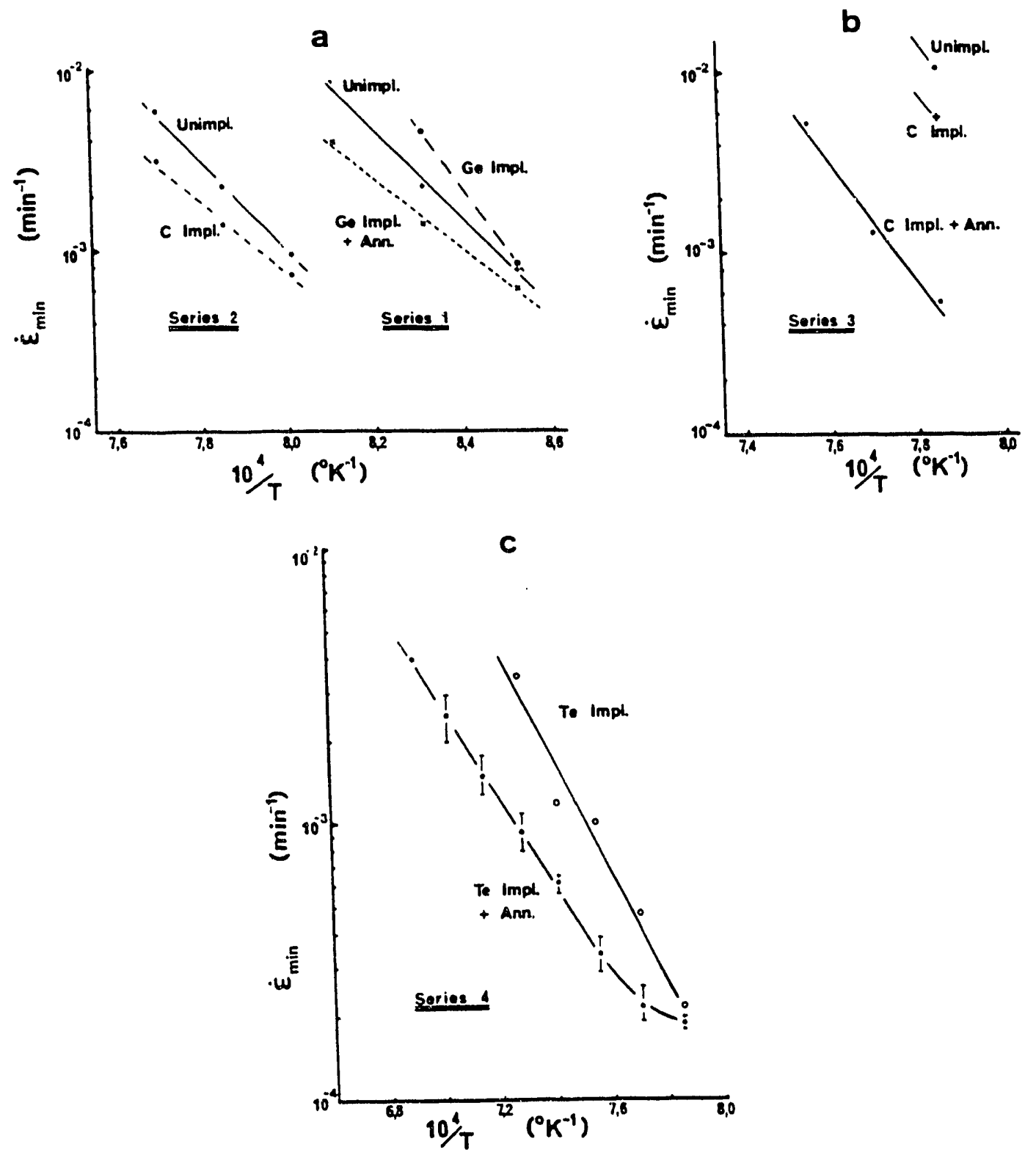

Figure 12. Creep results for Mo implanted with $\mathrm{Ge}, \mathrm{Te}$ and $\mathrm{C}$ as a function of temperature [8]. 
control, as-implanted and implanted+annealed specimens and results are shown in figure 12. In general, Te and Ge as-implanted samples showed an increase in creep rates though the annealed specimens showed a decrease in strain rate with a corresponding increase in creep resistance. This behavior was explained in terms of radiation damage. The heavy $\mathrm{Te}$ and $\mathrm{Ge}$ ions caused formation of large numbers of vacancies which resulted in self-diffusion controlled deformation processes. The annealing treatment decreased the number of residual point defects with a corresponding decrease in strain rate [8]. Carbon implantation on the other hand is a light ion irradiation resulting in smaller vacancy concentrations. However, $\mathrm{C}$ will occupy interstitial sites and according to the authors, the diffusion of the interstitial $\mathrm{C}$ atoms will govern the properties. The study showed the effects of ion species on creep properties of Mo [8].

Hall also implanted Te in type 304 stainless steel and studied high temperature properties, and the results are shown in Table 9 [62]. The implantation increased creep rates as well as improved the overall ductility. The author observed oxidation on the surface of the unimplanted specimens which penetrated and embrittled the grain boundaries. The implantation apparently suppressed oxidation on the surface and fractures were mainly transgranular [62].

Jata and Hubler have studied $\mathrm{Fe}$ and $\mathrm{Ce}$ implantation in $2124 \mathrm{Al}$ alloy [63]. They also found that the as-implanted specimens showed an increased strain rate but the implanted +annealed specimens showed a decreased creep rate. The authors suggest that in the as-implanted specimens, a large flux of vacancies were 
Table 9.

Minimum creep rates for unimplanted and Te-implanted type 304 SS [62]

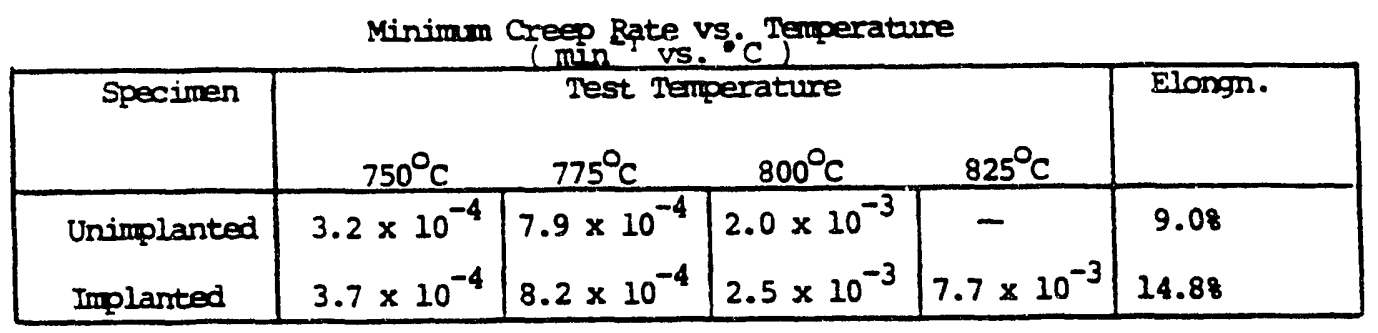


formed which would have migrated and coalesced as voids at the grain boundaries much faster than precipitate nucleation and growth during the test. The implanted+annealed specimens revealed stable $\mathrm{Al}_{3} \mathrm{Fe}$ and $\mathrm{Al}_{10} \mathrm{Fe}_{2} \mathrm{Ce}$ precipitates in the microstructure which probably imparted particle and sub-grain boundary strengthening. The annealing may also have eliminated the voids according to the authors [63].

\section{MECHANICAL PROPERTIES OF ION-IMPLANTED POLYMERS}

\section{Basic Effects}

The history of research on ion implantation of polymers can be traced back to radiation chemistry studies in the 1950s. High energy radiation from electron beams, $\mathrm{x}$-rays or $\beta$-rays was found to initiate ionization and radical formation [64,65]. This was observed to cause chain-scission and cross-linking depending upon dose rate and polymer structure. Most of these studies, however, have concentrated on chemical effects such as polymerization in the absence of catalysts and grafting to form copolymers [64]. The effects of irradiation of polymers using ionization radiations were shown to include: (1) fragmentation and cleavage of polymeric macromolecules resulting in loss of volatile species, (2) cross-linking, resulting in the formation of chemical bonds between molecules and (3) disappearance or formation of unsaturated groups in the molecular structure [66].

In the past decade, the implantation of $\mathrm{keV}$ or $\mathrm{MeV}$ ions has been used to modify surface properties of polymers. These have mostly concentrated on 
changes in optical and electrical properties of polymer surfaces $[9,67-70]$. Studies have also been performed on solubility and molecular weight distributions [71-74], and biocompatibility $[75,76]$.

There are several differences between irradiation of polymers using ionizing radiation and energetic ions. Marletta has described the differences as: (1) higher energy is deposited by the ions, typically 50 to $5000 \mathrm{eV} / \mathrm{nm}$ for $\mathrm{keV}$ ions, (2) two energy deposition mechanisms, electronic excitation and collisions, act simultaneously and their relative contributions strongly depends on the energy of the ions and (3) there is a higher yield (or G-value, which is the number of molecules released following absorption of $100 \mathrm{eV}$ radiation energy) for ionirradiation as compared to ionizing radiation [66]. It is thus clear that ion-polymer interactions are nonlinear events with high density energy deposition.

A review of ion beam effects in polymers and organic solids is given by Venkatesan et al. [9]. Typical processes for high energy ion-polymer interaction are shown in figure 13 for $2 \mathrm{MeV} \mathrm{Ar}{ }^{+}$implantation based on ion dose. The energy lost by the impinging ions results in the formation of ions and excited states. The electrons produced by ionization can cause secondary processes if their energy exceeds $100 \mathrm{eV}$. This results in bond rearrangements and chemical changes on the surface [9].

Almost all polymeric films undergo strong gas evolution during ion irradiation. The ejected species include small molecules, ionized components, hydrogen and 


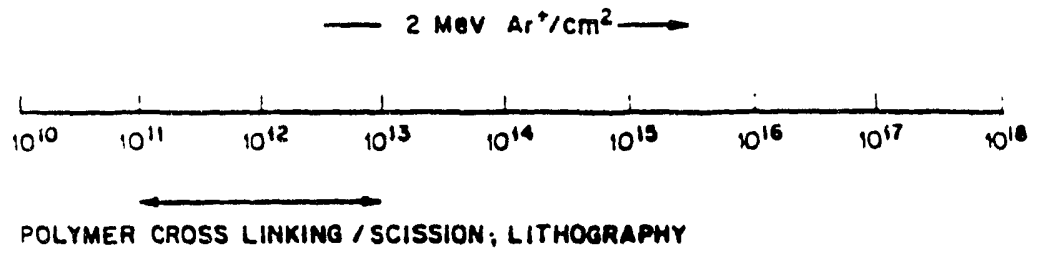

POLYMEA CROSS LINKING / SCISSION; LITHOBRAPHY

GEAM INDUCED POLYMERIZATION OF MONOMERS

POYYMER DISSOCIATION, OIFFUSION MEASUREMENT

OXYGEN PICK UP; LOSS OF INTEONITY; CHAMEE IN OPTICAL PROPERTIES

CARBONIZATION; MOACAMIC COMPOUMO BYNTHEBIS

HAMUE IN ELECTRONIC TRAMSPOAT

Figure 13. Typical processes occurring in polymers subjected to ion irradiation, as a function of dose [after 9]. 
Table 10.

Typical molecular species emitted from PE and PS subjected to ion irradiation. The table also shows G-values for the various species [9].

\begin{tabular}{|c|cc|cc|}
\hline Molecule & \multicolumn{2}{|c|}{ Polystyrene } & \multicolumn{2}{c|}{ Polyethylene } \\
(Mass) & $\begin{array}{c}100 \mathrm{keV} \\
\mathrm{He}^{+}\end{array}$ & $\begin{array}{c}200 \mathrm{keV} \\
\mathrm{Ar}^{+}\end{array}$ & $\begin{array}{c}100 \mathrm{keV} \\
\mathrm{He}^{+}\end{array}$ & $\begin{array}{c}200 \mathrm{keV} \\
\mathrm{Ar}^{+}\end{array}$ \\
\hline $\mathrm{H}_{2}(2)$ & 0.3 & 1.15 & 4.8 & 2.8 \\
$\mathrm{CH}_{4}(16)$ & $\sim 0$ & 0.012 & $\sim 0$ & 0.064 \\
$\mathrm{C}_{2} \mathrm{H}_{2}(26)$ & 0.02 & 0.61 & 0.15 & 0.3 \\
$\mathrm{C}_{3} \mathrm{H}_{5}(41)$ & -0 & 0.004 & 0.14 & 0.03 \\
$\mathrm{C}_{6} \mathrm{H}_{6}(78)$ & 0.04 & 0.015 & & \\
$\mathrm{C}_{8} \mathrm{H}_{8}(104)$ & 0 & 0.011 & & \\
\hline
\end{tabular}




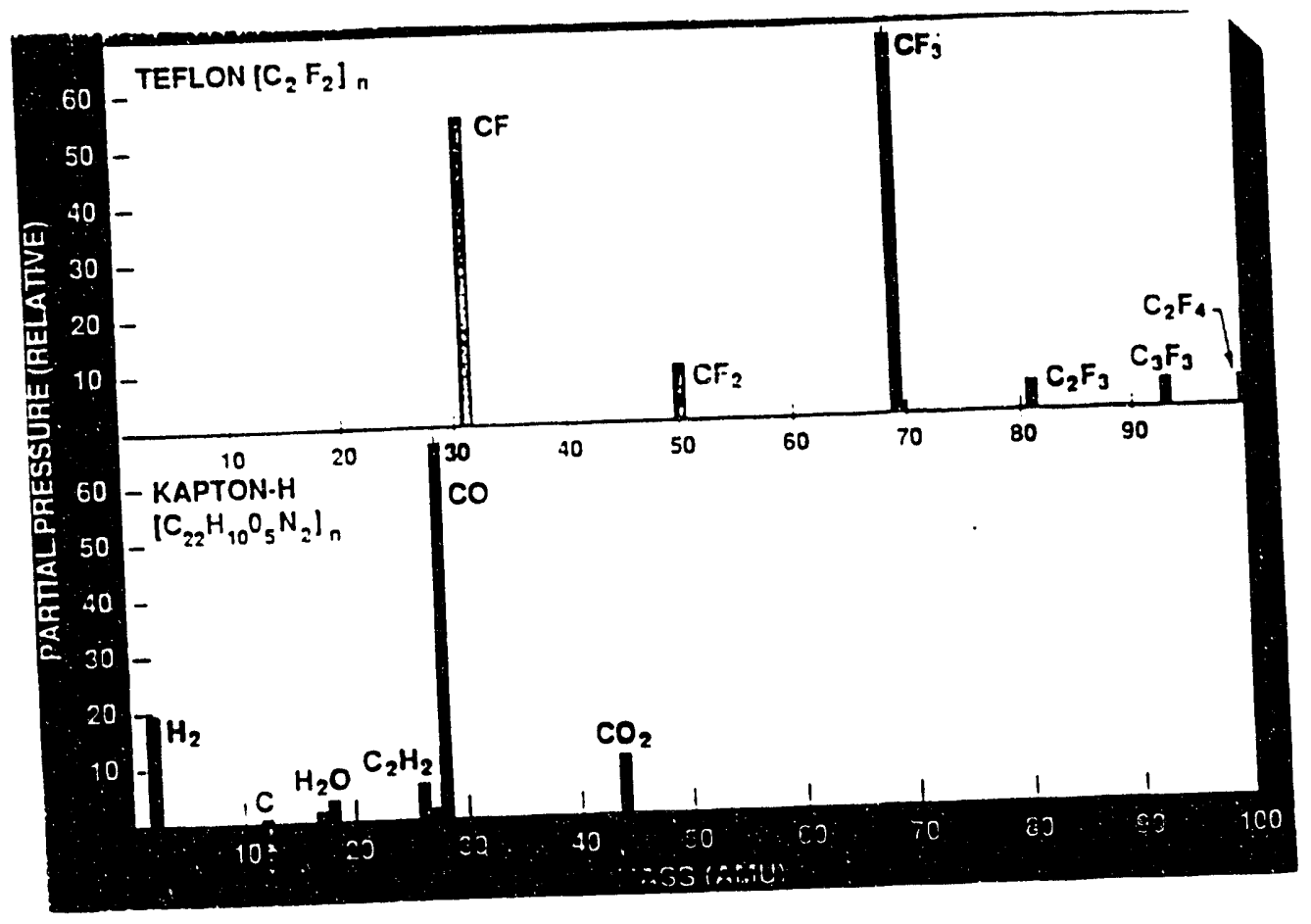

Figure 14. Residual gas analysis results for Teflon and Kapton during $200 \mathrm{keV}$ $\mathrm{Si}^{+}$implantation [77] 
species with higher molecular weight. Typical species emitted from common polymers are given in Table 10 [9]. Figure 14 shows the residual gas analysis of Teflon and Kapton during $200 \mathrm{keV} \mathrm{Si}{ }^{+}$implantation [77] showing typical gases observed during the first minute of irradiation. Typically, the emission is greatest at the beginning of the implantation and decreases slowly with time [77].

The chemical yield can be qualitatively characterized using the G-value, which is the number of molecules of specific gases released from a given polymer surface following absorption of $100 \mathrm{eV}$ of radiation energy [9]. The G-value can be estimated as:

$$
G=\frac{Q_{0}}{I} \frac{100}{E}
$$

where, $Q_{0}$ is the maximum emission yield, $I$ is the current and $E$ is the energy of the incident ions [9]. Typical values are shown in Table 10 for polystyrene (PS) and polyethylene (PE). Similarly, results obtained for PE and Kapton are shown in figure 15 as a function of average stopping power of the various ion-polymer combinations [78].

Ion irradiated polymers generally show a large reduction in hydrogen concentration, up to $80 \%$ in many cases. Similar results are seen for other elemental constituents of the polymers. However, no large changes have been observed in carbon concentration. Since the changes in elemental composition occur within the ion range, the technique represents a powerful method for changing polymer properties at the surface in a controlled manner [9]. 

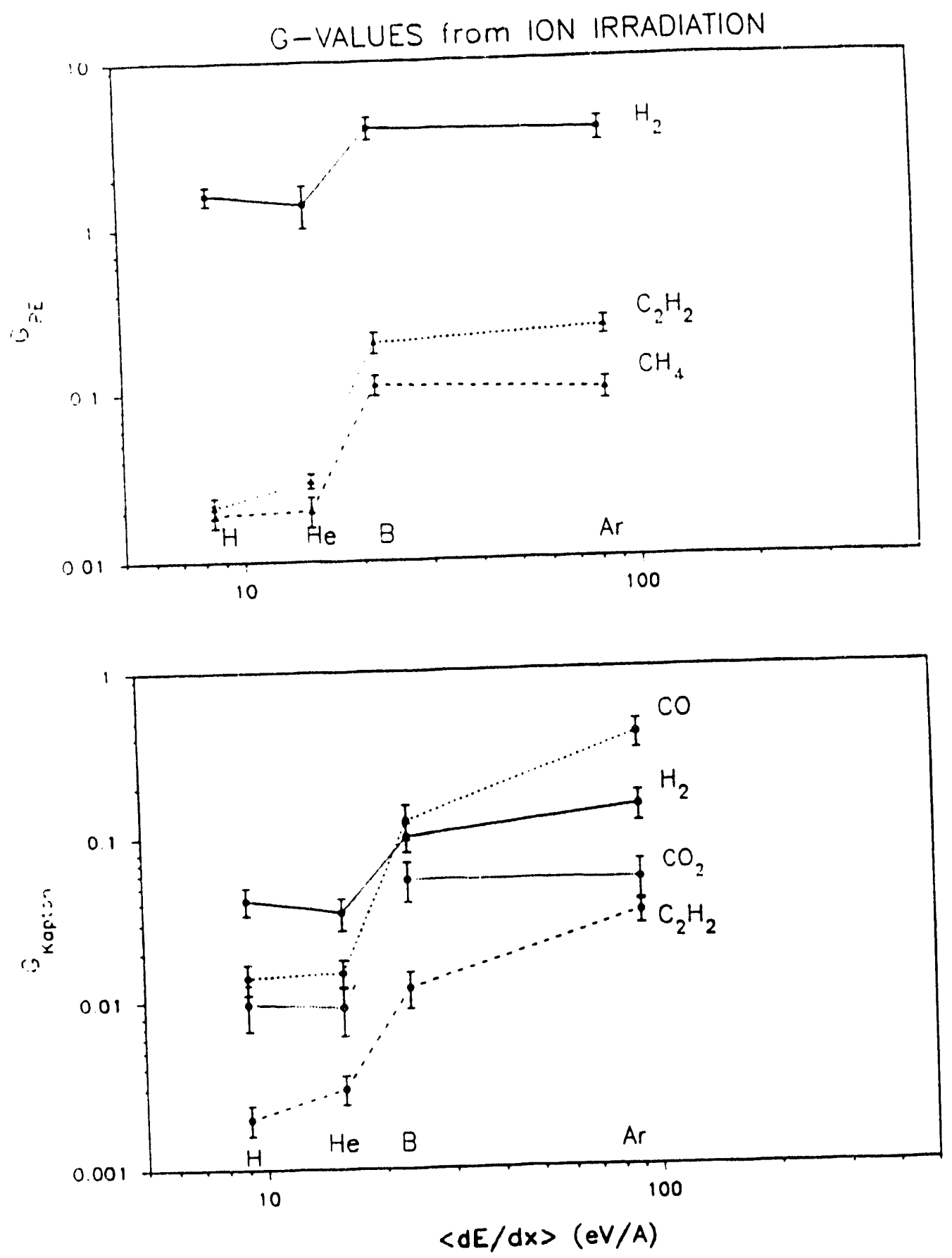

Figure 15. G-values obtained by Lewis et al. for various species ejected from $\mathrm{PE}$ and Kapton due to $\mathrm{H}, \mathrm{He}, \mathrm{B}$ and $\mathrm{Ar}$ implantation, as a function of stopping power [78]. 


\section{Microstructure}

Currently, there appears to be two schools of thought regarding ion-polymer interactions. Several authors suggest that during ion penetration, a plasma-like region is formed along the ion-tracks, where all existing bonds are broken $[69,70]$. There is a subsequent rearrangement of atoms causing the formation of a graphitized region which explains the "blackening" of the polymer as well as enhancements in electrical conductivity and optical properties $[69,70,79]$. A second school of thought suggests that "mild" and well defined chemical reactions are induced by the primary ion-polymer interactions, the sum of which produces a different chemical system. According to this model, the ion irradiated polymers show a continuous evolution of the primary chemical structure to the "carbonaceous" material which is finally obtained [66].

The sometimes drastic increases in conductivity of polymers by ion implantation led workers to examine the microstructures of ion implanted polymers. The conductivity enhancement has been described in terms of an "electron hopping mechanism" or tunnelling between individual conducting islands embedded in an insulating matrix based on a model due to Sheng and Abeles [79]. The islands have been described to consist of graphitic platelets or highly carbon enriched material [80-82]. Typical diameters of the carbonaceous regions estimated from the electronic conduction theory are in the order of $10-50 \mathrm{~nm}$ with mean (surface-to surface) distances of 0.1 to $20 \mathrm{~nm}$ for fluences under $1 \times 10^{15}$ ions $/ \mathrm{cm}^{2}[80]$. 
Fink et al. used small angle neutron scattering to show that two different structures were found in inn irradiated polymers. One consisted of small separate globular particles of the order of those predicted by the conduction theory, while the other consisted of coagulated globular particles. The authors suggested that these may be pre-stages of polymer carbonization [80]. Davenas et al. have shown that irradiation of PMMA and polystyrene films at high fluences forms hydrogenated carbon layers which are very similar to amorphous hydrogenated carbon films [83].

Foti et al. have used Raman spectroscopy to show that $\mathrm{Ar}^{+}$irradiated PS contains hydrogenated amorphous carbon. They found an increase in the number of graphitic clusters with dose [84]. Similarly, Ishitani et al. found amorphous carbon in the modified layer in oxygen implanted PE. They also report finding a very thin diamond-like carbon film on the outermost surface using surface enhanced Raman scattering [85]. Sofield et al. observed a graphitic layer at high energies and a diamond-like coating at lower energies for ion beam modification of poly-ether-ether-ketone (PEEK), again using a Raman microprobe indicating an energy threshold for microstructural evolution [86].

\section{Microhardness}

Hardness is not an inherent property of a material and is subject to several factors for interpreting the data. This is particularly true in the case of polymeric materials because of their visco-elastic nature. Conventional hardness measurement techniques in metals are based on the measurement of the indent 
dimensions. In polymers, the time interval between the removal of the loaded indenter and measurement is critical. Moreover, the time of interval of application of load is also important. The indentation hardness measurement is also affected by temperature, time, and the nonlinear stress-strain response apart from being a complex function of several properties such as modulus and indenter profile $[80,81]$.

There have been a few studies on surface hardening of polymers by surface attack, where for example, the etching of polyethylene with nitric or sulfuric acid has been found to strengthen the polymer surface [89-91]. One of the most effective methods of increasing polymer hardness is by crosslinking the macromolecules, which is possible due to the covalent nature of the carbon bond. Cross-linked polymers are used in several applications requiring resistance to high temperature and solvents, and for better mechanical properties [92].

One technique for cross-linking polymers is by means of ionizing radiation such as ultraviolet radiation and there are several applications of radiation curing of polymers [93]. However, there have been very few studies conducted to investigate hardness improvements using ion beams. In a recent study, Lee et al. have implanted several polymers with boron, nitrogen, carbon, silicon and iron singly or simultaneously using dual and triple beams [10]. The ultra low-load nanoindentation technique described earlier was used for the hardness measurements. The results are shown in figure 16. Kapton implanted with $\mathrm{B}^{+}$, $\mathrm{N}^{+}$and $\mathrm{C}^{+}$showed an improvement in hardness by a factor of 26 . The results 


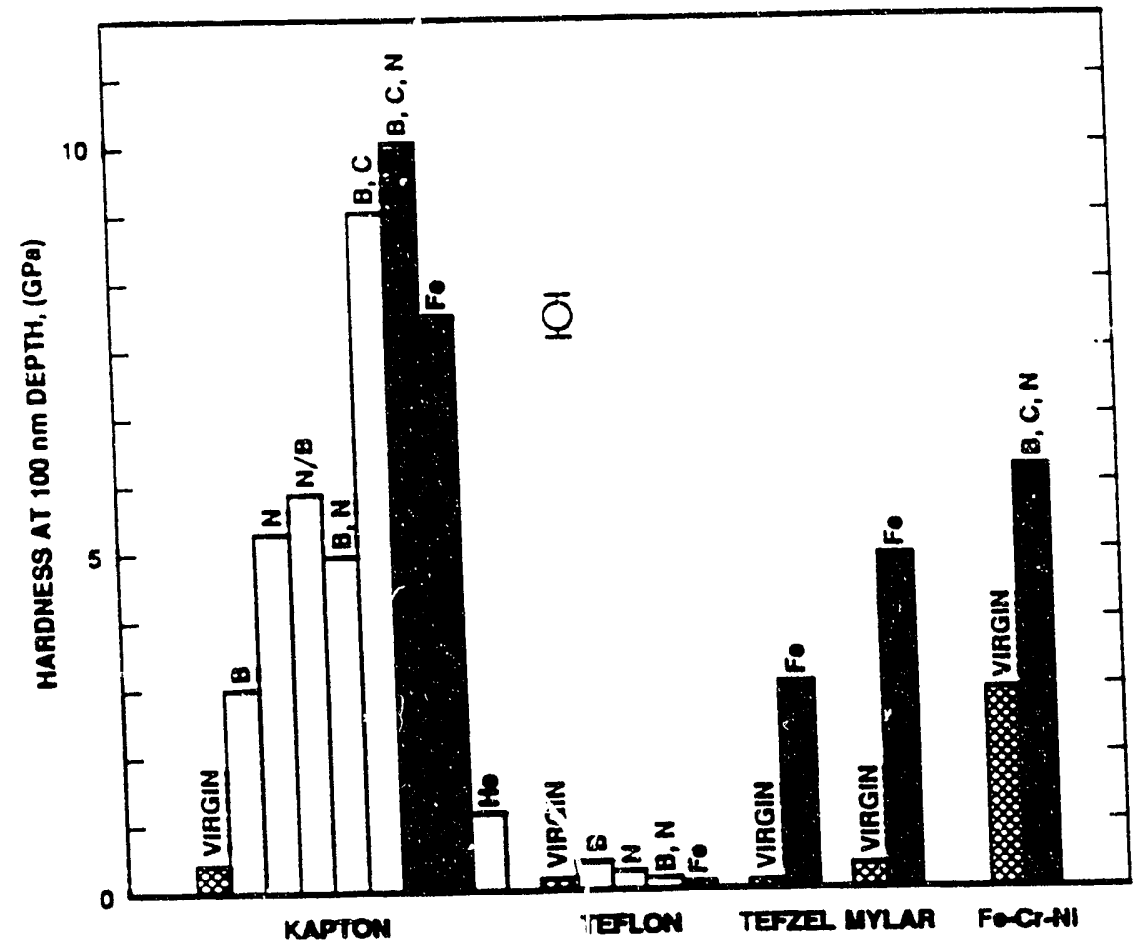

Figure 16. Hardness improvements in various polymers after ion implantation obtained by Lee et al. Hardness values, reported at $100 \mathrm{~nm}$ depth, were measured using the nanoindenter [10]. 
are compared with $\mathrm{B}, \mathrm{N}, \mathrm{C}$ implanted $\mathrm{Fe}-13 \mathrm{Cr}-15 \mathrm{Ni}$ stainless steel showing that in some cases, the surface hardness of implanted polymers can exceed that of metals. The authors have attributed the hardness increase in ion implanted polymers as due to three major factors: (1) three-dimensional cross-linking, (2) introduction of alloying elements which act as links for bonds, and (3) embedding hard particles on the polymer surface. The authors also indicate that ion implantation can be used to tailor the near-surface hardness of polymers [10].

Nishiyama et al. have implanted $1.5 \mathrm{MeV} \mathrm{Au}^{+}$and $\mathrm{O}^{+}$ions singly in polyethylene terephthalate (PET). They have used a specially designed microtome to measure cutting forces at specific depths to relate hardness and depth. Their results indicate that hardness increases with depth and the hardest region lies beyond the depth of the distribution maximum of the implanted ions [94].

A separate study was conducted on $\mathrm{B}^{+}$implanted polycarbonate to study dose and energy effects [95]. Boron was implanted at 100 and $200 \mathrm{keV}$ at three different doses at each energy. The hardness results are shown in figure 17. The hardness increase levelled off at higher doses suggesting the possibility of an optimum dose for hardness improvement [95]. Lewis and Lee have observed a good correlation between G- values of ion irradiated polymers with surface hardness improvements. The authors observed that enhanced G-values (indicating greater egress of molecules from the surface) also resulted in enhanced surface hardness suggesting that carbonization of the surface had occurred [78]. 


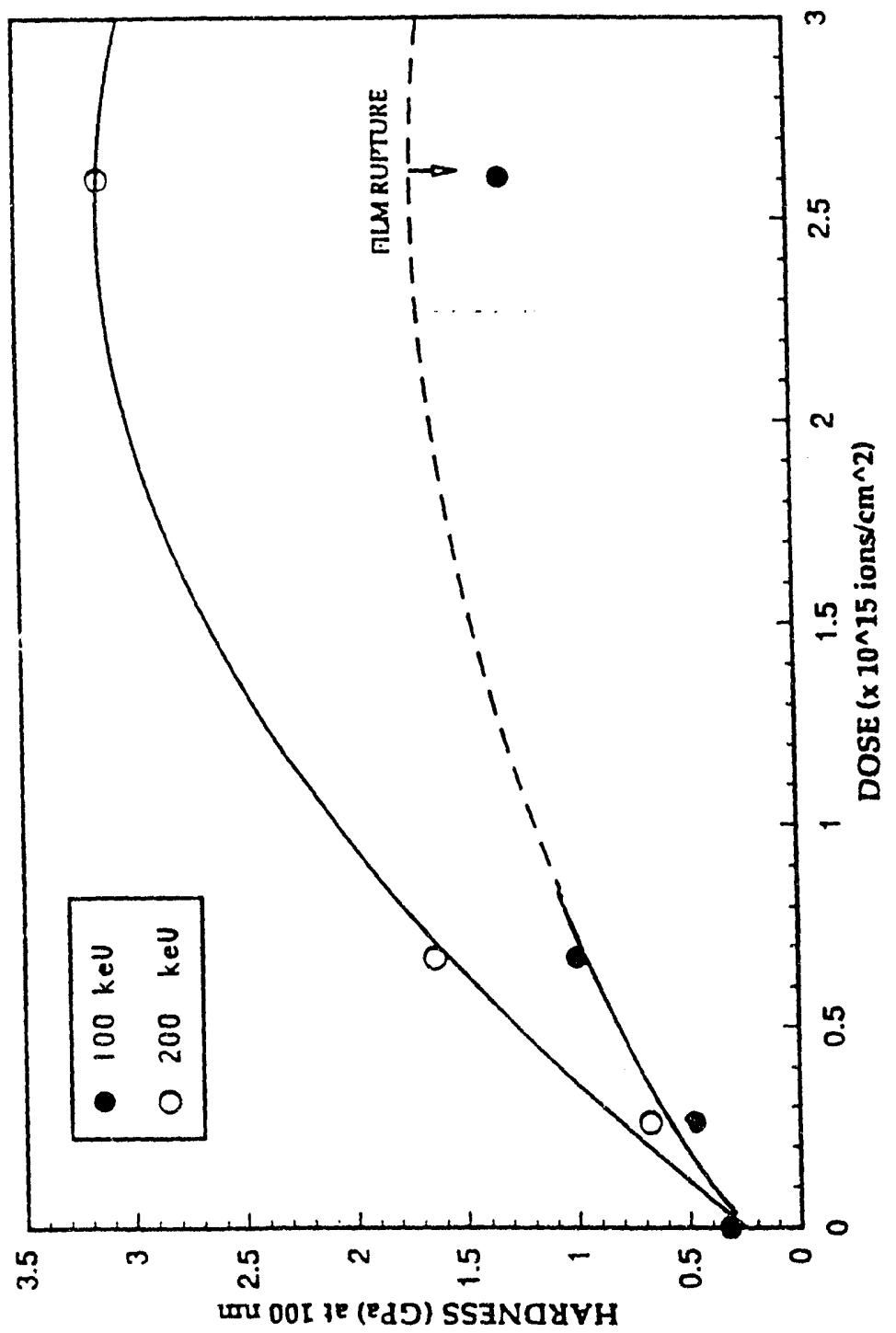

Figure 17. Hardness values of polycarbonate implanted with $\mathrm{B}^{+}$, given as a function of ion dose at two different energies [95]. 


\section{Wear}

Tribological properties of polymeric materials are of great importance due to their wide usage today in applications such as plastic bearings, gears and shafts. In general, polymers have a built-in lubricity unlike other classes of materials. Early pioneering research on wear of polymers was done by Tabor and co-workers at Cambridge, England, who have contributed greatly to the general field of tribology. A general introduction to wear in polymers is given by Steijn in ref [96].

Wear of polymers can be classified into three major forms: (1) adhesive or galling wear, (2) abrasive or cutting wear and (3) surface fatigue. This list can be extended to include corrosive wear and thermal wear. A more fundamental categorization, suggested by Briscoe [97] categorizes wear into two classes: cohesive and interfacial. Cohesive wear processes occur in relatively large volumes adjacent to the interface and include abrasive and fatigue wear. Interfacial wear, on the other hand, involves much thinner regions located in the vicinity of the interface; this includes adhesive wear. In general the wear process is not "monomechanistic", rather, there is an overlap of the different wear processes [97].

Adhesive wear is the most fundamental wear process. The frictional work has its origins in the adhesive forces between the contacting solids. There is an increase in local temperature. An important phenomenon is the transfer of a film of polymer onto the countersurface. This transfer is dependent upon load, sliding speed, time and type of polymer. Eventually, wear debris is formed [96]. 
Abrasive wear occurs by abrasion or gouging. This occurs when a hard, rough surface rubs against a softer countersurface and abrasive action occurs by grooving, cutting or ploughing. Abrasive particles present between the sliding surfaces can also add to this process. Surface fatigue is another source of failure where repetitive encounters between two surfaces, no matter how smooth, causes material breakdown $[96,97]$.

Surface modification is an obvious solution to wear control in polymers. Three main techniques have been investigated: (1) plasma treatment, (2) surface photopolymerization and (3) silicone modification [98]. Among these, only plasma treatment has been studied in some detail $[98,99]$ and has been found to be applicabie and useful in specific cases. Recently investigations on wear properties of ion-implanted polymers have been carried out at Oak Ridge National Laboratory $[10,95]$.

Lee et al. [10] performed reciprocating sliding wear tests on several polymers, both implanted and unimplanted using $9.53 \mathrm{~mm}$ (3/8 inch) diameter nylon and SAE 52100 high-carbon steel balls. Optical microscopy showed that ion implantation improved wear resistance in general as shown in figure 18 for Kapton. In particular, for the $\mathrm{B}, \mathrm{N}$ and $\mathrm{B}, \mathrm{N}, \mathrm{C}$ simultaneous implantations, no scratches were visible on the polymer surface after 10000 cycles. Although only a single load and a single speed were used in the study, the results were encouraging, considering the complex nature of the wear process [10]. 


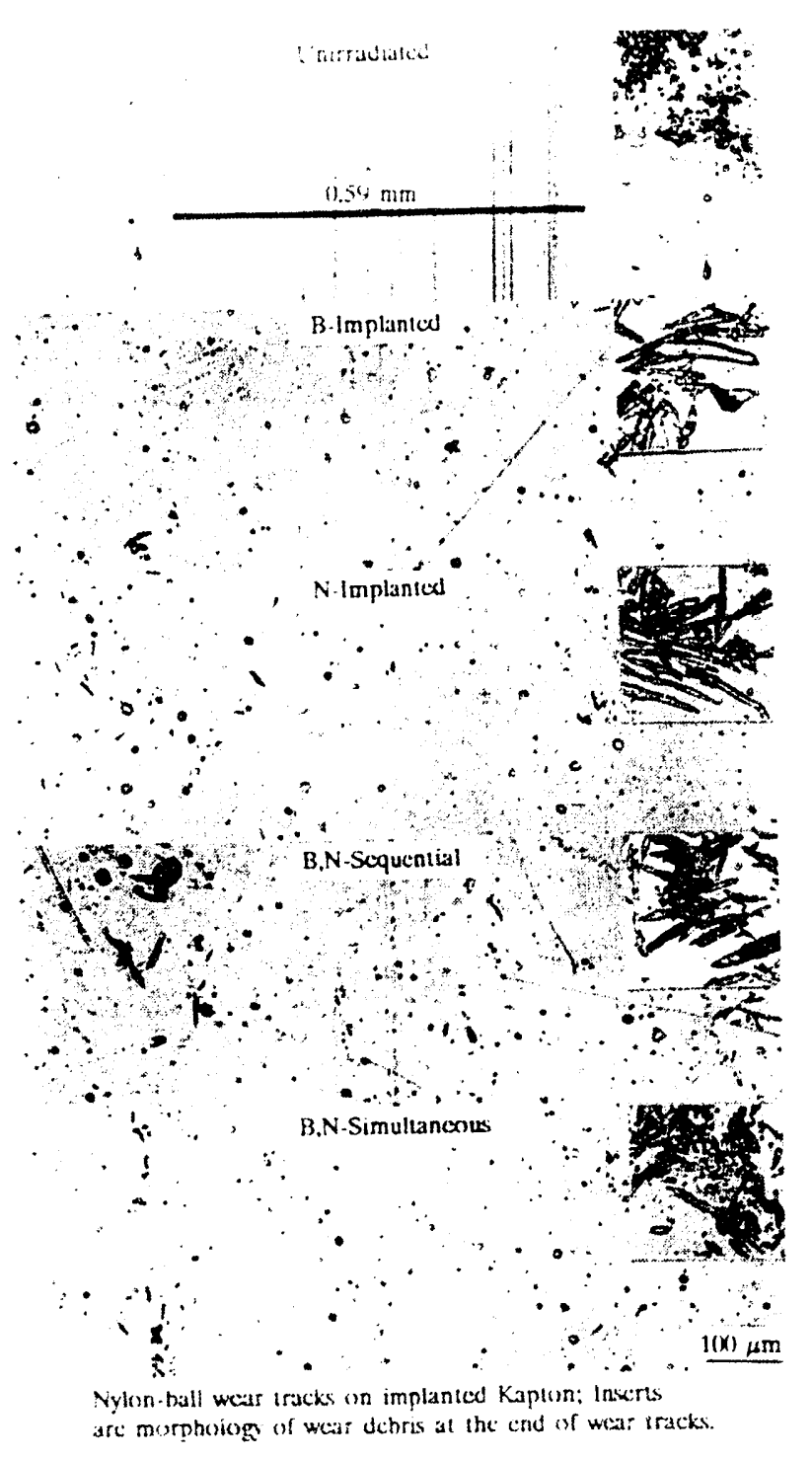

Figure 18. Optical micrographs of wear tracks on implanted Kapton tested using a nylon ball. Insets show morphology of wear debris for each case [10]. 
A study into the effects of ion dose and energy was performed on polycarbonate (PC) using boron ions [95]. Boron was implanted into PC at 100 and $200 \mathrm{keV}$ energies to three different doses. Wear properties were characterized using nylon, brass and steel balls. The wear mode was found to depend on ion dose, energy, ball type and normal load. Using the nylon ball, it was observed that there was an optimum dose corresponding to the intermediate dose at which no wear was observed after 10000 cycles. Friction coefficients were also reduced by over $40 \%$ by implantation. Results are shown in figure 19 . The implantations also changed the dominant wear mode, which was dependent upon ion dose [95]. 

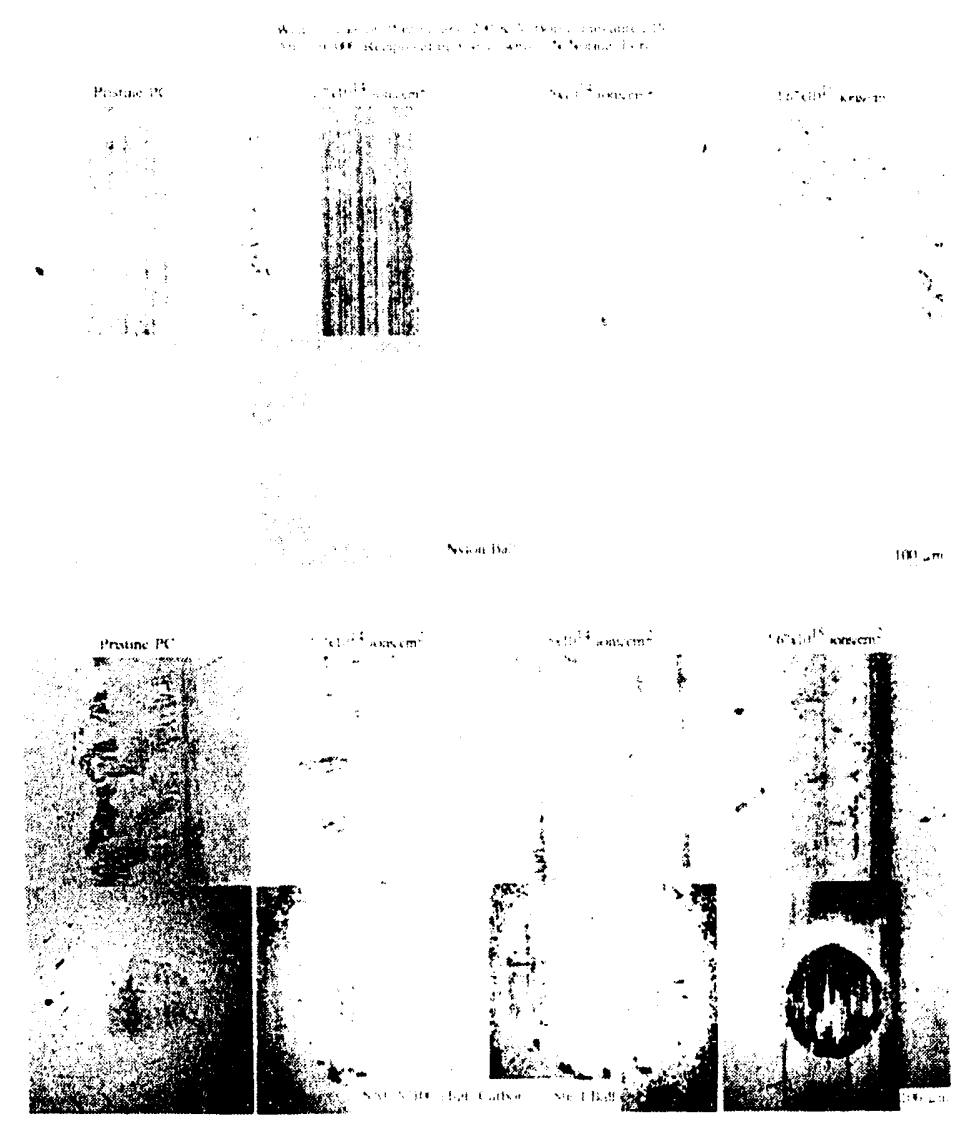

Figure 19. Wear tracks on $\mathrm{PC}$ impianted with $200 \mathrm{keV} \mathrm{B}{ }^{+}$at various doses. The intermediate dose implanted material showed no wear tracks. The wear of the nylon ball is also shown [95]. 


\section{EXPERIMENTAL PROCEDURES}

\section{SPECIMENS AND MATERIALS}

\section{$\underline{\text { Metals }}$}

\section{Fatigue}

Miniature bending fatigue specimens developed at Auburn University were used in this study [100]. The specimen configuration is shown in figure 20. The fatigue specimens were made from sheet material with thickness $760 \mu \mathrm{m}$ and have a gauge region of $6.35 \mathrm{~mm}\left(1 / 4^{\prime \prime}\right) \times 4.76 \mathrm{~mm}\left(3 / 16^{\prime \prime}\right)$. The gauge region has an hourglass shape with a minimum width of $3.175 \mathrm{~mm}\left(1 / 8^{\prime \prime}\right)$.

Eight model alloys based on the Fe-13Cr-15Ni alloy system were used in the study. The compositions of the eight alloys, designated as E1-E8, are given in table 11. The alloys are based on the Fe-13Cr-15Ni-2Mo-2Mn-0.2Ti-0.8Si-0.06C alloy (E1) with minor alloying elements removed or added. These alloys were chosen to determine the effects of these minor alloying elements in conjunction with the implanted ions. The alloys were developed at ORNL as part of the radiation effects program and their microstructures and mechanical properties have been previously characterized. In order to study the effects of grain boundaries in the alloys, single crystals of $\mathrm{Fe}-15 \mathrm{Cr}-15 \mathrm{Ni}$ were grown at ORNL using the Czochralski method. The single crystal samples were oriented 

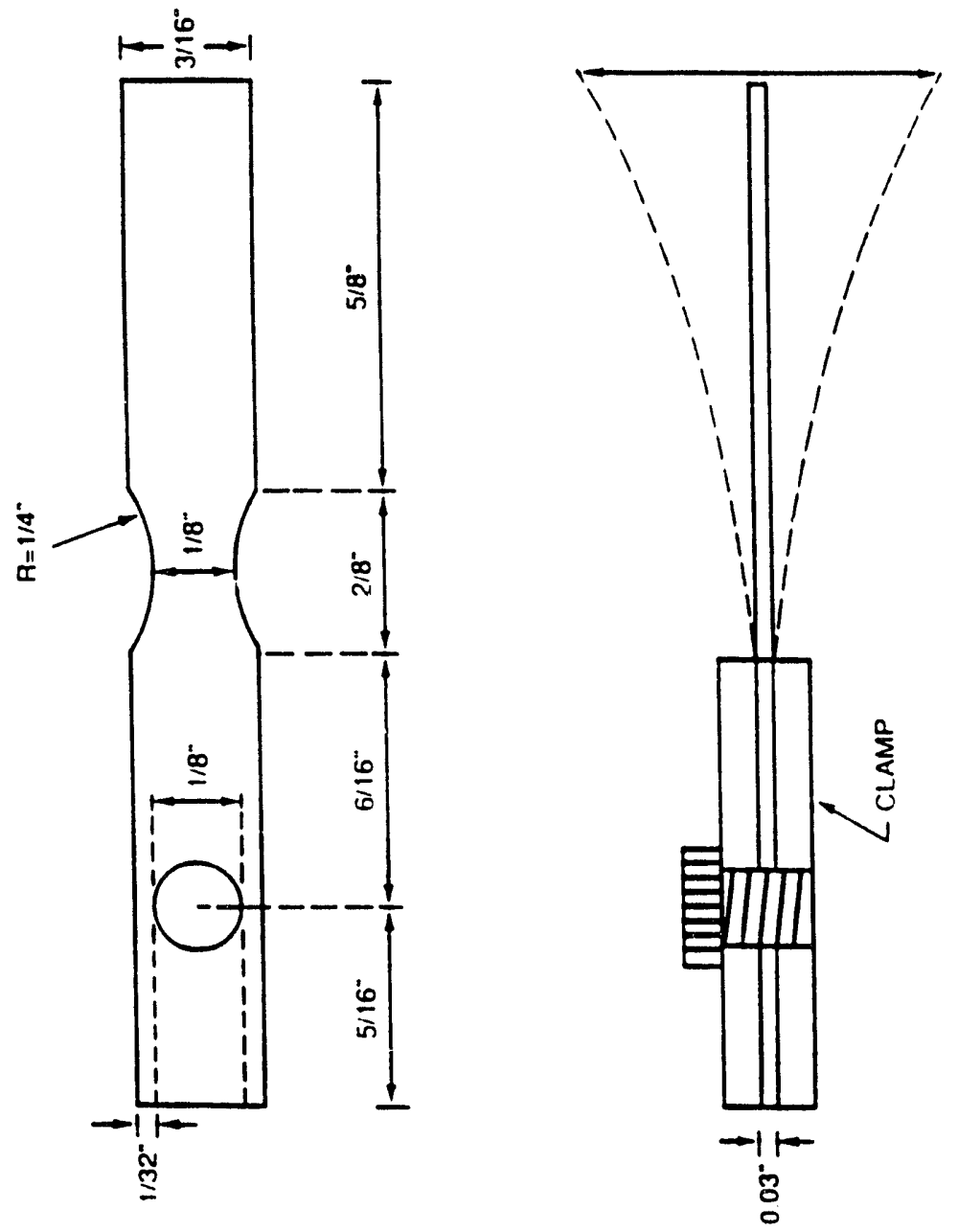

Figure 20. The miniature bending fatigue specimen used for the fatigue tests. 
Table 11.

Alloy compositions for the eight E-series alloys used in the study in weight percent.

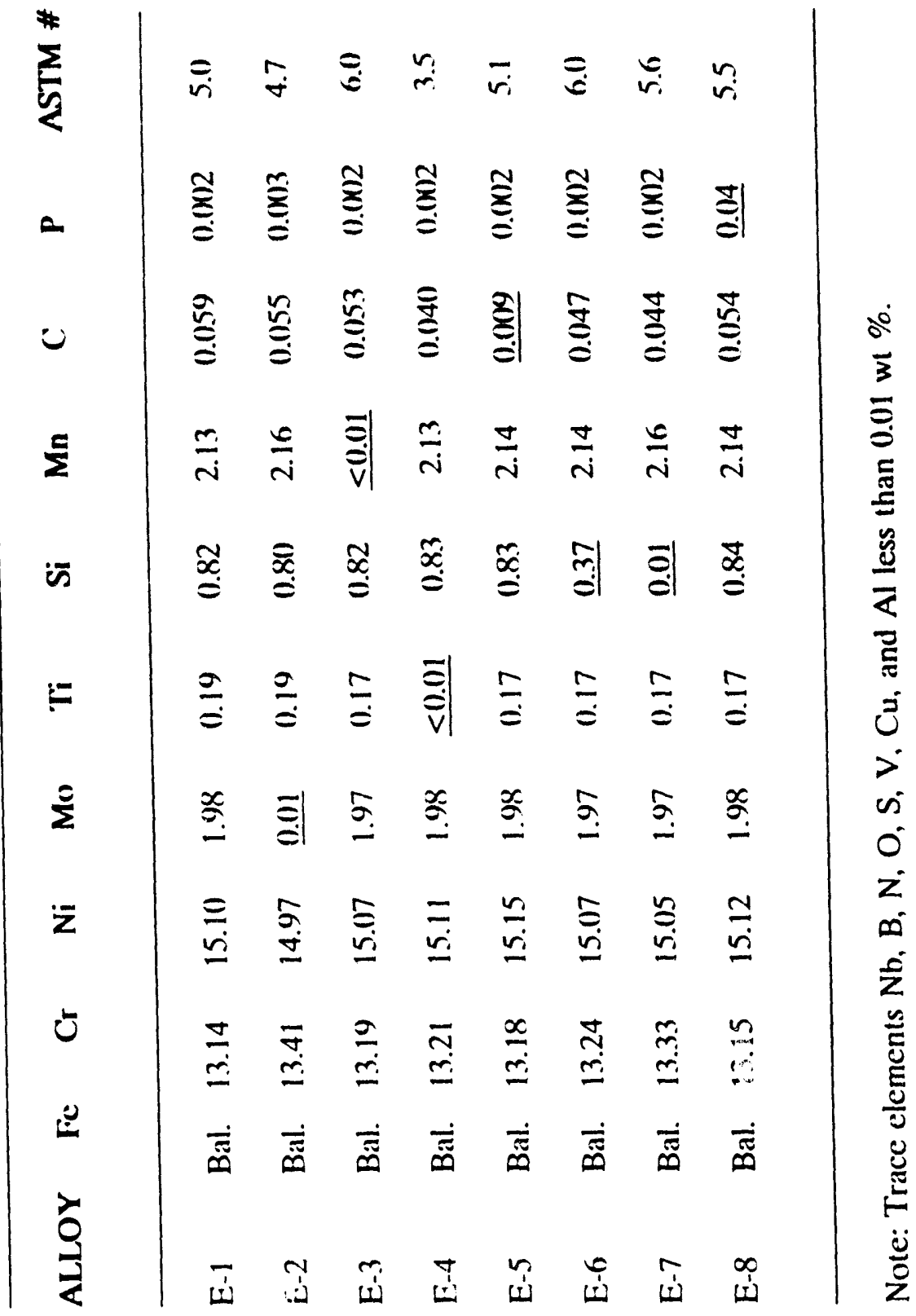


with the longitudinal sample axis along [100] using $x$-ray back reflection and were then machined using electric-discharge erosion.

All specimens were annealed at $1150^{\circ} \mathrm{C}$ for 15 minutes in vacuum. The resulting grain sizes are included in table 11 . The specimens were then electrochemically polished in a $60 \%$ methanol $-36 \%$ butyl cellusolve $-4 \%$ perchloric acid electrolyte at $-5^{\circ} \mathrm{C}$ using a $100 \mathrm{~mA}$ current at a D.C. voltage of $6 \mathrm{~V}$. Each specimen was polished for 4 minutes to eliminate machining surface defects.

\section{Creep}

Creep tests were performed on modified SS-3 tensile specimen configuration shown in figure 21 . The specimen is also made from $0.762 \mathrm{~mm}$ thick sheet material. The miniature specimen has a gauge length of $6.35 \mathrm{~mm}$ and a width of $1.52 \mathrm{~mm}$. The specimens were subjected to the same annealing and electropolishing treatments described in the previous section. The $\mathrm{E} 1$ and the $\mathrm{Fe}-13 \mathrm{Cr}-15 \mathrm{Ni}$ ternary alloys were used for the creep tests.

\section{Polymers}

Four polymers were used in this study: polyethylene (PE), polypropylene (PP), polystyrene (PS) and polyethersulfone (PES). The molecular structures of the repeating unit are shown in figure 22 . These four polymers were selected for the increasing complexity of the side groups as well as the backbone chain (in the case of PES). The polymers were obtained in the form of $76 \mu \mathrm{m}$ films, except PP which was obtained as $1 \mathrm{~mm}$ thick sheets. PE, PP and PS were obtained from Goodfellow Advanced Materials Company and PES was obtained from the Westlake 


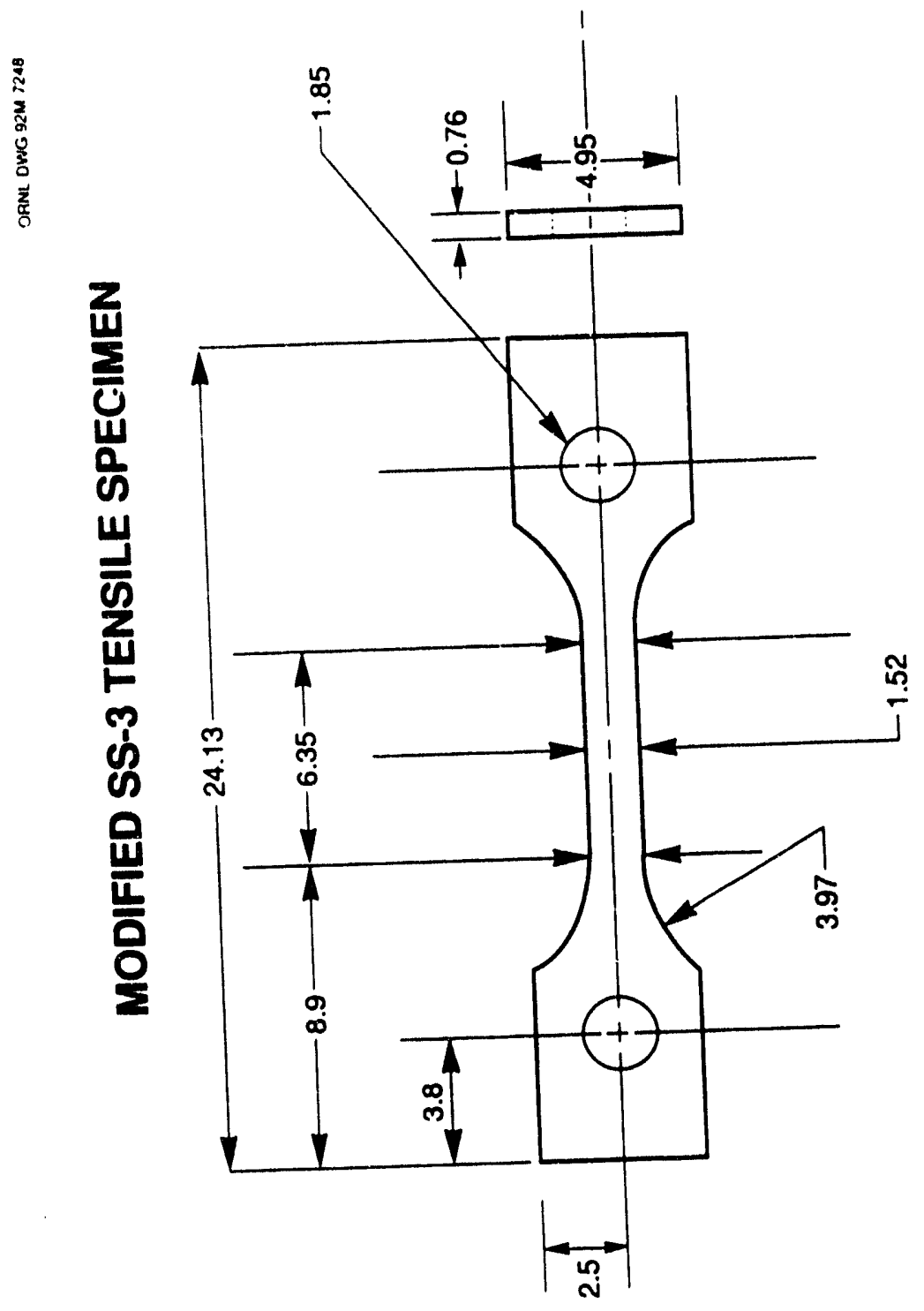

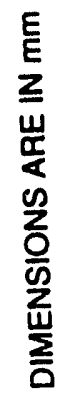

Figure 21. The modified SS-3 creep specimen configuration used in this study. 


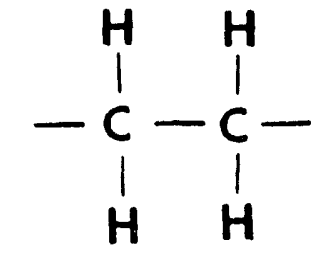

POLYETHYLENE<smiles>CCC(C)c1ccccc1</smiles>

POLYSTYRENE<smiles>CCC(C)C</smiles>

POLYPROPYLENE<smiles>Cc1ccc(Oc2ccc(S(C)(=O)=O)cc2)cc1</smiles>

POLYETHERSULFONE

Figure 22. Molecular structures of the repeating units for the four polymers used in this study. 
Plastics Company, both in Pennsylvania. Table 12 shows some physical and mechanical properties $\mathrm{c}$ : the four polymers including density, the glass transition temperature $\left(T_{\mathrm{g}}\right)$, melting temperature $\left(\mathrm{T}_{\mathrm{m}}\right)$, tensile strength and modulus. Of the four polymers, it can be seen that $\mathrm{PE}$ and $\mathrm{PP}$ are above $\mathrm{T}_{\mathrm{g}}$ at room temperature.

\section{ION IMPLANTATION}

The ion implantations were performed in the Triple Ion Facility in the Metals and Ceramics Division at ORNL. The facility has three Van de Graaff accelerators with voltage ratings of $400 \mathrm{kV}, 2.5 \mathrm{MV}$ and $5 \mathrm{MV}$. These are capable of being operated simultanecusly to implant three different ion species. A schematic representation of the facility is shown in figure 23 [101]. The maximum target sample area that can be implanted is $100 \mathrm{~mm}^{2}$.

The implantation chamber is divided into a loading chamber and a target chamber, which can be isolated from each other. The target chamber is a high vacuum chamber with vacuum level maintained at approximately $10^{-8}$ torr. The dose is determined by means of a computer which periodically measures the flux and calculates accumulated dose. The $\mathrm{X}-\mathrm{Y}$ profiles of the three ion beams are monitored by a system of miniature Faraday cups. The output $\mathrm{c}_{\mathrm{L}}^{\mathrm{f}}$ the Faraday cups is monitored by the computer and this information is used to adjust the beam output to obtain a uniform beam profile on the target. The computer output also determines when the final specified dose is attained so that the implantation can be terminated. Specimen 
Table 12.

Some physical and mechanical properties of the polymers used in this study

\begin{tabular}{lllll}
\hline Property & PE & PP & PS & PES \\
\hline Density $\left(\mathrm{g} / \mathrm{cm}^{3}\right)$ & 0.92 & 0.9 & 1.05 & 1.37 \\
$\mathrm{~T}_{\text {glass transition }}\left({ }^{\circ} \mathrm{C}\right)$ & -80 & 0 & 100 & 220 \\
$\mathrm{~T}_{\text {meling }}\left({ }^{\circ} \mathrm{C}\right)$ & 130 & 165 & $>95$ & $>220$ \\
Tensile Strength $(\mathrm{MPa})$ & $5-25$ & $25-250$ & $30-100$ & $70-95$ \\
Tensile Modulus $(\mathrm{GPa})$ & $0.1-0.3$ & $1-1.5$ & $2.3-4.1$ & $2.4-2.6$ \\
\end{tabular}




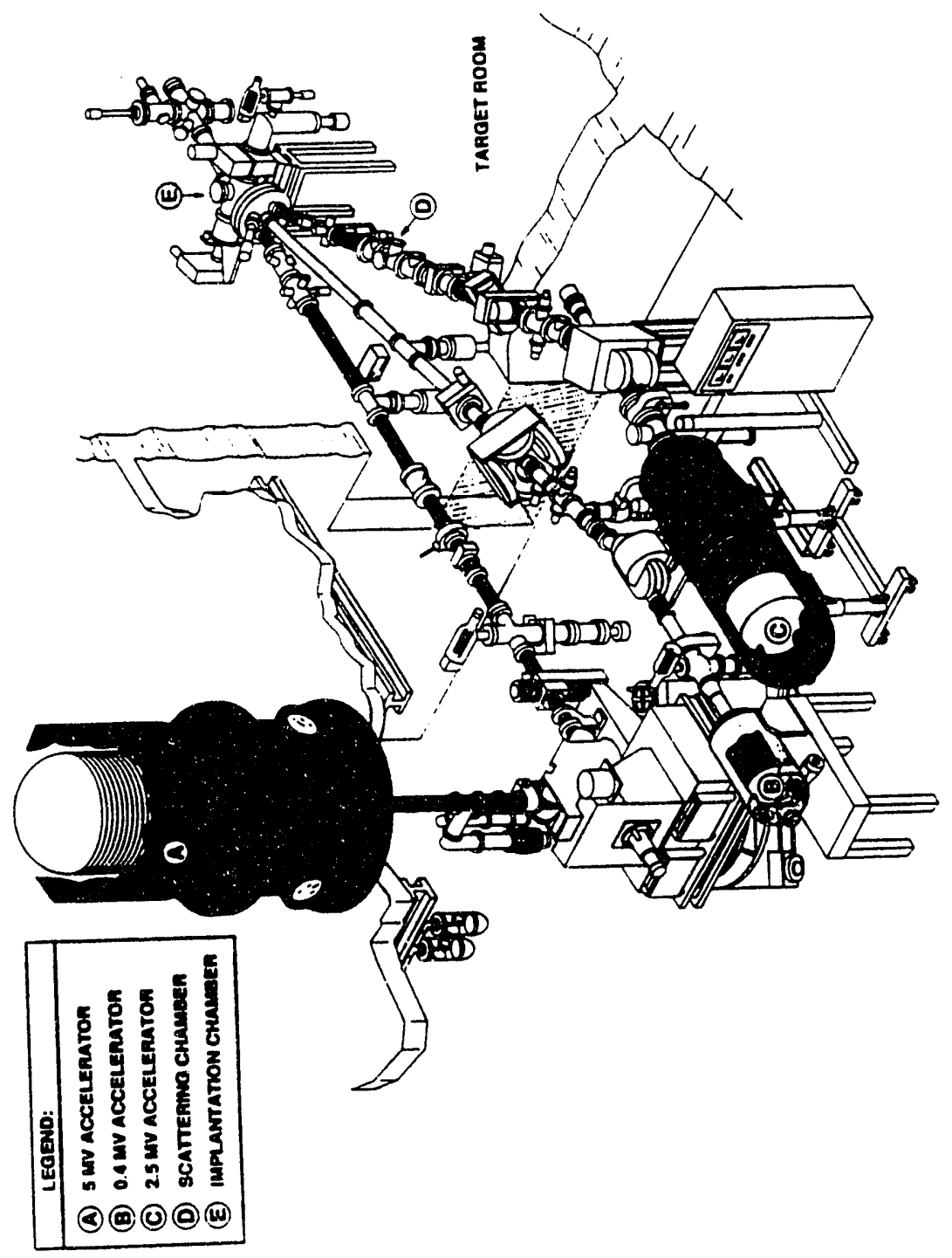

Figure 23. Schematic representation of the triple ion irradiation facility at ORNL. 
temperature is monitored by means of two thermocouples at the target stations. There are also provisions for measuring temperatures at specific locations on the specimens.

\section{$\underline{\text { Metals }}$}

The miniature fatigue specimen gauge regions were implanted simultaneously with $400 \mathrm{keV}$ boron $\left(\mathrm{B}^{+}\right)$and $1.1 \mathrm{MeV}$ nitrogen $\left(\mathrm{N}_{2}{ }^{+}\right)$ions using the $400 \mathrm{kV}$ and 2.5 $\mathrm{MV}$ accelerators, respectively. A dose of $2.3 \times 10^{16} \mathrm{ions} / \mathrm{cm}^{2}$ was used for each ion species corresponding to an accumulation of 1 at- $\%$ at peak deposition depth. These specific energies and dose were also used by Lee and Mansur in their study using simple $\mathrm{Fe}-13 \mathrm{Cr}-15 \mathrm{Ni}$ alloys [6]. Special holders were designed for implanting the specimens in the high vacuum target chamber and each specimen was subjected to four implantations, one for each surface and one for each edge. The ion flux was maintained at fairly low levels so that specimen temperature was maintained at under $80^{\circ} \mathrm{C}$ during the duration of the implantations.

\section{Polymers}

Each polymer was implanted with $200 \mathrm{keV} \mathrm{B}^{+}$at three different doses: $1.7 \times 10^{14}$, $5 \times 10^{14}$ and $1.7 \times 10^{15}$ ions $/ \mathrm{cm}^{2}$ corresponding to ion concentrations of 100,300 and 1000 appm. PS specimens were also implanted with $100 \mathrm{keV} \mathrm{B}^{+}$to the same three doses with 200,500 and $1000 \mathrm{keV} \mathrm{Ar}^{+}$to 300,1000 and 2000 appm. Comparisons of the effects of $\mathrm{B}^{+}$and $\mathrm{N}^{+}$-implantations into PS gave information regarding species dependence. The various implantation conditions are summarized in table 13. The polymer films were cut in squares of $110 \mathrm{~mm}^{2}$ prior to implantation. The polymer 
Table 13.

The various implantation conditions used for the four polymers studied.

\begin{tabular}{|c|c|c|c|}
\hline Polymer & Ion & Energy & Doses (ions $/ \mathrm{cm}^{2}$ ) \\
\hline $\begin{array}{l}\text { PE } \\
\text { PP } \\
\text { PS } \\
\text { PES }\end{array}$ & $\mathrm{B}^{+}$ & 200 & $\begin{array}{c}1.7 \times 10^{14} \\
5 \times 10^{14} \\
1.7 \times 10^{15}\end{array}$ \\
\hline PS & $\mathrm{B}^{+}$ & 100 & $\begin{array}{c}1.7 \times 10^{14} \\
5 \times 10^{14} \\
1.7 \times 10^{15}\end{array}$ \\
\hline PS & $\mathrm{Ar}^{+}$ & $\begin{array}{c}200 \\
500 \\
1000\end{array}$ & $\begin{array}{c}5 \times 10^{14} \\
1.7 \times 10^{15} \\
3.4 \times 10^{15}\end{array}$ \\
\hline
\end{tabular}


films were very sensitive to overheating caused by a high flux. The ion flux was therefore maintained under $100 \mathrm{nA} / \mathrm{cm}^{2}$ to prevent polymer meltdown.

\section{MECHANICAL TESTS}

\section{Fatigue Testing of Metal Specimens}

Fatigue tests were performed using a specialized bending fatigue machine (shown in figure 24) developed at Auburn University [102]. The specimen is positioned as a cantilever beam with one end fixed and the bending load applied at the other (free) end. All specimens were tested using a flexing frequency of $8.33 \mathrm{Hertz}$ (500 cycles per minute) with a sinusoidal waveform. A total deflection of $4.8 \mathrm{~mm}( \pm 2.4 \mathrm{~mm})$ was used at the point of loading. For comparison purposes, all specimens were tested at a single value of deflection.

The load is detected by a load cell consisting of four strain gauges in a Wheatstone Bridge network at the end of the cantilevered specimen holder arm. The null position for the Bridge is adjusted on the shutdown controller. The output of the load cell is monitored using an oscilloscope. Tests were automatically terminated when the load decayed to $80 \%$ of the original load.

\section{Creep Testing of Metal Specimens}

Creep tests were performed using a test setup custom designed at ORNL. All tests were performed at $600^{\circ} \mathrm{C}$. Tests were conducted using a constant load with an initial stress of $20 \mathrm{ksi}$ for the $\mathrm{B} 1$ specimens and $37 \mathrm{ksi}$ for the $\mathrm{E} 1$ specimens. The 


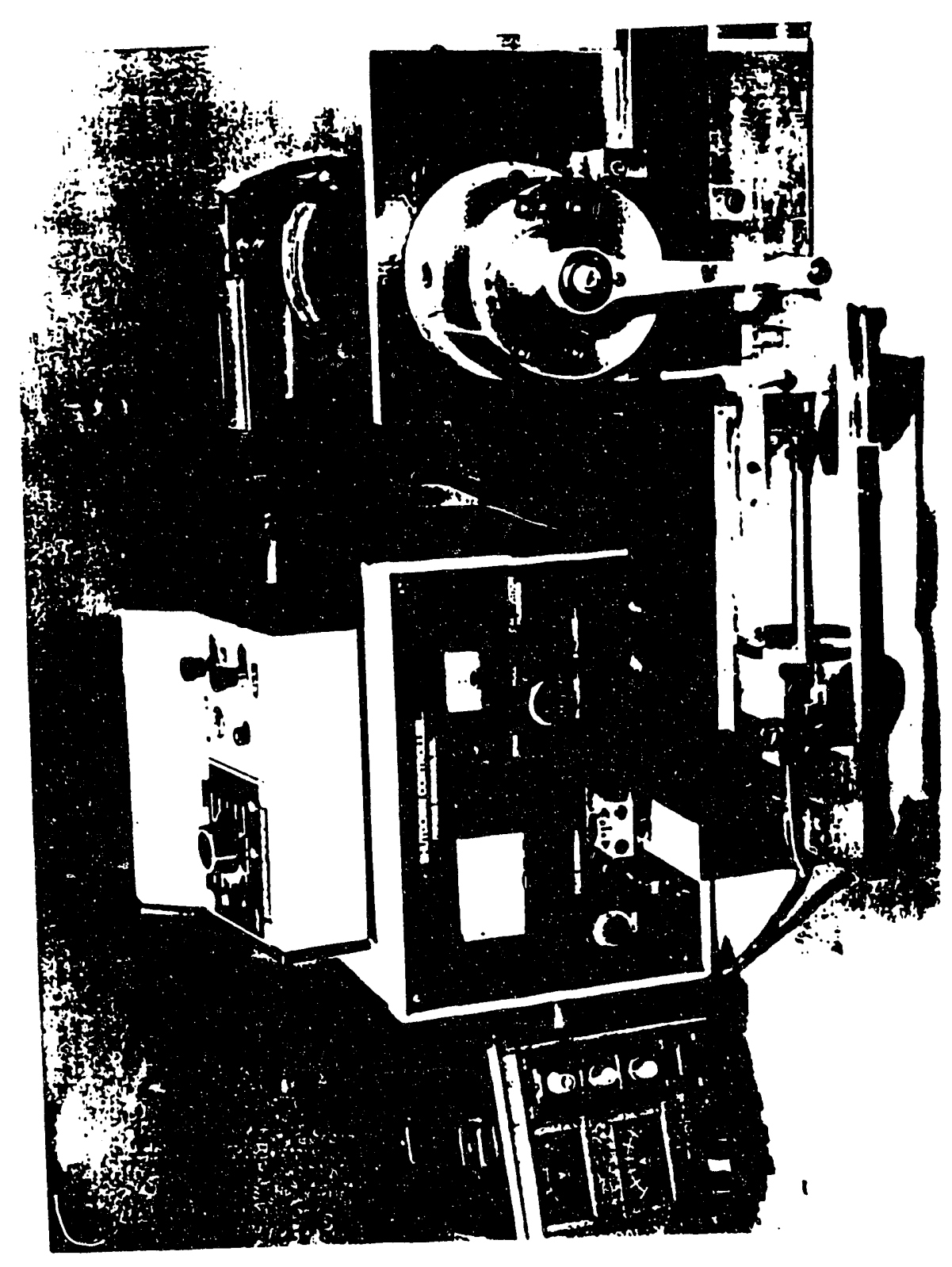

Figure 24. Bending fatigue machine used for testing the miniature fatigue specimens. 
vacuum in the specimen chamber was maintained at a level better than $10^{-7}$ torr. Two thermocouples were positioned touching the specimen gauge region to measure actual specimen temperature. The temperature of the specimen was raised to $600^{\circ} \mathrm{C}$ within 10 minutes and the load was applied immediately. A temperature controller maintained the specimen temnerature to within $600 \pm 2{ }^{\circ} \mathrm{C}$. The specimen extension was measured by means of an LVDT. A Hewlett Packard microcomputer was used to periodically record and print the LVDT extension, temperature

and vacuum level. Before each test the gauge length was measured accurately to calculate strains and results were obtained as strain as a function of time in hours.

\section{Microhardness}

\section{$\underline{\text { Knoop Hardness }}$}

Knoop microhardness measurements were carried out on a Leitz Metalloplan optical microscope. The microscope is equipped with a video camera attachment a television screen to image the indents and associated electronics to accurately measure the diagonals of the indent. Hardness $(\mathrm{H})$ is measured as the average load $(\mathrm{P})$ under the contact area $(\mathrm{A})$ of the indenter as :

$$
H=\frac{P}{A}
$$

Knoop tests can be carried out using loads of 2 to $250 \mathrm{~g}$. Loads in this study were limited to $2,5,10$ and $25 \mathrm{~g}$ due to the small depth of the implantations. The Knoop hardness measurements were used for rough measurements and more 
accurate determination of implanted layer strength was done using a nanoindentation technique described below.

Nanoindentation

In conventional hardness measurements, the contact area is determined by visually measuring the indent dimensions. However, for very thin surface layers, the penetration depths of the indenter is often deeper than the thickness of the layer even for very low loads. Moreover, the lower the indenter load, the greater is the margin of error in determining the indent dimensions. Recently, there have been several advancements in continuous load and depth sensing techniques using ultra low-loads to accurately determine near surface hardness [33-35].

In this study, the nanoindenterm was used for measuring near surface hardness based on ultra-low-load indentation. The instrument is capable of continuous control of load and displacement of the indenter with a displacement resolution of $0.4 \mathrm{~nm}$ and a force resolution of $300 \mathrm{nN}$. Five indents were made for each condition. Data are obtained in terms of load as a function of indenter depth. From this, the hardness at any depth up to the maximum indenter depth can be estimated. In this study, the hardness at $100 \mathrm{~nm}$ depth was chosen as a standard for comparison. For each indent, total depth of penetration was $500 \mathrm{~nm}$ with a rate of $10 \mathrm{~nm} / \mathrm{s}$. Unloading was carried out at $3.5 \mathrm{~nm} / \mathrm{s}$ with a hold period at $90 \%$ unloading to determine thermal drift rate of the indenter. The entire process is controlled by a computer. 


\section{Wear Testing of Polymers}

Reciprocating sliding wear tests were performed using a tribometer designed at ORNL. Nylon balls of $9.53 \mathrm{~mm}$ diameter were used as the countersurface with a $1 \mathrm{~N}$ normal force. A stroke length of $3 \mathrm{~mm}$ and an average speed of $0.01 \mathrm{~m} / \mathrm{s}$ was used for the tests. Each specimen was subjected to 10000 sliding cycles for an overall time period of 100 minutes. Tests were conducted at room temperature in a normal laboratory atmosphere.

The tangential force on the specimen was determined using a strain gauge bridge and was used to calculate the friction coefficient. Data acquisition and analysis was performed using a desktop personal computer interface. Readings were recorded at the following elapsed time periods (in minutes): $0.1,1,2,5,10,20,45,60,80$ and 100. Each reading recorded 1000 datapoints/s for $11 \mathrm{~s}$. Friction coefficient values were calculated at these times and plotted as a function of elapsed time. The frequency of recording readings was greater at the beginning of the tests since friction coefficient values changed rapidly during the first 10 minutes.

\section{SPECIMEN CHARACTERIZATION}

\section{Optical Microscopy}

A Leitz Metalloplan optical microscope was used for studying the surfaces of the metal and polymer samples before and after testing. The microscope was used to study slip band formation and fatigue crack initiation in metal specimens. In the 
polymer specimens, optical microscopy was used to examine wear tracks on the specimen after the wear tests.

\section{Transmission Electron Microscopy}

A Philips CM-12 electron microscope was used for microstructural examination of the fatigue specimens and to study implant layer microstructures. Both crosssectional and backthinned specimens were examined to study the implant layer microstructure. Cross-sectional specimens were obtained by first Ni-plating the gauge regions from the fatigue specimen. The Ni-plated material was then sliced and electro-discharge machining (EDM) was used to cut a $3 \mathrm{~mm}$ TEM disk with the Nisteel interface lying approximately along a diameter of the disk. The disks were then thinned in a Tenupol jet polisher with the electrolyte maintained at $-20^{\circ} \mathrm{C}$. The electrolyte used was the same as that used for electropolishing the fatigue specimens. The disks were thinned until a sufficiently thin region was obtained at the Ni-steel interface. Backthinned specimens were obtained by using EDM to cut TEM disks from the fatigue specimen gauge region and then polishing (or backthinning) the disks to the implanted region. 


\section{RESULTS AND DISCUSSION: METALS}

\section{RESULTS}

\section{Ion Depth Ranges}

The computer code TRIM (1990 Version) was used to determine the depth range of the implanted ions. TRIM (TRansport of Ions in Matter) is a MonteCarlo simulation program which follows individual ion histories in a target material for a large number of ion collisions [11]. Calculated ion ranges are shown in figure 25 for $400 \mathrm{keV}$ boron and $550 \mathrm{keV}$ nitrogen implantations. The peak depth of the implant distribution was close to $500 \mathrm{~nm}$ for each ion species. The peak concentration was calculated to be approximately $1 \times 10^{21}$ atoms $/ \mathrm{cm}^{3}$ for a fluence of $2.3 \times 10^{16}$ ions $/ \mathrm{cm}^{2}$ for each ion corresponding to approximately a $1 \%$ peak concentration in the $\mathrm{Fe}-\mathrm{Ni}-\mathrm{Cr}$ alloys.

The figure also shows the extent of ionization caused by the electronic energy loss shown as ionization energy as a function of depth. The nuclear damage is determined using the nuclear energy loss and the Kinchin-Pease model is used for calculating the number of displaced atoms [11]. The figure shows the vacancies formed due to nuclear collisions given as number of vacancies formed per ion as a function of depth. 

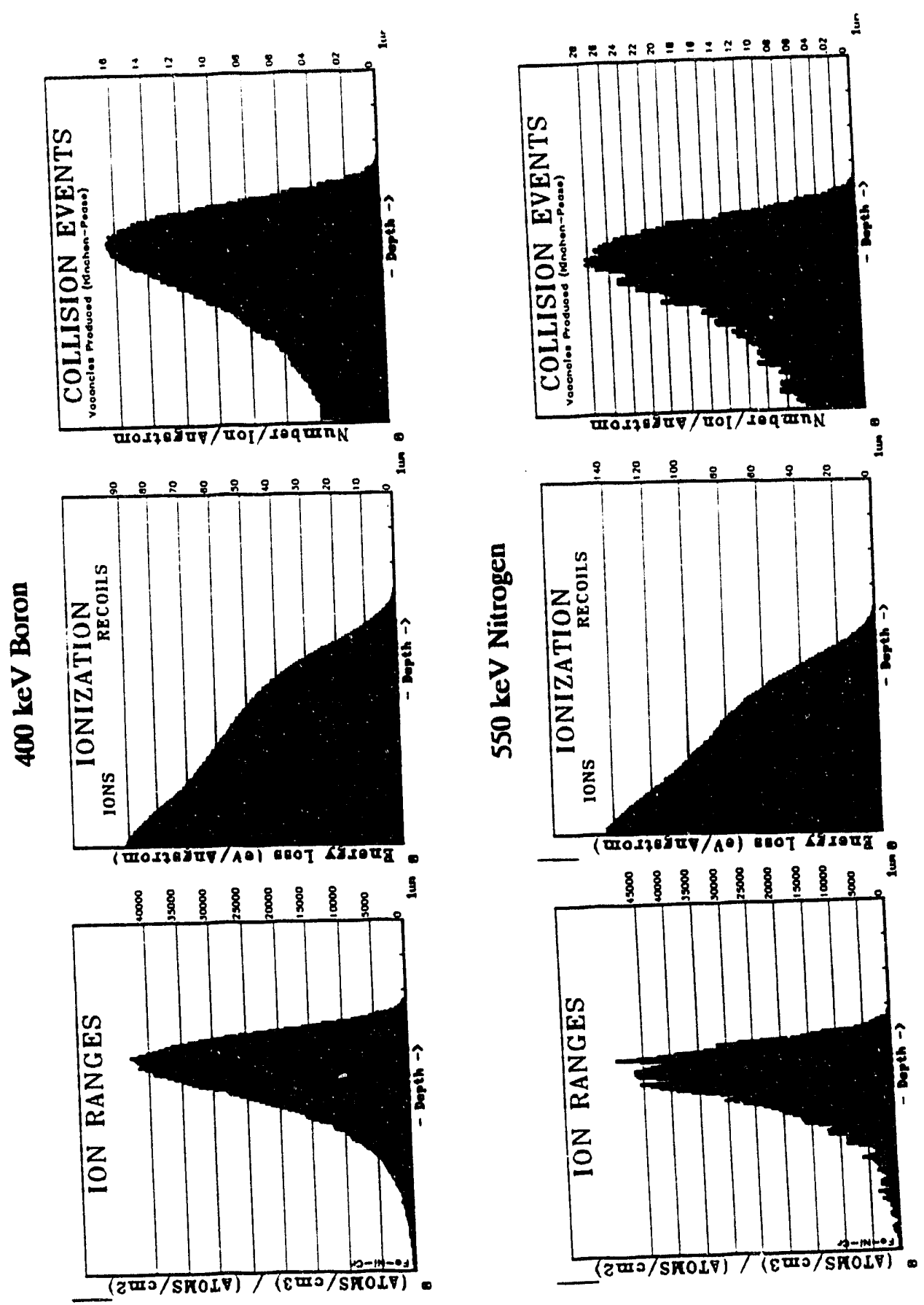

Figure 25. Results of TRIM calculations showing implant depth distribution for $400 \mathrm{keV} \mathrm{B}^{+}$and $550 \mathrm{keV} \mathrm{N}{ }^{+}$implantations. The figure also shows number of vacancies produced due to nuclear energy loss and ionization due to electronic energy loss. 


\section{Microhardness Results}

\section{Knoop}

Knoop microhardness measurements were performed using a $5 \mathrm{~g}$ load. The Knoop diamond has a ratio of long to short diagonal of $7: 1$ with a depth of indentation about $1 / 30$ of the long diagonal. This allows measuring hardness at shallow depths in materials. Results for the eight E-series alloys are shown in figure 26 and table 14. The hardness value shown for each sondition is the average of five measurements. The $\mathrm{B}, \mathrm{N}$ implantation increased near surface hardness of all eight alloys as indicated in the figure. However, the improvement varied from alloy to alloy indicating a dependence on the composition of the alloys. The greatest improvement (104\%) was observed for alloy E2 (no Mo), and the smallest increase (29\%) was observed for alloy E4 (no Ti). There is a variation in hardness values of the control specimens which can also be attributed to variations in solid solution strengthening and precipitate strengthening in the alloys due to differences in minor alloying element composition.

\section{$\underline{\text { Nanoindentation }}$}

Hardness measurements using the nanoindentation technique were made

directly on the fatigue specimens. As mentioned in the previous chapter, the nanoindentation technique utilizes depth sensing at ultra-low loads. Raw data is obtained in terms of load sensed as a function of displacement. Figure 27 shows typical results obtained for a control E1 specimen. The hardness calculated has 


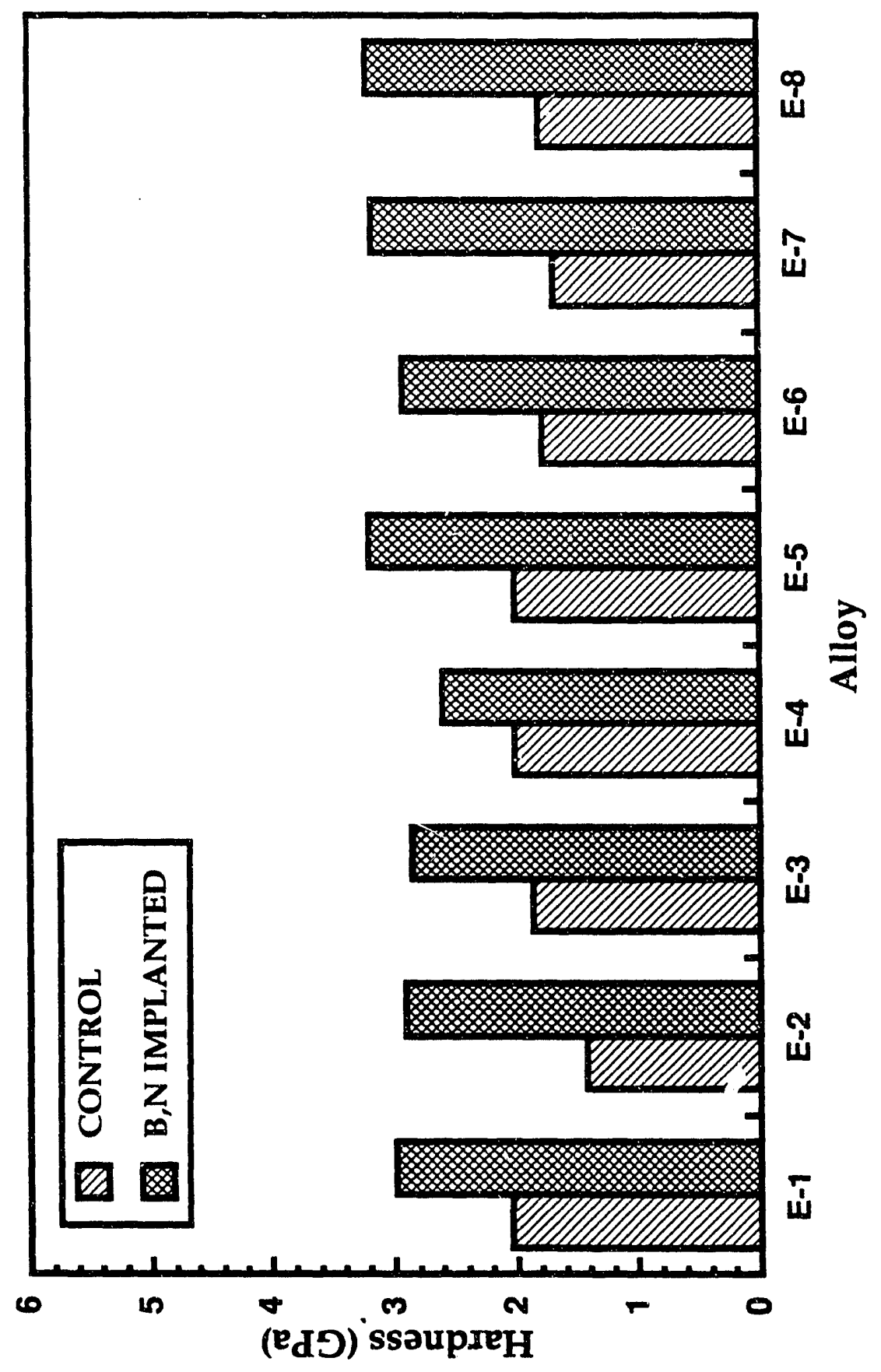

Figure 26. Knoop hardness results for the eight E-series alloys. 
Table 14.

Knoop hardness values and Nanoindentation hardness values (in GPa) for the eight E-series alloys showing percent increase in hardness due to the implantation

Alloy

Unimplanted $\frac{\text { Nanoindentation (Knoop Hardness) }}{\text { Implanted }} \%$ Change

E1

$4.5(2.05)$

$5.58(2.99)$

$24(46.3)$

E2

$3(1.43)$

$5.25(2.91)$

75 (104)

E3

3.325 (1.87)

$5.625(2.86)$

69 (53)

E4

3.45 (2.02)

$5.38(2.6)$

$56(29)$

E5

$3.28(2.02)$

$5.26(3.2)$

$60(58)$

E6

$3.75(1.8)$

$5.75(2.92)$

$53(64)$

E7

$3.75(1.7)$

$5.5(3.2)$

47 (88)

E8

$3.8(1.8)$

$6(3.2)$

58 (78) 

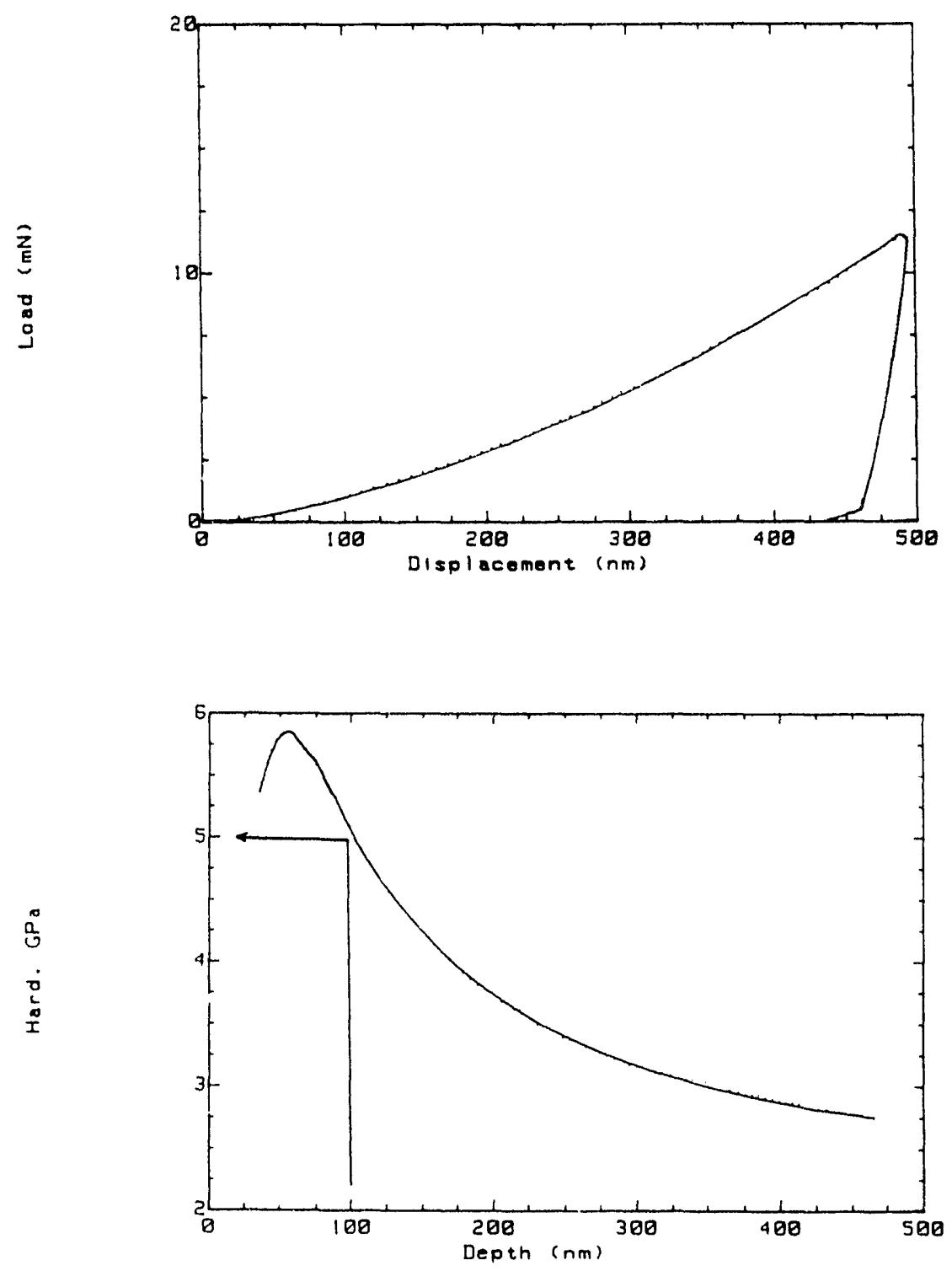

Figure 27. Typical nanoindentation results, shown here for the control E-1 specimen. Figure (a) shows the load-displacement plot from one indent and (b) shows calculated hardness values as a function of depth. 
been corrected for the effects of elasticity. From the hardness vs depth plot, the hardness values at $100 \mathrm{~nm}$ was determined and reported for comparison.

Figure 28 shows results of nanoindentation measurements for the eight Eseries alloys before and after implantation. The near surface hardness of all specimens increased after implantation, similar to the knoop hardness values observed as shown in table 14. The percentage hardness increases obtained using the two techniques are different for the alloys though some of them show similar trends. In both cases, E2 alloy showed the greatest increase in near-surface hardness. The differences could be attributed to the fact that the Knoop indenter contact area is much larger than that of the nanoindenter. Interestingly, while the hardness of the control alloys varied, the implanted alloys' hardness values were comparable in all eight alloys.

Fatigue Testing

Fatigue Data

For the control specimens, two to four specimens were tested for each alloy whereas for the B,N implanted samples, only one specimen was tested for each alloy. The fatigue test results for the eight alloys are shown in figure 29. It can be seen that the dual implantation reduced fatigue life for the eight alloys. The reduction in fatigue life varied from around $15 \%$ for alloys E1 and E6 to $45 \%$ for alloy E7 as shown in table 15. This is in contrast to the results obtained by Lee and Mansur [6] using simple $\mathrm{Fe}-13 \mathrm{Cr}-15 \mathrm{Ni}$ alloys (compositions given in table 2). They found that dual implantation with $\mathrm{B}$ and $\mathrm{N}$ under conditions identical to 


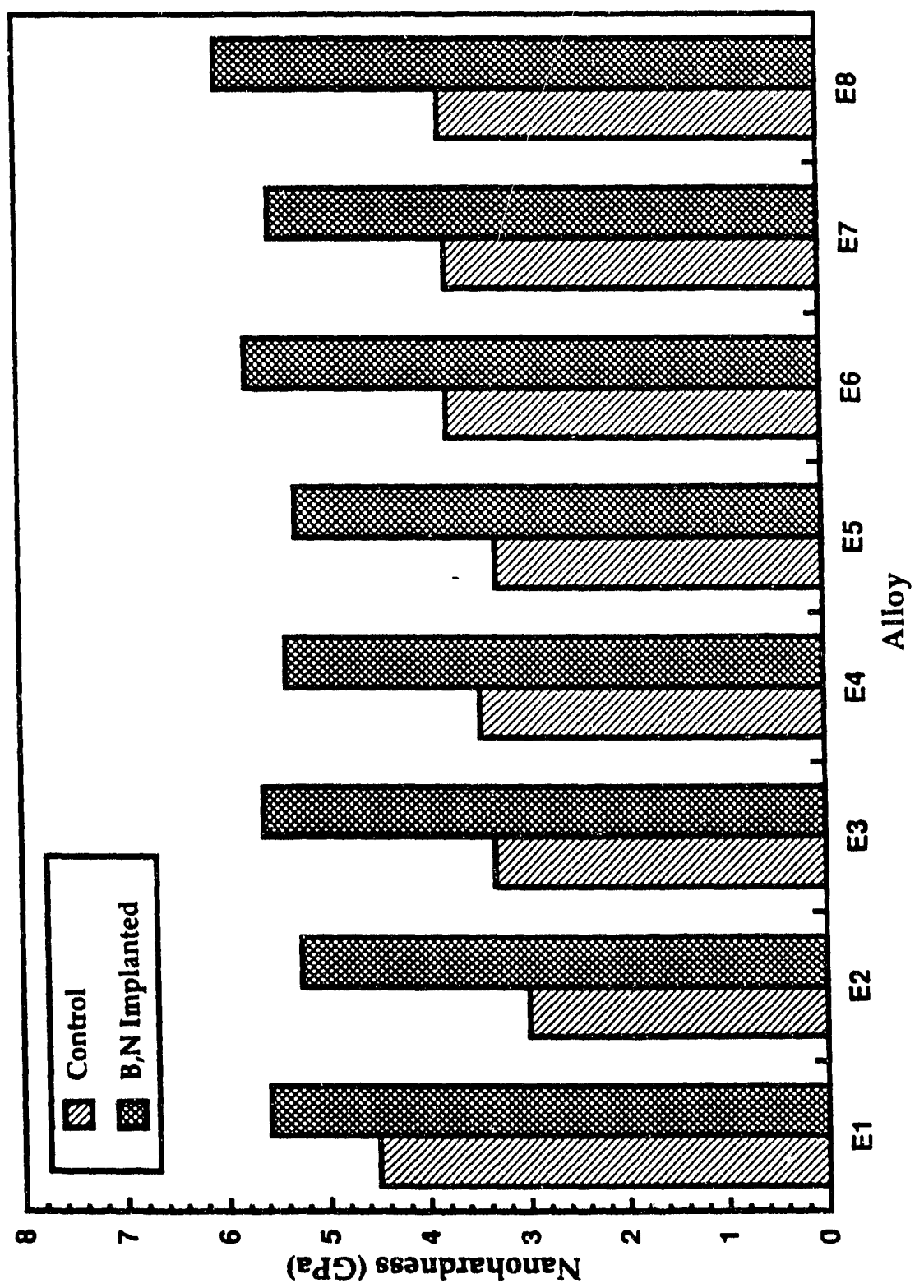

Figure 28. Nanoindentation hardness results for the E-alloys at a depth of $100 \mathrm{~nm}$. 


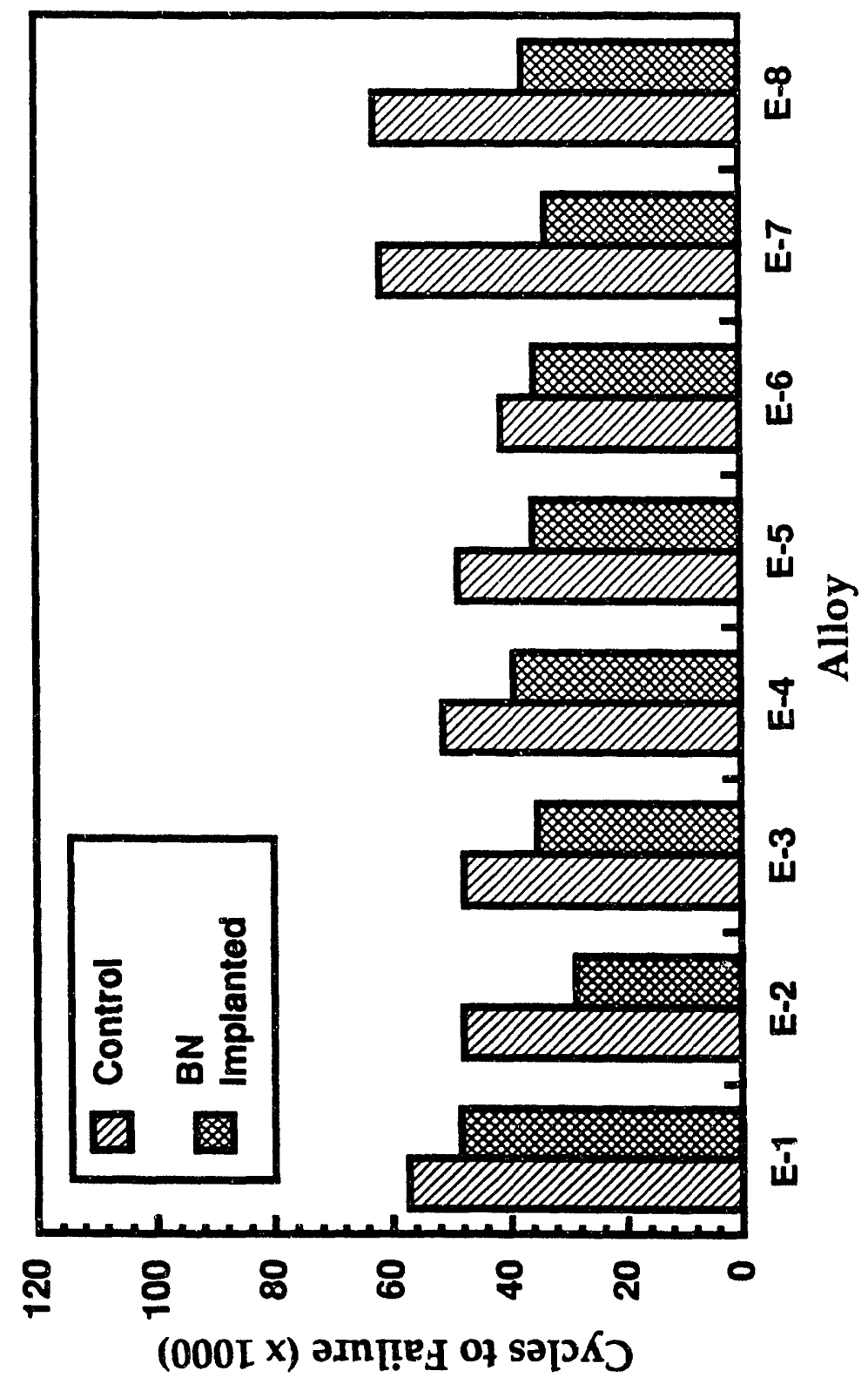

Figure 29. Fatigue test results for the control and B,N implanted E-series alloys showing a decrease in fatigue life after implantation for all eight alloys. 
Table 15.

Fatigue tests results for the eight E-series alloys indicating the percentage decrease in fatigue life for the implanted specimens

ALLOY

CYCLES TO FAILURE

\% CHANGE

UNIMPLANTED IMPLANTED

$\begin{array}{llll}\text { E-1 (Base) } & 57242 & 48342 & -15.55 \% \\ \text { E-2 (-Mo) } & 47835 & 28650 & -40.11 \% \\ \text { E-3 (-Mn) } & 47694 & 35194 & -26.2 \% \\ \text { E-4 (-Ti) } & 51180 & 39242 & -23.33 \% \\ \text { E-5 (-C) } & 48628 & 35803 & -26.4 \% \\ \text { E-6 (-0.5 Si) } & 41371 & 35531 & -14.12 \% \\ \text { E-7 (-Si) } & 61606 & 33530 & -45.6 \% \\ \text { E-8 }(+\mathrm{P}) & 62610 & 37305 & -40.42 \%\end{array}$


those used in this study, significantly increased fatigue life, up to $250 \%$ in one case, as mentioned in chapter 2. A comparison of the change in fatigue life and hardness due to implantation (figures 26,28 and 29) shows that in general, the greater the percentage increase in hardness, the greater is the reduction in fatigue life.

\section{Optical Microscopy}

Typical surface appearance is shown in figure 30 for control and implanted E4 and E5 specimens. The control specimens in general, had up to four major cracks along with a number of minor cracks in contrast to the implanted specimens which revealed one major crack and fewer minor cracks. A number of microcracks were observed in both cases although the implanted specimens showed fewer microcracks as well. Examination of the fatigue gauge regions after testing the specimens showed a suppression of slip bands on the surface. The fraction of grains with slip bands was greater for the control specimens than for the implanted specimens. Slip bands are manifestations of the movement of dislocations along preferred planes of atoms in the metal which causes the material between planes to be elevated or depressed at a free surface.

Slip bands in the control specimens were visible throughout the gauge region whereas in the implanted specimens, slip bands were confined to the immediate vicinity of the major crack. Slip bands in the control specimens, in general, had a wavy character in contrast to the implanted specimens in which the slip bands had 

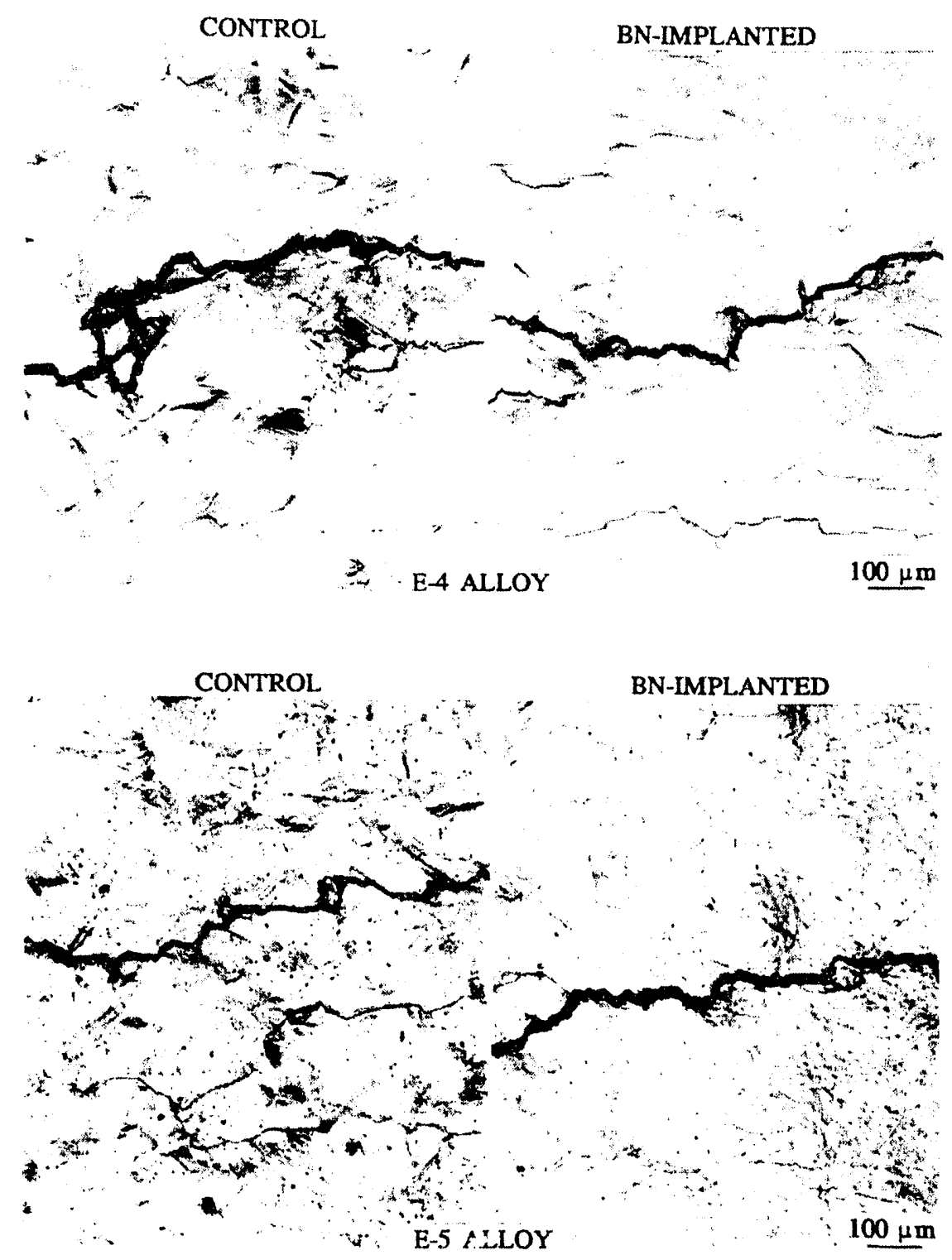

Figure 30. Optical micrographs of the surface of control and implanted specimens showing a suppression of slip at the surface in the implanted specimens. 
a planar character. This probably indicates a lowering of stacking fault energy due to the implantation which allows wider separation of partial dislocations and restricts cross slip and dislocation motion. Thus, the slip bands which form underneath the implanted layer are constrained from penetrating the layer and the slip bands that do penetrate the implanted layer cannot cross-slip thus causing the planar appearance at the surface.

The process of fatigue failure begins with the initiation of microcracks at various sites on the surface of the material. Typical crack initiation sites are slip bands, twins, grain boundaries and at the precipitate particle-matrix interface. Some of these microcracks eventually grow and coalesce to form larger cracks ultimately leading to fatigue failure [37]. In the control specimens, cracks were found to initiate primarily in slip bands. A few grain boundary cracks were also formed. Crack initiation in the control specimens was studied using interrupted tests where a specimen undergoing a fatigue test was periodically examined for surface features and crack formation. Results for one such test is shown in figure 31 for an E1 control specimen showing micrographs of one particular area in the gauge region photographed as a function of time. The photographs show the initiation of cracks in slip bands that eventually grow to form large cracks.

In the case of the implanted specimens, the availability of a limited number of specimens precluded a similar crack initiation study from being performed. However, examination of the specimen surfaces indicated the presence of a 

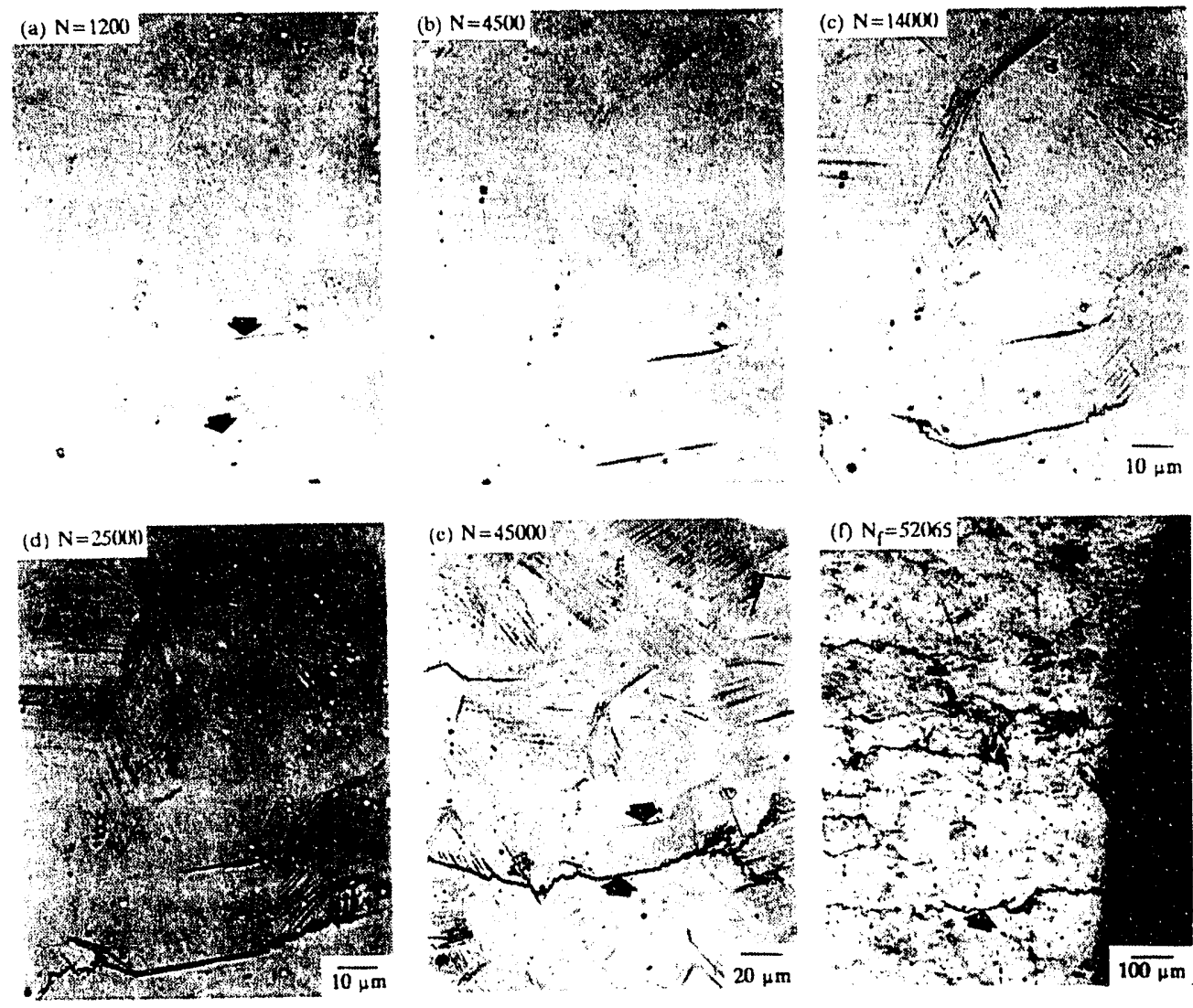

Figure 31. Crack initiation study in a control E-1 specimen showing crack initiation at slip bands and subsequent growth ( $\mathrm{N}$ is the number of elapsed cycles $)$. 

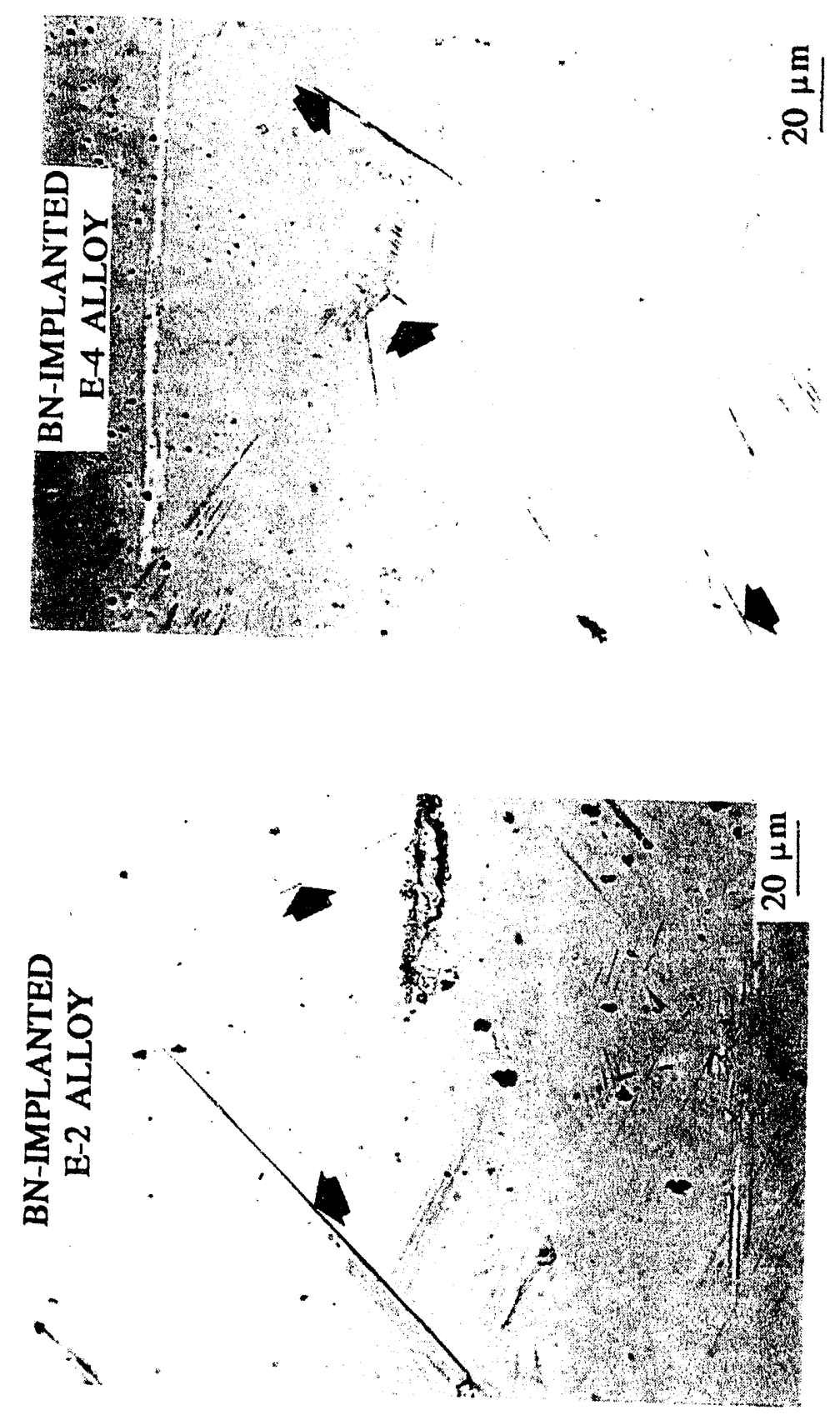

Figure 32. Optical micrographs of implanted E-specimens showing grain boundary cracks. 
number of grain boundary cracks as shown in figure 32. There were very few slip band cracks due the presence of fewer slip bands as compared to the control specimens indicating that grain boundary crack initiation was probably responsible for the final failure.

\section{$\underline{\text { Transmission Electron Microscopy }}$}

Transmission electron microscopy of the as-annealed E-alloys showed a basically featureless microstructure with very few dislocations evident. After fatigue testing, several distinct microstructures were observed depending upon location of examination on the fatigue specimen cross-section. In the fatigued specimens, near the neutral axis, the microstructure was very similar to the asannealed microstructure with very few dislocations as shown in figure 33(a). At intermediate locations, between the neutral axis and specimen surf 'ce, microstructures such as the one shown in figure 33(b) were observed. These have been termed "dislocation debris" by some researchers and represent precursors to the formation of dislocation cells [104]. Close to the specimen surface, dislocation cell structures were observed (figure 33(c)). The cells wi:s imperfectly formed with dislocations present within the cells. Figure 33(d) shows a labyrinth or Lstructure, an alternate form of cell structure, which was also observed near the specimen surface [104].

Examination of cross-sectional TEM specimens of the implanted alloys revealed a damaged surface region with peak damage close to $0.5 \mu \mathrm{m}$ as was estimated from TRIM calculations. Typical micrographs are shown in figure 34. 

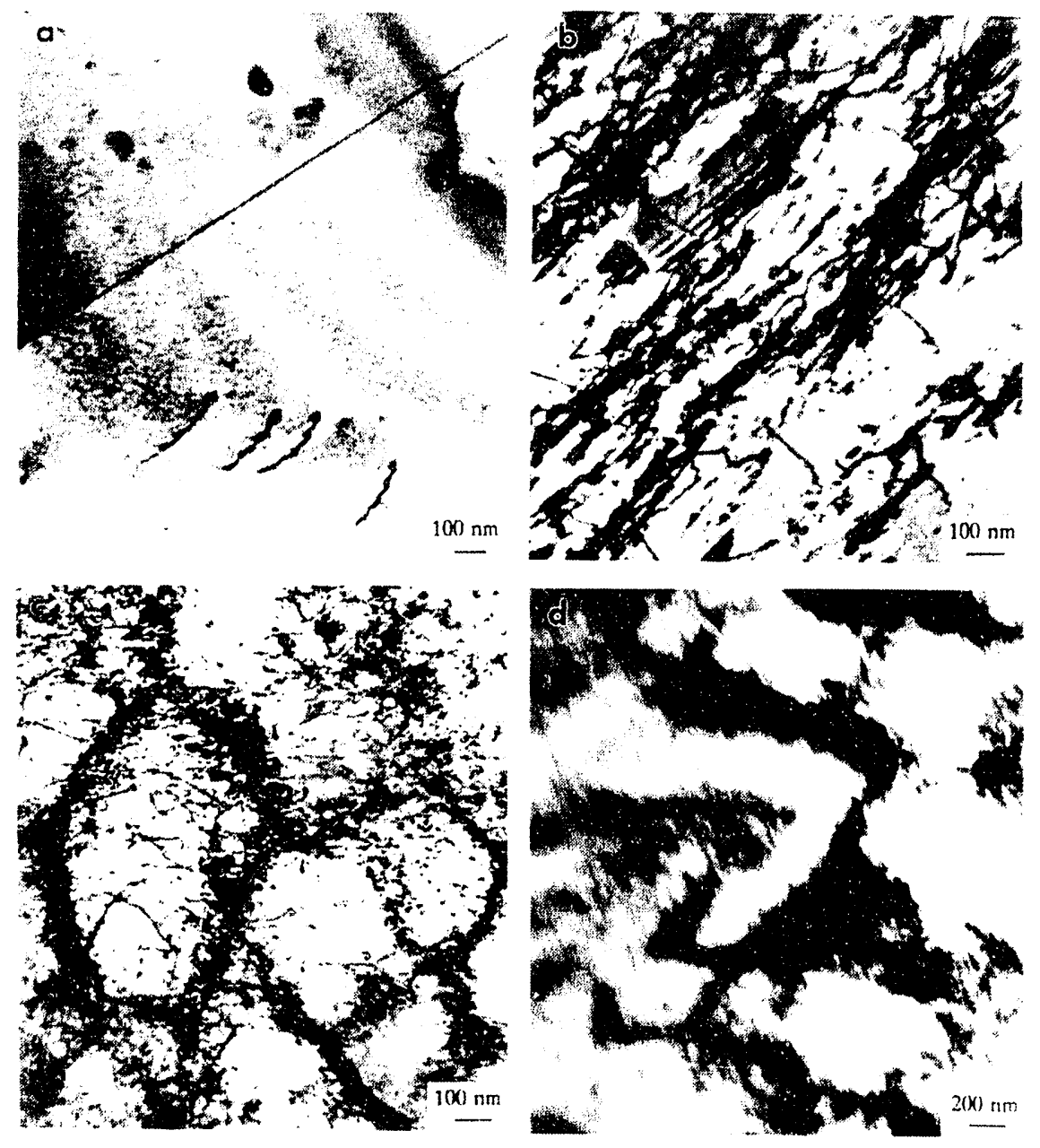

Figure 33. Typical TEM micrographs of control fatigue specimens showing microstructures as a function of position on the specimen crosssection. (a) close to the neutral axis, (b) intermediate locations, (c) cell structure close to the surface and (d) L-structure close to the specimen surface. 

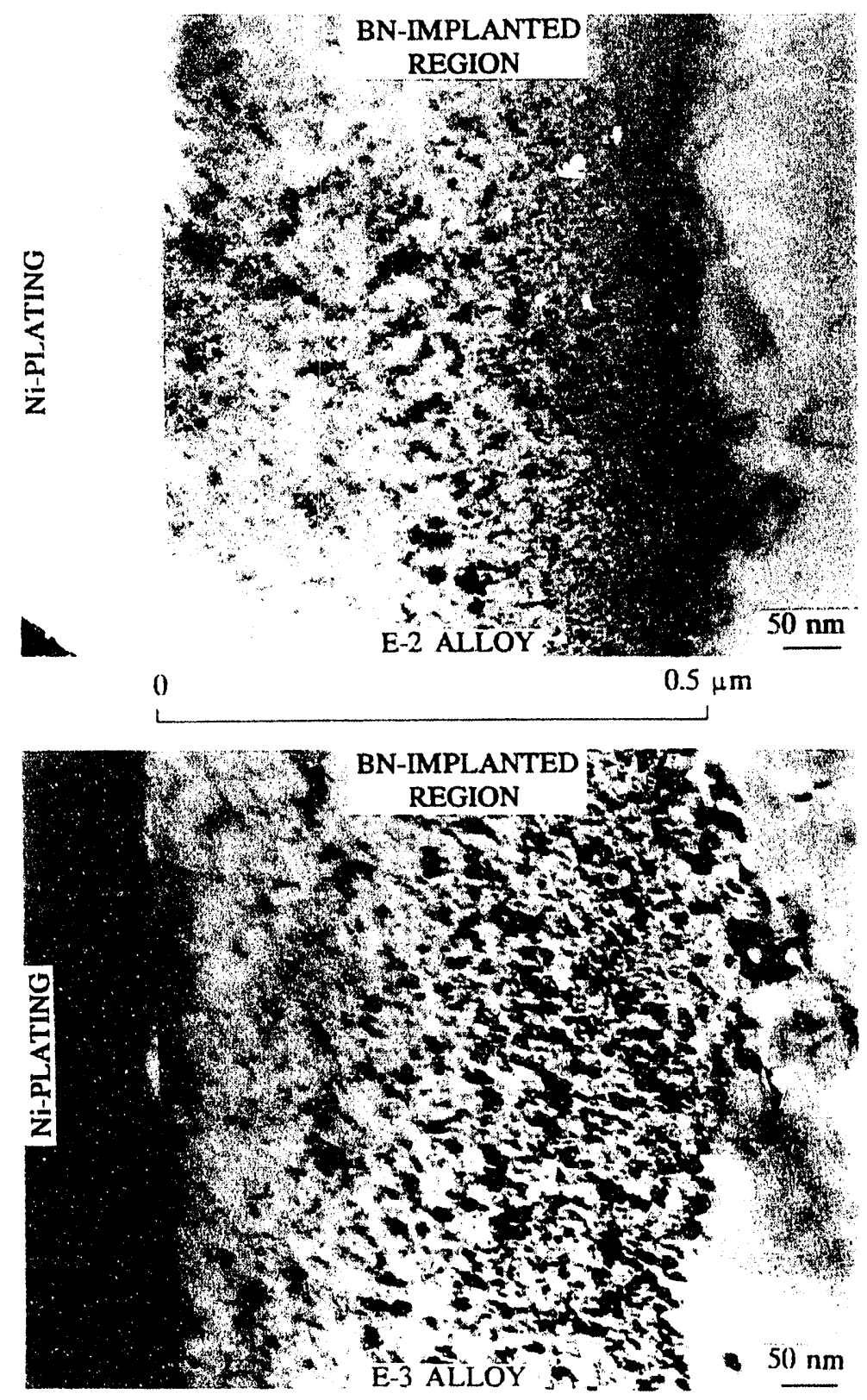

Figure 34. Typical cross-sectional TEM images of the implanted layer in fatigued specimens. 
The black-dot damage microstructure showed a mottled contrast. Electron diffraction did not reveal the presence of precipitate particles. The modest doses and low temperature implantation used in this study probably precluded formation of precipitate particles large enough to be detected by electron diffraction. Backthinned specimens were also examined in the TEM and typical microstructures are shown in figure 35 . The slip bands could be seen penetrating the implanted layer. The planar nature of the bands was evident.

\section{Creep Testing}

\section{Creep Data}

Creep test results are shown in figure 36 for the ternary B1 alloy. Results are shown for two control specimens, one $\mathrm{Ar}^{+}$-implanted specimen and one $\mathrm{B}^{+} / \mathrm{N}^{+}$implanted specimen. The implanted specimens showed a small negative creep region during primary creep and just before the onset of secondary creep. The implanted specimens clearly showed a smaller steady-state creep rate as compared to the control specimens with the $\mathrm{B}^{+} / \mathrm{N}^{+}$implanted specimen yielding the lowest strain rate. The $\mathrm{Ar}^{+}$-implantation increased the creep rupture life by approximately $45 \%$ and the $\mathrm{B}^{+} / \mathrm{N}^{+}$-implantation increased life by approximately $75 \%$. The implanted B1 specimens also showed a slightly higher ductility as compared to the unimplanted specimens.

Results are similarly shown for creep tests performed on the E1 alloys in figure 37. The control E1 specimens showed a fracture life of nearly twice that for the control B1 specimens in spite of the much higher initial stress level. This 

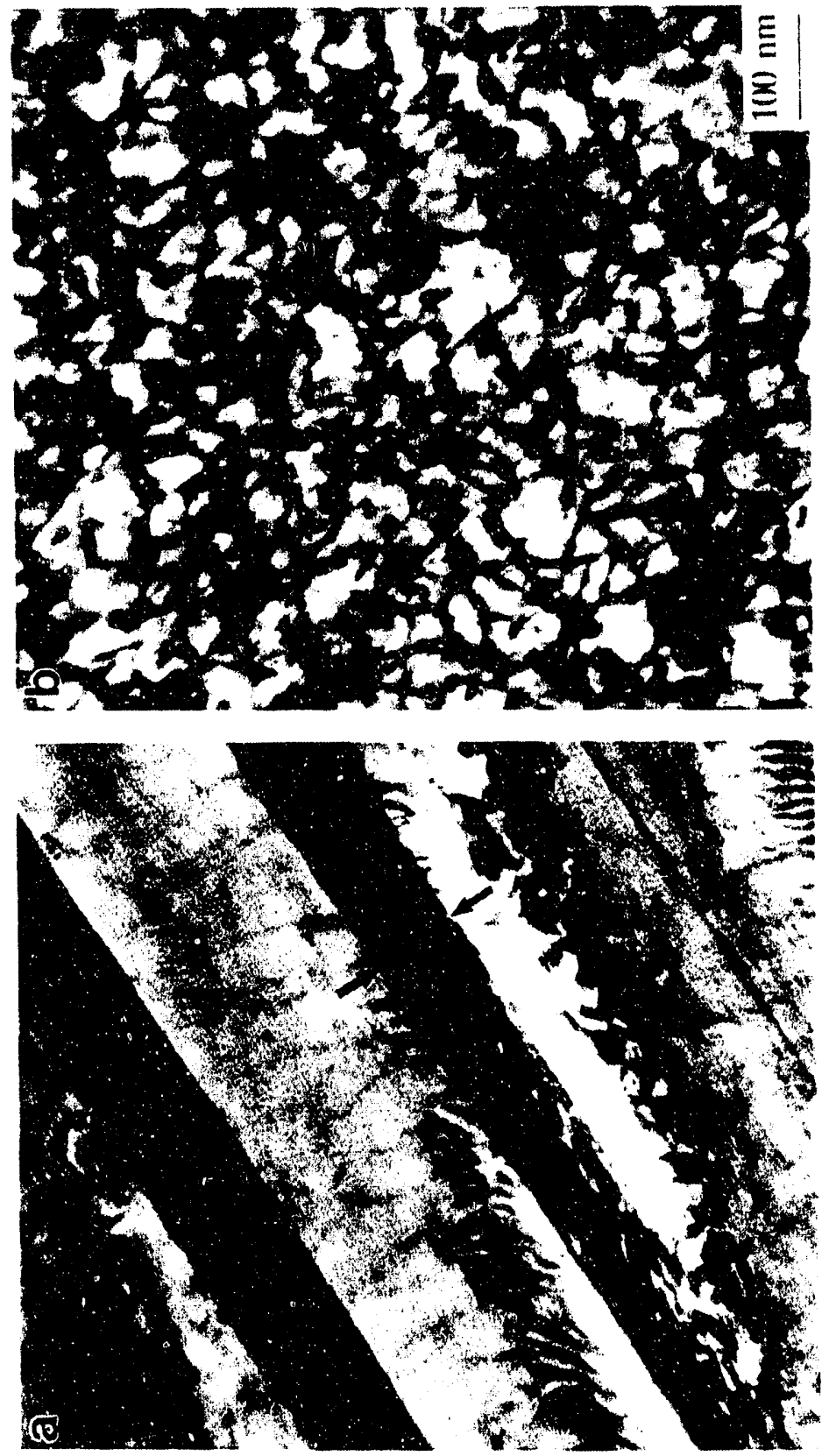

Figure 35 . Implant layer microstructures observed in a TEM using backihinned specimens. 


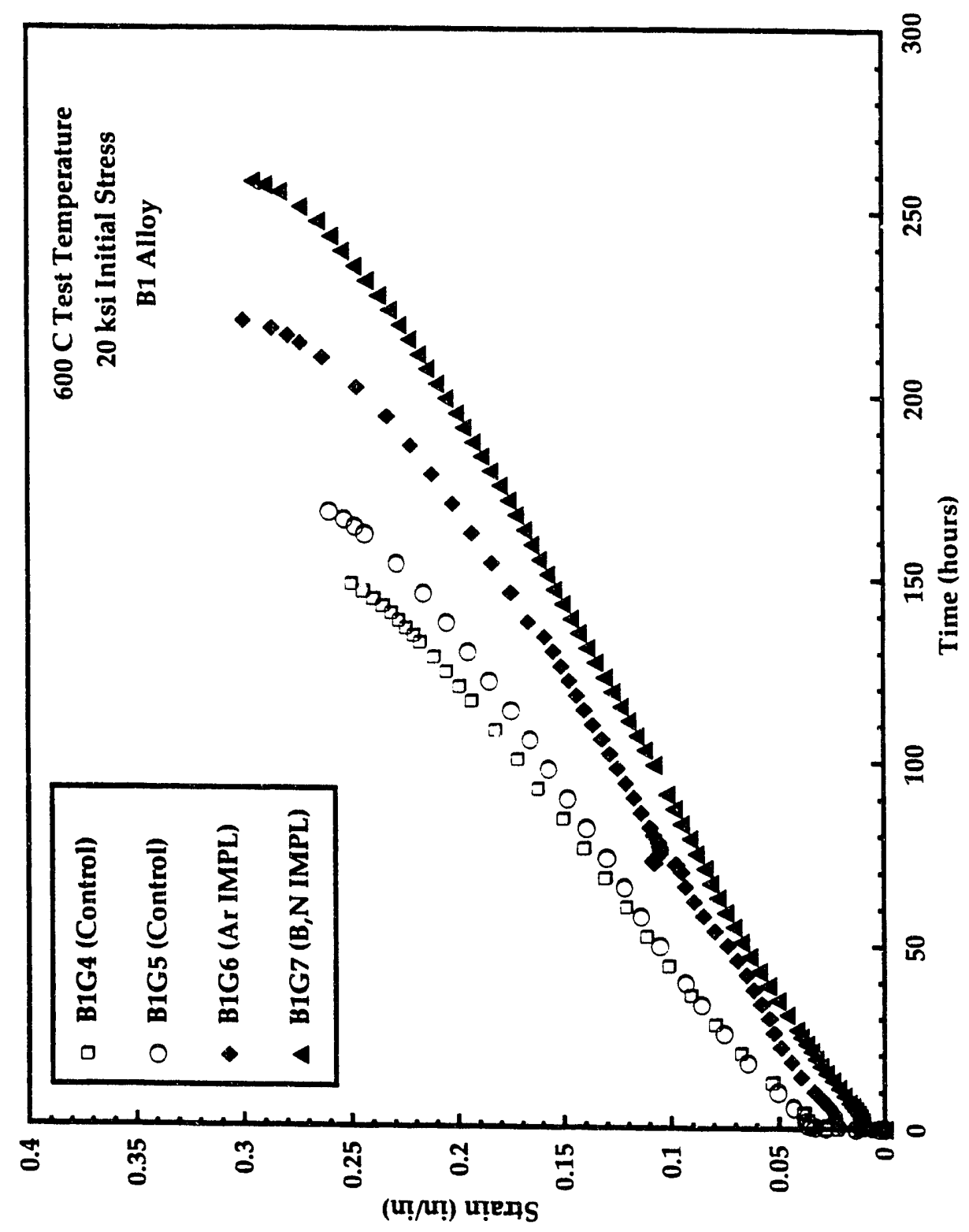

Figure 36. Creep test results for the $\mathrm{B} 1$ specimens for control, $\mathrm{Ar}^{+}$and $\mathrm{B}^{+} / \mathrm{N}^{+}$-implanted cases tested at $600^{\circ} \mathrm{C}$. 


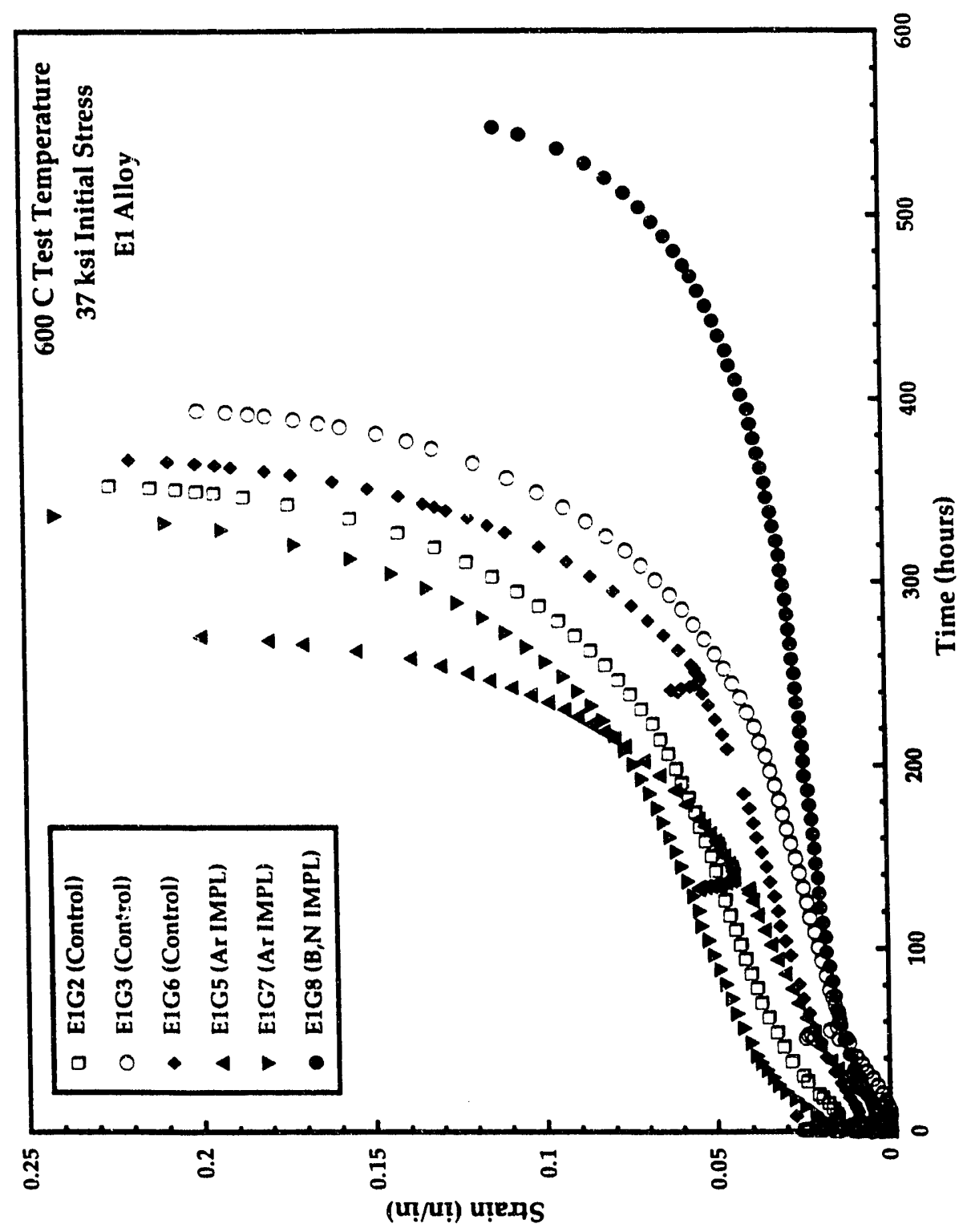

Figure 37. Creep tests results for the control, $\mathrm{Ar}^{+}$-implanted and $\mathrm{B}^{+} / \mathrm{N}^{+}$implanted $\mathrm{E} 1$ specimens tested at $600^{\circ} \mathrm{C}$. 
can be attributed to precipitate and solid solution strengthening. The $\mathrm{B}^{+} / \mathrm{N}^{+}$. implanted specimen had a total life of approximately 560 hours, an increase of $72 \%$ over the control specimen rupture life. Unlike the $\mathrm{Ar}^{+}$-implanted $\mathrm{B} 1$ alloy however, $\mathrm{Ar}^{+}$-implantation had only a minor effect on creep life of the E1 alloy and in fact, the life was decreased to a small extent. Again, the $\mathrm{B}^{+} / \mathrm{N}^{+}$-implanted specimen showed the smallest creep rate although it's ductility was significantly reduced. All E1 specimens showed a small negative creep region during transient creep. The steady state creep rates as well as plastic strain to rupture for all specimens are given in table 16.

\section{Optical Microscopy}

All specimens failed by intergranular creep fracture (ICF). However, the mode of failure was different in the two alloys. Figure 38 shows the surface of the B1 control specimen. The specimen failed by the formation of spherical " $r$ " type cavities [103] at grain boundaries and their subsequent growth and coalescence. Several cavities were also observed in the matrix of the grains, evident when the microscope was defocussed. The imflanted specimens revealed a very similar surface appearance and there were no obvious differences. Both control and implanted specimens revealed slip bands in most grains.

The intergranular cracks formed in the E1 ailoys were very different as shown in figure 39 for an unimplanted E1 specimen. These type of g.b. cracks are termed wedge or "w" cracks and are mainly formed at the junction of three 
Table 16.

Steady state creep rates for the B1 and E1 creep specimens

Specimen Implantation Condition $\quad$ Minimum Creep Strain $\underline{\text { Strain to }}$ rate $\quad \underline{\text { fracture }}$

$(\mathrm{mm} / \mathrm{mm} / \mathrm{sec})$

B1 Alloy (20 ksi Initial Stress)

$\begin{array}{llll}\text { B1G4 } & \text { Unimplanted } & 1.22 \times 10^{-3} & 0.25 \\ \text { B1G2 } & \text { Unimplanted } & 1.10 \times 10^{-3} & 0.26 \\ \text { B1G6 } & 1 \mathrm{MeV} \mathrm{Ar}^{+} & 8.75 \times 10^{-4} & 0.30 \\ \text { B1G5 } & 400 \mathrm{keV} \mathrm{B}^{+} / 550 \mathrm{keV} \mathrm{N}^{+} & 8.5 \times 10^{-4} & 0.29\end{array}$

E1 Alloy (37 ksi Initial Stress)

$\begin{array}{llll}\text { E1G2 } & \text { Unimplanted } & 1.75 \times 10^{-4} & 0.225 \\ \text { E1G3 } & \text { Unimplanted } & 1.37 \times 10^{-4} & 0.21 \\ \text { E1G6 } & \text { Unimplanted } & 1.4 \times 10^{-4} & 0.22 \\ \text { E1G5 } & 1 \mathrm{MeV} \mathrm{Ar}^{+} & 2.4 \times 10^{-4} & 0.20 \\ \text { E1G7 } & 1 \mathrm{MeV} \mathrm{Ar}^{+} & 2 \times 10^{-4} & 0.21 \\ \text { E1G8 } & 400 \mathrm{keV} \mathrm{B}^{+} / 550 \mathrm{keV} \mathrm{N}^{+} & 5.4 \times 10^{-5} & 0.12\end{array}$



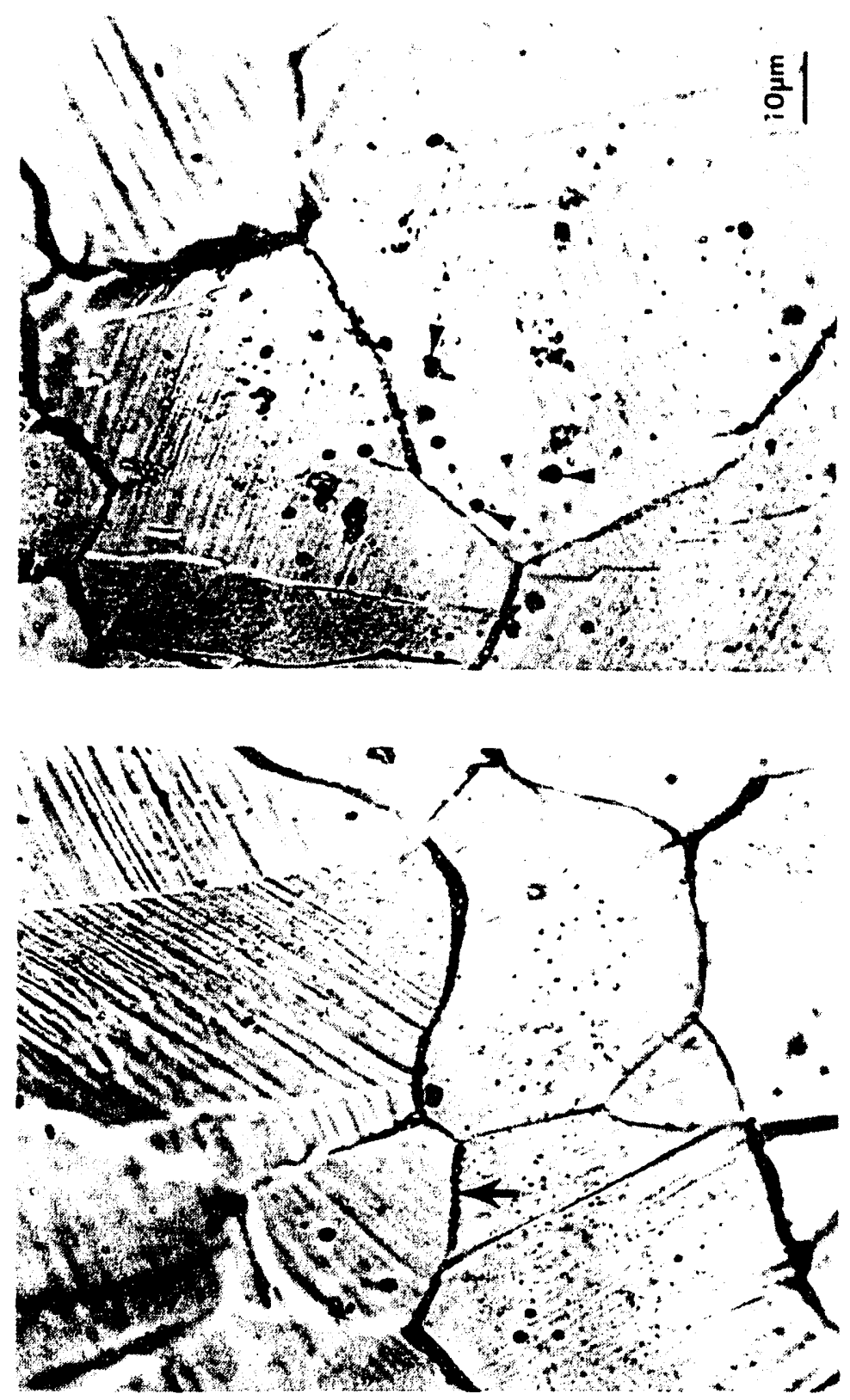

Figure 38. The surface of the control B1 specimen after the creep tes: showing " $r$ " type cracks and voids. 


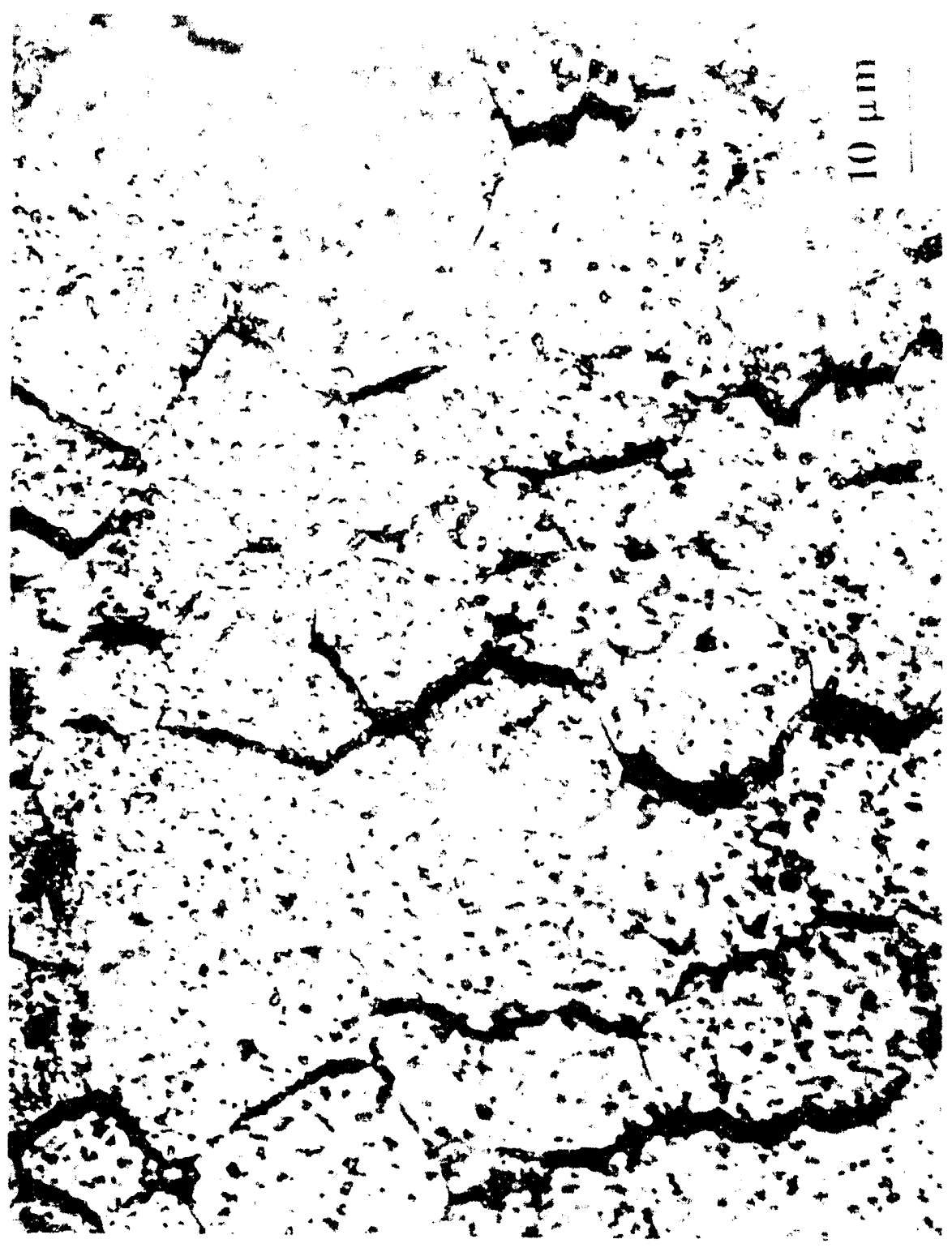

Fisure 39 . The surate of the control El specimen showing wedge type cracks primarily at ariple grain junctions. 
adjoining grains. The cracks are thought to be formed by g.b. sliding [103]. The implanted E1 specimens also showed no essential differences as compared to the control E1 specimens. There were a large number of precipitate particles evident on the surface of the specimen, both in the matrix as well as at grain boundaries.

\section{DISCUSSION}

\section{Fatigue}

\section{Ion Implantation Effects}

Several consequences of ion implantation on mechanical properties have been suggested by researchers and they can be examined in light of the present study. Residual stresses are an important factor [50]. Residual compressive stresses are probably induced by the implantation since the implanted ions most likely will occupy interstitial sites. The residual compressive stress would be beneficial during the tension part of the fatigue cycle, though not during the compression cycle.

Radiation damage may also be an important factor. The implantation results in the creation of several point defects at the surface, which form clusters and Frank loops, as evinced by TEM examination. The damage microstructure strengthens the surface. In an earlier study, $\mathrm{Fe}^{++}$was implanted onto four $\mathrm{B}$ series alloys, which are simple $\mathrm{Fe}-13 \mathrm{Cr}-15 \mathrm{Ni}$ alloys (composition given in table 2) [104]. The self-implantation increased surface hardness but had no significant effects on fatigue life. Radiation damage caused by ion implantation is probably 
not an important factor in fatigue. Morrison et.al. found no improvement in the fatigue life of $\mathrm{Ni}$ after self-implantation which was attributed to cyclic softening of the hardened layer. The authors observed formation of clear channels which were penetrated by PSBs [57].

The formation of precipitate particles due to the implantation hinders dislocation movement, which can delay crack initiation. Fine precipitates can also make surface emerging slip homogeneous, decreasing the chances of crack initiation at su.face inhomogeneities [50,58]. As mentioned earlier, in this study, TEM could not discern the presence of precipitates, probably due to the overlapping strain fields of the large concentration of lattice defects. In any case, the dose used was quite modest and implantation was performed at room temperature. Therefore, any precipitates that may have formed were probably too small to be detected in the TEM. High resolution electron microscopy or the atom probe field ion microscopy can be used to detect precipitates on the order of $1 \mathrm{~nm}$. An earlier atom probe study of nitrogen implanted $\mathrm{Fe}-13 \mathrm{Cr}-12 \mathrm{Ni}$ alloy did reveal the presence of small precipitate clusters [105].

The hardness improvements found in the implanted $\mathrm{Fe}-13 \mathrm{Cr}-15 \mathrm{Ni}$ alloys are the result of residual stresses, radiation damage, precipitate strengthening as well as solid soluition strengthening. These effects caused the formation of a thin, hard layer with an increased yield strength on the surface causing a reduction in surface plastic strain, which is reflected in the hardness increases observed. 
It is clear from the optical micrographs that slip band formation was suppressed at the surface due to the presence of the implanted layer. It has been shown that slip bands do form in the material underneath the implanted layer, but are effectively prevented from penetrating the layer [6]. The implanted layer also appears to have a lower stacking fault energy than the control material since slip in the implanted specimens was planar in contrast to the wavy slip observed in the control specimens. The lowering of SFE prevents cross-slip, thus forming the planar slip bands observed on the surface as opposed to the wavy slip observed in the control specimens.

\section{Possible Fatigue Mechanisms}

The dominant effect of implantation on fatigue appears to be a shift to grain boundary crack initiation from slip band cracking. This shift is responsible for the observed reduction in fatigue life. It was shown that in the control specimens, cracks primarily initiated in slip bands, although some grain boundary cracks were also observed. In the implanted specimens, the slip bands were greatly suppressed. The applied stress was then relieved by crack formation in grain boundaries that were favorably oriented with respect to the bending moment. Kim and Laird have investigated grain boundary crack nucleation in high strain fatigued copper. They have shown that grain boundaries that were favorable to act as crack initiation sites had the following properties: (1) They lie at an angle of $30-90^{\circ}$ with respect to the stress axis, (2) the boundaries join highly mis-oriented 


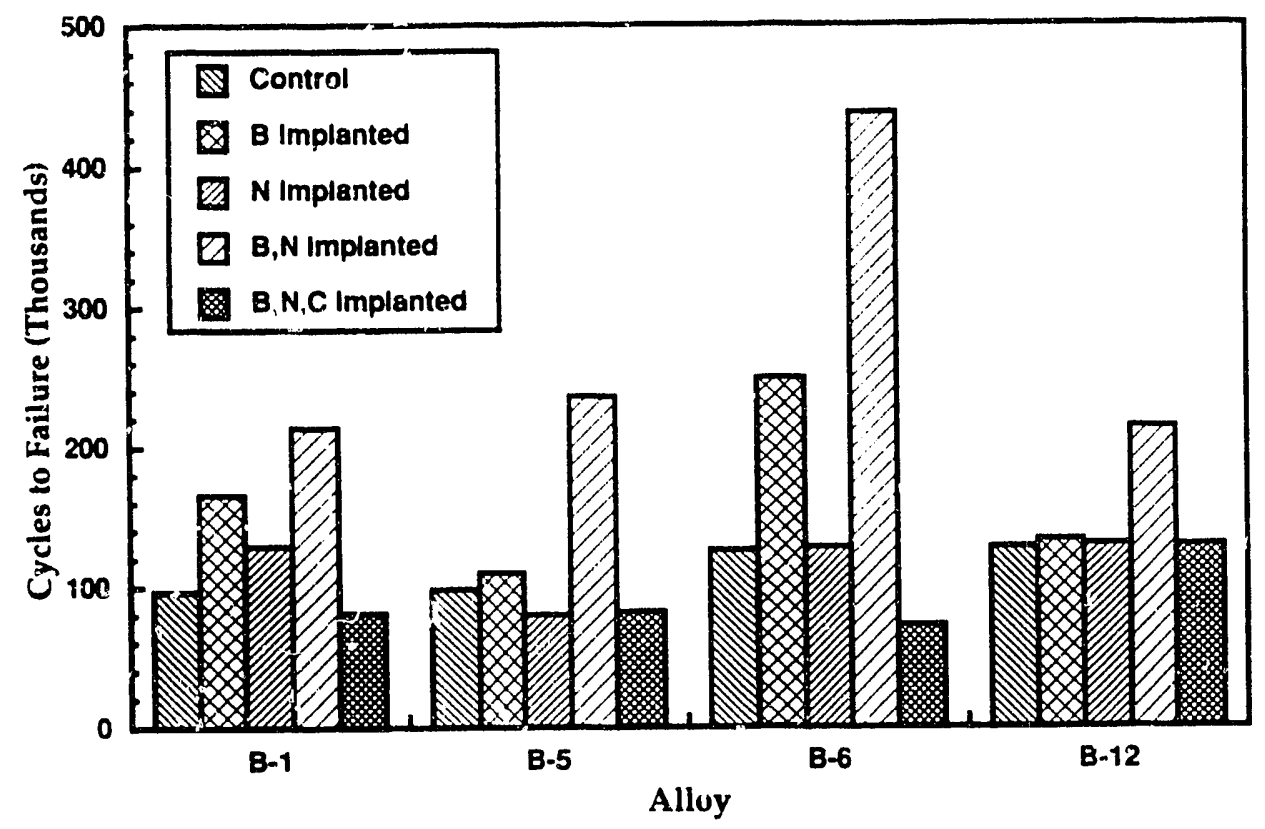

Figure 40. Fatigue results for the B-series alloys showing triple implantation reduced fatigue life though dual implantat: 'significantly increased it [104]. 
grains and (3) a dominant slip system in one of the adjacent grains is directed at the grain boundary at the surface [106].

This hypothesis is supported by results obtained for the B-series alloys th $t$ were studied by Lee and Mansur. They observed that dual implantation with B and $\mathrm{N}$ significantly improved fatigue life. In a later study, the alloys were implanted with $\mathrm{B}, \mathrm{N}$ and $\mathrm{C}$ simultaneously [104]. The results are shown in figure 40. The triple implantation, in contrast to the dual implantation, showed no improvement or in some cases reduced fatigue life as compared to the control specimens. Optical microscopy revealed grain boundary cracks only in the triple implanted specimens as shown in figure 41 .

The B-series results can be compared to the E-series alloys data from this study. In the E-alloys, due to additional alloying elements, the strength is inherently greater than the B-alloys. Thus dual implantation was sufficient to cause the shift to grain boundary cracking. In the B-alloys, only triple implantation caused sufficient strengthening for the promotion of grain boundary cracking. The dual implantation suppressed slip band formation on the surface just enough to decrease slip band crack initiation, so that fatigue life was improved. There thus appears to be an optimum level of strengthening for maximum fatigue life improvement in the alloys.

These results are similar to those of a dose dependence study on the fatigue behavior of Ni by Hohmuth et al. [48]. They observed an optimum dose for $\mathrm{B}$ implantation in $\mathrm{Ni}$ (table 7). At doses higher than the optimum, the authors 


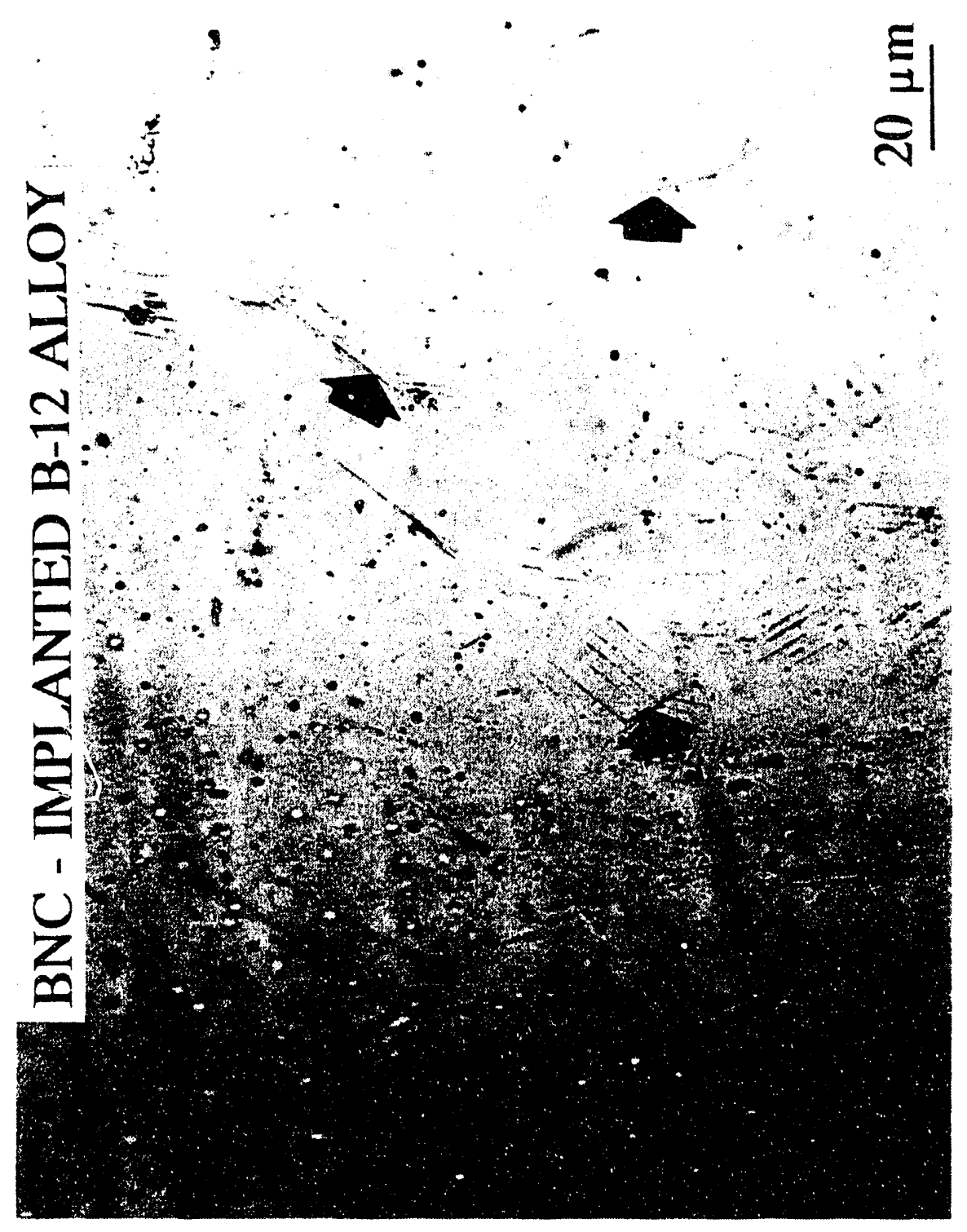

Figure 4!. Optical microscopy of B.N.C implanted B1 alloy specimen showing grain houndary cracks. No G.B. cracks were observed in the control single of dual implanted specimens. 


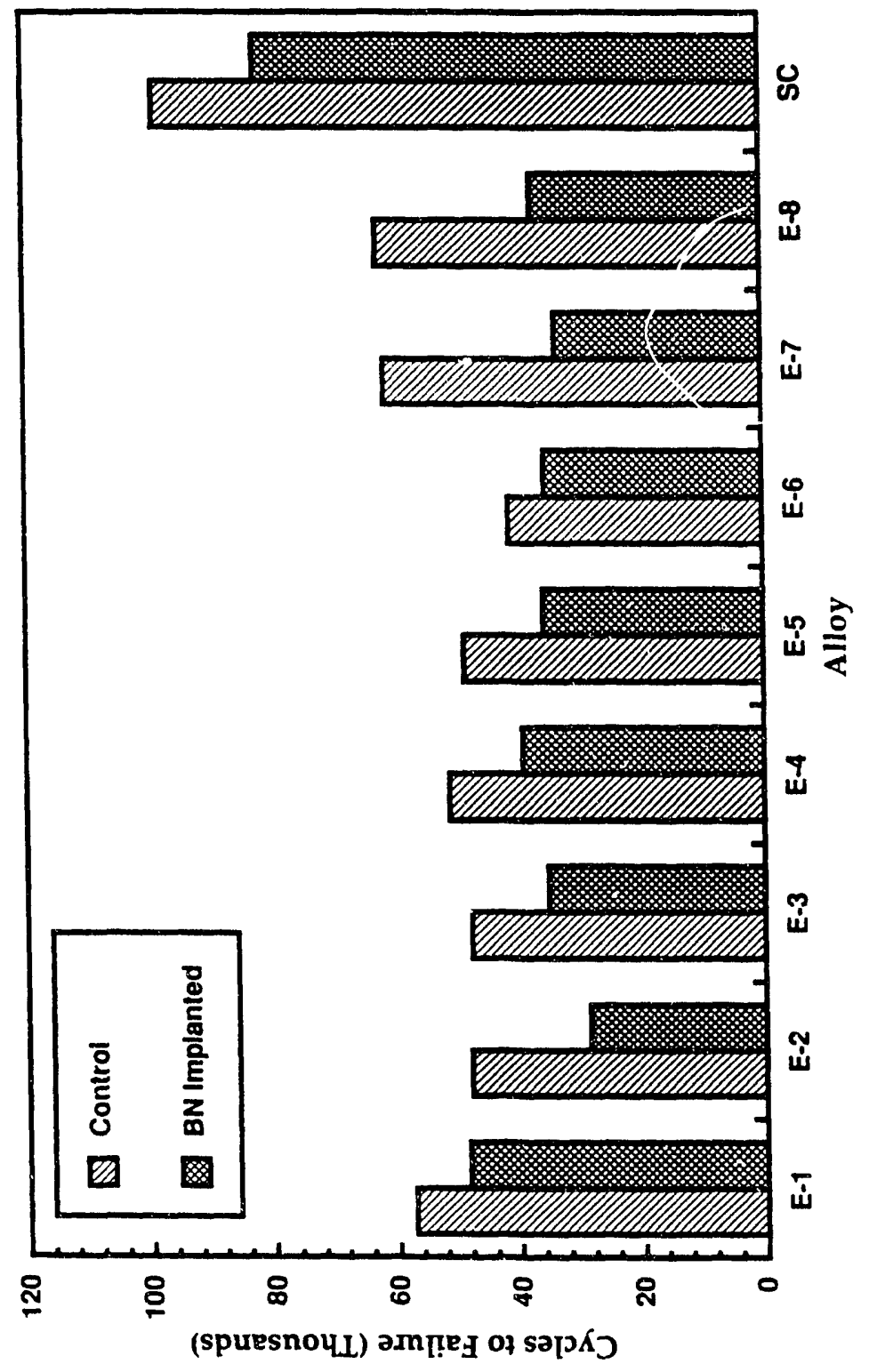

Figure 42. Fatigue test results for the control and B,N implanted single crystal $\mathrm{Fe}-15 \mathrm{Cr}-15 \mathrm{Ni}$ specimens compared with the E-series specimen results. 
observed grain boundary cracks. It can be speculated that for the $\mathrm{Fe}-13 \mathrm{Cr}-15 \mathrm{Ni}$ alloys, an optimum surface strengthening level exists which yields the best fatigue life. This strength level would be dependent on grain size.

To further explore this idea, single crystals of $\mathrm{Fe}-15 \mathrm{Cr}-15 \mathrm{Ni}$ were implanted with $\mathrm{B}$ and $\mathrm{N}$ to the same doses used for the $\mathrm{E}$ and $\mathrm{B}$-alloys. The results of fatigue tests are shown in figure 42. The implantation decreased fatigue life of the single crystal specimens. Optical microscopy showed that slip bands were formed over the entire gauge region as shown in figure 43. The specimens were oriented with the longitudinal axis along the [100] direction. Two sets of slip bands were observed perpendicular to each other and oriented at $45^{\circ}$ to the [100] direction. The slip bands correspond to two $\{111\}<110>$ systems, the preferred slip system for fcc metals.

In the implanted specimens, most of the slip bands were suppressed from penetrating the implant layer. However, a few intense slip bands were formed and all cracks initiated from these intense slip bands as shown in figure 44. It appears that while slip was suppressed in general, a few slip bands managed to escape to the surface and further applied stress was concentrated along these slip bands leading to an earlier crack initiation.

\section{Model for Observed Fatigue Behavior}

The Basic EGM Model for FCC Single Crystals

We can invoke the model proposed by Essmann, Gösele and Mughrabi (EGM model) $[107,108]$ to understand the mechanisms suggested in this study. The 


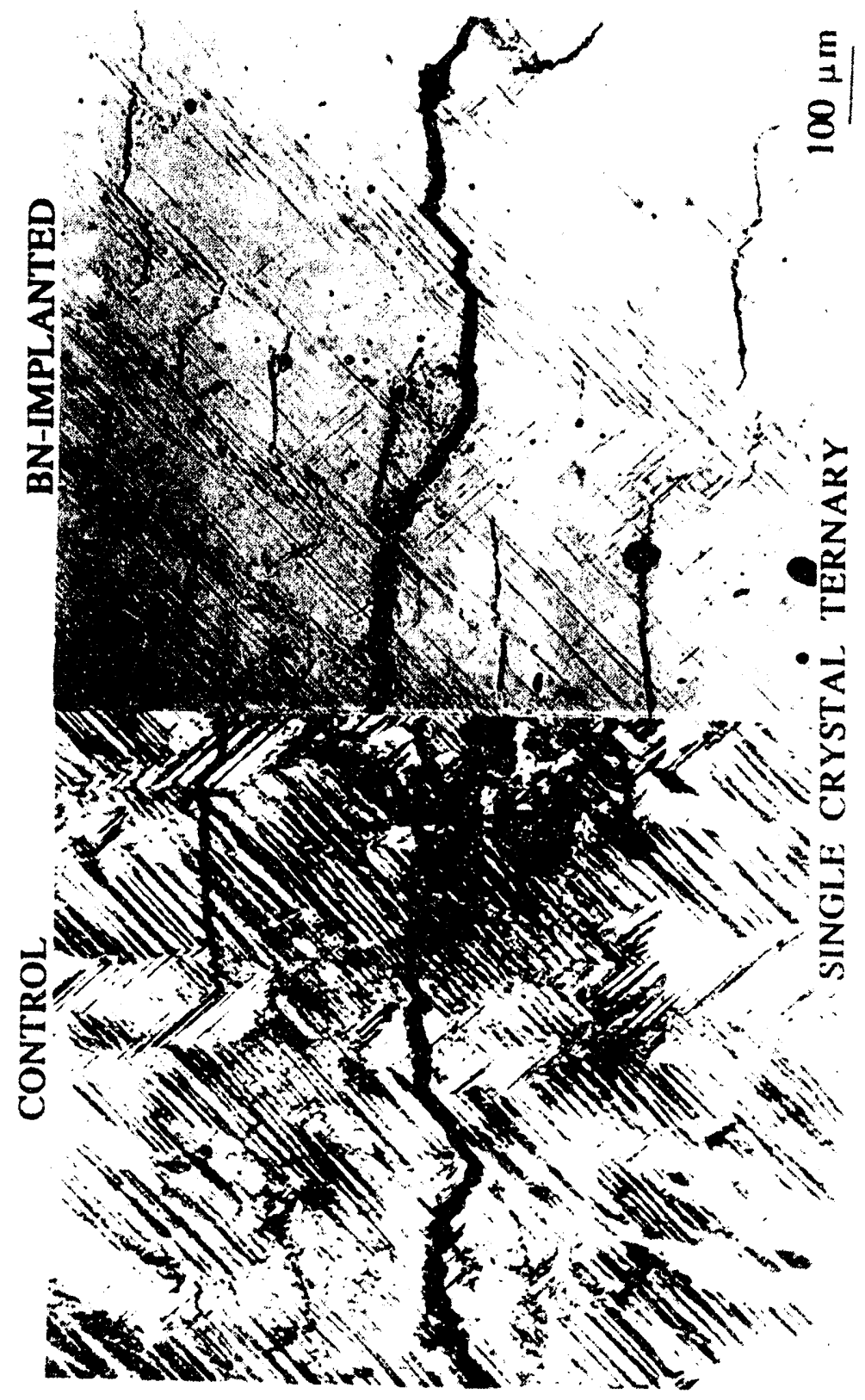

Figure 43. Optical micrographs of the control and implanted single crystal specimen surfaces showing the suppression of slip bands. 

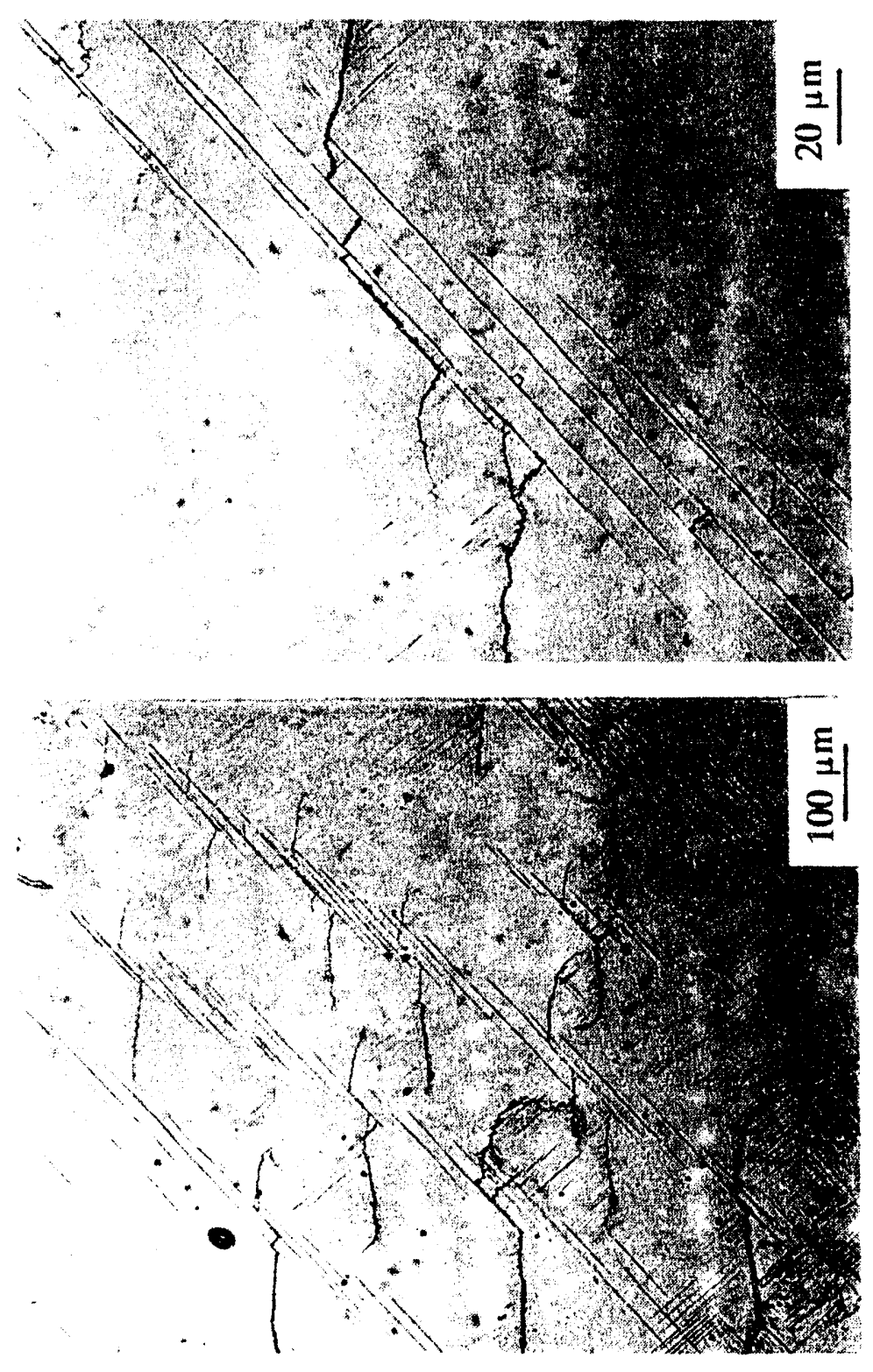

Figure 44. Crack initiation at intense slip bands on the B.N implanted single crystal specimens. 
EGM model was developed to describe crack initiation in FCC metals and alloys under conditions of low to intermediate strain amplitudes. The basic tenets of the model are generally accepted and have been verified experimentally [109]. The model is based on dislocation processes that occur in persistent slip bands (PSBs) which are the sites for fatigue crack initiation at a surface.

During cyclic fatigue, initially a number of dislocation sources become active. After a certain period, a steady-state is reached, generally referred to as cyclic saturation, during which dislocation densities remain constant due to annihilation processes. These annihilation processes result in the formation of vacancies. In pure fcc metals such as copper, which has been studied extensively for fatigue dislocation structures, edge dislocations predominantly form the walls in PSBs as well as the veins in the matrix, which are dense multipolar arrays. Typical dislocation densities in walls are $6 \times 10^{15} \mathrm{~m}^{-2}$ and in veins are $3 \times 10^{15} \mathrm{~m}^{-2}$. In the low dislocation density regions separating veins in the matrix and walls in the PSBs, dislocations are mainly of screw character [107].

PSBs form above a certain plastic shear strain amplitude $\gamma_{\mathrm{pl}}$ in the material, in the form of thin lamellae of high slip activity parallel to the primary glide plane. PSBs consist of nearly equidistant spaced dislocation walls with narrow edgedislocation dipoles, separated by channels with low dislocation density. Within the channels, strain is carried by gliding screw dislocations. The typical extrusions on the surface of fatigued metals are formed due to irreversibilities in the glide process. Irreversible slip is mainly confined to PSBs after cyclic saturation is 


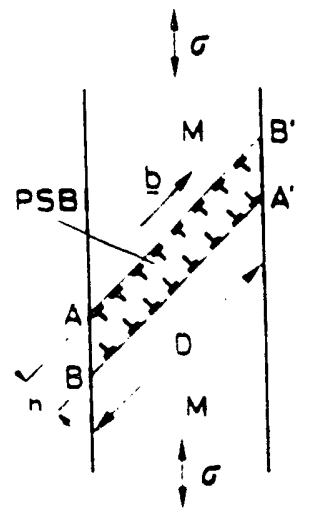

a)

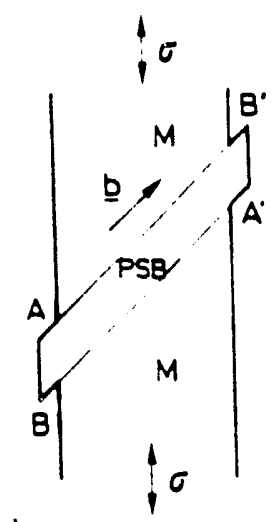

b)

Figure 45. Model of PSB in a single crystal specimen forming extrusions at both ends. 
achieved. It has been shown that point defects are formed along dislocation walls by mutual annihilation of unlike edge dislocations [109].

The surface profile, according to the EGM model is developed by the formation of extrusions and subsequent surface roughening by random irreversible slip. The formation of extrusions in a single crystal is shown in figure 45 . The interface dislocations (along $\mathrm{AB}^{\prime}$ and $\mathrm{A}^{\prime} \mathrm{B}$ ) correspond to arrays built of interstitial-type dipoles. Because of the interstitial nature, a net residual compressive stress is built up in the direction of $\bar{b}$. If $\mathrm{m}$ is the number of interface dislocation-dipoles then,

$$
m \bar{b}=\overline{C_{v}^{s a t}} D
$$

where $D$ is the single crystal dimension measured along the Burger's vector $\bar{b}$ and $\overline{\mathrm{C}}_{\mathrm{v}}^{\text {sat }}$ is the mean atomic fractional concentration of vacancies in the PSBs. $\overline{\mathrm{C}}_{\mathrm{v}}^{\text {sat }}$ is given by:

$$
\overline{C_{v}^{s a t}}=\frac{n y_{e}^{2} \overline{\rho_{e}^{s a t}} \bar{b}}{2 y_{p}}
$$

where $y_{e}$ is the critical annihilation distance for edge dislocations, $y_{p}$ is the capture distance for point defects, $\bar{\rho}_{\mathrm{e}}^{\text {sat }}$ is the local density of edge dislocations in the walls, $\mathrm{n}$ is the volume fraction of walls in PSBs (typically 0.1). For pure FCC metals, it 
has been estimated that $y_{c} \approx 1.6 \mathrm{~nm}$ and $\bar{p}_{e}^{\text {sat }} \approx 6 \times 10^{-4} \mathrm{~m}^{-2}$. Assuming $y_{\mathrm{p}} \approx \bar{C}, \overline{\mathrm{C}}_{\mathrm{v}}^{\text {sat }}$ is calculated to be $6 \times 10^{-4}$. The elastic compressive internal strain is given by:

$$
\epsilon_{i n t}=-\frac{m \bar{b}}{D}=-\overline{C_{v}^{s a t}}
$$

Therefore,

$$
\sigma_{\text {inz }}=\epsilon_{\text {ins }} E=-\overline{C_{v}^{\text {saxt }}} E
$$

where $\mathrm{E}$ is the Young's Modulus of elasticity. Thus, extrusions form on both sides of the PSBs as shown in figure 45. The total possible height of extruded material along $b$ is given by:

$$
e=m \bar{b}=\overline{C_{v}^{\text {sax }}} D
$$

This is for the case where no vacancies escape into the matrix, an assumption valid at low temperatures. There are two types of stress raisers at the extrusions, namely the PSB-matrix interface and surface roughness as shown in figure 46. Studies suggest that fatal cracks initiate at positions $\mathrm{A}$ and $\mathrm{A}^{\prime}$ in figure 45 , though cracks form earlier at B and B' [110].

Model Applied to Polycrystals

In polycrystals, PSBs form similarly in grains that have a favorable orientation, that is, slip systems with a high Schmid factor $(\sim 0.5)$ [109]. In an internal grain, 
a

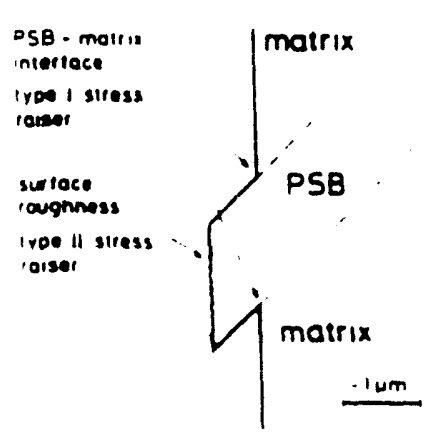

b

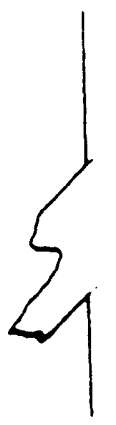

Figure 46. (a) Stress raisers at the extrusion on the surface formed at low number of cycles. (b) shows the roughening of the extrusions to form type II stress raisers after a large number of cycles. 


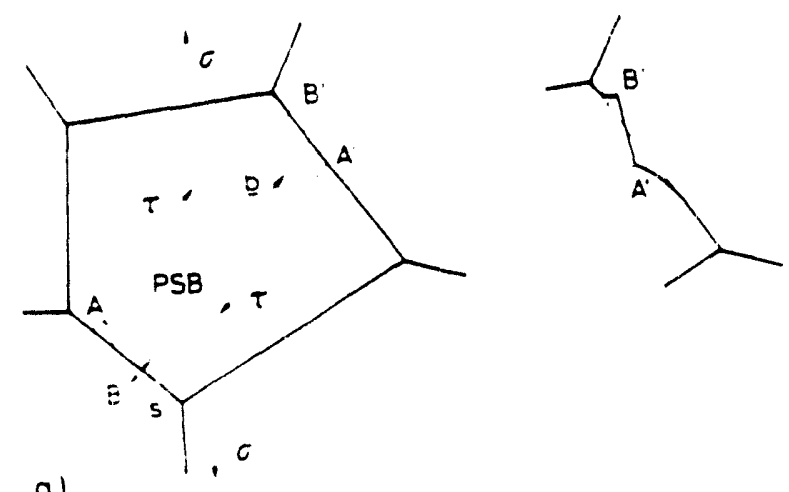

a)

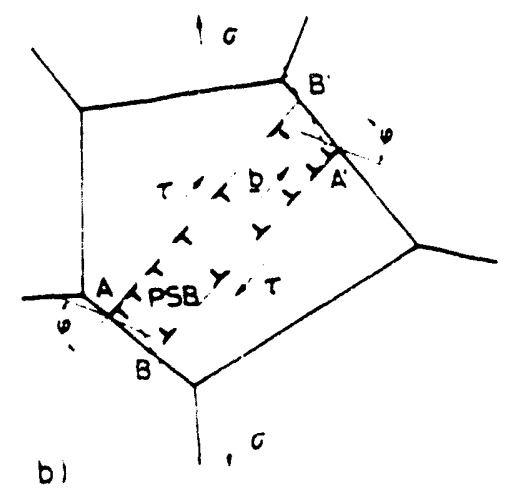

Figure 47. A PSB within a grain showing effects on the grain boundaries. (a) shape assumed by the grain boundar displacements due to the pile-up. (h) angle of pile-up with the grain boundary. 
the effects of PSB formation is shown in figure 47. Here the PSB-matrix interface dislocations pile-up against grain boundaries. Under the applied stress, the displacements at the grain boundary assurne the shape shown in figure 47(a). The boundary is subjected to transverse compressive stresses at B' and tensile stresses at $\mathrm{A}^{\prime}$. There is also the long range pile-up of dislocations at $\mathrm{A}$ and $\mathrm{A}^{\prime}$ as seen in figure $47(\mathrm{~b})$. The pile-up effect is counteracted by overall shear displacement. The displacement $\mathbf{s}$ would be:

$$
s=h \gamma_{p l, P S B}
$$

where $h$ is the width of the PSB perpendicular to the walls and $\gamma_{\mathrm{pl}, \text { PSB }}$ is the plastic shear strain on the PSB. Using a simple approximation, the pile-up effect due to $\mathrm{m}$ dislocations becomes dominant when:

$$
m \bar{b}>0.5 s
$$

Using equation (1), we get:

$$
D>\frac{h \gamma_{p l, P S B}}{2 \overline{C_{v}^{s a t}}}
$$

As per Stroh's analysis [111], the tensile stress at the head of a pile up is largest along a plane with an angle of $70.5^{\circ}$ with the pile-up as shown in figure 47(b), which in many cases lies almost in the grain boundary. Thus repeated piling up of PSB-matrix interface dislocations causes grain boundary cracking. Stroh's condition can be stated as: 


$$
m \tau \geq \frac{3 \pi^{2} \alpha_{e f f}}{8 \bar{b}}
$$

where $\alpha_{\text {eff }}$ is the effective surface energy and $r$ is the acting shear stress.

Using equation (8) we obtain:

$$
D \geq \frac{3 \pi^{2} \alpha_{e f f}}{8 \overline{C_{v}^{\text {sat }}} \tau_{P S B}}
$$

Model Applied to Ion Implanted Polycrystals

This analysis can now be extended to the present study to ion implanted specimens. Considering a grain at the alloy surface in a control specimen, the slip band would exit at the surface forming an extrusion as shown in figure 48(a). The height above the surface along the glide plane is s. Figure 48(b) shows the effect of an implanted layer on the surface. Under the action of an applied stress, $\sigma$, the slip band, prevented from exiting at the surface would impinge on the grain boundary. The necessary condition for this would be:

$$
m \bar{b} \geq s
$$

From equations (1) and (6), 


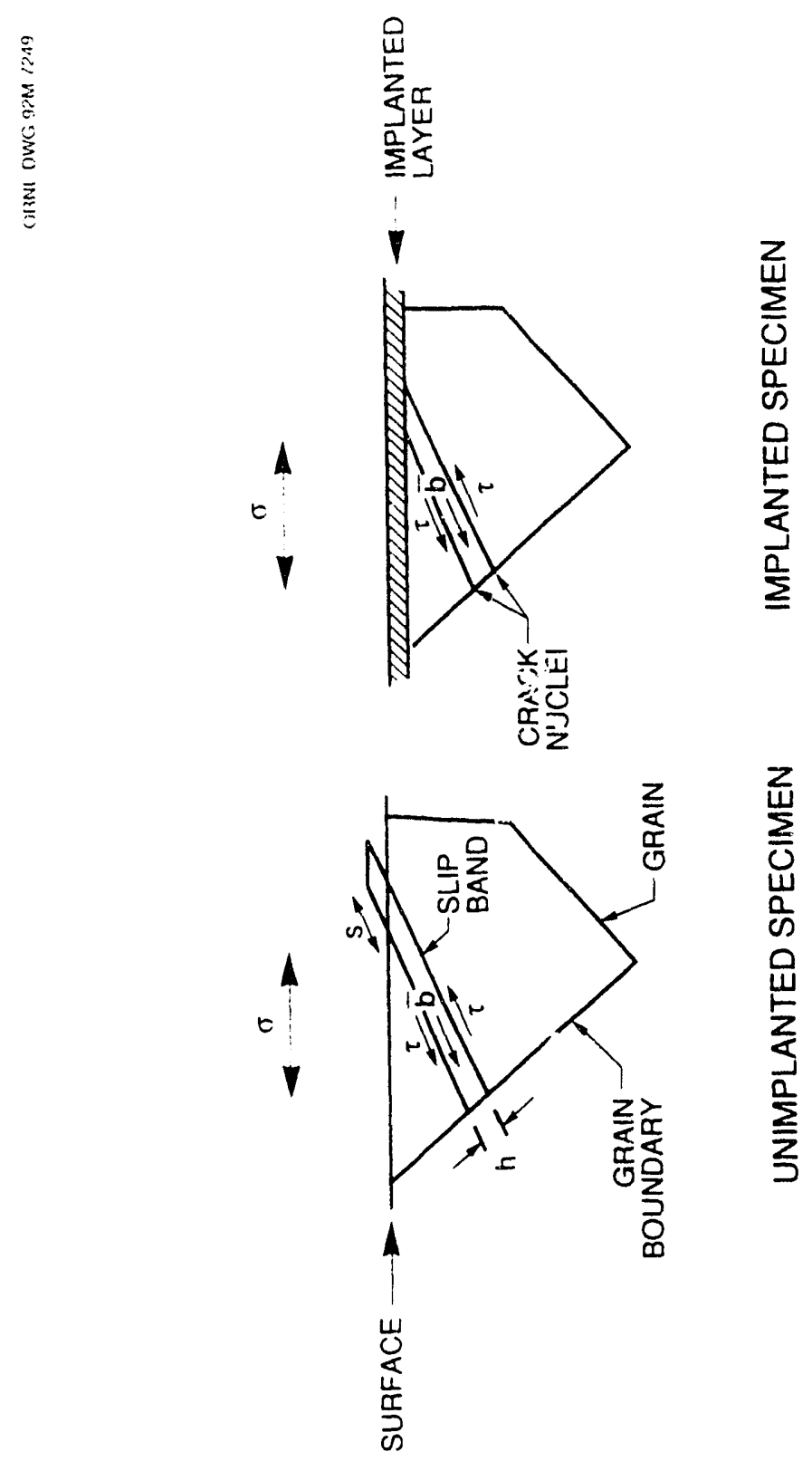

Figure 48. Effects of the presence of an implanted layer at the specimen surface. 


$$
D \geq \frac{h \gamma_{p l, P S B}}{\overline{C_{v}^{s a x}}}
$$

This would be the condition for the formation of a grain boundary crack due to suppression of slip bands at the surface caused by the ininglanted layer.

The results of the present study can be examined ir: light of the modified EGM model. The optical micrographs in figure 30 clearly show formation of extrusions by slip bands in several grains which are favorably oriented for slip with respect to the stress axis. These slip bands were also observed using TEM as shown in figure $35(\mathrm{~b})$. In the implanted specimen however, there were very few slip bands visible, indicating a suppression of slip due to the implanted layer similar to figure $48(\mathrm{~b})$. In those grains that were favorably oriented for slip band extrusions to form, the suppression of slip would conceivably cause initiation of cracking at adjacent grain boundaries.

Equation (12) may be used to obtain the condition for formation of grain boundary cracks. For a pure fcc metal such as copper, a typical PSB width $h$ is approximately $1 \mu \mathrm{m}, \overline{\mathrm{C}}_{v}^{\text {sat }}$ has been estimated to be $6 \times 10^{-4}$ and $\gamma_{\mathrm{pl}, \mathrm{PSB}} \approx 7.5 \times 10^{-5}$ [109]. Using these values,

$$
D \geq 12.5 \mu m \text {. }
$$


This would be the condition for the interface-dislocation pile-up effect to become dominant. Since the ASTM grain sizes of the eight E-series alloys are in the range of ASTM numbers 3.5 to 6 , this condition is easily satisfied since the minimum necessary ASTM number can be calculated to be 9.7 from $\mathrm{D}=12.5 \mu \mathrm{m}$. This indicates that the suggested mechanism of a shift to grain boundary cracking from slip band cracking due to the presence of the implanted layer is clearly feașible.

The EGM model is based on the formation of PSBs during high cycle fatigue. The above arguments would obviously be more realistic only when several parallel PSBs are acting simultaneously on a grain boundary. A similar qualitative model has also been proposed by Tanaka and Mura [112]. Their model suggests the formation of several embryonic cracks at the grain boundary by the action of several parallel slip bands. These cracks eventually join to form the g.b. crack under the applied stress. The EGM model thus provides theoretical evidence for the proposed mechanisms for fatigue crack initiation in this study.

\section{Creep}

\section{Ion Implantation Effects}

The ion implantation effects on creep properties are similar to those for fatigue properties. The major difference is the temperature of testing. While the fatigue tests were performed at room temperature, the creep tests were performed at $600^{\circ} \mathrm{C}$ which would alter the surface implant layer microstructure 
significantly. Moreover, diffusion kinetics become more significant at higher temperatures.

In a study on helium pre-injected (110 appm) solution annealed type $316 \mathrm{SS}$ [113], the microstructure of the as-implanted material consisted of fine, dense, "black-dot" damage similar to the as-implanted microstructure of the alloys used in this study, as shown in the fatigue specimens. After aging the He-injected alloy at $600^{\circ} \mathrm{C}$, it was observed that the loop damage coarsened and formed larger Frank loops. The nature of the loops was also identified to be interstitial [113]. It is probable that in the implanted specimens, the $600^{\circ} \mathrm{C}$ test temperature must have resulted in the formation of Frank loops which have been shown to cause strengthening of the microstructure [113].

Radiation damage is also a significant factor. The large number of vacancies created would become mobile at $600^{\circ} \mathrm{C}$ and also act as nucleation sites for precipitate formation in the E1 alloy. Previous studies on ion implantation effects on high temperature deformation properties have indicated the importance of point defects. The formation of precipitates is also of significance. In the unimplanted specimens, the $\mathrm{B} 1$ alloys only contain $0.078 \mathrm{wt} \% \mathrm{Cr}_{2} \mathrm{O}_{3}$. Aging has no effect on the B1 alloy.

The E1 alloy on the other hand contains $0.187 \mathrm{wt} \%$ of TiO, TiC, MC and $\mathrm{T}_{i 0} \mathrm{~S}_{3}$. After aging at $600^{\circ} \mathrm{C}$, additional Laves, $\mathrm{MC}, \mathrm{M}_{23} \mathrm{C}_{6}$ and Eta phases were formed after 24 hours [114]. The point defects can act as nucleation sites for the precipitates, particularly fine MC particles. The precipitates in the unimplanted 
material are relatively coarse. This additional formation of fine precipitate phase causes further strengthening and contributes to the creep resistance of the material. $\mathrm{Ar}^{+}$-implantation can also aid in the strengthening of the matrix. The insoluble $\mathrm{Ar}$ is expected to form bubbles in the material which can also pin dislocations [115], contributing to the strengthening effect.

\section{Mechanisms of Intergranular Creep Fracture}

In general, low strain rates and high temperatures favor intergranular creep fracture (ICF). In addition, composition, microstructure, grain size and grain boundary migration and sliding are other important factors [7]. ICF requires the formation of voids at grain boundaries (g.b.). Voids generally form at all grain boundaries but only those located on boundaries normal to the tensile axis coalesce and grow to form macroscopic fracture [103].

Typically, ICF can be classified into two categories: (1) formation of spherical " $r$ " voids and subsequent coalescence, and (2) wedge or " $w "$ type voids. Wedge type voids are generally associated with high stresses and " $r$ " voids are associated with low stress ICF [116]. During ICF, extensive permanent deformation is restricted to regions adjacent to grain boundaries [103].

Intergranular cavities typically nucleate throughout the creep process beginning with the primary creep stage. Classically, it has been assumed that vacancy migration and clustering at interfaces under the action of tensile stresses are responsible for void nucleation. However, more recently it has been suggested that stress concentrations are required to account for the observed rates of cavity 
nucleation [116]. Stress concentrations could arise at grain boundaries by several means such as presence of particles at the g.b.s, presence of irregularities, dissolved gases or interactions of g.b.s with slip bands giving rise to irregularities. These are illustrated in figure 49 (a) $[106,116]$.

Wedge cracking is more commonly associated with triple grain junctions with transverse grain boundaries as shown in figure 50 and are associated with higher stresses. Formation of wedge cracks is usually associated with sliding at triple junctions [116]. It has however been shown that diffusional creep processes can relieve stresses at triple junctions and thus stress concentrations alone are not sufficient to cause cavitation by sliding. The formation of "w" cracks is probably a result of rapid cavity growth and coalescence due to higher stresses at triple junctions. In fact, it has been suggested that " $\mathrm{r}$ " and " $\mathrm{w}$ " cracks are probably different limiting conditions of the same basic process $[116,117]$.

Growth of cavities is thought to occur by several processes. Cavities can grow by grain boundary diffusion through mass-transport from cavity surfaces to the adjacent grain boundary [116]. Mass-transfer can occur along the grain bourdary or through the surrounding crystal lattice at higher temperatures. The cavities are believed to maintain their equilibrium shape. Fracture results when the larger and closely spaced cavities grow together. Surface diffusion in cavity growth is important. When surface diffusion is finite, the cavity does not maintain its equilibrium shape and can become elongated and attain a crack like shape $[106,116,117]$ 
MECHANISMS OF IIITERGRANULAR

CAVITY NUCLEATION

a

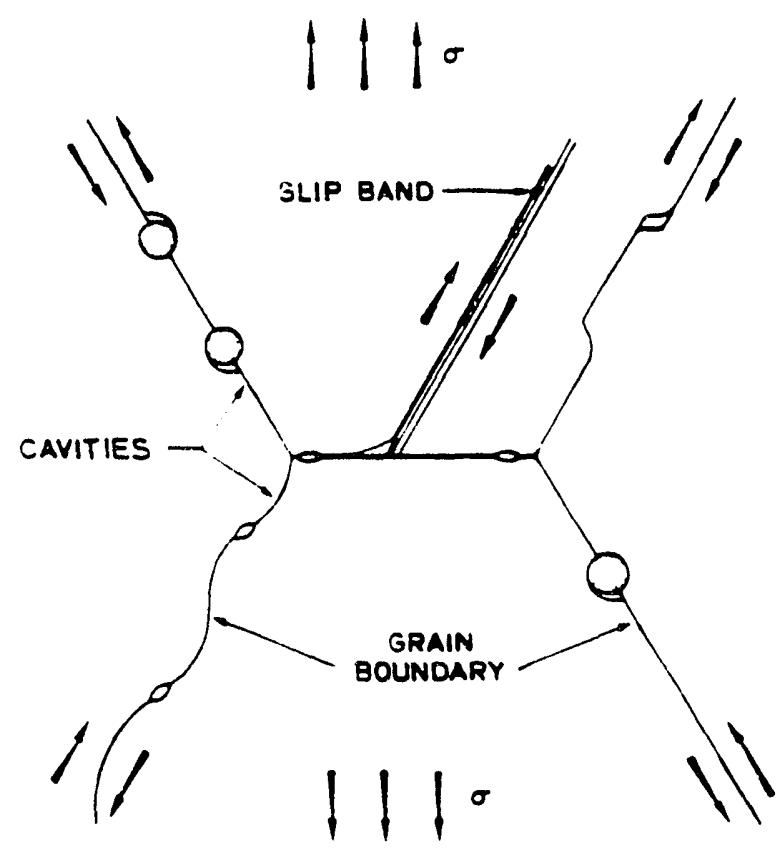

b
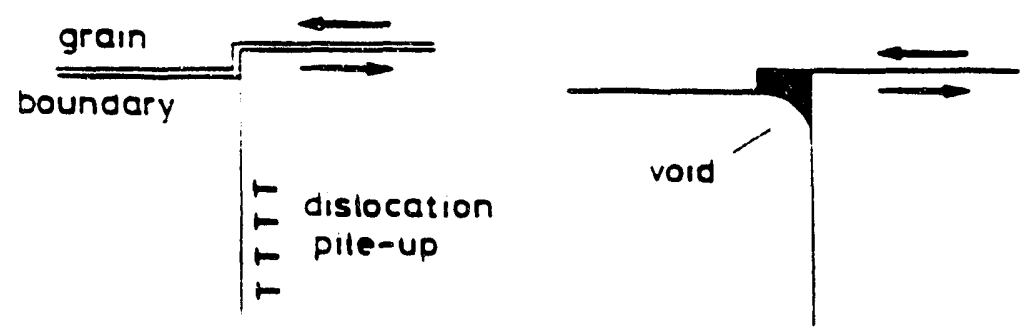

Figure 49. (a) Possible mechanisms of " $r$ " type void formation at grain boundaries indicating various sources of stress concentration. (b) Formation of " $r$ " voids by interaction of g.b. with a slip band and subsequent sliding at the g.b. [117]. 
Closely shaped cavities can have overlapping diffusional fields so that matter is deposited in the grain boundary between cavities. The rate of separation of the two grains and cavity-growth rate is controlled by diffusion. When the spacing between cavities exceed the diffusion distance, cavity growth is controlled by diffusion and creep processes. Macroscopic cracks can also form and grow by creep flow. Here, the crack tip advances by cavitation processes due to the crack tip stress field.

\section{Possible Creep Mechanisms in the Present Study}

The mode of creep fracture can be used to interpret the effects of ion implantation. Results showed that creep rates for the $\mathrm{B}^{+} / \mathrm{N}^{+}$-implanted specimens were lower not only during steady-state creep but also during primary creep. This indicates that void initiation was delayed from the primary stage due to the implantation.

The B1 alloy specimens showed round " $r$ " voids initiating at grain boundaries. In the B1 specimens, since there are very few precipitates, the likely mechanism would be the formation of voids by interaction with slip bands by forming ledges and subsequent sliding at the g.b. as shown in figure 49(b) [117]. Figure 38 clearly shows slip bands in almost all grains. Slip bands can be seen ending at grain boundaries which could be partly responsible for " $r$ " voids initiating at the boundaries. 


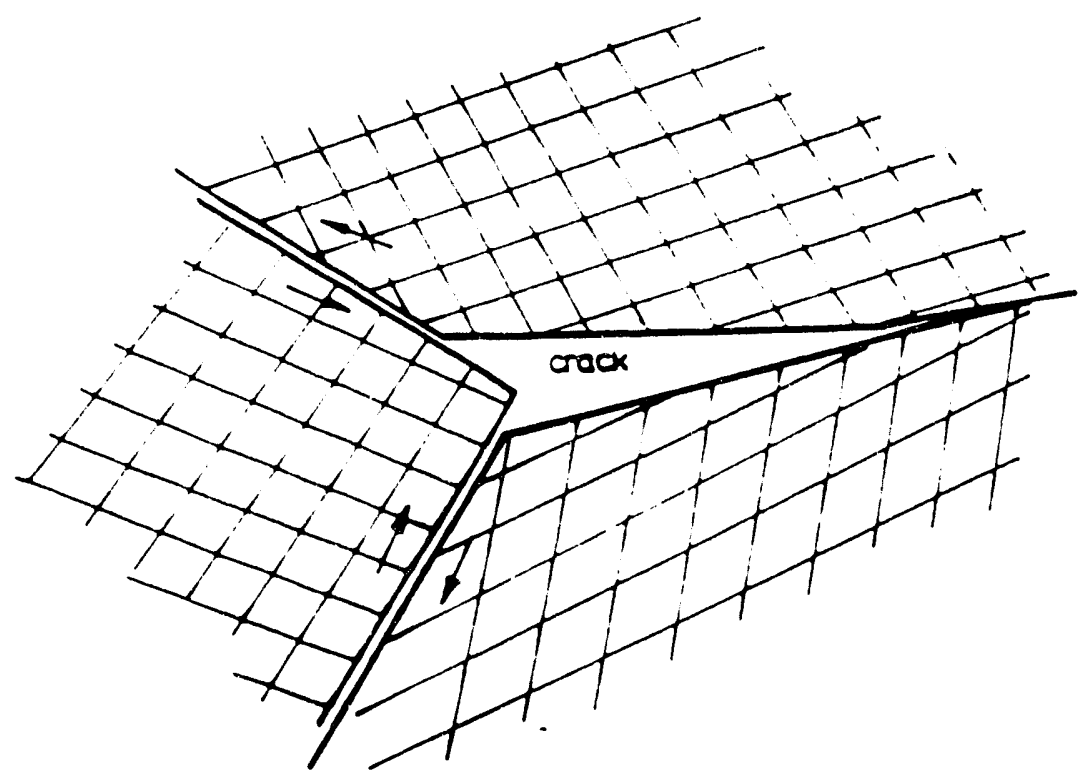

Figure 50. Grain boundary sliding at a triple point junction causing "w" type wedge crack [116]. 
The $\mathrm{B}^{+} \mathrm{N}^{+}$-implantation would restrict dislocation motion in the surface material, delaying slip band movement and delaying the formation of voids at g.b.s. For the $\mathrm{B} 1$ alloy, $\mathrm{Ar}^{+}$implantation also caused a decrease in the creep rate though not to the extent as for the $\mathrm{B}^{+} / \mathrm{N}^{+}$-implanted specimen. This can be explained in terms of competing effects of $\mathrm{Ar}^{+}$bubble formation at the g.b.s and strengthening due to suppression of dislocation motion due to radiation damage and bubbles in the matrix. It is clear that for the B1 alloy, the strengthening effect was more dominant leading to the observed increase in creep life.

The E1 specimens failed by the formation of wedge cracks at g.b.s. Wedge cracks have been found to form by grain boundary sliding at triple point junctions as shown in figure 50. It has also been suggested that wedge cracks can be formed as a result of rapid cavity growth and coalescence due to higher stresses [116]. It is clear that stress concentrations are formed at triple points. Since surface grains are strengthened by loop formation and precipitate strengthening, this would reduce the extent of sliding at the triple point junctions at the surface. The decrease in ductility also hints at the reduced extent of sliding at triple points.

A linear relationship has been observed between g.b. sliding distance and total elongation. Since total strain is the sum of slip in grains and g.b. sliding, there is a close relationship between crystalline slip and g.b.sliding [118]. Thus strengthening of the matrix as well as increasing shear strength, as by ion implantation, should reduce the extent of g.b.sliding. It was also observed that $\mathrm{Ar}^{+}$-implantation did not have a significant effect on creep properties, in fact it decreased the overall 
rupture life. This can be explained in terms of $\mathrm{Ar}^{+}$bubble formation at g.b.s. This would be expected to accelerate the g.b. cracking and is probably a dominant mechanism as compared to the strengthening effect in the matrix.

The mode of failure depends on the stress level applied to the specimens. Although both the $\mathrm{B} 1$ and the $\mathrm{E} 1$ specimens failed by intergranular cracking, the B1 specimens failed by " $r$ " type cracks typically observed at lower stresses, and the E1 specimens failed by "w" type wedge cracks, typically found at higher stresses. Thus, the failure modes for the two cases were operating at different regimes. However, some general conclusions may still be drawn about the effects of ion implantation on high temperature deformation. The implanted layer, though constituting a small fraction of the total specimen volume, had a significant effect on the high temperature creep properties. It is clear that the surface plays a major role in creep deformation. Radiation damage is an important factor and the creation of point defects and their subsequent migration is probably of significance. The creep mechanisms discussed thus far can only be confirmed by additional creep testing and extensive TEM examination. 


\section{RESULTS AND DISCUSSION: POLYMERS}

\section{RESULTS}

\section{Ion Implantation Effects}

TRIM (1990 version) was used to calculate ion depth ranges for the four polymers under the different conditions used. Table 16 shows the results of the TRIM calculations. The peak depths of the implants, in general, were in the range of $500-800 \mathrm{~nm}$. Residual gas analysis (RGA) was performed on PS during irradiation. The pressure in the UHV target chamber is normally around $1 \times 10^{-8}$ torr. During the first few minutes of the irradiation, due to egress of gaseous species from the polymer surface, the pressure in the chamber typically rose by one or two orders of magnitude. The various gaseous species observed included $\mathrm{H}_{2}, \mathrm{CH}_{4}, \mathrm{C}_{2} \mathrm{H}_{2}, \mathrm{C}_{3} \mathrm{H}_{4}$ and $\mathrm{C}_{6} \mathrm{H}_{6}$. G-values, defined as the number of radiolytic events for absorption of $100 \mathrm{eV}$ of radiation, were calculated for these species for Ar implantation of PS and the results are shown in figure 51. The radiolytic events in this case would be the chemical formation of gaseous species [78].

Typically, the polymer surface changed color and became darker during the course of the implantation. The color change was dependent on the ion energy and dose used. Figure 52 shows the typical color changes that occurred for PS during $\mathrm{B}^{+}$implantation at 100 and $200 \mathrm{keV}$ implantations. The specimen surface 
Table 16.

Results of TRIM calculations for the four polymers implanted under various conditions

\begin{tabular}{lll}
\hline Polymer & Implantation & Peak Implant Depth (nm) \\
\hline PE & $200 \mathrm{keV} \mathrm{B}^{+}$ & 815 \\
PP & $200 \mathrm{keV} \mathrm{B}^{+}$ & 843 \\
PES & $200 \mathrm{keV} \mathrm{B}^{+}$ & 880 \\
PS & $200 \mathrm{keV} \mathrm{B}^{+}$ & 809 \\
PS & $100 \mathrm{keV} \mathrm{B}^{+}$ & 464 \\
PS & $200 \mathrm{keV} \mathrm{Ar}^{+}$ & 284 \\
PS & $500 \mathrm{keV} \mathrm{Ar}^{+}$ & 658 \\
PS & $1000 \mathrm{keV} \mathrm{Ar}^{+}$ & 1180 \\
\hline
\end{tabular}




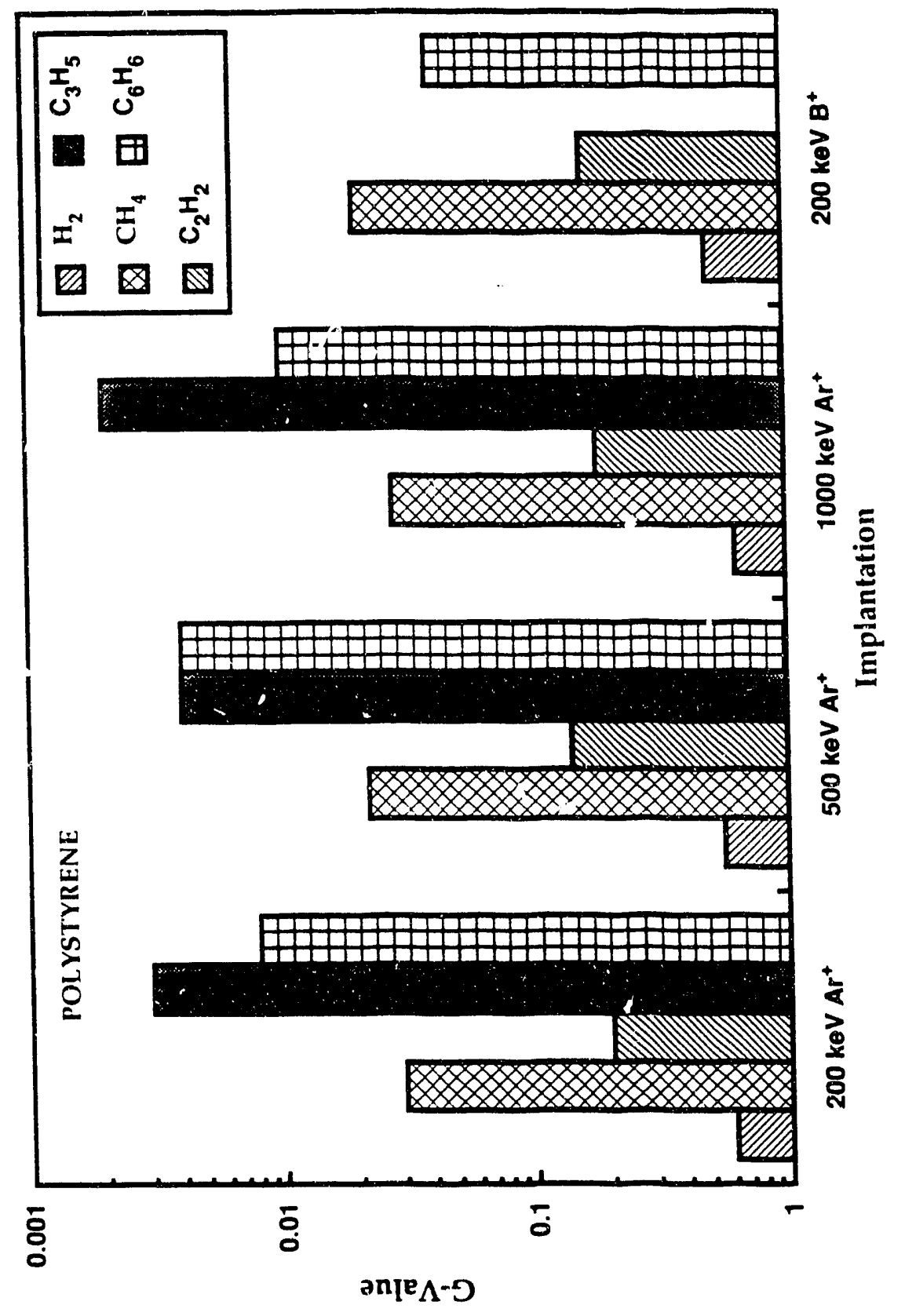

Figure 51. G-values for different gaseous species released from the polymer surface during irradiation, shown here for Ar implantation of PS. 
BCRON IMPLANTED POLYSTYKIENI
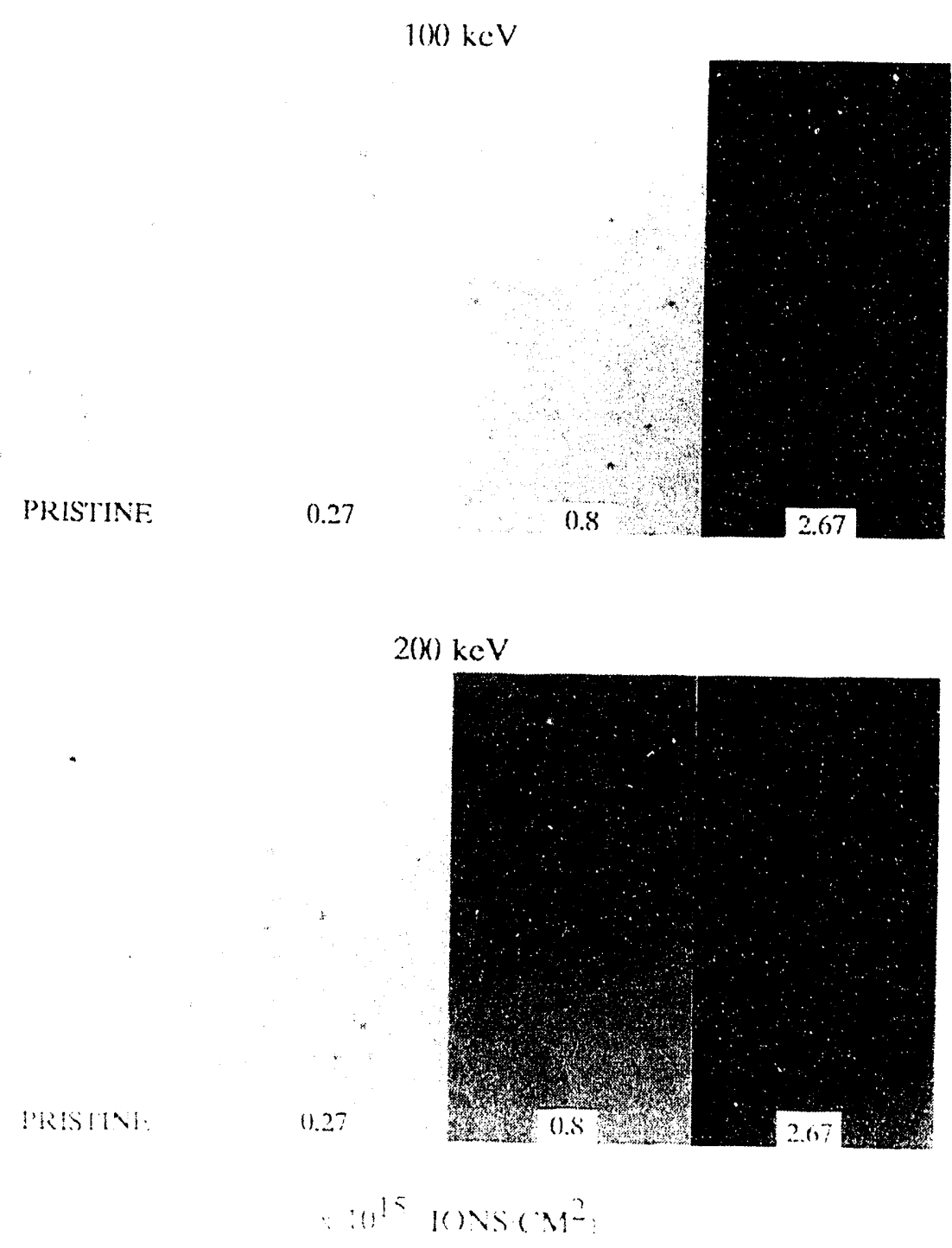

Figure 52. Typical color changes obsered during ion irradiation of polymers. shown here for PS at two energies. 
became darker with increasing dose and energy. At very high doses and energies, the surface turned completely black and this has been documented by other researchers as well [9]. A thermocouple was attached to the specimen holder and was used to monitor the temperature. Measured temperature was approximately $30^{\circ} \mathrm{C}$ during the irradiation.

\section{Microhardness Results}

The near-surface hardness changes observed in the implanted polymers were characterized using the nanoindentation technique. The raw data was obtained as load sensed by the diamond indenter as a function of indentation depth. Hardness was then calculated as a function of depth. Typical nanoindentation results are shown in figure 53 for pristine and $200 \mathrm{keV} \mathrm{B}{ }^{+}$implanted PES $\left(1.7 \times 10^{15}\right.$ ions $\left./ \mathrm{cm}^{2}\right)$. The hardness increase in this case was from about $0.35 \mathrm{GPa}$ to $2.3 \mathrm{GPa}$.

The hardness results for $200 \mathrm{keV} \mathrm{B}$ implanted PE, PP, PS and PES are shown in figure 54. The results shown are hardness values at $100 \mathrm{~nm}$ depth which was chosen for comparison since it has been determined that at the $100 \mathrm{~nm}$ depth, the hardness was almost indepenaent of substrate, indentation rate and indentation method [119]. Figure 55 similarly shows the effects of ion energy and species in the case of PS. The effects of 100 and $200 \mathrm{keV} \mathrm{B}^{+}$implantation as well as 200 , 500 and $1000 \mathrm{keV} \mathrm{Ar}{ }^{+}$are shown in the figure.

The results clearly indicate that the hardness increases with increasing dose and energy. For $200 \mathrm{keV} \mathrm{B}^{+}$implantation, PS showed the highest value of 

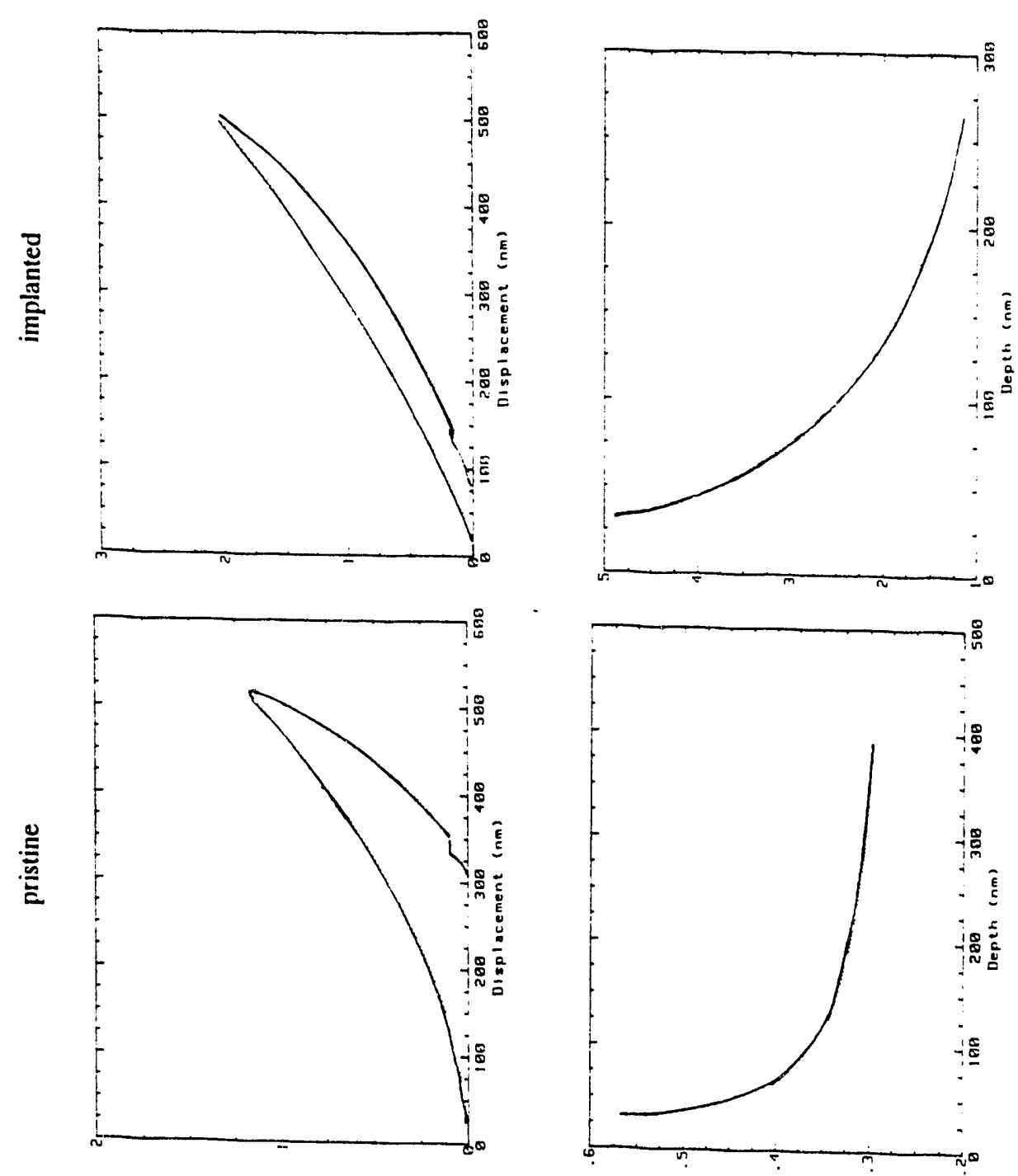

(NW) DIO?

Da DDRH

Figure 53. Typical nanoindentation hardness results shown here for pristine and $200 \mathrm{keV} / 1.7 \times 10^{15} \mathrm{~B}^{+} / \mathrm{cm}^{2}$ implanted PES. 


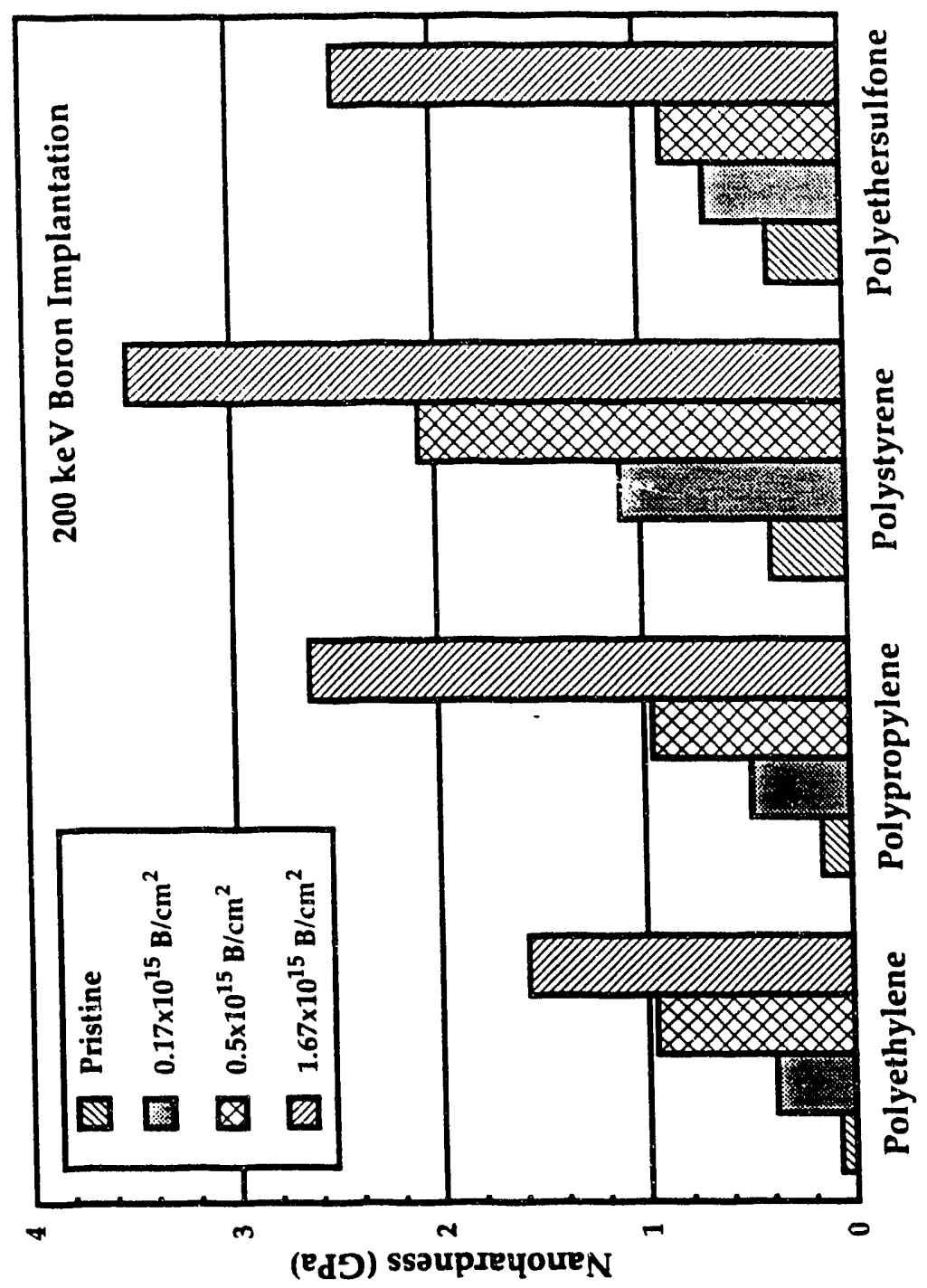

Figure 54. The hardness results for $200 \mathrm{keV} \mathrm{B}^{+}$implanted PE, PP, PS and PES as a function of dose. 

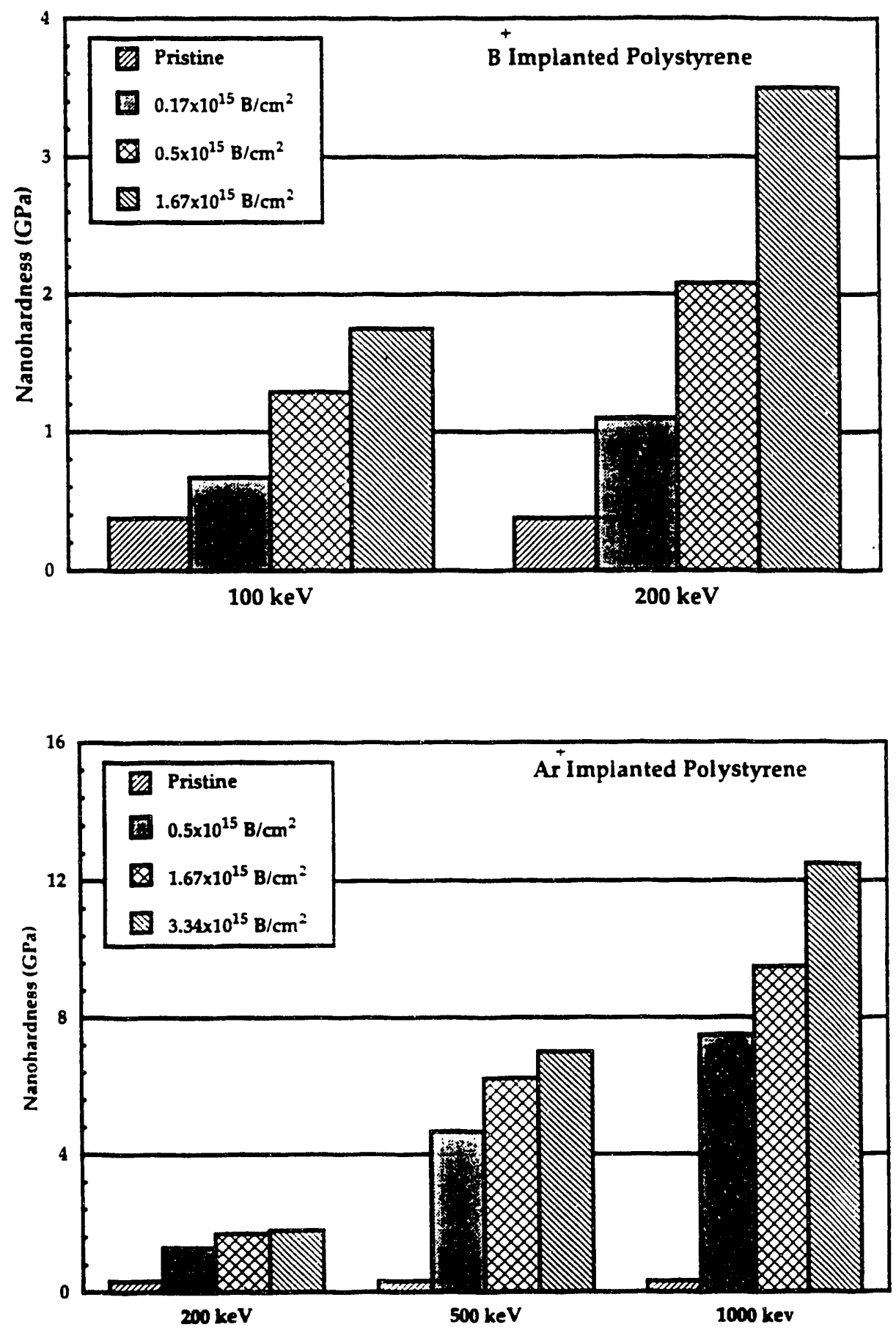

Figure 55. Hardness results for (a) $\mathrm{B}^{+}$- and (b) $\mathrm{Ar}^{+}$- implanted $\mathrm{P}$ 's at various energies showing ion energy and species effects. 
hardness of around $3.5 \mathrm{GPa}$ at the highest dose. However, hardness increases obtained with $\mathrm{Ar}^{+}$were even greater. At the highest energy of $1000 \mathrm{keV}$ and dose of 2000 appm, the hardness value recorded was over $12 \mathrm{GPa}$, much higher than the values measured for stainless steels (approximately $3 \mathrm{GPa}$ ).

Figure 56 shows the hardness results for the $\mathrm{B}^{+}$implanted polymers in terms of measured hardness values and hardness increase. It can be seen that, in general, the less complex the molecular structure, the greater is the relative increase in hardness as compared to the unimplanted material. However, absolute (measured) hardness values are higher for the more complex molecular structure. This reflects the inherently higher hardness of the pristine polymers with a more complex molecular makeup. There is a clear structure dependence on hardness improvements by ion implantation of polymers.

\section{Tribological Properties of Ion Implanted Polymers}

The tribological properties of the $\mathrm{B}^{+}$implanted polymers were studied as an example of a possible technological application of ion implantation of polymers. Wear tests were conducted using a nylon ball as a countersurface. The wear tracks on the contact surfaces (implanted polymer and nylon ball) were subsequently examined in an optical microscope and photographed. Figures 57-60 show optical micrographs of wear tracks on $200 \mathrm{keV} \mathrm{B}^{+}$implanted PE, PP, PES and PS respectively and corresponding wear on nylon ball, as a function of dose. Figure 60 , in addition, shows wear tracks on $100 \mathrm{keV} \mathrm{B}{ }^{+}$implanted PS as well. It 

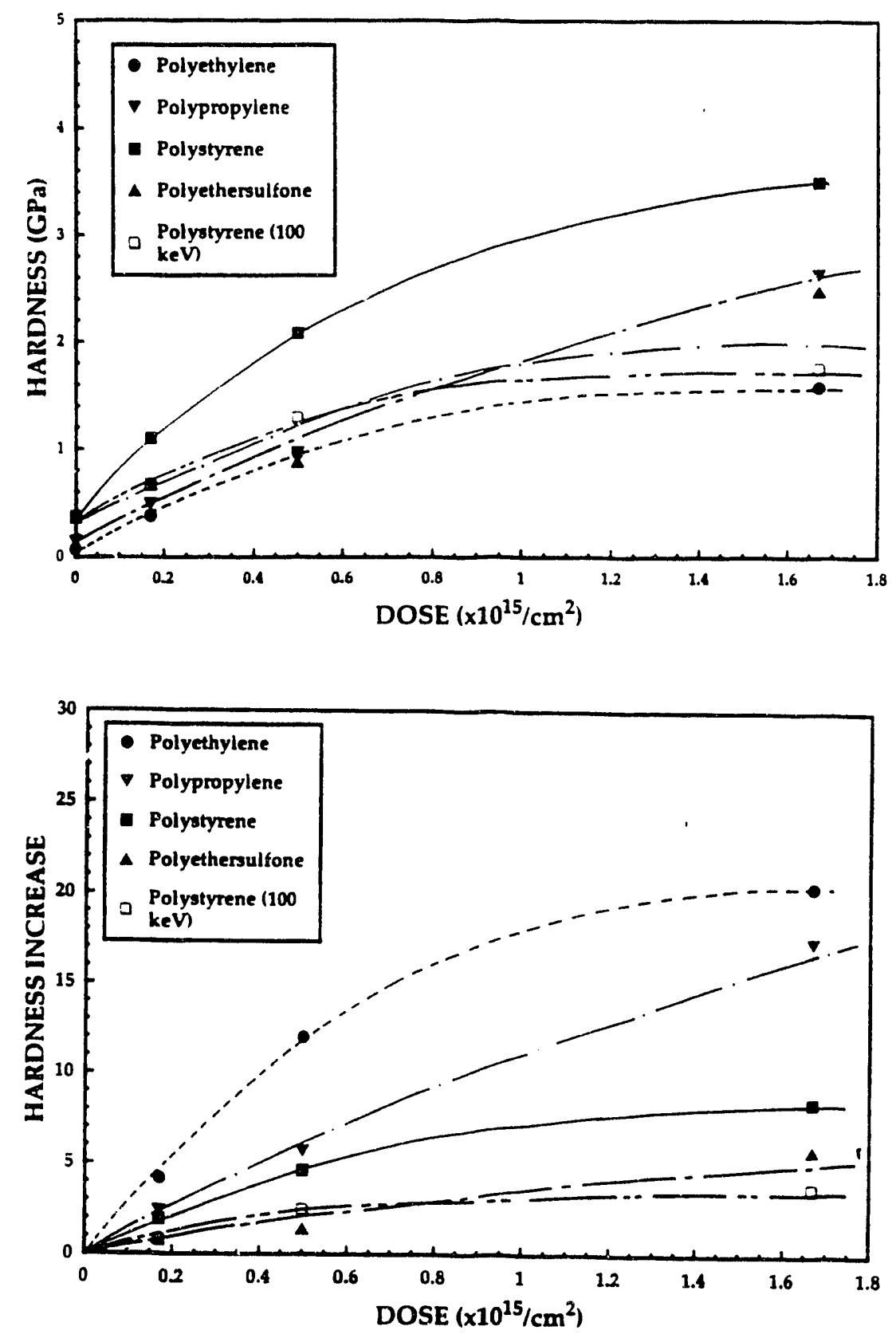

Figure 56. Hardness results for the $\mathrm{B}^{+}$implanted polymers in terms of measured hardness values and hardness increases, as a function of dose. 


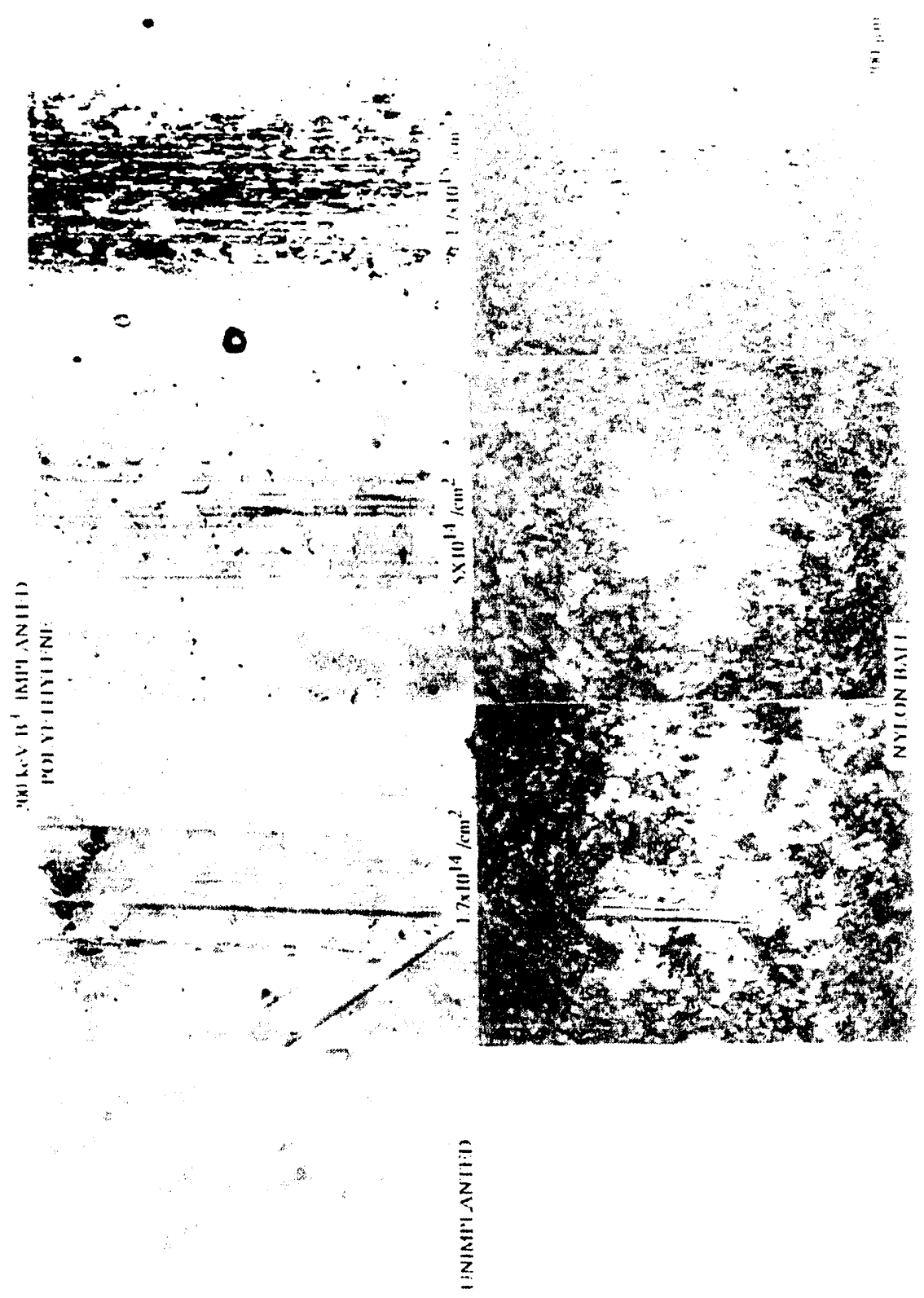

Figure 57. Resuits of wear tests on $\mathrm{B}^{+}$implanted PE as a function of dose. 


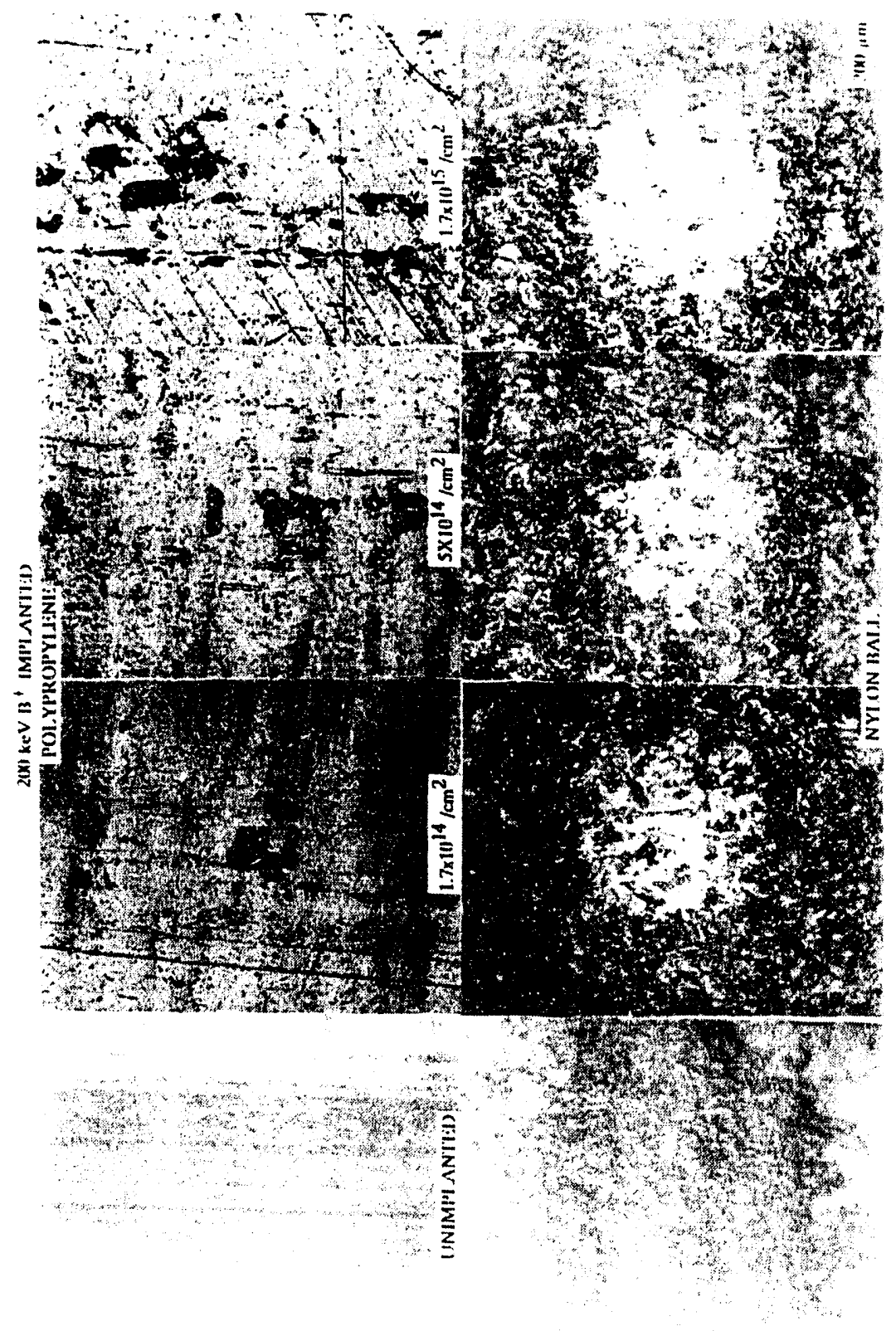

Figure 58. Results of wear tests on $\mathrm{B}^{+}$implanted $\mathrm{PP}$ as a function of dose. 


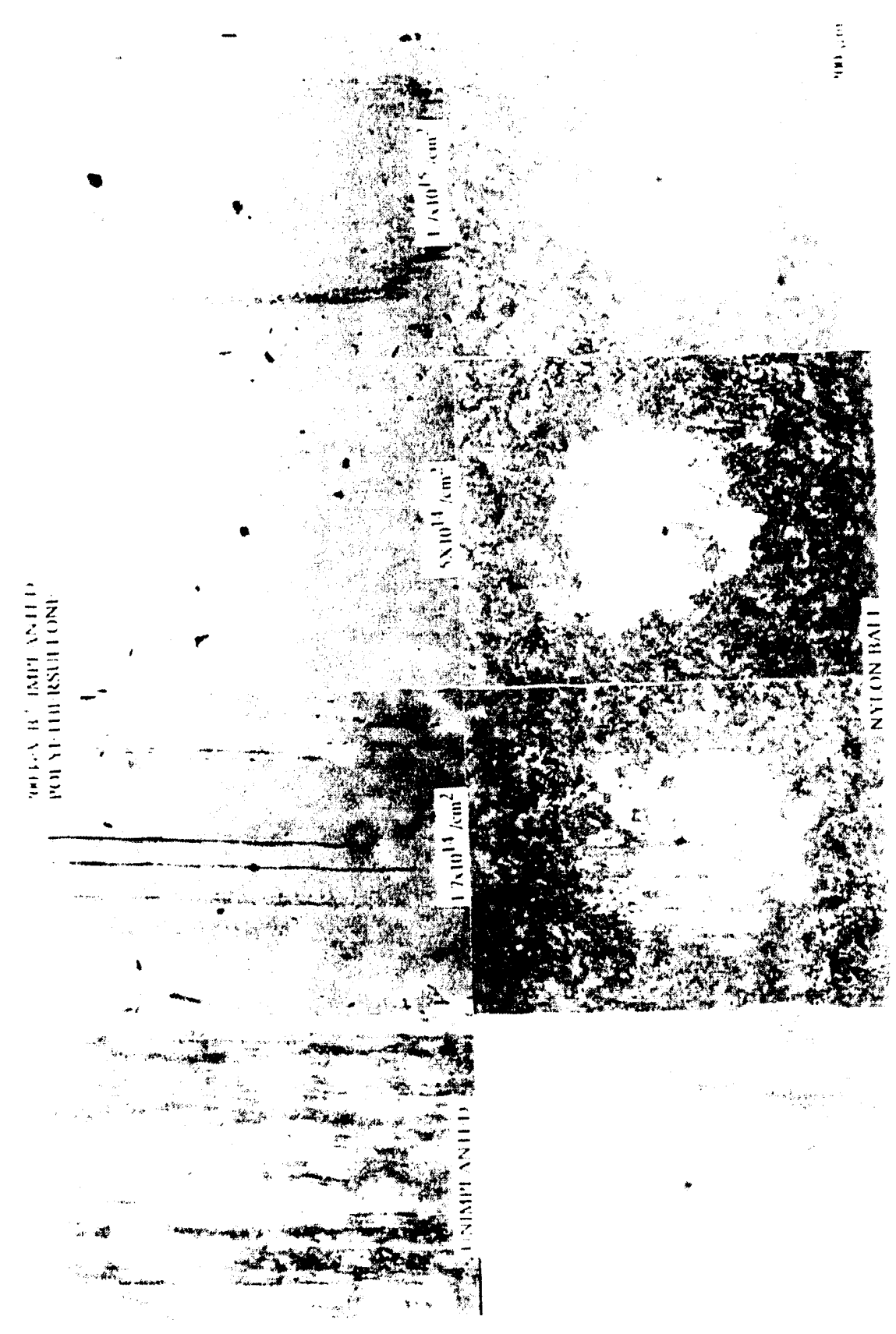

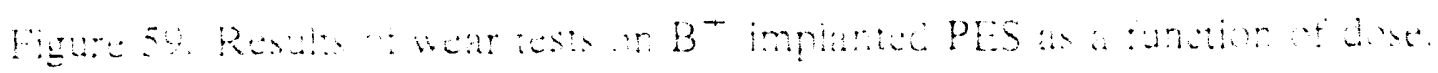



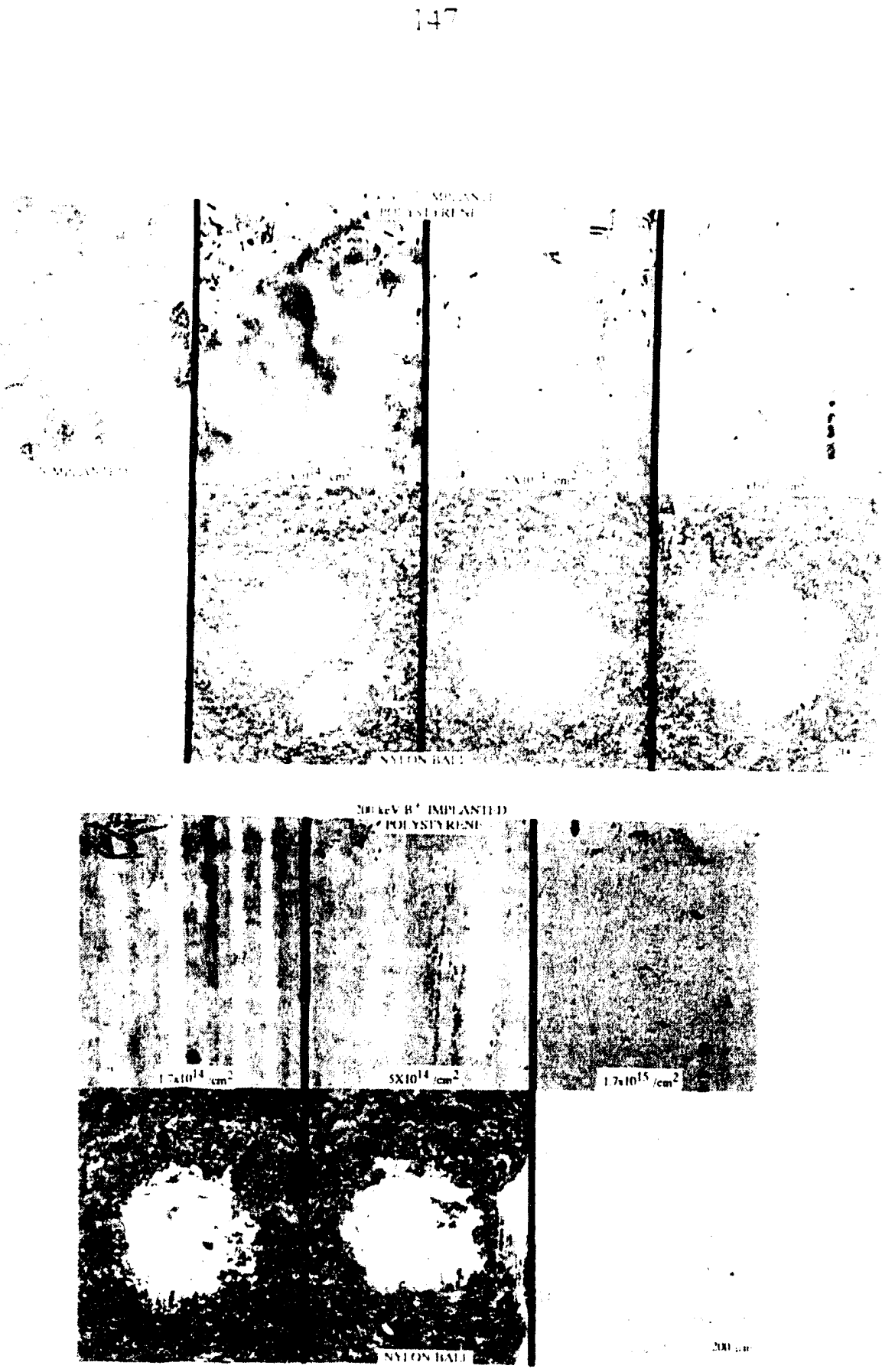

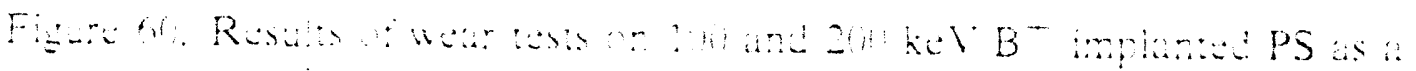


is clear that the implantation improved wear properties of the polymers at even the lowest doses.

An earlier study on polycarbonate has shown that there was an optimum ion dose at which best wear improvement was observed [120]. This was observed in this study also. The optimum dose for PS was the lowest dose $\left(0.17 \times 10^{15}\right.$ ions $\left./ \mathrm{cm}^{2}\right)$ at both energies. In the case of PES and PP, it was the intermediate dose $\left(0.5 \times 10^{15}\right.$ ions $\left./ \mathrm{cm}^{2}\right)$ and for PE the optimum dose was the lowest dose also.

The improvement in wear properties was most striking in the case of PS and PES, where no wear tracks were visible on the polymer surface even after 10000 sliding cycles. The PP surface was not very smooth before the implantation, and hence, at the intermediate dose, though wear tracks were barely visible, several cracks were evident. In the case of PE though the lowest dose case yielded the best improvement, it was evident that a dose lower than that would have further improved wear properties.

Figure 61 shows friction coefficient data for the wear tests on PS as a function of time, as a typical case. In the earlier study of $\mathrm{B}^{+}$implanted $\mathrm{PC}$, it was observed that the condition for best wear improvement also yielded the lowest friction coefficient values [120]. That was not found to be true in this study. In PS, the pristine material showed the lowest friction coefficient values. There was no consistent relationship between dose and friction coefficients for the other polymers as well. 

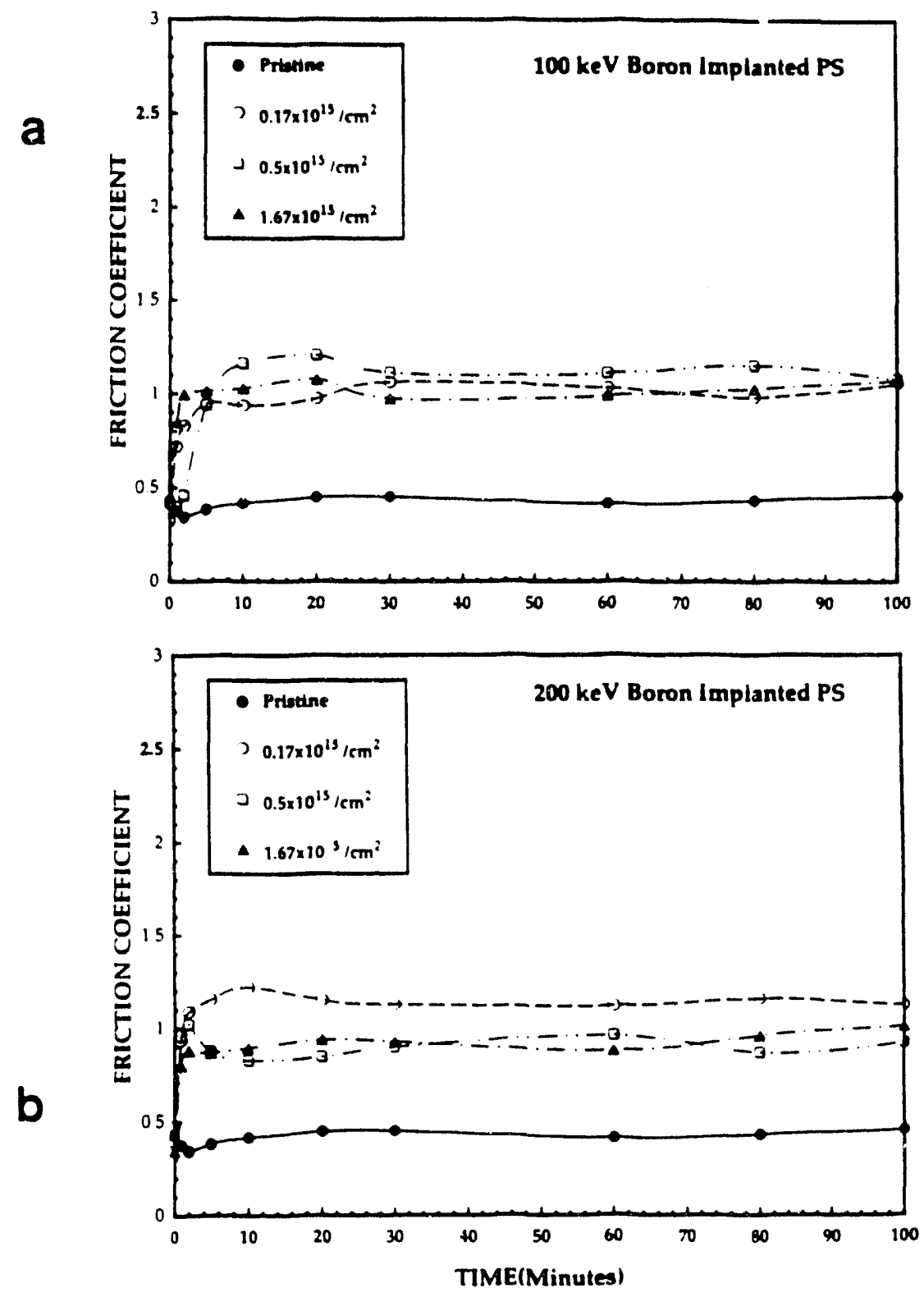

Figure 61. Friction coefficient data for the wear tests on 100 and $200 \mathrm{keV} \mathrm{B}^{+}$ implanted PS as a function of time. 


\section{DISCUSSION}

\section{Ion Irradiation Effects}

Ion implantation increased near surface hardness of all four polymers studied in this investigation, even at the lowest doses. This is an important effect si-ce it opens up a variety of possible applications for the ion-beam treated polymers. The observed hardness increases had a sensitive dependence on ion dose and energy, ion species, and structure of polymer. Each of these factors were examined in this study. Ion irradiation of polymers is significantly different from ion irradiation in other materials such as metais and ceramics, principally due to the vastly different structure of polymeric materials. The egress of gases from the polymer s.rfface during ion irradiation is a good example of this. The release of gases indirectly gives some insight into the processes occurring in polymers during ion irradiation.

Ion irradiation causes irreversible changes in the chemistry of polymers. One of the major consequences is the breakage: of bonds, yielding several small molecules. These diffuse to the surface and are released as gaseous species, readily detecte $i$ by residual gas analysis. The modification of microstructure can be caused by both electronic and nuclear energy losses and recently there has been some speculation about the relative contributions of the two processes [69]. Electronic energy loss has been shown to induce several chemical events in polymers leading to bond rearrangement [9]. 
However, recent results suggest that energy loss of ions due to atomic recoil causes the formation of most of the carbon containing gases released from polymers during implantation [77]. Figure 15 compares the G-values for the various typical gaseous species released during irradiation of the polymers. Irradiation with electromagnetic radiation or fast neutrons mainly resulted in release of $\mathrm{H}_{2}$ whereas irradiation with ions caused a greater yield of $\mathrm{C}$ containing species as well. There is obviously some contribution of nuclear energy loss to the microstructural changes observed. When G-values are plotted against average stopping power, the shape of the curves was non-linear, with an incremental step at stopping power value of around $180 \mathrm{eV} / \mathrm{nm}$ corresponding to nuclear stopping [78]. This indicates the significance of nuclear recoil for generation of gases since the number of radiolytic events increase abruptly. This has been observed by other researchers as well [9].

Temperature effects also need to be considered here. Thermocouples attached to the specimen holders did not register temperatures greater than $30^{\circ} \mathrm{C}$. However, since polymers are insulators, surface temperatures must have been much higher. The ion fluxes were limited to under $0.1 \mu \mathrm{A} / \mathrm{cm}^{2}$ to ensure excessive heating did not occur. The Stefan-Boltzman radiation law can be invoked to calculate surface temperatures [95]:

$$
E=2 \epsilon \sigma T^{4}
$$


where $E$ is the beam energy input per unit area, $T$ is the absolute target temperature, $\sigma$ is the Stefan-Boltzman constant, $\epsilon$ is the emissivity and the factor 2 is included for both surfaces of the film. Considering the highest dose rate used in the study of $1 \mathrm{MeV} \mathrm{Ar}{ }^{+}$at $0.1 \mu \mathrm{A} / \mathrm{cm}^{2}$, and considering unit emissivity, surface temperature would be $87^{\circ} \mathrm{C}$. However, emissivity is an unknown factor and for a much lower value, say 0.1 , surface temperatures are significantly higher. An interesting outcome of this would be to raise local temperature above $T_{g}$ in the polymers which would result in vastly different chemical reaction paths. It must be noted here that when high fluxes over $0.15 \mu \mathrm{A} / \mathrm{cm}^{2}$ were used, the ion beams raised temperatures sufficient enough to melt the polymer film over the area of irradiation.

The color changes observed are qualitative manifestations of optical property changes which include modifications of transmission and refractive indices of the polymers. The darkening observed with increasing dose is due to carbonization of the surface which can also be related to electrical conductivity enhancements with increasing dose [9].

\section{Hardness}

\section{Measurement Technique}

The ultra-low-load nanoindentation technique used in this study can be further examined. It is clear that conventional microhardness measurements such as Knoop hardness are not effective in the case of polymers due to the difficulty in accurate measurement of indents. Short term elastic and viscoelastic recovery and 
non-linear stress-strain response in addition to difficulty in viewing indents complicate the process. Conventional techniques are especially inadequate for measuring hardness at shallow depths such as in ion implanted polymers.

The nanoindentation technique, which continually monitors load as a function of indenter displacement to calculate hardness does away with optical measurement of indents and was therefore used in this study. However, the interpretation of results is complicated because of the visco-elastic nature of polymers. The current nanoindentation model used for analyzing the nanoindentation results has been described by Oliver and Pharr [121]. There are two basic assumptions of the model, namely, linear elasticity and time-dependent plasticity. These may not be entirely valid for polymers.

Recently, Lee et al. have examined nanoindentation of ion implanted polymers in detail [119]. Figure 62 shows typical effects observed during indentation of polymers and the relevant terms used in the analysis. For the calculation of hardness and modulus, the load on the indenter $(\mathrm{P})$, total displacement of the indenter $\left(h_{t}\right)$, elastic stiffness of the contact (S) and an accurate geometrical description of the indenter are required. The stiffness (S) is determined by obtaining the slope of the initial portion of unloading. This technique was used to determine the hardness in this study. Lee et al. have found that substrate effects, creep, as well as loading and unloading rates affect the measurements. However, hardness at $100 \mathrm{~nm}$ depth was found to have a consistent value regardless of substrate, indentation rate or mode [119]. Thus, the hardness values reported in 


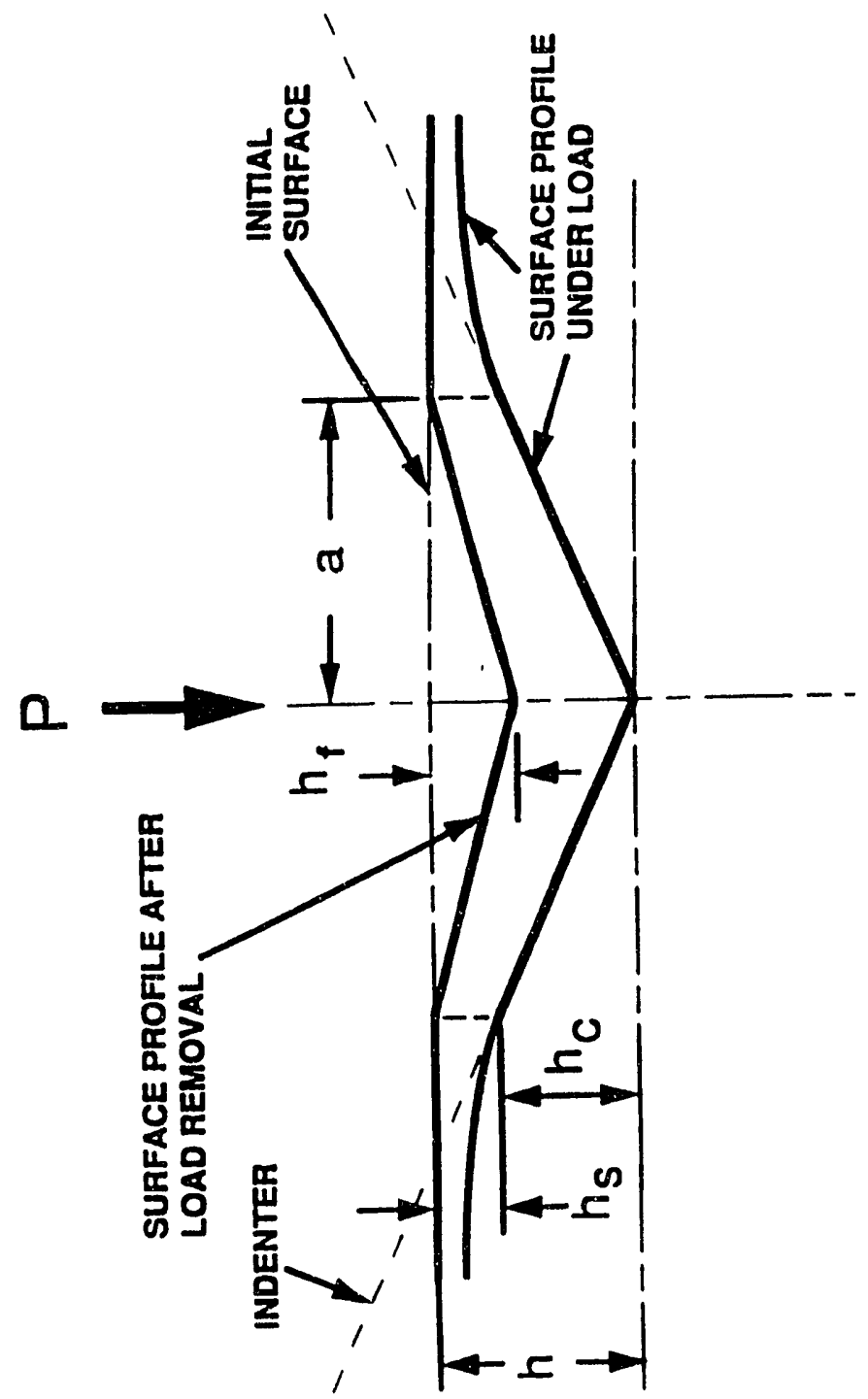

Figure 62. Analysis of nanoindentation of polymers. 
this study are valid for comparison purposes. Hardness is not a fundamental property of a material and depends on elastic modulus, yield strength and strain hardening capacity. The hardness values of the ion implanted polymers in this study were measured under identical conditions using the same loading and unloading rates, the same diamond indenter under similar conditions. The measurements represent a good estimation of the surface mechanical properties for comparative purposes.

Ion Dose, Energy and Species Effects

The major effects of ion implantation of polymers that lead to hardness improvements are ionization and bond breakage, eventually leading to crosslinking, branching and chain-scission along with radical formation, gas evolution and micro-alloying $[95,120]$. The polymer molecular structure is therefore an important factor. Figure 56 shows hardness increases with respect to those of the unimplanted polymers. In general, the less complex the molecular structure, the greater is the relative increase in hardness. This can be related to efficiency of cross-linking. However, absolute (measured) hardness values are higher for the more complex molecular structure. This can be attributed to inherently higher hardness of :he unimplanted polymer with the more complex structure. This is due to the reduced flexibility of the molecular chains and a consequently greater resistance to indenter penetration during hardness testing. The atomic density of the polymers is also a factor. The atomic densities of PE, PP, PS and PES are 14.2, 11.6, 9.7 and $8.3\left(\mathrm{x} 10^{28}\right.$ ions $\left./ \mathrm{m}^{3}\right)$ respectively. The more complex the side 
groups or the main chain, the less effective would be the packing of molecules. There would thus be fewer sites available in unit volume for cross-linking and chain-scission during ion irradiation.

The structure of the molecular backbone chain is also of significance. The hardness data for PS and PES can be compared for this purpose. While the hardness values of unimplanted PS and PES are very similar, at a given dose, for $200 \mathrm{keV} \mathrm{B}^{+}$implantation, the hardness of PS is greater than that of PES. Chainscission and subsequent cross-linking occurred to a smaller extent in PES due to the presence of more complex groups in the PES chain.

During ion irradiation of polymers, chain-scission and cross-linking occur simultaneously [95]. Chain-scission occurs due to bond breakage by ionization as well as atomic displacements due to nuclear stopping. Cross-linking results from reactions between free radicals and through dangling bonds, produced for example by elimination of $\mathrm{H}$ atoms from $\mathrm{C}-\mathrm{H}$ bonds. This competition between the two processes could explain the dose dependence observed in this study. Increasing dose increases the extent of cross-linking which results in increased hardness values. This process continues until all possible linkable sites are exhausted. Subsequently, chain-scission would become the dominant mechanism and thereafter, hardness should decrease. This could explain the levelling of hardness values at higher doses and conceivably, higher doses would decrease the hardness yielding an optimum dose at a given ion energy for a particular ion type. 
It has been shown for PS implanted with $\mathrm{B}^{+}$and $\mathrm{Ar}^{+}$that increased energy yields higher hardness values. This is probably due to the greater depth of implantation and a consequently greater volume of material at the surface which is cross-linked. Moreover, at lower energies, the efficiency of chain-scission and side-group breakage would be lower leading to a smaller extent of cross-linking. Also, at different energies, local temperatures along the ion paths are probaily different causing different chemical reactions at different energies.

Apart from damage effects, the implanted ion itself may contribute towards hardness improvements through several mechanisms. The monovalent $\mathrm{H}$ atoms could be replaced by multivalent B atoms resulting in extra dangling bonds leading to more effective cross-linking. As in metals, hard particles such as some forms of borides could form contributing to the hardness. A preliminary ESCA study on B implanted PS showed that most of the implanted B was in the free state in the implanted region. Some of the $\mathrm{B}$ was in the form of $\mathrm{B}_{2} \mathrm{O}_{3}$, and $\mathrm{B}(\mathrm{OH})_{3}$ presumably from oxygen adsorbed at the surface of the polymer prior to implantation. A third peak was also detected which could not be identified. This presumably could be some new precipitate structure formed by B. However, the chemical effect contribution is small as compared to the damage effects as seen for B and Ar implantation of PS, where Ar implantation caused greater hardness improvements. 
Implant Layer Microstructure

It has been shown that in ion implanted polymers, due to the release of various molecular species, in general, there is an enrichment of carbon at the surface which can be related to the hardness improvements [10]. In a related study, Tefzel, a copolymer of tetrafluoroethylene and ethylene, was implanted simultaneously with $400 \mathrm{keV} \mathrm{B}^{+}, 700 \mathrm{keV} \mathrm{N}^{+}$and $600 \mathrm{keV} \mathrm{C}^{+}$ions to a dose of $3 \times 10^{15}$ ions $/ \mathrm{cm}^{2}$ for each ion [122]. The hardness of Tefzel increased by over 66 times due to the implantation. TEM of the implanted layer revealed a patch type contrast with bright and dark regions (figure 63) whereas the pristine material showed a basically featureless, uniform contrast. EELS was used to decide whether the contrast was due to variation in local atomic concentration or due to thickness effects.

EELS conclusively showed that the bright regions in the TEM image had up to a $15 \%$ higher carbon concentration as compared to the darker regions [122]. This relates well with earlier studies on conductivity enhancements in ion irradiated polymers which have shown the presence of similar carbon rich islands $[80,84]$. In the present study on tefzel, the average size of the C-rich regions was around $40 \mathrm{~nm}$, consistent within the framework of the conduction model for ion implanted polymers [122].

The EELS spectra also showed that the implanted layer spectra were similar to those of amorphous carbon $[122,123]$ which has been noted by other 

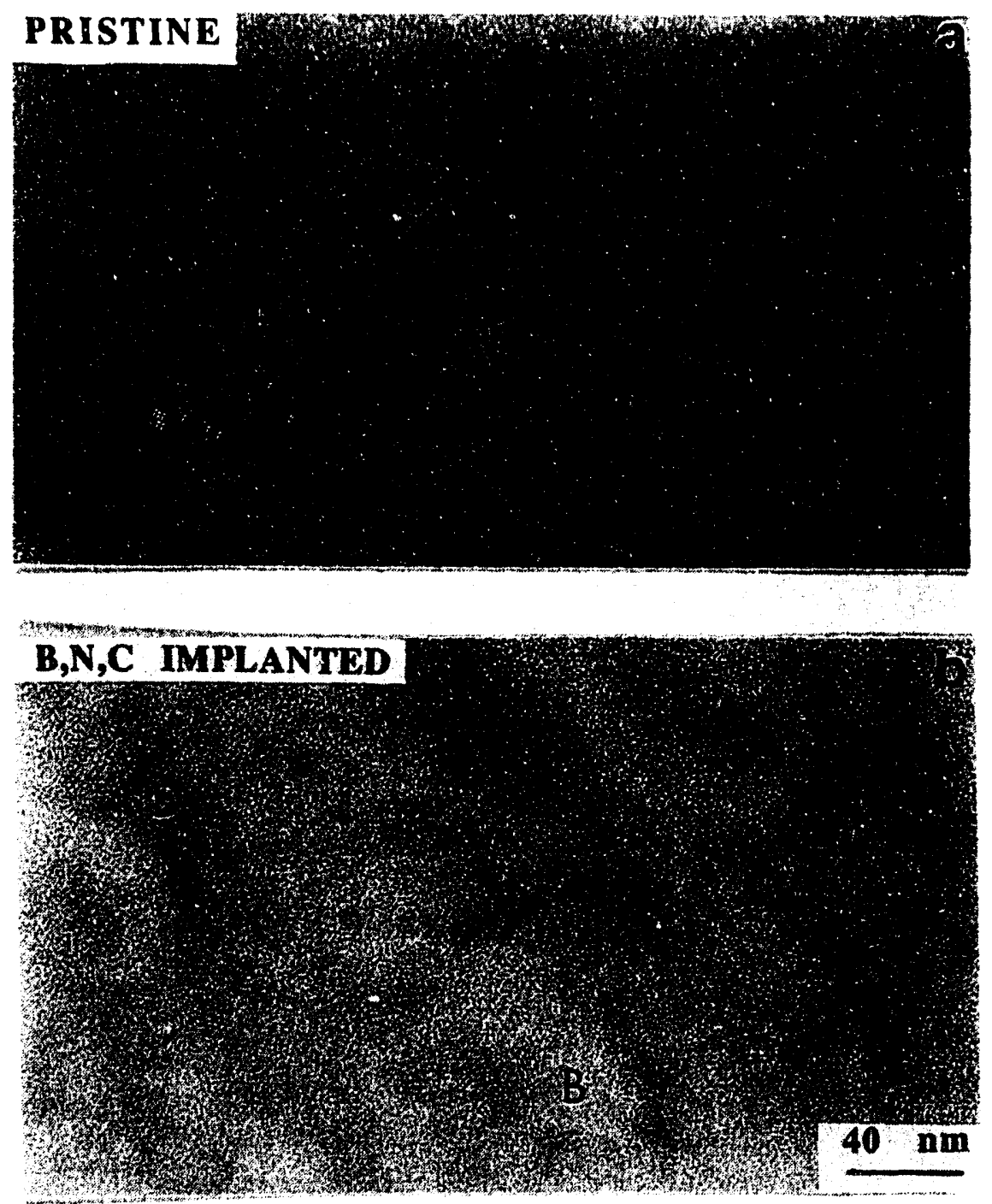

Figure 63. TEM of unimplanted and B.N.C implanted tefzel showing bright and dark regions. EELS showed that the bright regions had a $15 \%$ greater C concentration than the dark regions [105]. 

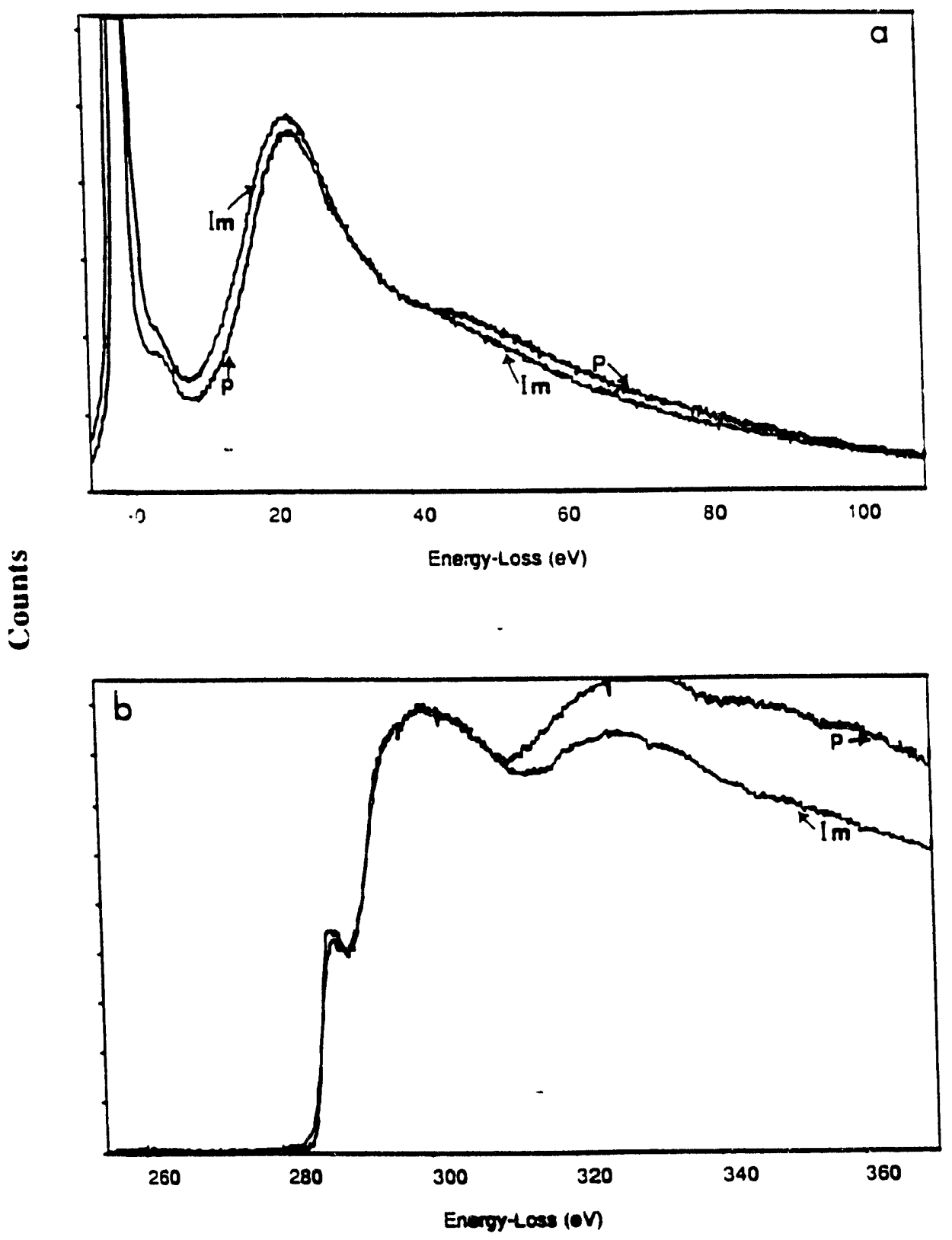

Figure 64. EELS spectra for the B,N,C implanted Tefzel [122]. P is the curve for the pristine material and $\mathrm{Im}$ for the implanted material. (a) shows the low-energy loss and (b) the C-K edge loss after subtraction of background. 
researchers as well $[83,124,125]$. The structure has been visualized to be a network of independent clusters of $\mathrm{sp}^{2}$ bonded carbon atoms, with $\mathrm{sp}^{3}$ sites present and hydrogen preferentially bonded in the $\mathrm{sp}^{3}$ configuration [126]. The $\mathrm{sp}^{3}$ tetrahedral (diamond type) bonding would be expected to significantly contribute towards hardness and the $\mathrm{sp}^{3} / \mathrm{sp}^{2}$ ratio is an important factor contributing to hardness in hydrogenated amorphous $C$ [127]. An interesting aspect of the EELS analysis was the strong broadened peak observed at $300 \mathrm{eV}$ as shown in figure 64. Fine structures in EELS spectra of diamond, amorphous carbon and graphite did not show such a peak [123]. However, the $300 \mathrm{eV}$ peak does appear in the EELS spectra of $\mathrm{C}_{60}$ (Buckminsterfullerenes) [128]. This interesting possibility of the presence of $\mathrm{C}_{60}$ molecules in the ion implanted polymers needs to be further explored.

In an ongoing study, the electrical conductivities of the Ar implanted PS were studied and the results are shown in figure 65 and compared with corresponding hardness increases. The trends followed for the two properties are very similar indicating that the underlying microstructural causes are probably the same, namely, carbon enrichment and bonding.

Raman spectroscopy studies were also performed on the $\mathrm{B}^{+}$implanted PS and the Raman spectra are shown in figure 66. It is interesting to compare these spectra with those of other forms of carbon. There are two characteristic peaks observed for carbon. Diamond shows a first-order Raman peak at $1332 \mathrm{~cm}^{-1}$ (D- 

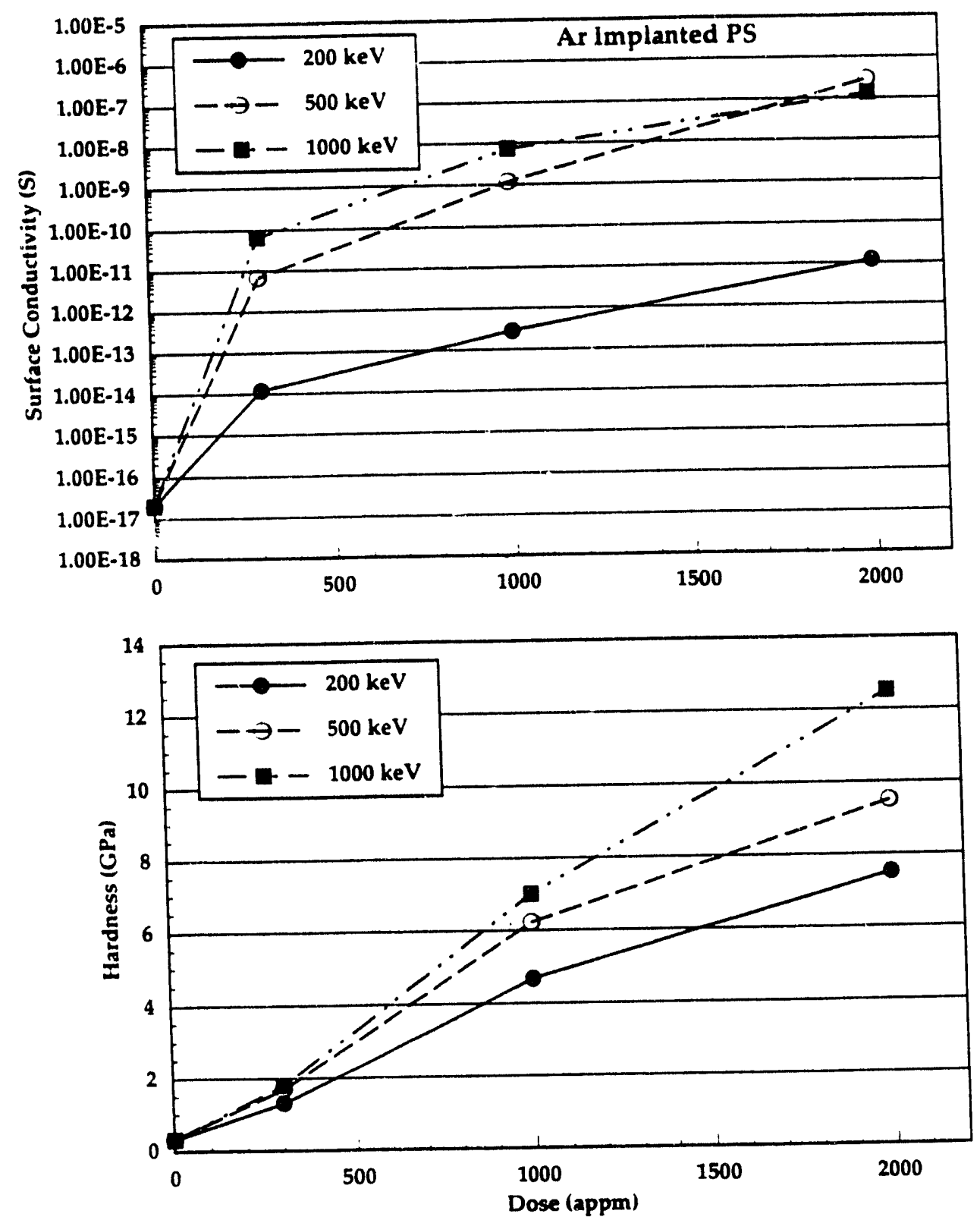

Figure 65. Conductivity changes in Ar implanted PS as a function of ion dose and energy compared with hardness changes in the same materials. 

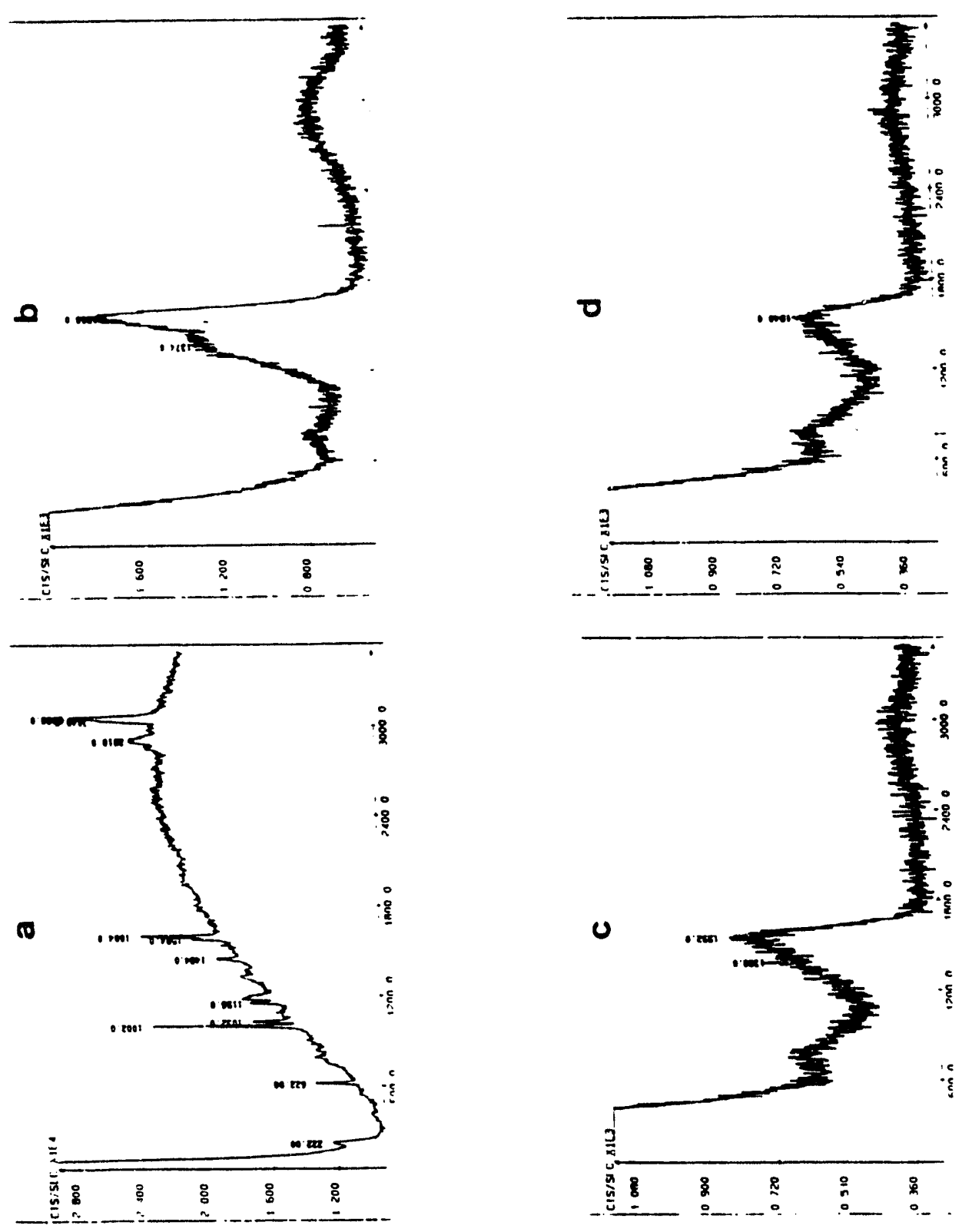

Figure 66. Raman spectra for unimplanted and Ar implanted PS obtained for various doses: (a) unimplanted, (b) $5 \times 10^{14}$, (c) $1.7 \times 10^{15}$ and (d) $3.4 \times 10^{15}$ ions $/ \mathrm{cm}^{2}$. 
peak) whereas single crystal graphite shows a single peak at about $1575 \mathrm{~cm}^{-1}$ (Gpeak) [129]. These peaks can be used as diagnostic features.

The spectra obtained for the implanted polymers is very similar to those obtained for amorphous C-films such as diamond-like C-films (DLC) [129]. The low dose implanted PS shows two peaks at 1374 and $1566 \mathrm{~cm}^{-1}$. With increasing dose, the $D$ peak shifts to a higher wavenumber whereas the $G$ peak shifts to a lower wavenumber. Moreover, the intensities of the two peaks decreased with increasing dose, with the spectra resembling those of diamond-like C-films. It has been shown that the Raman spectra of DLC films are distinctly different from graphitic carbon [129] and the structure of ion implanted polymers must be structurally similar to DLC films and different from graphitic carbon [129].

It has been shown by Tuinstra and Koenig that the ratio of the intensities of the two peaks $I_{D} / I_{G}$ is an important parameter and is proportional to the inverse of the graphite microcrystallite size [130]. The ratios for Ar implanted PS in figure 66 are, in general, over 1, again very similar to the ratios obtained for DLC films [129] indicating that the local order or microcrystallite size is very small, on the order of a few nm. Similar Raman Spectroscopy results were also obtained for the B,N,C implanted Tefzel [122].

It has been suggested that in DLC films, tetrahedral $\mathrm{sp}^{3}$ bonded $\mathrm{C}$ is present though only as a small percentage [129]. Theoretical modelling studies by Beeman et al. have also shown the same effect [131]. The authors modelled vibrational properties of amorphous $\mathrm{C}$ containing varying percentages of four-fold $\mathrm{sp}^{3}$ bonds, 
from $0 \%$ to $100 \%$. They found that with increasing percentage of four-fold coordinated atoms, the $\mathrm{G}$ peak at $1575 \mathrm{~cm}^{-1}$ shifted towards the a lower wavenumber. This is similar to the effect observed with increasing dose in the $\mathrm{Ar}$ implanted PS. Thus the percent of $\mathrm{sp}^{3}$ bonds appears to increase with dose and this probably contributes to the hardness increase found in the implanted PS. The structure probably consists of diamond-like regions connected by large graphitic regions [131].

\section{Tribological Properties}

Wear behavior of materials are in general not well understood, even more so in the case of polymers. In general, one has to rely heavily on extensive empirical precedents from previous wear studies [97]. The present study on wear of ion irradiated polymers is by no means extensive but some basic conclusions may be drawn.

Wear is a combination of several different modes such as adhesion, abrasion, fatigue and delamination. In a given system, certain modes dominate [95]. In general, in this study, wear on the polymer surfaces was clearly reduced by ion beam treatment. In PS (the lowest dose) and PES (intermediate dose), no wear was evident on the surface even after 10000 cycles using a nylon ball.

Qualitatively, it appears that the wear mode shifted from (1) adhesive and ridging wear, to (2) no wear, and eventually to (3) surface fatigue and abrasive wear with increasing dose. Since the surface hardness of the polymers also increased with 
dose, an approximate correlation could be made between hardness and wear mechanisms.

Abrasive wear and adhesive wear were evident in the unimplanted polymers. The main mechanism is the shearing off of asperities. Ratner et al. have suggested the following relation for the wear volume $\mathrm{W}$ per unit distance of sliding:

$$
W=\frac{k \mu}{H \in \sigma}
$$

where $\mu$ is the coefficient of friction, $\mathrm{H}$ is the hardness, $\epsilon$ is the percentage elongation to failure, $\sigma$ is the tensile strength and $\mathrm{k}$ is a constant [132]. Wear rate is thus inversely proportional to the hardness as observed in this study. Transfer films have been found to form on the countersurfaces during wear of polymers due to adhesive wear [97]. These films eventually form typical debris observed during wear tests. In this study, transfer films were not detected on the nylon ball or the polymer surface. In a related study using metal balls as the counterfaces, films were detected [133] but the effect of the transfer films have not been studied in detail in this study.

At the optimum dose, it was observed that no wear tracks were visible at the surface indicating a suppression of abrasive and adhesive wear. At higher doses however, surface fatigue became the dominant mechanism. It was evident that higher doses made the polymer surface hard and brittle. Fatigue cracks were evident in these cases. Since the implanted layer rests on the soft substrate, it was 
consequently weakened. In some cases, as in the high dose implanted PE, the surface fatigue had caused small debris particles to form on the surface which caused additional abrasive wear damage. Thus, the optimum dose caused sufficient strengthening to reduce adhesive and abrasive wear but did not harden it to the extent to cause surface fatigue cracking. 


\section{COMPARISON OF IMPLANTATION EFFECTS IN METAIS AND POLYMERS}

Ion implantation has been shown in this study to be capable of significant changes in various surface-related mechanical properties in materials. In particular, the atomic and molecular structure of the material subjected to implantation is of significance for rationalizing the observed changes.

\section{METALS}

This study showed that a surface layer thickness of the order of one $\mu \mathrm{m}$ was affected by the implantation. From this thin layer, significant effects on surface hardness, cyclic fatigue properties and high temperature creep properties were obtained. Metals are crystalline materials and the main effect of the implantation was the disruption of the ordered crystal lattice at the surface. This effect has been shown to be mainly due to nuclear collisions, wherein the energy of the incoming ion is transferred by elastic collisions to the host atoms creating the damage [2]. Subsequently, there is a production of point defects and related processes such as point defect agglomeration, radiation-enhanced-diffusion and radiation-induced-segregation [24].

These microstructural changes had significant effects on mechanical properties. Mechanical properties are a direct consequence of behavior of dislocations in the 
crystal lattice. This study showed some of the effects of ion implantation on the fatigue properties of metals. Dislocation movement in the form of slip bands at the material surface is directly related to fatigue properties of metals, and by affecting this movement of dislocations, the fatigue properties were altered. The various consequences of ion implantation such as lattice damage, precipitate formation and induced residual stresses in the surface layer contribute towards altering the behavior of dislocations in metals.

The effects on fatigue properties due to ion implantation are to be expected since fatigue cracks are known to initiate at the surface. However, the effects on creep properties were somewhat surprising since deformation occurs throughout the material. The significant improvements observed in the high temperature deformation properties in this study reaffirm two facts: (1) the surface of materials are important for high temperature properties and (2) although elevated temperatures alter the implantation modified surface layer the implanted layer has a significant effect. The present work represents the first effort to use multiple ion implantation to alter creep properties of metallic alloys. The study also demonstrated the synergistic nature of implantation effects since expected improvements in properties, especially fatigue properties, were not realized due to the presence of grain boundaries. 


\section{POLYMERS}

Ion implantation of polymers is a relatively new field as compared to metals and ceramics. The obvious difference is the disparity in molecular structure. Polymers consist of long-chain macromolecules and the changes induced by ion implantation are permanent, whereas in metals, in many cases, annealing can eliminate the damage.

There are several unique aspects to the implantation of polymers. The implantation results in breaking of bonds and in the formation of smaller molecular species, some of which escape from the surface. The identification of these gases and their relative quantities gives insight into processes occurring during implantation. Another significant aspect is that electronic energy losses rather than nuclear losses may be significant in contrast to the case in metals where nuclear collisions are more important in terms of damage. This has been discussed in several papers recently $[69,77-80,83,84]$ but there has been no consensus thus far. Ongoing studies at ORNL have recently shown that ionization may be the doninant factor for improvements in surface-mechanical properties and correlations were made with the extent of ionization energy loss and hardness improvements [134].

The unique aspect of the present investigation is the application of ion implantation for the improvement of mechanical properties. Most previous studies have concentrated on electrical and optical properties. The present work is part of an effort at ORNL that has clearly proven the efficacy of ion 
implantation for significant improvements in mechanical properties. In particular, it was shown that a specific implantation condition (in terms of dose and energy) exists which yields optimum mechanical properties improvement. This was related to two major effects occurring simultaneously, namely, cross-linking due to ionization and molecular chain-scission due to nuclear energy losses. By judiciously optimizing the relative ratio of these two effects, significant improvements in mechanical properties can be achieved.

Ion implantation represents a unique method to tailor surfaces, as shown in this study by the ion dose and energy effects in polymers. Effects of ion implantation on polymers are generally discussed in terms of a change in chemistry at the surface rather than structural damage as in metals and ceramics. This aspect is important for understanding basic mechanisms. While the present study has explored technologically relevant aspects of changes in mechanical properties of metals and polymers, a more important outcome of the study was a better insight into basic controlling mechanisms. 


\section{CONCLUSIONS}

The effects of ion implantation on several surface-sensitive mechanical properties of metals and polymers have been investigated in the present study. The investigation resulted in the following conclusions:

\section{METALS}

\section{Fatigue}

Eight complex (E-series) alloys based on the Fe-13Cr-15Ni-2Mo-2Min-0.2Ti$0.8 \mathrm{Si}-0.06 \mathrm{C}$ composition were implanted simultaneously with $400 \mathrm{keV} \mathrm{B}^{+}$and 550 $\mathrm{keV} \mathrm{N} \mathrm{N}^{+}$to doses of $2.3 \times 10^{16}$ ions $/ \mathrm{cm}^{2}$ for each species. Bending fatigue tests were conducted using miniature specimens. Single crystal Fe-15Cr-15Ni specimens were also implanted with $\mathrm{B}^{+}$and $\mathrm{N}^{+}$and tested for fatigue life. The following conclusions resulted from the study:

1. The simultaneous dual implantation caused a significant improvement in nearsurface hardness. However, the fatigue life of the eight alloys decreased.

2. Optical microscopy revealed that the implantation caused suppression of slip band formation and crack initiation at slip bands. This, however, caused a transformation from slip band crack initiation, which is the operative failure mechanism in the unimplanted alloys, to grain boundary cracking. 
3. Supporting evidence was obtained from an earlier study of multiple-ionimplantation of four simple (B-series) $\mathrm{Fe}-13 \mathrm{Cr}-15 \mathrm{Ni}$ alloys. Implanting the alloys simultaneously with $\mathrm{B}$ and $\mathrm{N}$ significantly increased fatigue life. However, triple implantation with B, N, C decreased fatigue life. Only the triple implanted specimens showed grain boundary cracks. Thus, the triple ion implantation caused sufficient strengthening for the transformation to grain boundary cracking in the simple B-series alloys whereas, in the complex E-series alloys, which have an inherently higher strength, dual implantation was sufficient to cause the shift in crack initiation mechanism.

4. The fatigue life of the single crystal specimens also decreased after implantation due to a concentration of slip along fewer but intense slip bands leading to earlier crack initiation.

5. The results suggest the existence of an optimal level of strengthening for improvement in fatigue properties by suppressing normal slip band crack initiation. Additional strengthening causes the applied stress to be relieved at grain boundaries leading to crack initiation and a consequently lower fatigue life.

\section{Creep}

The complex Fe-13Cr-15Ni-2Mo-2Mn-0.2Ti-0.8Si-0.06C (E1) alloy and the ternary $\mathrm{Fe}-13 \mathrm{Cr}-15 \mathrm{Ni}$ (B1) alloy were implanted simultaneously with $400 \mathrm{keV} \mathrm{B}$ and $550 \mathrm{keV} \mathrm{N}^{+}$and tested for high temperature deformation properties. Creep tests were conducted using SS-3 miniature tensile specimens at $600^{\circ} \mathrm{C}$. Specimens 
of each alloy were also implanted with $1 \mathrm{MeV} \mathrm{Ar}^{+}$to a dose of $2.3 \times 10^{16}$ ions $/ \mathrm{cm}^{2}$ to investigate the effects of inert gas implantation.

1. The simultaneous dual implantation improved the overall creep life of the E1 alloy at $600^{\circ} \mathrm{C}$ by $72 \%$ with a decrease in minimum creep rate. However, the ductility of the alloy was decreased. The specimen failed by the formation of intergranular wedge type cracks at triple grain junctions. The implantation strengthened the matrix of surface grains reducing the extent of grain boundary sliding. This also accounts for the reduced ductility.

2. The $\mathrm{B}^{+} / \mathrm{N}^{+}$-implantation also improved overall creep life of the $\mathrm{B} 1$ alloy by $75 \%$ with a consequent decrease in minimum creep rate. In contrast to the complex alloy, ductility was also increased. The B1 alloy also failed by intergranular fracture by formation of round " $\mathrm{r}$ " type voids at grain boundaries and subsequent coalescence and growth. The voids were probably formed by the interaction of slip bands and grain boundaries. The implantation delayed slip band and void formation at the grain boundaries as suggested by the reduced primary and secondary creep rates.

3. The $\mathrm{Ar}^{+}$-implantation increased creep life of the ternary B1 alloy by about $45 \%$ but reduced the life of the complex E1 alloy. This was attributed to competing effects of $\mathrm{Ar}^{+}$bubble formation at grain boundaries and strengthening caused by damage and $\mathrm{Ar}^{+}$bubbles in the matrix. The strengthening effect was dominant in the B1 alloy whereas the effect of $\mathrm{Ar}^{+}$ bubble formation at grain boundaries dominated in the E1 alloy. 


\section{POLYMERS}

Four polymers, polyethylene (PE), polypropylene (PP), polystyrene (PS) and polyethersulfone (PES) were implanted with $200 \mathrm{keV} \mathrm{B}{ }^{+}$-ions to three different doses of $1.67 \times 10^{14}, 5 \times 10^{14}$ and $1.7 \times 10^{15}$ ions $/ \mathrm{cm}^{2}$. The polymers represent increasing molecular complexity of side groups and also main backbone-chain in the case of PES. PS was also subjected to $100 \mathrm{keV} \mathrm{B}^{+}$-implantation to study an energy effect. PS, in addition, was implanted with 200,500 and $1000 \mathrm{keV} \mathrm{Ar}^{+}$to $5 \times 10^{14}, 1.7 \times 10^{15}$ and $3.4 \times 10^{15}$ ions $/ \mathrm{cm}^{2}$. The polymers were investigated for changes in near-surface hardness using a nanoindentation technique.

\section{Hardness}

1. The ion implantation always increased the near-surface hardness of the polymers. The hardness increased with increasing dose and energy. For a given dose, the relative increase in hardness decreased with increasing complexity of side-groups, even though absolute (measured) hardness values were higher. However, brth relative increase and measured hardness values were lower with increasing complexity of the polymeric backbone chain.

2. Hardness improvements are a direct consequence of cross-linking. Crosslinking and chain-scission are competing processes that occur during irradiation and at higher doses, chain-scission becomes more efficient as suggested by the reduced hardness increase with increasing dose.

3. The implanted region consisted of carbon-rich regions as evidenced by transmission electron microscopy and electron-energy-loss spectroscopy. This 
carbon enrichment drastically improved conductivity with the same trend as for hardness, suggesting similar microstructural causes. Raman spectroscopy suggested the presence of four-fold $\mathrm{sp}^{3}$ (diamond) type bonds in the implanted region along with the majority $\mathrm{sp}^{2}$ bonds. The four-fold coordinated bonds could also have contributed to the hardness improvement.

\section{Tribological Properties}

The $\mathrm{B}^{+}$-implanted polymers were investigated for tribological property changes using a reciprocating wear test machine using nylon balls as the counter-surface with a normal load of $1 \mathrm{~N}$ for 10000 cycles at 100 cycles per minute.

1. The $\mathrm{B}^{+}$-implantation, in general, improved wear properties of the polymers. However, there was an optimum dose that resulted in the best wear improvement. This corresponded to the lowest dose for PS and PE, and the intermediate dose for PES and PP.

2. No wear tracks were observed for PS and PES at the optimum dose even after 10000 sliding cycles.

3. No specific correlations could be made between friction coefficient values, hardness and wear resistance. In general, there was a shift in the dominant wear mechanism with increasing dose from adhesive wear to minimal wear to surface fatigue and abrasive wear. 


\section{REFERENCES}

1. J. K. Hirvonen, "Introduction", in: Ion Implantation, Treatise on Materials Science and Engineering, ed. J. K. Hirvonen, vol.18, (Academic Press, 1980) pp. 1-6.

2. E. W. Thomas, "The Physics of Ion Implantation", in: Ion Plating and Implantation: Applications to Materials, ed. R. F. Hochman, (ASM, 1986) pp. 7-14.

3. R. F. Hochman, "Surface Modification by Ion Processes- An Emerging Technology", in Ion Plating and Implantation: Applications to Materials, ed. R. F. Hochman, (ASM, 1986) pp. 1-6.

4. C. Laird, "The Fatigue Limits of Metals", Mat. Sci. Eng., 22 (1976) 231-236.

5. R. G. Vardiman, "The Modification of Fatigue Properties by Ion Implantation", in: Ion Plating and Implantation: Applications to Materials, ed. R. F. Hochman, (ASM, 1986) pp. 107-114.

6. E. H. Lee and L. K. Mansur, "Effects of Simultaneous $\mathrm{B}^{+}$and $\mathrm{N}^{+}$Implantation on Microhardriess and Fatigue of Fe-13Cr-15Ni Alloys", J. Mat. Res., 4 (6) (1989) 1371-1378.

7. F. Garofalo, Fundamentals of Creep and Creep Rupture in Metals, (Macmillan Company, New York, 1965), p. 44.

8. I. W. Hall, "The Effect of Ion Implantation on the High Temperature Deformation of Molybdenum", Met.Trans., 12A (1981) 2093-2099.

9. T. Venkatesan, L. Calcagno, B. S. Ellman and G. Foti, "Ion Beam Effects in Organic Molecular Solids and Polymers", in: Ion Beam Modification of Insulators, ed. P. Mazzoldi and G. W. Arnold (Elsevier, 1987) pp. 301-379.

10. E. H. Lee, M. B. Lewis, P. J. Blau and L. K. Mansur, "Improved Surface Properties of Polymer Materials by Multiple Ion Beam Treatment", J. Mater. Res., 6(3) (1991) 310-379.

11. J. F. Ziegler, J. P. Biersack and U. Littmark, The Stopping and Range of Ions in Solids, vol.1, (Pirgamon Press, 1985) pp. 1-13. 
12. E. Rutherford, "The Sputtering of $\alpha$ and $\beta$ Particles by Matter and The Structure of the Atom", Phil. Mag., 21 (1911) 669-688.

13. N. Bohr, "On the Decrease of Velocity of Swiftly Moving Electrified Particles in Passing through Matter", Phil. Mag., 30 (1915) 581-612.

14. A. D. Brailsford, "New Uses of Ion Implantation", Ford Motor Co. Report SR79-131 (1979).

15. G. Dearnaley, J. H. Freeman, R. S. Nelson and J. Stephen, Ion Implantation, (North Holland Publishers, Amsterdam, 1973).

16. P. D. Townsend, J. C. Kelly and N. E. W. Hartley, editors, Ion Implantation, Sputtering and their Applications, (Academic Press, New York, 1976).

17. F. Eisen and L. T. Chadderton, editors, Ion Implantation in Semiconductors, (Gordon and Breach, New York, 1971).

18. N. E. W. Hartley, G. Dearnaley and J. F. Turner, in: Ion Implantation in Semiconductors and other Materials, ed. B. L. Gowder, (Plenum Press, New York, 1973) pp. $423-436$.

19. N. E. W. Hartley, in: Ion Implantation, Treatise on Materials Science and Engineering, ed. J. K. Hirvonen, vol.18, (Academic Press, 1980), pp. 321-371.

20. N. E. W. Hartley, "Tribological Effects in Ion-Implanted Metals",Inst. Phys. Conf. Ser., 28 (1976) 210-223.

21. S. T. Picraux, "Physics of Ion Implantation", in: Surface Engineering: Surface Modification of Materials, ed. R. Kossowsky and S. C. Singhal, (Martinus Nijhoff Publ., Dordrecht, 1984) p. 3-31.

22. L. K. Mansur, "Mechanisms and Kinetics of Radiation Effects in Metals and Alloys", in: Kinetics of Non-Homogeneous Processes, ed. G. R. Freeman, (J. Wiley and Sons, 1987), pp. 377-463.

23. G. H. Kinchin and R. S. Pease, "The Displacement of Atoms in Solids by Radiation", Rep. Prog. Phys., 18 (1955) 1-51.

24. C. J. MacHargue, "Ion Implantation in Metals and Ceramics", Int. Metals. Rev., 31(2) (1986) 49-76.

25. R. Hutchings, "The Subsurface Microstructure of Nitrogen-Implanted Metals", Matl. Sci. engr., 69 (1985) 129-138. 
26. W-W. Hu, H. Herman, C. R. Clayton, J. Kozubowski, R. A. Kant, J. K. Hirvonen and R. K. MacCrone, "Surface-Related Mechanical Properties of Nitrogen-Implanted 1018 Steel", in: Ion Implantation Metallurgy, ed. C. M. Preece and J. K. Hirvonen, (TMS-AIME, 1979), pp. 92-102.

27. R. A. Kant, S. M. Myers and S. T. Picraux, "Experimental Study of Precipitation in an Ion-Implanted Metal: Sb in Al", J. Appl. Phys., 50 (1979) 214-222.

28. P. M. Ossi, "Ion-Beam-Induced Amorphization", Matl. Sci. Engr., 90 (1987) 55-68.

29. K. Hohmuth, B. Rauchenbach, K. Kolitsch and E. Richter, "Formation of Compounds by Metalloid Ion Implantation in Iron", Nucl. Instrum. Meth., 209/210 (1983) 249-253.

30. Metals Handbook, Ninth Edition, vol.8, Mechanical Tesiing, (ASTM, 1985), p. 71.

31. N. E. W. Hartley, G. Dearnaley and J. F. Turner, in: Ion Implantation in Semiconductors and other Materials, ed. B. L. Gowder, (Plenum Press, New York, 1973) pp. 356-359.

32. R. A. Kant, J. K. Hirvonen, A. R. Knudson and J. S. Wollam, "Surface Hardening of Beryllium by Ion Implantation", Thin Solid Films, 63 (1979) 27-30.

33. J. B. Pethica, in: Ion Implantation into Metals, ed. V. Ashworth, W. A. Grant and R. P. M. Procter, (Pergamon Press, New York, 1982) pp. 147-156.

34. W. C. Oliver, R. Hutchings and J. B. Pethica, "The Wear Behavior of NitrogenImplanted Metals", Met. Trans., 15A (1984) 2221-2229.

35. D. Newey, H. M. Pollock and M. A. Wilkins, in: Ion Implantation in Semiconductors and other Materials, ed. B. L. Gowder, (Plenum Press, New York, 1973) pp. 157-166.

36. R. Hutchings, W. C. Oliver and J. B. Pethica, "Hardness and Wear Correlations in Nitrogen-Implanted Metals", in: Surface Engineering: Surface Modification of Materials, ed. R. Kossowsky and S. C. Singhal, (Martinus Nijhoff Publ., Dordrecht, 1984), pp. 170-184.

37. R. J. Bourcier, D. M. Follstaedt, S. M. Myers and H. Polonis, MRS Proc., 157 (1990) 801-805.

38. R. J. Bourcier, D. M. Follstaedt, M. T. Dugger and S. M. Myers, "Mechanical Characterization of Several Ion-Implanted Alloys: Nanoindentation Testing, Wear Testing, Finite Element Modeling", Nucl. Instrum. Meth., B59/60 (1991) 905-908. 
39. M. E. Fine, "Fatigue Resistance of Metals", Met. Trans., 11A (1980) 365-379.

40. A. W. Sleeswyk, H. J. Kok and G. Boom, "Effect of C-Ion Implantation on L.C.F. Life of $\mathrm{Cu}, \mathrm{Ni}$ and AISI 310", Scripta Met., 14 (1980) 919-922.

41. H. Bakhru, W. Gibson, C. Burr, A. J. Kumnick and G. E. Welsch, "Modification of the Fatigue Behavior of Copper and Stainless Steel by Ion Implantation", Nucl. Instrum. Meth., 182/183 (1981) 959-964.

42. G. Welsch, J. J. Wang, H. Bakhru, A. Mashayekhi, W. Gibson and R. K. MacCrone, "Fatigue Deformation Behavior of Nitrogen-Ion-Implanted Surface Layers of Type 304 Stainless Steel", Thin Solid Films, 107 (1983) 305-314.

43. A. Kujore, S. B. Chakrabortty, E. A. Starke, Jr., and K. O. Legg, "The Effect of Ion Implantation on the Fatigue Properties of Polycrystalline Copper", Nucl. Instrum. Meth., 182/183 (1981) 949-958.

44. P. Heydari, E. A. Starke, Jr., S. B. Chakrabortty and K. O. Legg, in: Ion Implantation into Metals, ed. V. Ashworth, W. A. Grant and R. P. M. Procter, (Pergamon Press, New York, 1982), p. 172.

45. K. V. Jata, J. Han, E. A. Starke, Jr. and K. O. Legg, "Ion Implantation Effect on Fatigue Crack Initiation in Ti-24V", Scripta Met., 17 (1983) 479-483.

46. K. V. Jata and E. A. Starke, Jr., "Surface Modification by Ion ImplantationEffects on Fatigue", J. Met., 35(8) (1983) 23-27.

47. W. L. Grube and S. R. Rouze, "The Effects of Ion-Implanted Nitrogen on the Fatigue Behavior of Plain Carbon Steel", in: Microstructural Science 11, ed. DeHoff, Brown and McCall, (Elsevier Publ., 1983), pp. 51-61.

48. K. Hohmuth, E. Richter, B. Rauchenbach and C. Blochwitz, "Fatigue and Wear of Metalloid-Ion-Implanted Metals", Matl. Sci. Engr., 69 (1985) 191-201.

49. J. Mendez, P. Violan and J. P. Villain, "Modifications in Fatigue Surface Damage by Ion Implantation in Polycrystalline Copper", Scripta Met., 16 (1982) 179-182.

50. H. Herman, "Surface Mechanical Properties - Effects of Ion Implantation", Nucl. Instrum. Meth., 182/183 (1981) 887-898.

51. P. W. Kao and J. G. Byrne, "Ion Implantation Effects on Fatigue and Surface Hardness", Fatigue of Eng. Mat. Struc., 3 (1981) 271-276. 
52. R. G. Vardiman and R. A. Kant, "The Improvement of Fatigue Life in Ti-6Al-4V by Ion Implantation", J. Appl. Phys., 53(1) (1982) 690-694.

53. R. G. Vardiman and J. E. Cox, "A study of the Mechanisms of Fatigue Life Improvement in an Ion Implanted Nickel-Chromium Alloy", Acta. Met., 33(11) (1985) 2033-2039.

54. D. S. Grummon, J. W. Jones and G. S. Was, "Fatigue Damage Accumulation in Nickel Modified by Ion Beam Surface Microalloying", Met. Trans, 19A (1988) 2775 2778.

55. D. S. Grummon, J. W. Jones, J. M. Meridon, G. S. Was and L. Rehn, "Slip Band Distribution and Morphology in Cyclically Deformed Nickel Polycrystals with Ion Beam Mixed Surface Films", Nucl. Instrum. Meth., B19/20 (1987) 227-231.

56. D. S. Grummon, D. J. Morrison, J. W. Jones and G. S. Was, "Ion Implantation and Fatigue Crack Initiation: Interactions of Persistant Slip Bands with Modified Surface Layers", Matl. Sci. Engr., A115 (1989) 331-336.

57. D. J. Morrison, J. W. Jones, D. E. Alexander and G. S. Was, "Influence of Cyclic Deformation on Surface Microstructure and Hardness of Ion-Implanted Nickel", Met. Trans., 22A (1991) 1633-1646.

58. W-W. Hu, C. R. Clayton, H. Herman and J. K. Hirvonen, "Fatigue-Life Enhancement by Ion Implantation", Scripta Met., 12 (1978) 697-698.

59. T. H. Courtney, Mechanical Behavior of Materials, (McGraw Hill, New York, 1990), p. 263.

60. F. Garofalo, Fundamentals of Creep and Creep Rupture in Metals, (Macmillan Company, New York, 1965) p. 55.

61. I. R. Kramer, "Surface Layer Effects on the Mechanical Behavior of Metals", in: Advances in the Mechanics and Physics of Surfaces, ed. R. M. Latanision and T. E. Fischer, (Harwood Academic Publishers, Chur, Switzerland, 1986), pp. 212-226.

62. I. W. Hall, "Creep of Te-Implanted Stainless Steel", Scripta Met., 16 (1982) 749752.

63. K. V. Jata and G. K. Hubler, "The Effect of Fe and Ce Ion Implantation on the High Temperature Deformation Behavior of a 2124 Aluminum Alloy", J. Vac. Sci. Tech., A3(6) (1985) 2677-2679. 
64. R. F. Gould, "Preface", in: Irradiation of Polymers, ed. R. F. Gould (ACS Publications, 1967) pp. vii.

65. A. Charlesby, "Radiation Mechanics in Polymers", in: Irradiation of Polymers, ed. R. F. Gould (ACS Publications, 1967) pp. 1-21.

66. G. Marletta, "Chemical Reactions nad Physical Property Modifications Induced by keV Ion Beams in Polymers", Nucl. Instrum. Meth., B46 (1990) 295-305.

67. T. Venkatesan, R. C. Dynes, B. Wilkens, A. E. White, J. M. Gibson adn R. Hamm, "Comparison of Conductivity Produced in Polymers and Carbon Films by Pyrolysis and High Energy Ion Irradiation", Nucl. Instrum. Meth., B1 (1984) 599-604.

68. J. Davenas, X. L. Xu, G. Boiteux and D. Sage, "Relation Between Structure and Electronic Properties of Ion-Irradiated Polymers", Nucl. Instrum. Meth., B39 (1989) 754.

69. D. Fink, M. Müller, L. T. Chadderton, P. H. Cannington, R. G. Elliman and D. C. MacDonald, "Optically Absorbing Layers on Ion Beam Modified Polymers: A study of their Evolution and Properties", Nucl. Instrum. Meth., B32 (1988) 125-130.

70. J. Davenas, G. Boiteux, X. L. Xu and E. Adem, "Role of the Modifications Induced by Ion Beam Irradiation in the Optical and Conducting Properties of Polyimide", Nucl. Instrum. Meth., B32 (1988) 136-141.

71. T. M. Hall, A. Wagner and L. F. Thompson, "Ion Beam Exposure Characteristics of Resists: Experimental Results", J. Appl. Phys., 53(6) (1982) 3997-4010.

72. I. Adesida, C. Anderson and C. D. Wolf, "Resist Exposure with Light Ions", J. Vac. Sci. Technol., B1 (1983) 1182-1185.

73. O. Puglisi, "Ion Beam Effects on Polymers: the Influence of Energy Loss and Molecular Parameters", Mater. Sci. Eng., B2 (1989) 167-175.

74. Y. Aoki, N. Kouchi, H. Shibata, S. Tagawa, Y. Tabata and S. Imamura, "Radiation Effects of Ion Beams on Polystyrene Resist Films", Nucl. Instrum. Meth., B33 (1988) 799-802.

75. J. D. Carlson, J. E. Banes, A. M. Guzman and P. P. Pronko, "Surface Property Changes Induced in Poly(1-Hexene) Elastomer by High Energy Ion Irradiation", Nucl. Instrum. Meth., B7/8 (1985) 507-512.

76. Y. Suzuki, M. Kusakabe, M. Iwaki and M. Suzuki, Nucl. Instrum. Meth., B32 (1988) 120. 
77. M. B. Lewis and E. H. Lee, "Residual Gas and Ion-Beam Analysis of IonIrradiated Polymers", Nucl. Instrum. Meth., B61 (1991) 457-465.

78. M. B. Lewis and E. H. Lee, "Chemical G-Values of Ion-Irradiated Polymers", Instrum. Meth., B69 (1992) 241.

79. T. Venkatesan, R. C. Dynes, B. Wilkens, A. E. White, J. M. Gibson and R. Hamm, "Comparison of Conductivity Produced in Polymers and Carbon Films by Pyrolysis and High Energy Ion Irradiation", in: Ion Implantation and Ion Beam Processing of Materials, ed. G. K. Hubler, O. W. Holland, C. R. Clayton and C. W. White, vol.27 (MRS Symposium Proceedings, North Holland, New York, 1984) pp. 449-454.

80. D. Fink, K. Ibel, P. Goppelt, J. P. Biersack, L. Wang and M. Behar, "Ion Beam Induced Carbon Clusters in Polymers", Nucl. Instrum. Meth., B46 (1990) 342-346.

81. A. J. Lovinger, S. R. Forest, M. L. Kaplan, P. H. Schmidt and T. Venkatesan, "Structural and Morphological Investigation of the Development of Electrical Conductivity in Ion-Irradiated Thin Films of an Organic Material", J. Appl. Phys., 55 (1984) 476-482.

82. T. Venkatesan, S. K. Forest, M. L. Kaplan, C. A. Murray, P. H. Schmidt and B. L. Wilkens, "Ion-Beam-Induced Conductivity in Polymer Films", J. Appl. Phys., 54 (1983) 3150-3153.

83. J. Davenas, P. Thevenard, G. Boiteux, M. Fallavier and X. L. Xu, "Hydrogenated Carbon Layers Produced by Ion Beam Irradiation of PMMA and Polystyrene Films", Nucl. Instrum. Meth., B46 (1990) 317-323.

84. G. Foti and R. Reitano, "Structure and Bonding in Ion Irradiated Polystyrene", Nucl. Instrum. Meth., B46 (1990) 306-308.

85. A. Ishitani, K. Shoda, H. Ishida, T. Watanabe, K. Yoshida and M. Iwaki, "Characterization of Oxygen-Implanted Polyethylene by Various Analytical Techniques", Nucl. Instrum. Meth., B39 (1989) 783-786.

86. C. J. Sofield, S. Sugden, C. J. Bedell, P. R. Graves and L. B. Bridwell, "Ion Beam Modification of Polymers", Accepted for Publication in Nucl. Instrum. Meth. (In Press).

87. R. P. Brown, in Handhook of Plastics Test Methods, (Longman Scientific and Technical, 1988), pp. 107-116. 
88. Polymers, An Encyclopedic Sourcebook of Engineering Properties, ed. J. I. Kroschwitz, (John Wiley and sons, New York, 1987), p. 415.

89. F. J. Balta-Calleja, "Dependence of Micro-Indentation Hardness on the Superstructure of Polyethylene", Colloid Polym. Sci., 254 (1976) 258-266.

90. J. Martinez-Salazar, D. R. Rueda, M. E. Cagiao, E. Lopez Cabarcos and F. J. Balta-Calleja, Polym. Bull., 10 (1983) 553.

91. F. J. Balta-Calleja, C. Fonseca, J. M. Perena and J. G. Fatou, J. Mater. Sci. Lett., 3(6) (1984) 509-511.

92. R. A. Dickie, S. S. Labana and R. S. Bauer, "Preface", Cross-Linked Polymers: Chemical properties and Applications, (ACS, Washington, D.C., 1988), p. 9.

93. R. E. Knight, "Areas of Application of UV Curing", Radiation Curing of Polymers, ed. D. R. Randell, Special Publication No. 64, (Royal Society of Chemistry, London, 1987) p. 1.

94. N. Nishimiya, K. Ueno, M. Noshiro and M. Satou, "Chemical Processes and Surface Hardening in Ion-Implanted Polyester Films", Nucl. Instrum. Meth., B59/60 (1991) 1276-1280.

95. E. H. Lee, G. R. Rao and L. K. Mansur, "Improved Hardness and Wear Properties of B-Ion Implanted Polycarbonate", J. Mater. Res., 7(7) (1992) (in Press).

96. R. P. Steijn, "Friction and Wear", in: Failure of Plastics, ed. W. Brostow and R. D. Corneliussen, (Hanser Publishers, New York, 1986), pp. 357-392.

97. B. Briscoe, "Wear of Polymers: An Essay on Fundamental Aspects", Tribol. Internat., 14 (1981) 231-243.

98. L-H. Lee, "Various Approaches in Controlling the Wear of Polymers", in: Polymer Wear and it's Control, ed. L-H. Lee, (ACS, Washington D.C., 1985), p. 82.

99. H. K. Yasuda, "Modifications of Polymer Surfaces by Plasma Treatment and Plasma Polymerization", in: Polymer Wear and it's Control, ed. L-H. Lee, (ACS, Washington D.C., 1985), p. 89.

100. G. R. Rao, A. Rowcliffe and B. A. Chin, "Development of Miniature Bending Fatigue Specmens", J. Nucl. Mater., 179-181 (1991) 438-440.

101. M. B. Lewis, W. R. Allen, R. A. Buhl, N. H. Packan, S. W. Cook and L. K. Mansur, "Triple Ion Irradiation Facility", Nucl. Instrum. Meth., B43 (1989) 243-253. 
102. G. R. Rao, "Bending Fatigue Tests for Surface-Modified Materials Applications", M.S. Thesis, Auburn University, (1988).

103. T. H. Courtney, Mechanical Behavior of Materials, (McGraw Hill, New York, 1990) pp. 503-520.

104. G. R. Rao, E. H. Lee and B. A. Chin,"Ion Implantation Effects on Fatigue Properties of Fe-13Cr-15Ni Alloys", Surface and Coatings Tech., 51 (1992) 112-117.

105. J. A. Spitznagel, B. O. Hall, N. J. Doyle, R. Jayaram, R. W. Wallace, J. R. Townsend and M. K. Miller, "Effects of Nitrogen and Helium Ion Implantation on Uniaxial Tensile Properties of 316 SS Foils", Mater. Res. Soc. Symp. Proc., vol.27 (Elsevier Science Publ., 1984) p. 597-601.

106. W. H. Kim and C. Laird, "Crack Nucleation and Stage I Propagation in High Strain Fatigue-II. Mechanism", Acta Met., 26 (1978) 789-799.

107. U. Essmann, U. Gösele and H. Mughrabi, "A Model of Extrusions and Intrusions in Fatigued Metals", Phil. Mag. A, 44(2) (1981) 405-426.

108. H. Mughrabi, R. Wang, K. Differt and U. Essmann, in Fatigue Mechanisms, ed. J. Lankford, D. L. Davidson, W. L. Harris and R. P. Wei, ASTM STP 811 (ASTM, 1982) pp.5-45.

109. H. Mughrabi, in Defects, Fracture and Fatigue, ed. G. C. Sih and J. W. Provan, (Martinus Nijhoff Publ., 1983) pp.139-146.

110. A. Hunsche and P. Neumann, "Quantitative Measurement of Persistent Slip Band Profiles and Crack Initiation", Acta. Mat., 34(2) (1986) 207-217.

111. E. Smith and J. T. Barnby, "Crack Nucleation in Crystalline Solids", Met. Science Jour., 1 (1967) 56-64.

112. K. Tanaka and T. Mura, "A Dislocation Model for Fatigue Crack Initiation", J. Appl. Mech., 48 (1981) 97-103.

113. P. J. Maziasz, "Effects of He-Content on Microstructural Development in Type 316 Stainless Steel Under Neutron Irradiation", Ph.D Dissertation, (University of Tennessee, Knoxville, TN) pp. 100-104.

114. E. H. Lee, Oak Ridge National Laboratory, Unpublished Work. 
115. E. H. Lee, N. H. Packan, M. B. Lewis and L. K. Mansur, "Effects of Rapidly Pulsed Ion Bombardment on Microstructure and Phase Stability in a Ti-Modified Stainless Steel", Nucl. Instrum. Meth., B16 (1986) 251-259.

116. W. D. Nix and J. C. Gibeling, "Mechanisms of Time-Dependent Flow and Fracture of Metals", in: Flow and Fracture at Elevated Temperatures, ed. R. Raj, (ASM, 1985), pp. 7-14.

117. R. Lagneborg, "Creep: Mechanisms and Theories", in: Creep and Fatigue in High Temperature Alloys, (Applied Science Publ., London, 1981) pp. 61-68.

118. G. E. Dieter, Mechanical Metallurgy, (McGraw Hill Book Co., 1986) pp. 453 456.

119. E. H. Lee, Y. Lee, W. C. Oliver and L. K. Mansur, "Hardness Measurements of $\mathrm{Ar}^{+}$-Beam Treated Polyimide by Depth-Sensing Nanoindentation", Submitted to J. Mater. Res.

120. G. R. Rao, E. H. Lee and L. K. Mansur, "Structure and Dose Effects on Ion Beam Modification of Polymers", MRS Symposium Proceedings, "Thin Films Stresses and Mech. Properties III", ed. W. D. Nix, J. C. Bravman, E. Arzt and L. B. Freund, vol. 239 (1992) 189-194.

121. W. C. Oliver and G. M. Pharr, J. Mater. Res., 7(6), (1992) 1564-1583.

122. G. R. Rao, Z. L. Wang and E. H. Lee, "Microstructural Effects on Surface Mechanical Properties in Ion Implanted Polymers", Submitted to J. Mater. Res.

123. R. F. Egerton and M. J. Whelan, "The Electron Energy Loss Spectrum and Band Structure of Diamond", J. Electron Spectroscopy, 3 (1974) 232-236.

124. G. Compagnini, R. Reitano, L. Calcagno, G. Marletta and G. Foti, "Hydrogenated Amorphous Carbon Synthesis by Ion Beam Irradiation", Appl. Surface Science, 43 (1989) 228-231.

125. L. Calcagno and G. Foti, "Density Enhancement in Ion Implanted Polymers", Nucl. Instrum. and Meth., B59/60 (1991) 1153-1158.

126. J. Robertson and E. P. O'Reilly, "Electronic and Atomic Structure of Amorphous Carbon", Phy. Rev. B, 35 (6) (1987) 2946-2957.

127. B. Dischler, A. Bubenzer and P. Koidl, "Bonding in Hydrogenated Hard Carbon Studied by Optical Spectroscopy", Solid State Communications, 48(2) (1983) 105-108. 
128. P. L. Hansen, P. J. Fallon and W. Kratschmer, "An EELS study of Fullerite $\mathrm{C}_{60} / \mathrm{C}_{70}$ ", Chem.Phys.Letters, 181(4) (1991) 367-372.

129. D. S. Knight and W. B. White, "Characterization of Diamond Films by Raman Spectroscopy", J. Mater. Res., 4(2) (1989) 385-393.

130. F. Tuinstra and J. L. Koenig, J. Chem. Phys., 53 (1970) 1126.

131. D. Beeman, J. Silverman, R. Lynds and M. R. Anderson, "Modeling Studies of Amorphous Carbon", Phy. Rev.B, 30(2) (1984) 870-875.

132. M. Vaziri, R. T. Spurr and F. H. Stott, "An Investigation of the Wear of Polymeric Materials", Wear, 122 (1988) 329-342.

133. Y. Lee, E. H. Lee and L. K. Mansur, "Hardness and Wear Properties of BoronImplanted Poly(ether-ether-ketone) and Poly-ether-imide", Surf. Coatings Tech., 51 (1992) 267-272.

134. E. H. Lee, Oak Ridge National Laboratory, Private Communication. 
ORNL/M-2711

\section{INTERNAL DISTRIBUTION}

1-2. Central Research Library

3. Document Reference Section

4-5. Laboratory Records Department

6. Laboratory Records, ORNL-RC

7. ORNL Patent Office

8-10. M\&C Records Office

11. W. R. Allen

12. P. A. Angelini

13. J. Bentley

14. P. J. Blau

15. E. E. Bloom

16. L. A. Boatner

17. D. N. Braski

18. R. A. Buhl

19. T. D. Burchell

20. S. W. Cook

21. W. R. Corwin

22. D. F. Craig

23. S. A. David

24. N. D. Evans

25. K. Farrell

26. E. L. Fuller, Jr.

27. M. L. Grossbeck

28. D. M. Hembree, Jr.

29. L. L. Horton

30. R. J. Jayaram

31. E. A. Kenik

32. R. L. Klueh

33. E. H. Lee
34. M. B. Lewis

35. S. T. Mahmood

36. L. K. Mansur

37. P. J. Maziasz

38. C. J. McHargue

39. W. C. Oliver

40. J. E. Pawel

41. D. F. Pedraza

42-46. G. R. Rao

47. J. B. Roberto

48. A. F. Rowcliffe

49. V. K. Sikka

50. P. S. Sklad

51. L. Snead

52. R. E. Stoller

53. R. W. Swindeman

54. C. A. Wang

55. Z. L. Wang

56. J. R. Weir, Jr.

57. C. W. White

58. J. M. Williams

59. C. S. Yust

60. S. J. Zinkle

61. Y. A. Chang (Consultant)

62. H. W. Foglesong (Consultant)

63. J. J. Hren (Consultant)

64. M. L. Savitz (Consultant)

65. J. G. Simon (Consultant)

66. K. E. Spear (Consultant)

\section{EXTERNAL DISTRIBUTION}

67-73. AUBURN UNIVERSITY, Department of Mechanical Engineering, Wilmore Labs, Auburn, AL 36849
B. A. Chin
J. Henderson
B. Z. Jang
W. A. Jemian
M. Thakur
R. C. Wilcox
R. H. Zee 
74. CASE WESTERN RESERVE UNIVERSITY, Department of Metallurgy and Materials Science, Cleveland, $\mathrm{OH} 44106$

G. Welsch

75. FORD MOTOR COMPANY, Scientific Research Staff, 21500 Oakwood Ave., P.O. Box 2053, Dearborn, MI 48121

A. D. Brailsford

76. GRAND CANYON UNIVERSITY, Department of Natural Sciences, 3300 W. Camelback Road, Phoenix, AZ 85017

W. A. Coghlan

77. UNIVERSITY OF MICHIGAN, Department of Nuclear Engineering, 2600 Draper Road, Ann Arbor, MI 48109

G. S. Was

78-81. U.S. DOE, Forrestal Building, 1000 Independence Ave., S.W., Washington, DC 20585

J. B. Darby, Jr. (ER-131, MS GS-236/GTN)

R. J. Gottschall (ER-131)

C. A. Sorrell (CE-232)

F. W. Wiffen (ER-533, GTN)

82. U.S. DOE, OAK RIDGE OPERATIONS OFFICE, P.O. Box 2008, Oak Ridge, TN 37831-6269

Assistant Manager for Energy Research and Development

83-84. U.S. DOE, OFFICE OF SCIENTIFIC AND TECHNICAL INFORMATION, P.O. Box 62, Oak Ridge, TN 37831

For distribution by microfiche as shown in DOE/OSTI-4500, Distribution Categories UC-322

(Ceramics/Advanced Materials) and UC-365

(High-Temperature Materials). 

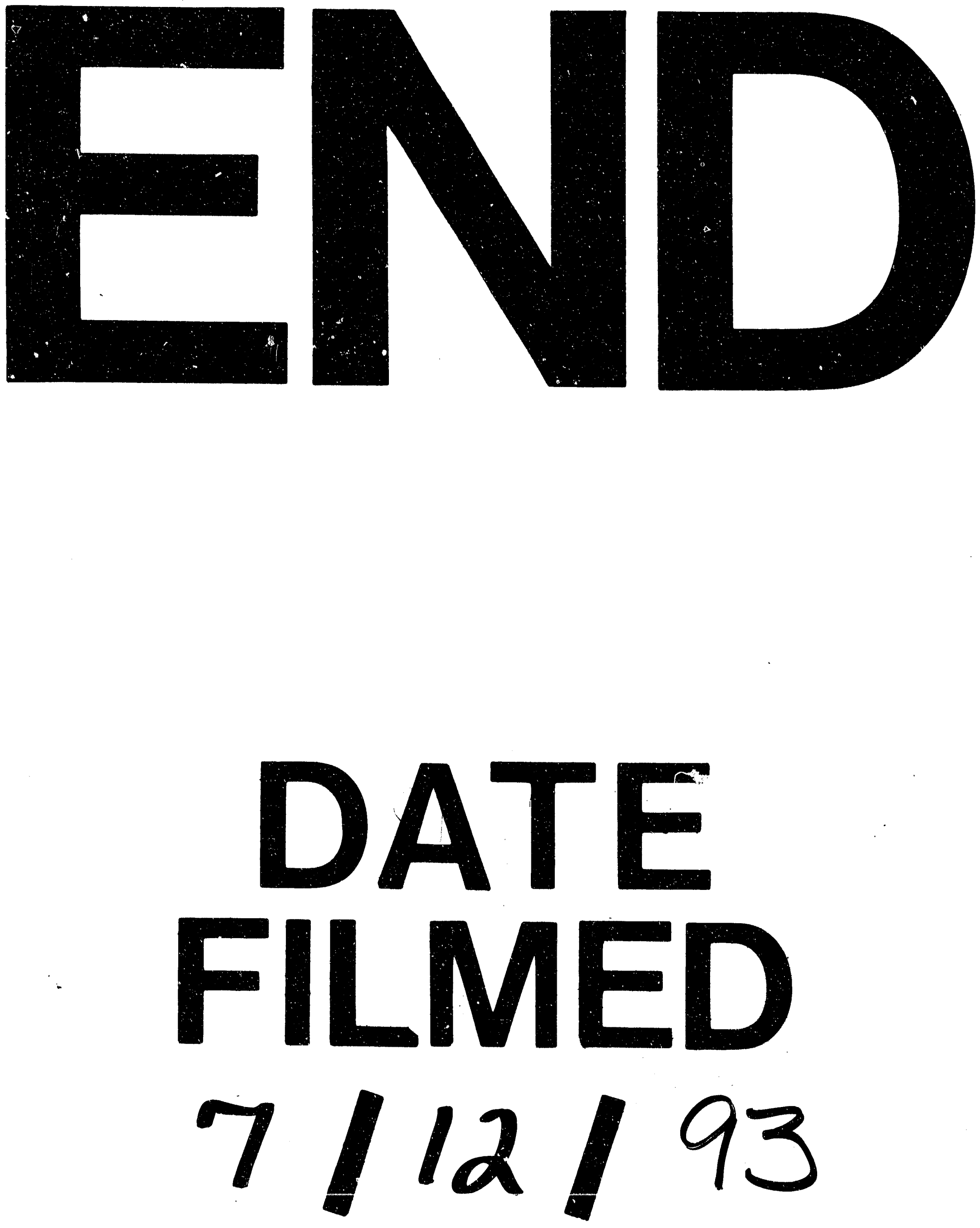
